\title{
Health and economic outcomes in axial spondyloarhthritis
}

Citation for published version (APA):

Webers, C. J. P. (2021). Health and economic outcomes in axial spondyloarhthritis: A matter of perspective. [Doctoral Thesis, Maastricht University]. Maastricht University. https://doi.org/10.26481/dis.20210610cw

Document status and date:

Published: 01/01/2021

DOI:

$10.26481 /$ dis.20210610cw

Document Version:

Publisher's PDF, also known as Version of record

\section{Please check the document version of this publication:}

- A submitted manuscript is the version of the article upon submission and before peer-review. There can be important differences between the submitted version and the official published version of record.

People interested in the research are advised to contact the author for the final version of the publication, or visit the DOI to the publisher's website.

- The final author version and the galley proof are versions of the publication after peer review.

- The final published version features the final layout of the paper including the volume, issue and page numbers.

Link to publication

\footnotetext{
General rights rights.

- You may freely distribute the URL identifying the publication in the public portal. please follow below link for the End User Agreement:

www.umlib.nl/taverne-license

Take down policy

If you believe that this document breaches copyright please contact us at:

repository@maastrichtuniversity.nl

providing details and we will investigate your claim.
}

Copyright and moral rights for the publications made accessible in the public portal are retained by the authors and/or other copyright owners and it is a condition of accessing publications that users recognise and abide by the legal requirements associated with these

- Users may download and print one copy of any publication from the public portal for the purpose of private study or research.

- You may not further distribute the material or use it for any profit-making activity or commercial gain

If the publication is distributed under the terms of Article $25 \mathrm{fa}$ of the Dutch Copyright Act, indicated by the "Taverne" license above, 
Health and economic outcomes

in axial spondyloarthritis

A matter of perspective 
ISBN/EAN: 978-94-6416-506-7

Copyright (C) 2021 Casper Webers

Layout and Cover design by Yasmin Katlich, persoonlijkproefschrift.nl Printed by Ridderprint, ridderprint.nl

All rights reserved. No part of this thesis may be reproduced, stored or distributed in any way or by any means without the prior permission of the author, or when applicable, of the publishers of the scientific papers.

Printing of this thesis was financially supported by Maastricht University. 


\title{
Health and economic outcomes
}

\section{in axial spondyloarthritis}

\author{
A matter of perspective
}

\author{
PROEFSCHRIFT \\ ter verkrijging van de graad van doctor aan de Universiteit Maastricht, \\ op gezag van de Rector Magnificus, Prof. dr. Rianne M. Letschert \\ volgens het besluit van het College van Decanen, \\ in het openbaar te verdedigen \\ op donderdag 10 juni 2021 om 10.00 uur
}

door

Casper Johannes Petrus Webers 


\section{Promotores}

Prof. dr. A. Boonen

Prof. dr. A. van Tubergen

\section{Beoordelingscommissie}

Prof. dr. C. Dirksen (voorzitter)

Prof. dr. B. Fautrel (Sorbonne Université \& Hôpital Universitaire Pitié-Salpêtrière, Parijs)

Prof. dr. J. Kooman

Dr. M. Pierik

Prof. dr. A. Weel-Koenders (Maasstadziekenhuis \& Erasmus Universiteit, Rotterdam) 


\section{Contents}

$\begin{array}{ll}\text { List of abbreviations } & 7\end{array}$

$\begin{array}{lll}\text { Chapter } 1 & \text { General introduction } & 11\end{array}$

Chapter 2 Gender-attributable differences in outcome of ankylosing spondylitis: longterm results from the Outcome in Ankylosing Spondylitis International Study Rheumatology (Oxford), 2016

Chapter 3 Depression in ankylosing spondylitis and the role of disease-related and contextual factors: a cross-sectional study

Arthritis Research \& Therapy, 2019

Chapter $4 \quad$ Infliximab treatment reduces depressive symptoms in patients with ankylosing spondylitis: an ancillary study to a randomized controlled trial (ASSERT)

Arthritis Research \& Therapy, 2020

Chapter 5 Sick leave and its predictors in ankylosing spondylitis: long-term results from the Outcome in Ankylosing Spondylitis International Study

RMD Open, 2018

Chapter 6 Employment and the role of personal factors among patients with ankylosing spondylitis: a Dutch cross-sectional case-control study RMD Open, 2018

Chapter 7 Valuing treatment with infliximab for ankylosing spondylitis using a willingness-to-pay approach

Arthritis Care \& Research, 2018

Chapter 8 Cost-effectiveness of diagnostic algorithms for axial spondyloarthritis in the Netherlands: a model-based economic evaluation

Submitted for publication

Chapter 9 Development, usability and acceptability of an integrated eHealth system for spondyloarthritis in the Netherlands (SpA-Net)

RMD Open, 2019

Chapter 10 Summary and general discussion

Chapter 11 Impact paragraph

$\begin{array}{ll}\text { Addendum Nederlandse samenvatting } & 242\end{array}$

Dankwoord 266

Curriculum Vitae $\quad 271$

List of publications $\quad 272$ 


\section{Supplementary materials}

Throughout this thesis, there are several references to supplementary materials (Supplementary Files, Supplementary Tables and Supplementary Figures). These supplementary materials are available from the author upon request, and will also be published online alongside this thesis in the Current Research Information System of Maastricht University (https://cris.maastrichtuniversity.nl/). 


\section{List of abbreviations}

$95 \% \mathrm{Cl} \quad 95 \%$ confidence interval

AAU Acute anterior uveitis

AIC Akaike information criterion

AS Ankylosing spondylitis

ASAS Assessment of SpondyloArthritis international Society

ASAS20 Assessment of SpondyloArthritis international Society criteria for $20 \%$ improvement

ASAS40 Assessment of SpondyloArthritis international Society criteria for $40 \%$ improvement

ASAS-HI Assessment of SpondyloArthritis international Society Health Index

ASDAS Ankylosing Spondylitis Disease Activity Score

ASQoL Ankylosing Spondylitis Quality of Life score

ASSERT Ankylosing Spondylitis Study for the Evaluation of Recombinant Infliximab Therapy

axSpA Axial spondyloarthritis

BASDAI Bath Ankylosing Spondylitis Disease Activity Index

BASFI Bath Ankylosing Spondylitis Functional Index

BAS-G Bath Ankylosing Spondylitis Global Score

BASMI Bath Ankylosing Spondylitis Metrology Index

bDMARD Biological disease-modifying antirheumatic drug (biological)

BER Berlin algorithm

BIC Bayesian information criterion

BMI Body mass index

CES-D Center for Epidemiological Studies Depression scale

CFI Comparative fit index

CLBP Chronic low back pain

COI Cost-of-illness

CRP C-reactive protein

CSDMARD Conventional synthetic disease-modifying antirheumatic drug

CVM Contingent valuation method

DMARD Disease-modifying antirheumatic drug

DOWSA Deterministic one-way sensitivity analysis

DREAM Dutch Rheumatoid Arthritis Monitoring registry

EAM Extra-articular manifestation

EASIC European Ankylosing Spondylitis Infliximab Cohort

eHealth Electronic health

EMR Electronic medical record

ePROM Electronic patient-reported outcome measure 


\begin{tabular}{|c|c|}
\hline ESR & Erythrocyte sedimentation rate \\
\hline EULAR & European League Against Rheumatism \\
\hline FN & False negative \\
\hline $\mathrm{FP}$ & False positive \\
\hline GBD & Global Burden of Disease \\
\hline GEE & Generalised estimating equation \\
\hline GRAPPA & Group for Research and Assessment of Psoriasis and Psoriatic Arthritis \\
\hline HADS & Hospital Anxiety and Depression Subscale \\
\hline HADS-D & Hospital Anxiety and Depression Subscale, depression subscale \\
\hline HAQ-S & Health Assessment Questionnaire for Spondyloarthropathies \\
\hline HLA-B27 & Human leucocyte antigen B27 \\
\hline$H R$ & Hazard ratio \\
\hline HRQoL & Health-related quality of life \\
\hline HTA & Health technology assessment \\
\hline $\mathrm{IBD}$ & Inflammatory bowel disease \\
\hline IBP & Inflammatory back pain \\
\hline ICF & International Classification of Functioning, Disability and Health \\
\hline ICUR & Incremental cost-utility ratio \\
\hline IFX & Infliximab \\
\hline $\mathrm{IL}$ & Interleukin \\
\hline iNMB & Incremental net monetary benefit \\
\hline IRR & Incidence rate ratio \\
\hline LDA & Low disease activity \\
\hline M1 & Modification 1 of the Berlin algorithm \\
\hline M2 & Modification 2 of the Berlin algorithm \\
\hline MHDA & Moderate to high disease activity \\
\hline MRI-SI & Magnetic resonance imaging of the sacroiliac joints \\
\hline mSASSS & Modified Stoke Ankylosing Spondylitis Spinal Score \\
\hline nr-axSpA & Non-radiographic axial spondyloarthritis \\
\hline NRS & Numerical rating scale \\
\hline NSAID & Non-steroidal anti-inflammatory drug \\
\hline OASIS & Outcome in Ankylosing Spondylitis International Study \\
\hline OMERACT & Outcome Measures in Rheumatology \\
\hline OR & Odds ratio \\
\hline PREM & Patient-reported experience measure \\
\hline PROM & Patient-reported outcome measure \\
\hline PSA & Probabilistic sensitivity analysis \\
\hline$A$ & Psoriatic arthritis \\
\hline
\end{tabular}




$\begin{array}{ll}\text { QALY } & \text { Quality-adjusted life year } \\ \text { QoL } & \text { Quality of life } \\ \text { r-axSpA } & \text { Radiographic axial spondyloarthritis } \\ \text { RA } & \text { Rheumatoid arthritis } \\ \text { RCT } & \text { Randomized controlled trial } \\ \text { RDCl } & \text { Rheumatic Disease Comorbidity Index } \\ \text { RMD } & \text { Rheumatic and musculoskeletal disease } \\ \text { RMSEA } & \text { Root mean square error of approximation } \\ \text { SCQ } & \text { Self-Administered Comorbidity Questionnaire } \\ \text { SD } & \text { Standard deviation } \\ \text { SEM } & \text { Structural equation modelling } \\ \text { SER } & \text { Standardised employment ratio } \\ \text { SF-36 } & \text { Short Form } 36 \\ \text { SF-36MCS } & \text { Short Form } 36 \text { Mental Component Summary score } \\ \text { SF-36PCS } & \text { Short Form } 36 \text { Physical Component Summary score } \\ \text { SJC } & \text { Swollen joint count } \\ \text { SL } & \text { Sick leave } \\ \text { SpA } & \text { Spondyloarthritis } \\ \text { SPACE } & \text { SPondyloArthritis Caught Early study } \\ \text { SPASS } & \text { Social Role Participation in Ankylosing Spondylitis Study } \\ \text { SRPQ } & \text { Social Role Participation Questionnaire } \\ \text { TiH } & \text { Transparency in Healthcare } \\ \text { TJC } & \text { Tender joint count } \\ \text { TLI } & \text { Tucker-Lewis fit index } \\ \text { TN } & \text { True negative } \\ \text { TNF } & \text { Tumour necrosis factor } \\ \text { TNFi } & \text { Tumour necrosis factor alpha inhibitor } \\ \text { TP } & \text { True positive } \\ \text { tsDMARD } & \text { Targeted synthetic disease-modifying antirheumatic drug } \\ \text { WAS } & \text { Visual analogue scale } \\ \text { WAl } & \text { Value of information } \\ \text { Work Productivity and Activity Impairment questionnaire } \\ \text { WAnegative binomial }\end{array}$


Chapter 1

General introduction 


\section{Background}

Axial spondyloarthritis (axSpA) is a chronic inflammatory disorder which typically manifests itself in the lower spine and the sacroiliac joints.' In the majority of the patients, the age of onset of symptoms is between 20 and 30 years. Low back pain is typically the key symptom, although extraspinal manifestations occur frequently and include peripheral arthritis and enthesitis as well as inflammatory bowel disease, psoriasis and anterior uveitis. Susceptibility to axSpA is strongly associated with the presence of human leucocyte antigen (HLA)-B27.,3

AxSpA is nowadays considered to represent a spectrum of disease. Historically a distinction has been made between ankylosing spondylitis (AS) with structural damage to the sacroiliac joints on plain radiography, and non-radiographic axSpA (nr-axSpA) without radiographic damage to the sacroiliac joints. ${ }^{4}$ Currently, the term radiographic axSpA ( $r$-axSpA) is preferred for patients with radiographic sacroiliitis. ${ }^{5}$ The reported prevalence of axSpA and its subtypes varies by geographic region, depending on the HLAB27 background prevalence. ${ }^{6}$ The prevalence of AS in Europe is estimated to be around $0.25 \%,{ }^{6}$ and the prevalence of the whole group of axSpA is estimated to be three to four times as high.?

A diagnosis of axSpA is made using the rheumatologist's clinical judgement. In the diagnostic work-up of axSpA, several clinical manifestations and other parameters, such as laboratory tests and imaging modalities, are used. However, none of these parameters have excellent predictive value for diagnosis on their own, ${ }^{8}$ and diagnosis is typically based on combinations of these parameters, with increasing probability of axSpA when the number of positive parameters increases. Despite the acknowledgement of nr-axSpA over the last decade, which should improve early detection, patients are typically diagnosed several years after the start of symptoms. ${ }^{9}$ Reducing this 'delay in diagnosis' would benefit both the individual patient and society, as timely treatment leads to improvement of symptoms, ${ }^{10,11}$ increases probability of response to treatment ${ }^{12,13}$ and possibly inhibits disease progression, ${ }^{14-18}$ and reduces adverse work outcome and costs. ${ }^{19}$

Both pharmacological and non-pharmacological treatment options are recommended for management of axSpA. Non-pharmacological treatment includes patient education, physical therapy and exercise. ${ }^{20}$ When pharmacological treatment is required, nonsteroidal anti-inflammatory drugs (NSAIDs) are recommended as initial therapy. If these fail and the disease is active, biological disease-modifying antirheumatic drugs (bDMARDs) are indicated. ${ }^{20,27}$ 


\section{The patient perspective on outcome in axSpA}

As a chronic inflammatory disorder with a relatively early onset of symptoms in life, the impact of axSpA on the individual patient is substantial. The burden of axSpA and the resulting disability can be discussed using the International Classification of Functioning, Disability and Health (ICF) model (see Figure 1.1). ${ }^{22}$ The ICF model is a biopsychosocial framework, and integrates both biomedical and psychosocial aspects into one model to represent health and disability. The ICF model has two important components: 'Functioning and disability' and 'Contextual factors'. ${ }^{23}$

\section{Functioning and disability}

In the ICF model, human functioning is classified on three levels: (1) the body (or body part), in relation to body structures and functions; (2) the individual and (3) this person in a social context. Dysfunctioning at a level leads to disability at this level, classified as (1) impairment, due to dysfunction at the body level; (2) activity limitations, due to dysfunction at the whole person level, and (3) participation restrictions, due to dysfunction at the social context level.

- Level 1. Body (part): In axSpA, several bodily structures and functions are affected, resulting in significant impairments. The axial skeleton is inflamed at the entheses, leading to structural damage (deformation, erosion) and new bone formation. ${ }^{24}$ Peripheral joints, para-articular structures, and other organs (intestine, eyes, skin) are also frequently involved. ${ }^{25}$ Similarly, related bodily functions, such as musculoskeletal functioning, are affected. Patients experience pain, stiffness and fatigue, and experience impairment in physical function.

- Comorbidities, both physical and mental in nature, are common in patients with axSpA. ${ }^{26-28}$ Comorbidity in axSpA has recently been gaining attention, and has been shown to be associated with significant impact on functioning and quality of life. ${ }^{29}$ Most studies of comorbidity in axSpA seem to focus on physical comorbidities, such as cardiovascular disease and osteoporosis. ${ }^{26}$ However, patients with axSpA are also at increased risk of affective disorders, in particular depression. ${ }^{27}$ Recent EULAR recommendations proposed screening for depression, among other comorbidities, in patients with chronic inflammatory rheumatic diseases, supporting the importance of mental health in these patients. ${ }^{30}$ The pathophysiology behind comorbid depression in AS is unclear and is likely multifactorial. Inflammation could play a direct causal role in this regard. ${ }^{31}$ Understanding the different factors, and their interrelations, could help to identify which patients are at an increased risk for depressive symptoms and might benefit from additional or different treatment. 
- Level 2. Individual: considering the individual as a whole, several activities are impaired in axSpA. Due to the bodily structures and functions that are affected on the first level, patients experience limitations in mobility, housekeeping and self-care. ${ }^{32}$

- Level 3. Social: axSpA restricts participation in several societal roles. The key aspect of this level is interaction with the environment. Participation in society can take many forms and includes intimate and family relations, travelling, employment and education. Patients consider these different roles in society as important, but also experience restrictions fulfilling them. ${ }^{33,34}$ An example is employment, which ranks among the three most important social roles among patients. ${ }^{34}$ Research in the pre-bDMARD era has shown that patients with AS were less frequently employed compared to the general population. ${ }^{35}$ If employed, patients with axSpA are less satisfied with their performance at work and experience more physical difficulty in this role, compared to the general population. ${ }^{34}$ They are also more often absent from work, both in the short term (sick leave) and longer term (work disability), and report to be less productive while at work. ${ }^{19,36-38}$ This likely affects career prospects as well as psychological wellbeing and self-esteem. ${ }^{39}$ Explaining employment and work-related outcomes, such as absenteeism, could help identify which patients might need support in their worker role and reduce long-term adverse work outcome.

Of note, activities and participation (levels 2 and 3) are often not strictly separated, and classification of a domain, for example mobility, as an 'activity' or 'participation' depends on the individual situation. ${ }^{22}$ The burden of disease on all these levels has substantial impact on quality of life. ${ }^{40}$

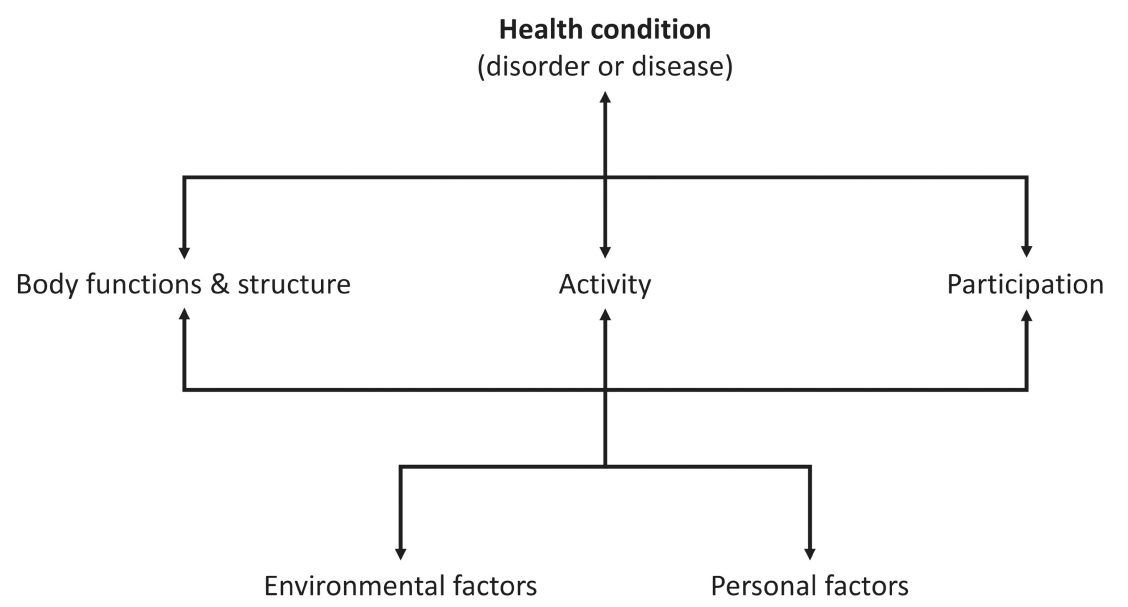

Figure 1.1. Diagram of the International Classification of Functioning, Disability and Health model as proposed by the World Health Organization. ${ }^{22}$ 


\section{Contextual factors}

An important notion in the ICF model is that disability and functioning are considered to be outcomes of interactions between health conditions, such as axSpA, and contextual factors. Contextual factors can be external (environmental) or internal (personal). Examples of environmental factors are the country one resides in and its legal and social regulations. Personal factors include factors such as gender, age and education but also personality, coping styles and past experiences. These contextual factors influence how one experiences dysfunction and disability. ${ }^{22}$ Recent recommendations for management of axSpA acknowledge the importance of the individual patient's context. ${ }^{20}$

Over the last decades, context has been increasingly acknowledged as an essential factor in the relation between axSpA and functioning..$^{41}$ Examples of factors studied include the impact of gender on radiographic progression (levels 1 and 2), or the impact of the working environment on sick leave (level 3). ${ }^{42,43}$ Nonetheless, some contextual factors have only been investigated in few patients, or only cross-sectionally, or not at all. Knowledge on relevant contextual factors and their influence is essential when improving the health of these patients. For example, while it is generally accepted that male and female patients with axSpA differ with regard to several outcomes, such as radiographic damage, most studies on this topic were cross-sectional or had only a limited follow-up period. ${ }^{44,45}$ Awareness of gender-attributable differences over time is important, as it could lead to a better understanding of the disease course, and improve the outcome for both male and female patients with axSpA.

\section{Valuation of health and outcome}

Traditionally, health in AS was assessed using the Assessment of SpondyloArhritis international Society (ASAS) core outcome domains. These domains include those aspects of health typically affected in AS, such as pain, stiffness and physical functioning. ${ }^{46}$ This approach is limited in helping to understand the overall health, as this was not included as an outcome domain. In order to overcome this, several methods to assess overall health are available. For example, preference-based methods have been developed, which explore the non-monetary value for overall health state and changes in health. An alternative to these are contingent valuation methods (CVMs), which explore the monetary value for (changes in) health state. ${ }^{47}$ Examples of CVMs are willingness-to-pay or willingness-to-accept approaches, which ask patients how much money they would pay or accept for a certain improvement or worsening in health, respectively. ${ }^{47-49}$ Like preference-based methods, results of CVMs can be compared across diseases. While CVMs such as willingness-to-pay approaches have strong theoretical grounds and can be a useful approach to evaluate treatment benefits, they are not as commonly used as traditional methods. This is unfortunate, as they can shed an additional perspective on the patient's valuation of treatments, ${ }^{47}$ and can be especially worthwhile for costly treatments that require a comprehensive view on their value. 


\section{The societal perspective on outcome in axSpA}

Due to the chronicity and multidimensional impact of axSpA on participation, the societal burden of axSpA is considerable. This burden is mainly of economic nature, and affects all payers of society, including hospitals, insurers and employers but also patients and their families.

\section{Costs of axSpA management}

The costs of management of axSpA are substantial. Patients are routinely followed-up over prolonged periods, and often in need of (para)medical treatments. Comorbidities further increase mangement costs. For most aspects of disease management, the costs of care for axSpA are comparable to those of other rheumatic disorders. ${ }^{50}$ bDMARDs are an important driver of costs of management. While the introduction of these drugs has led to unprecedented improvements in function and quality of life, they have come at a cost: bDMARDs are expensive and have substantial budget impact (annual drug costs range from approximately $€ 10,000$ to $€ 15,000$ ). ${ }^{51}$ In cost-of-illness studies, costs of bDMARDs constitute up to $60 \%$ of total costs. ${ }^{52,53}$ This has been a frequent topic of discussion. Several studies have investigated the cost-effectiveness of bDMARDS, mainly of the tumor necrosis factor alpha inhibitor (TNFi) type, in axSpA. ${ }^{54}$ The majority of these (mostly industrysponsored) studies reported favorable results, and currently bDMARDs are approved and reimbursed for axSpA in most countries. Importantly, the recent introduction of (less costly) biosimilar alternatives to these originator drugs has led to more favorable pricing of bDMARDs, a trend that might continue in the future.

\section{Productivity losses}

Employment is not only an important outcome for patients with axSpA, but also for society. Employment among patients is decreased, while adverse work outcome is increased. Consequently, the work-related burden of axSpA for society is high. This is reflected by the cost of illness. Of note, historically, the proportion of total costs that could be attributed to productivity loss was high (around 50-75\%). ${ }^{55,56}$ However, this number seems notably lower in early axSpA (10-30\%), possibly due to the introduction of bDMARDs. ${ }^{53}$ Biological DMARDs are costly (driving medical costs), but also improve work outcome (reducing productivity losses), thereby leading to a redistribution of costs. It should be noted that the method used to value productivity costs has an important influence on the results of these studies. ${ }^{56,57}$ 


\section{Economic evaluation of axSpA}

With the development of new technologies, such as novel diagnostic modalities and therapeutic interventions, healthcare (and health) is continuously improving. While society is definitely willing to pay for health, society also has limits in what it can afford. This means that society has to make a choice: which healthcare technologies should be paid for? In order to inform this decision, the potential health gains of different options (alternatives), usually expressed as quality-adjusted life-years (QALYS), are balanced against their cost. This is an economic evaluation. The purpose is to improve the uptake of cost-effective technologies and avoid the uptake of technologies that are of doubtful value. It should be kept in mind that the final decision is informed not only by economic evaluations, but also by organisational, social, legal and ethical aspects. ${ }^{58}$

The history of economic evaluations for a specific disease usually follows the discovery of new technologies for use in in healthcare, especially if these are costly and could have substantial budget impact. It is therefore not surprising that over the last decades most economic evaluations in axSpA investigated the cost-effectiveness of bDMARDs. ${ }^{54}$ While the concept of an economic evaluation might seem straightforward, the many aspects and uncertainties of modelling axSpA over a prolonged period of time have led to widely varying estimates in these studies.

Interestingly, although any technology (preventive, therapeutic or diagnostic) can be investigated in an economic evaluation, the majority of these studies in axSpA focused on therapeutics. In a way, this makes sense, as therapeutics are generally more costly, and therefore less likely to be approved without justification of their costs. However, the added cost of diagnostic or preventive technologies could be just as high, as the consequences for all types of costs are relevant. For example, while a new diagnostic technology in axSpA might not be as costly as a new drug, it would be expected to not only affect under- and overdiagnosis, but also under- and overtreatment (and the associated costs and health effects). Overdiagnosis and overtreatment are potential consequences of the increasing focus on early diagnosis of axSpA. ${ }^{59}$ Also, while different new diagnostic modalities are being developed and investigated, it is unlikely that all of these will eventually be considered useful for daily practice. Being able to determine during an early stage of development which technologies are more likely to be (cost-)effective, will support targeted investment and reduce research waste. ${ }^{60,61}$ Studies assessing the economic feasibility of future diagnostic modalities in axSpA are lacking, while this information would be very valuable when deciding which new modalities are worthwhile to explore and in which subgroup they are most needed. 


\section{Fulfilling the needs of all}

It is clear that patients and society have a different perspective on axSpA. The same can be stated regarding their needs. In care for axSpA, and SpA in general, patients need to be well-informed, involved in decision-making and have insight into their health state. Healthcare professionals should provide individualized care, taking the patient's context into account, and aimed at outcomes that matter to their patients. This requires regular and personalised monitoring of relevant outcomes using validated instruments. Society, i.e. the payers, needs transparency on outcomes, safety and efficiency, while unwarranted variation among care providers should be minimised.

In order to fulfill these needs, and capture the different perspectives on axSpA, registration of relevant outcomes in daily practice is essential, while at the same time capturing data for research. Unfortunately, the way care is provided using electronic medical records (EMRs) in their current form is not fit for this purpose. ${ }^{62}$ Disease measures that matter to patients are often not available and cannot easily be evaluated over time. Patients lack access to individual information on their health state, and transparency between care providers and centers is limited.

New developments, such as online monitoring tools, could support high-quality, personalized and efficient care for patients with SpA. ${ }^{63-69}$ Development of such systems could be considered the next step in improving quality of care for these patients, which would benefit all involved. From the patient's perspective, all domains that are relevant to his or her health could be captured. In addition to disease-specific domains, such as disease activity or physical functioning, this would include generic domains like overall health and work outcome. Altogether, this would provide a comprehensive view of health and disability within the context of the patient. In addition, if patients were provided the results of the instruments used to capture these domains, they could become well-informed and able to actively participate in decision-making.

On the population level, aggregated data could be used to identify and study subgroups, based on disease-specific or contextual factors, which would allow for tailored management and indirectly benefit the individual patient. From the society's perspective, data on outcomes, safety and practice variation could be captured and used to improve the quality and efficiency of care delivered. This would help maximize the health outcomes that we can achieve with the available budget, which would also benefit society as it is expected to reduce costs in non-healthcare sectors. 


\section{Aims and outline of this thesis}

This thesis describes several aspects of axSpA from the patient's and/or societal perspective. Based on the knowledge gaps as described above, the main research questions of this thesis are:

- Are there gender-attributable differences in clinical outcomes and radiographic progression in patients with AS over time?

- Which factors contribute to depressive symptoms in patients with AS, and how are these factors related to each other? Does treatment with TNFi affect depressive symptoms, and if so, is this effect mediated by an improvement in AS-related symptoms or a direct consequence of reduced inflammation?

- Which factors, contextual or disease-related, explain sick leave in patients with AS over time? Is the employment of patients with AS still decreased in comparison to the general population in the current bDMARD era?

- How do patients with AS value treatment with a TNFi in monetary terms?

- What is the comparative cost-effectiveness of the currently available diagnostic algorithms for axSpA? Can diagnosis of axSpA be improved in a cost-effective manner, using current and future developments?

- Can we develop and implement an integrated eHealth system for (tele-)monitoring and reporting of health-related data of patients with SpA, including an EMR and real-time quality management system, in order to facilitate integration of the patient's, healthcare provider's and society's perspective on quality of care?

In Chapter 2 of this thesis, we describe a longitudinal analysis of the Outcome in Ankylosing Spondylitis International Study (OASIS) cohort on gender-attributable differences in several outcomes, in patients with AS over a 12-year follow-up period. In Chapter 3, contextual and disease-related factors from the cross-sectional Social Role Participation in Ankylosing Spondylitis Study (SPASS) are integrated for the development of a comprehensive model of depressive symptoms in AS using structural equation modelling. In Chapter $\mathbf{4}$, we evaluate the effect of a TNFi (compared to placebo) on depressive symptoms in patients with active AS in an ancillary study of the Ankylosing Spondylitis Study for the Evaluation of Recombinant Infliximab Therapy (ASSERT), a randomized controlled trial. This ancillary study also addresses the question whether comorbid depression in AS is secondary to ASrelated symptoms or driven directly by inflammation. In Chapter $\mathbf{5}$, we present the results of a longitudinal analysis of sick leave in employed patients with AS in OASIS. The pattern of sick leave over time is described, and potential determinants of sick leave over time are investigated, including prior sick leave itself. In Chapter 6, the employment rates of patients with AS in the bDMARD era are compared to general population controls, using data from SPASS. In addition, the role of mastery, a contextual factor reflecting level of control over 
life and disease, in regard to employment is investigated in both populations. In Chapter 7, we evaluate how patients with AS value treatment with a TNFi in monetary terms, using a willingness-to-pay approach, in the European Ankylosing Spondylitis Infliximab Cohort (EASIC). In Chapter 8, the results of a cost-effectiveness analysis of several diagnostic algorithms for axSpA in the Netherlands are presented. In addition, several hypothetical diagnostic scenarios are investigated, to assess the potential value of improving diagnostic accuracy for axSpA. In Chapter $\mathbf{9}$, the development of an integrated registry and qualitymanagement system for SpA in the Netherlands is described, as well as the usability and acceptability of this system among patients and care providers. Finally, in Chapter $\mathbf{1 0}$ the findings of these studies are summarized and discussed, and in Chapter $\mathbf{1 1}$ the scientific and societal impact of this thesis is discussed. 


\section{References}

1. Sieper J, Poddubnyy D. Axial spondyloarthritis. Lancet 2017;390:73-84.

2. Brown MA, Kennedy LG, MacGregor AJ, Darke C, Duncan E, Shatford JL, et al. Susceptibility to ankylosing spondylitis in twins: the role of genes, HLA, and the environment. Arthritis Rheum 1997;40:1823-1828.

3. van der Linden $S M$, Valkenburg HA, de Jongh BM, Cats A. The risk of developing ankylosing spondylitis in HLA-B27 positive individuals. A comparison of relatives of spondylitis patients with the general population. Arthritis Rheum 1984;27:241-249.

4. Rudwaleit M, van der Heijde D, Landewe R, Listing J, Akkoc N, Brandt J, et al. The development of Assessment of SpondyloArthritis international Society classification criteria for axial spondyloarthritis (part II): validation and final selection. Ann Rheum Dis 2009;68:777-783.

5. Boel A, Molto A, van der Heijde D, Ciurea A, Dougados M, Gensler LS, et al. Do patients with axial spondyloarthritis with radiographic sacroiliitis fulfil both the modified New York criteria and the ASAS axial spondyloarthritis criteria? Results from eight cohorts. Ann Rheum Dis 2019;78:1545-1549.

6. Stolwijk C, van Onna M, Boonen A, van Tubergen A. Global Prevalence of Spondyloarthritis: A Systematic Review and Meta-Regression Analysis. Arthritis Care Res (Hoboken) 2016;68:1320-1331.

7. Bakland G, Nossent HC. Epidemiology of spondyloarthritis: a review. Curr Rheumatol Rep 2013;15:351.

8. Rudwaleit M, van der Heijde D, Khan MA, Braun J, Sieper J. How to diagnose axial spondyloarthritis early. Ann Rheum Dis 2004;63:535-543.

9. Sykes MP, Doll H, Sengupta R, Gaffney K. Delay to diagnosis in axial spondyloarthritis: are we improving in the UK? Rheumatology (Oxford) 2015;54:2283-2284.

10. Callhoff J, Sieper J, Weiss A, Zink A, Listing J. Efficacy of TNFalpha blockers in patients with ankylosing spondylitis and non-radiographic axial spondyloarthritis: a meta-analysis. Ann Rheum Dis 2015;74:1241-1248.

11. Kroon FP, van der Burg LR, Ramiro S, Landewe RB, Buchbinder R, Falzon L, et al. Non-steroidal anti-inflammatory drugs (NSAIDs) for axial spondyloarthritis (ankylosing spondylitis and nonradiographic axial spondyloarthritis). Cochrane Database Syst Rev 2015 CD010952.

12. Rudwaleit M, Listing J, Brandt J, Braun J, Sieper J. Prediction of a major clinical response (BASDAI 50) to tumour necrosis factor alpha blockers in ankylosing spondylitis. Ann Rheum Dis 2004;63:665-670.

13. Rudwaleit M, Claudepierre P, Wordsworth P, Cortina EL, Sieper J, Kron M, et al. Effectiveness, safety, and predictors of good clinical response in 1250 patients treated with adalimumab for active ankylosing spondylitis. J Rheumatol 2009;36:801-808.

14. Haroon N, Inman RD, Learch TJ, Weisman MH, Lee M, Rahbar MH, et al. The impact of tumor necrosis factor alpha inhibitors on radiographic progression in ankylosing spondylitis. Arthritis Rheum 2013;65:2645-2654 
15. Braun J, Baraliakos X, Hermann KG, Deodhar A, van der Heijde D, Inman R, et al. The effect of two golimumab doses on radiographic progression in ankylosing spondylitis: results through 4 years of the GO-RAISE trial. Ann Rheum Dis 2014;73:1107-1113.

16. van der Heijde D, Landewe R, Einstein S, Ory P, Vosse D, Ni L, et al. Radiographic progression of ankylosing spondylitis after up to two years of treatment with etanercept. Arthritis Rheum 2008;58:1324-1331.

17. van der Heijde D, Salonen D, Weissman BN, Landewe R, Maksymowych WP, Kupper H, et al. Assessment of radiographic progression in the spines of patients with ankylosing spondylitis treated with adalimumab for up to 2 years. Arthritis Res Ther 2009;11:R127.

18. van der Heijde D, Landewe R, Baraliakos X, Houben H, van Tubergen A, Williamson P, et al. Radiographic findings following two years of infliximab therapy in patients with ankylosing spondylitis. Arthritis Rheum 2008;58:3063-3070.

19. Boonen A, Brinkhuizen T, Landewe R, van der Heijde D, Severens JL. Impact of ankylosing spondylitis on sick leave, presenteeism and unpaid productivity, and estimation of the societal cost. Ann Rheum Dis 2010;69:1123-1128.

20. van der Heijde D, Ramiro S, Landewe R, Baraliakos X, Van den Bosch F, Sepriano A, et al. 2016 update of the ASAS-EULAR management recommendations for axial spondyloarthritis. Ann Rheum Dis 2017;76:978-991.

21. van der Horst-Bruinsma IE, Oostveen JCM, van Denderen JC, de Sonnaville PB, Nurmohamed MT, van Tubergen A, et al. Guideline for the diagnosis and treatment of axial spondyloarthritis [Richtlijn voor de diagnostiek en behandeling van axiale spondyloartritis]. Nederlandse Vereniging voor Reumatologie 2014.

22. World Health Organization. International classification of functioning, disability and health: ICF. Geneva: World Health Organization; 2001.

23. World Health Organization. How to use the ICF: A practical manual for using the International Classification of Functioning, Disability and Health (ICF). Geneva: World Health Organization, 2013.

24. Maksymowych WP, Chiowchanwisawakit P, Clare T, Pedersen SJ, Ostergaard M, Lambert RG. Inflammatory lesions of the spine on magnetic resonance imaging predict the development of new syndesmophytes in ankylosing spondylitis: evidence of a relationship between inflammation and new bone formation. Arthritis Rheum 2009;60:93-102.

25. Stolwijk C, Essers I, van Tubergen A, Boonen A, Bazelier MT, De Bruin ML, et al. The epidemiology of extra-articular manifestations in ankylosing spondylitis: a population-based matched cohort study. Ann Rheum Dis 2015;74:1373-1378.

26. Molto A, Etcheto A, van der Heijde D, Landewe R, van den Bosch F, Bautista Molano W, et al. Prevalence of comorbidities and evaluation of their screening in spondyloarthritis: results of the international cross-sectional ASAS-COMOSPA study. Ann Rheum Dis 2016;75:1016-1023.

27. Zhao S, Thong D, Miller N, Duffield SJ, Hughes DM, Chadwick L, et al. The prevalence of depression in axial spondyloarthritis and its association with disease activity: a systematic review and meta-analysis. Arthritis Res Ther 2018;20:140. 
28. Lowe B, Willand L, Eich W, Zipfel S, Ho AD, Herzog W, et al. Psychiatric comorbidity and work disability in patients with inflammatory rheumatic diseases. Psychosom Med 2004;66:395-402.

29. Nikiphorou E, Ramiro S, van der Heijde D, Norton S, Molto A, Dougados M, et al. Association of Comorbidities in Spondyloarthritis With Poor Function, Work Disability, and Quality of Life: Results From the Assessment of SpondyloArthritis International Society Comorbidities in Spondyloarthritis Study. Arthritis Care Res (Hoboken) 2018;70:1257-1262.

30. Baillet A, Gossec L, Carmona L, Wit M, van Eijk-Hustings Y, Bertheussen H, et al. Points to consider for reporting, screening for and preventing selected comorbidities in chronic inflammatory rheumatic diseases in daily practice: a EULAR initiative. Ann Rheum Dis 2016;75:965-973.

31. Miller $\mathrm{AH}$, Raison $\mathrm{CL}$. The role of inflammation in depression: from evolutionary imperative to modern treatment target. Nat Rev Immunol 2016;16:22-34.

32. Kiltz U, Essers I, Hiligsmann M, Braun J, Maksymowych WP, Taylor WJ, et al. Which aspects of health are most important for patients with spondyloarthritis? A Best Worst Scaling based on the ASAS Health Index. Rheumatology (Oxford) 2016;55:1771-1776.

33. Gignac MA, Backman CL, Davis AM, Lacaille D, Mattison CA, Montie P, et al. Understanding social role participation: what matters to people with arthritis? J Rheumatol 2008;35:1655-1663.

34. van Genderen S, Plasqui G, Landewe R, Lacaille D, Arends S, van Gaalen F, et al. Social Role Participation in Patients With Ankylosing Spondylitis: A Cross-Sectional Comparison With Population Controls. Arthritis Care Res (Hoboken) 2016;68:1899-1905.

35. Boonen A, Chorus A, Miedema H, van der Heijde D, van der Tempel H, van der Linden S. Employment, work disability, and work days lost in patients with ankylosing spondylitis: a cross sectional study of Dutch patients. Ann Rheum Dis 2001;60:353-358.

36. van der Weijden MA, Boonen A, van der Horst-Bruinsma IE. Problems in work participation and resource use should not be underestimated in patients with early spondyloarthritis. J Rheumatol 2014;41:2413-2420.

37. Castillo-Ortiz JD, Ramiro S, Landewe R, van der Heijde D, Dougados M, van den Bosch F, et al. Work Outcome in Patients With Ankylosing Spondylitis: Results From a 12-Year Followup of an International Study. Arthritis Care Res (Hoboken) 2016;68:544-552.

38. Gordeev VS, Maksymowych WP, Schachna L, Boonen A. Understanding presenteeism in patients with ankylosing spondylitis: contributing factors and association with sick leave. Arthritis Care Res (Hoboken) 2014;66:916-924.

39. Floderus B, Goransson S, Alexanderson K, Aronsson G. Self-estimated life situation in patients on long-term sick leave. J Rehabil Med 2005;37:291-299.

40. Kiltz $U$, van der Heijde D. Health-related quality of life in patients with rheumatoid arthritis and in patients with ankylosing spondylitis. Clin Exp Rheumatol 2009;27:S108-111.

41. Gordeev VS, Maksymowych WP, Evers SM, Ament A, Schachna L, Boonen A. Role of contextual factors in health-related quality of life in ankylosing spondylitis. Ann Rheum Dis 2010;69:108-112. 
42. Baraliakos $X$, Listing J, von der Recke A, Braun J. The natural course of radiographic progression in ankylosing spondylitis: differences between genders and appearance of characteristic radiographic features. Curr Rheumatol Rep 2011;13:383-387.

43. Chorus AM, Boonen A, Miedema HS, van der Linden S. Employment perspectives of patients with ankylosing spondylitis. Ann Rheum Dis 2002;61:693-699.

44. Lee W, Reveille JD, Davis JC, Jr., Learch TJ, Ward MM, Weisman MH. Are there gender differences in severity of ankylosing spondylitis? Results from the PSOAS cohort. Ann Rheum Dis 2007;66:633-638.

45. Rudwaleit M, Haibel H, Baraliakos X, Listing J, Marker-Hermann E, Zeidler H, et al. The early disease stage in axial spondylarthritis: results from the German Spondyloarthritis Inception Cohort. Arthritis Rheum 2009;60:717-727.

46. Sieper J, Rudwaleit M, Baraliakos X, Brandt J, Braun J, Burgos-Vargas R, et al. The Assessment of SpondyloArthritis international Society (ASAS) handbook: a guide to assess spondyloarthritis. Ann Rheum Dis 2009;68 Suppl 2:ii1-44.

47. Klose T. The contingent valuation method in health care. Health Policy 1999;47:97-123.

48. O'Brien B, Gafni A. When do the "dollars" make sense? Toward a conceptual framework for contingent valuation studies in health care. Med Decis Making 1996;16:288-299.

49. Diener A, O'Brien B, Gafni A. Health care contingent valuation studies: a review and classification of the literature. Health Econ 1998;7:313-326.

50. Huscher D, Merkesdal S, Thiele K, Zeidler H, Schneider M, Zink A, et al. Cost of illness in rheumatoid arthritis, ankylosing spondylitis, psoriatic arthritis and systemic lupus erythematosus in Germany. Ann Rheum Dis 2006;65:1175-1183.

51. Zorginstituut Nederland / www.medicijnkosten.nl; 2019 [cited 2019 December 1]. Available from: http://www.medicijnkosten.nl/.

52. Strombeck B, Englund M, Bremander A, Jacobsson LT, Kedza L, Kobelt G, et al. Cost of illness from the public payers' perspective in patients with ankylosing spondylitis in rheumatological care. J Rheumatol 2010;37:2348-2355.

53. Harvard S, Guh D, Bansback N, Richette P, Dougados M, Anis A, et al. Costs of early spondyloarthritis: estimates from the first 3 years of the DESIR cohort. RMD Open 2016;2:e000230.

54. Gaujoux-Viala C, Fautrel B. Cost effectiveness of therapeutic interventions in ankylosing spondylitis: a critical and systematic review. Pharmacoeconomics 2012;30:1145-1156.

55. Ward MM. Functional disability predicts total costs in patients with ankylosing spondylitis. Arthritis Rheum 2002;46:223-231.

56. Franke LC, Ament AJ, van de Laar MA, Boonen A, Severens JL. Cost-of-illness of rheumatoid arthritis and ankylosing spondylitis. Clin Exp Rheumatol 2009;27:S118-123.

57. van den Hout WB. The value of productivity: human-capital versus friction-cost method. Ann Rheum Dis 2010;69 Suppl 1:i89-91.

58. Drummond MF, Sculpher MJ, Claxton K, Stoddart GL, Torrance GW. Methods for the Economic Evaluation of Health Care Programmes. 4th ed. Oxford: Oxford University Press; 2015. 
59. Landewe RBM. Overdiagnosis and overtreatment in rheumatology: a little caution is in order. Ann Rheum Dis 2018;77:1394-1396.

60. Macleod MR, Michie S, Roberts I, Dirnagl U, Chalmers I, loannidis JP, et al. Biomedical research: increasing value, reducing waste. Lancet 2014;383:101-104.

61. IJzerman MJ, Steuten LM. Early assessment of medical technologies to inform product development and market access: a review of methods and applications. Appl Health Econ Health Policy 2011;9:331-347.

62. Newman ED, Lerch V, Billet J, Berger A, Kirchner HL. Improving the quality of care of patients with rheumatic disease using patient-centric electronic redesign software. Arthritis Care Res (Hoboken) 2015;67:546-553.

63. Richter JG, Chehab G, Schneider M. Electronic health records in rheumatology: emphasis on automated scoring and additional use. Clin Exp Rheumatol 2016;34:S62-S68.

64. van der Vaart R, Drossaert CH, Taal E, Drossaers-Bakker KW, Vonkeman HE, van de Laar MA. Impact of patient-accessible electronic medical records in rheumatology: use, satisfaction and effects on empowerment among patients. BMC Musculoskelet Disord 2014;15:102.

65. Porter ME, Teisberg EO. How physicians can change the future of health care. JAMA 2007;297:1103-1111.

66. Sokka T. Go, go, GoTreatIT! Clin Exp Rheumatol 2016;34:S91-S95.

67. Catarinella FS, Bos WH. Digital health assessment in rheumatology: current and future possibilities. Clin Exp Rheumatol 2016;34:S2-S4.

68. Sargious A, Lee SJ. Remote collection of questionnaires. Clin Exp Rheumatol 2014;32:S-168-172.

69. Kiltz U, Boonen A, Braun J, Richter JG. Electronic assessment of disease activity and functioning in patients with axial spondyloarthritis: challenges and unmet needs. Clin Exp Rheumatol 2016;34:S57-S61. 


\section{Chapter 2}

Gender-attributable differences in outcome of ankylosing spondylitis: long-term results from the Outcome in Ankylosing Spondylitis International Study

Casper Webers, Ivette Essers, Sofia Ramiro, Carmen Stolwijk, Robert Landewé, Désirée van der Heijde, Filip van den Bosch, Maxime Dougados, Astrid van Tubergen

Rheumatology (Oxford) 2016;55:419-428 


\section{Abstract}

\section{Objective}

To investigate gender-attributable differences regarding clinical outcome (disease activity, physical function and quality of life [QoL]) and radiographic damage in patients with ankylosing spondylitis (AS) over time.

\section{Methods}

Data from the Outcome in AS International Study were used. Disease activity was assessed by the Bath AS Disease Activity Index (BASDAI), AS Disease Activity Score, and C-reactive protein; physical function by Bath AS Functional Index; QoL by the Short Form 36, AS Quality of Life (ASQoL) and EuroQoL; and radiographic damage by the modified Stoke AS Spine Score (mSASSS). Cross-sectional comparative analyses were done at baseline. Next, separate models were created to assess gender-attributable differences on each outcome measure over time using time-adjusted generalized estimation equations.

\section{Results}

A total of 216 patients (154 [72.3\%] males, mean age 43.6 years [SD 12.7], symptom duration 20.5 years [SD 11.8], mean follow-up duration 8.3 years [SD 4.1]) were included. At baseline, male compared with female patients had lower self-reported disease activity (BASDAI 3.2 vs 3.9, $p=0.03$ ) but more radiographic damage (mSASSS 13.8 vs 6.5, $p=0.02$ ). No significant gender-attributable differences in other clinical parameters were found. In multivariable analysis, male gender was significantly associated with a better ASQoL ( $B=-1.18,95 \%$ confidence interval $[\mathrm{Cl}]-2.17$ to $-0.20, p=0.02)$, and in a separate model with a higher mSASSS over time $(B=8.24,95 \% C l 4.38$ to $12.09, p<0.01)$.

\section{Conclusion}

In this prospective cohort study, no gender-attributable differences in disease activity or physical function over time were found. However, radiographic damage was more severe in males. Furthermore, males had a better QoL over time. 


\section{Introduction}

Ankylosing spondylitis (AS) is a chronic rheumatic disorder that can result in important disability and impairment of quality of life (QoL). ${ }^{1}$ For a long time, AS has been considered as a disease occurring predominantly in males, with an estimated male to female ratio of 9:1.2,3 More recent data show that AS also frequently occurs in females. ${ }^{4-6}$ Nowadays, it is estimated that the male to female ratio is approx. 2-3:1.7 Because of this previous misconception, the majority of AS populations studied in the past consisted predominantly of male patients. The results from these studies are, therefore, mainly applicable to the male and, at best, only part of the female population with AS.

Studies from the last decade have shown that there might be gender-attributable differences in patients with AS regarding disease characteristics, clinical outcome, radiographic damage and response to treatment. Female patients were found to have a longer delay in diagnosis, ${ }^{4,7}$ and an equal ${ }^{4}$ or higher age at disease onset. ${ }^{6,8-10}$ With respect to clinical manifestations, some studies reported that female patients suffer more often from peripheral arthritis, ${ }^{17-13}$ although other studies failed to demonstrate this., ${ }^{8,14}$ One study suggested that psoriasis is more common among male patients with AS, while the prevalence of inflammatory bowel disease (IBD) does not seem to be gender-related; ${ }^{6}$ conflicting results with respect to a gender-related difference in the prevalence of acute anterior uveitis have been reported. , $^{814}$ With regard to patient-reported outcomes, female patients report worse scores on (nocturnal) back pain, 9,10,14 disease activity, ,11,13 functional outcome, ${ }^{9,10}$ and QoL. ${ }^{15}$ Radiographic damage to the spine is on average more severe in male patients. ${ }^{4,8,11,12,16-18}$ Finally, females with AS show on average a worse treatment response with respect to both disease activity and functional outcome. ${ }^{10}$ Unfortunately, most of these studies were cross-sectional, limiting the drawing of conclusions about gender-attributable differences in disease course over time. Longitudinal studies exploring these gender-attributable differences with respect to outcome over time are scarce or have only a short follow-up period..$^{17}$

Awareness of these gender-attributable differences is, however, important, and could lead to a better understanding of the disease course and improvement of care in general and the outcome for female patients with AS in particular, who have been underreported in the past. The aim of the present study was to investigate gender-attributable differences with respect to clinical outcomes (disease activity, physical function and QoL) and radiographic damage in patients with AS over a 12-year follow-up period. 


\section{Methods}

\section{Patients}

For this study, data from the Outcome in AS International Study (OASIS) were used. OASIS is an ongoing longitudinal observational multicentre study, initiated in September 1996. A total of 217 consecutive patients from the Netherlands, Belgium and France who met the modified New York Criteria for AS ${ }^{19}$ were included. All patients were treated according to standard care, which included both pharmacological treatment (nonsteroidal anti-inflammatory drugs [NSAIDs], disease-modifying antirheumatic drugs [DMARDs], analgesics and/or biologics) and non-pharmacological treatment (exercises, physiotherapy). Biologics were prescribed on indication since 2002. All patients signed informed consent for the OASIS study. The OASIS study protocol was approved by the respective ethics committee from every participating centre. The approval and consent included this analysis.

\section{Demographic, clinical and radiographic characteristics}

Information about gender, age, human leucocyte antigen (HLA)-B27 status, hip involvement, duration of symptoms, and time of diagnosis was collected at baseline. Patients were assessed for clinical outcomes every year during the first 6 years of follow-up and every 2 years thereafter, and for radiographic outcome every 2 years.

Disease activity was measured with the Bath Ankylosing Spondylitis Disease Activity Index (BASDAI), ${ }^{20}$ Ankylosing Spondylitis Disease Activity Score (ASDAS) with C-reactive protein (CRP) ${ }^{21}$ and laboratory tests (erythrocyte sedimentation rate [ESR] and CRP). Physical function was assessed by the Bath Ankylosing Spondylitis Functional Index (BASFI).22 QoL was measured with the Ankylosing Spondylitis Quality of Life score (ASQoL), ${ }^{23}$ the Short Form 36 (SF-36) ${ }^{24,25}$ and the European Quality of Life scale (EuroQoL). ${ }^{26}$ The EuroQoL was assessed at baseline and all subsequent visits. The ASQoL and SF-36 were not yet available at baseline, but first used at 4 years of follow-up and all assessments thereafter. The severity of back pain experienced during the week prior to a follow-up visit was assessed by a 10-cm visual analogue scale. The Bath Ankylosing Spondylitis Global Score (BAS-G) was used for global assessment of the patient's well-being. ${ }^{27}$ Presence and degree of enthesitis were assessed using the Mander Enthesitis Index. ${ }^{28}$ The Bath Ankylosing Spondylitis Metrology Index (BASMI) was used to assess spinal mobility. ${ }^{29}$ Radiographic damage to the spine was scored with the modified Stoke AS Spine Score (mSASSS). ${ }^{30,31}$ Two independent expert readers had scored the radiographs at every time point in chronological time order, with good interobserver reliability, ${ }_{16}^{16}$ and the mean of their scores has been used for final calculation of the mSASSS. Information about pharmacological treatment (use of NSAIDs, DMARDs and biologics) has been retrieved 
at every visit using clinical records and data from the pharmacists. Use of NSAIDs was converted into the Assessment of SpondyloArthritis International Society-NSAID score. ${ }^{32}$

\section{Statistical analysis}

Descriptive statistics were used to calculate the mean with SD for continuous data, and frequencies were calculated for dichotomous data. Gender-attributable differences at baseline were explored with an independent t-test, Mann-Whitney test or chi-square test, as appropriate. For small samples (expected count $<5$ ), Fisher's exact test was applied.

Gender-attributable differences over time were visually investigated by plotting the mean of the group, stratified for gender, at all assessments during follow-up for each of the outcome variables. Next, possible associations between gender and each of the outcome variables (disease activity, physical function, QoL and radiographic damage) over time were assessed by generalized estimating equation (GEE) analyses. An exchangeable correlation structure was chosen. Variables from the univariable GEE analysis with a $p<$ 0.20 were further explored in the multivariable analysis. A forward selection method was chosen for building the models. ASDAS-CRP was preferred over BASDAI as a measure of disease activity in multivariable analysis. If the regression coefficient of the association of primary interest (including the variable gender) changed $\geq 10 \%$ upon inclusion of a new variable, this new variable was considered a relevant confounder and kept in the model. Collinearity was checked for, and relevant interactions between the variables were explored and corrected for if necessary. For all multivariable analyses, $p<0.05$ was considered significant. A sensitivity analysis was performed with data from the subgroup of patients who completed the entire follow-up period of 12 years (12-year completers) in order to detect possible selection bias due to loss of follow-up. All statistics were performed with SPSS v.20.0 (IBM, Armonk, NY, USA).

\section{Results}

At baseline, 216 patients were included in the OASIS cohort. One patient from the original 217 patients was excluded from further analysis because of inconsistencies in baseline and follow-up data. Of these 216 patients, 62 (28.7\%) were female. Table 2.1 shows the comparisons of baseline characteristics between male and female patients. Female patients compared with male patients were older $(p=0.02)$, had a longer duration of symptoms $(p=0.03)$, a longer delay in diagnosis $(p=0.04)$, and had significantly higher scores in self-reported disease activity (BASDAI) $(p=0.03)$, tender joint count $(p<0.01)$ and the Mander enthesitis index $(p<0.01)$. Male patients had significantly more radiographic damage $(p=0.02)$ and higher CRP $(p=0.04)$. 
Table 2.1. Baseline characteristics of the total study population and for the male and female patients separately

\begin{tabular}{|c|c|c|c|c|}
\hline Variable & $\begin{array}{l}\text { Total group } \\
(\mathrm{n}=216)\end{array}$ & $\begin{array}{c}\text { Males } \\
(n=154)\end{array}$ & $\begin{array}{c}\text { Females } \\
(n=62)\end{array}$ & $\mathbf{p}^{*}$ \\
\hline Age, years & $43.6(12.7)$ & $42.3(12.4)$ & $46.8(12.8)$ & 0.02 \\
\hline Age at onset symptoms, years & $23.2(9.1)$ & $23.1(9.4)$ & $23.3(8.3)$ & 0.92 \\
\hline Duration of symptoms, years & $20.5(11.8)$ & $19.2(10.8)$ & $23.5(13.4)$ & 0.03 \\
\hline Delay in diagnosis, years & $8.9(8.5)$ & $8.0(7.7)$ & $10.8(9.9)$ & 0.04 \\
\hline HLA-B27 positive, n (\%) & $174(84.5)$ & $128(87.1)$ & $46(78.0)$ & 0.10 \\
\hline History of IBD, n (\%) & $15(7.0)$ & $12(7.8)$ & $3(4.9)$ & 0.46 \\
\hline History of psoriasis, n (\%) & $9(4.2)$ & $6(3.9)$ & $3(4.9)$ & 0.72 \\
\hline History of $A A U, n(\%)$ & $39(18.1)$ & $28(18.2)$ & $11(18.0)$ & 0.98 \\
\hline Hip involvement, $n(\%)$ & $45(21.2)$ & $38(25.3)$ & $7(11.3)$ & 0.02 \\
\hline \multicolumn{5}{|l|}{ Medication use, current } \\
\hline NSAID, n (\%) & $146(67.6)$ & $103(66.9)$ & $43(69.4)$ & 0.73 \\
\hline ASAS NSAID score & $57.5(53.9)$ & $57.6(52.3)$ & $57.3(58.1)$ & 0.97 \\
\hline DMARDs, n (\%) & $18(8.3)$ & $15(9.7)$ & $3(4.8)$ & 0.24 \\
\hline Smoking (current), n (\%) & $55(39.6)$ & $45(45.5)$ & $10(25.0)$ & 0.03 \\
\hline CRP, mg/l & $18.0(24.4)$ & $19.5(25.0)$ & $14.2(22.8)$ & 0.04 \\
\hline Elevated CRP, n (\%) ${ }^{+}$ & $101(48.3)$ & $76(51.0)$ & $25(41.7)$ & 0.22 \\
\hline $\mathrm{ESR}, \mathrm{mm} / \mathrm{h}$ & $14.6(15.7)$ & $14.5(16.7)$ & $14.8(13.0)$ & 0.13 \\
\hline ASDAS-CRP & $2.7(1.1)$ & $2.7(1.1)$ & $2.8(0.9)$ & 0.74 \\
\hline BASDAI (0-10) & $3.4(2.1)$ & $3.2(2.2)$ & $3.9(1.9)$ & 0.03 \\
\hline BASFI (0-10) & $3.4(2.6)$ & $3.5(2.7)$ & $3.2(2.5)$ & 0.44 \\
\hline Back pain $(0-10)$ & $3.5(2.4)$ & $3.3(2.4)$ & $4.1(2.2)$ & 0.04 \\
\hline BAS-G (0-10) & $3.9(2.6)$ & $3.7(2.6)$ & $4.2(2.4)$ & 0.25 \\
\hline EuroQoL (0-100) & $68.8(15.5)$ & $69.4(16.3)$ & $67.2(13.2)$ & 0.34 \\
\hline ASQoL ${ }^{\ddagger}$ & $6.2(4.5)$ & $5.8(4.2)$ & $7.2(5.0)$ & 0.16 \\
\hline SF-36PCS & $37.8(11.2)$ & $38.7(10.8)$ & $35.8(11.8)$ & 0.16 \\
\hline SF-36MCS ${ }^{\ddagger}$ & $51.5(11.9)$ & $52.9(11.1)$ & $48.3(13.1)$ & 0.03 \\
\hline Swollen joint count & $0.8(2.6)$ & $0.8(2.9)$ & $0.9(2.0)$ & 0.18 \\
\hline Tender joint count & $3.2(5.0)$ & $2.7(5.1)$ & $4.4(4.7)$ & $<0.01$ \\
\hline BASMI (0-10) & $3.8(1.6)$ & $3.9(1.7)$ & $3.7(1.3)$ & 0.50 \\
\hline $\begin{array}{l}\text { Mander enthesitis index } \\
(0-90)\end{array}$ & $10.6(15.6)$ & $8.2(13.5)$ & $16.6(18.7)$ & $<0.01$ \\
\hline mSASSS (0-72) & $11.6(16.2)$ & $13.8(17.8)$ & $6.5(9.7)$ & 0.02 \\
\hline
\end{tabular}

Values are expressed as mean (SD) unless otherwise stated. ${ }^{\star}$ Two-tailed males vs females. For continuous data, independent t-tests were used for normally distributed variables and Mann-Whitney tests for non-normally distributed variables. For categorical data, chi-square tests were used. Fisher's exact test was used for small samples (expected count $<5$ ). ${ }^{+} \mathrm{CRP}$ levels $\geq 10 \mathrm{mg} / \mathrm{l}$ were considered elevated. ${ }^{\ddagger}$ ASQoL, SF-36PCS and SF-36MCS were first used at 4 years of follow-up. AAU, acute anterior uveitis; ASAS, Assessment of SpondyloArthritis International Society; ASDAS, Ankylosing Spondylitis Disease Activity Score; ASQoL, Ankylosing Spondylitis Quality of Life score; BASDAI, Bath Ankylosing Spondylitis Disease Activity Index; BASFI, Bath Ankylosing Spondylitis Functional Index; BASMI, Bath Ankylosing Spondylitis Metrology Index; BAS-G, Bath Ankylosing Spondylitis Global Score; CRP, C-reactive protein; DMARD, disease-modifying antirheumatic drug; ESR, erythrocyte 
sedimentation rate; EuroQoL, European Quality Of Life scale; HLA-B27, human leucocyte antigen B27; IBD, inflammatory bowel disease; mSASSS, modified Stoke Ankylosing Spondylitis Spine Score; NSAID, non-steroidal anti-inflammatory drug; SF-36MCS, Short Form 36 Mental Component Summary score; SF-36PCS, Short Form 36 Physical Component Summary score.

\section{Gender-attributable differences over time}

The average follow-up duration was not significantly different for male and female patients (mean 8.1 vs 8.9 years, $p=0.15$ ). Forty-three patients (19.9\%) used a biologic at some stage during follow-up. The association between gender and each of the outcomes (disease activity, physical function, QoL and radiographic damage) over time was assessed in the total population and in the subset of the 12-year completers $(n=98)$. Because the results did not differ substantially for the 12-year completers, only the results for the total population will be described here.

Figure 2.1 shows that female compared with male patients had higher self-reported disease activity (BASDAI), lower CRP and similar ASDAS scores over time. Interestingly, CRP levels and ASDAS decreased in both groups over time. Mean BASFI scores were similar for male and female patients over time. With regard to QoL, the ASQoL was found to be higher (i.e. worse) in female patients, especially in the first years of follow-up; however, no (large) differences in EuroQoL or SF-36 scores between female and male patients over time were seen. Progression in radiographic damage was seen in both male and female patients, but was more rapid in male patients over time.

\section{Disease activity}

Univariable GEE analysis showed an association between male patients and a lower BASDAl over time ( $\mathrm{B}=-0.67,95 \%$ confidence interval $[\mathrm{Cl}]-1.25$ to $-0.10, \mathrm{p}=0.02)$. On the other hand, CRP levels were higher in male patients over time $(B=4.82,95 \% \mathrm{Cl} 1.45$ to 8.20, $\mathrm{p}<0.01)$. ASDAS scores were not significantly different between male and female patients in univariable analysis $(B=-0.03,95 \% \mathrm{Cl}-0.29$ to $0.24, p=0.85)$. Because ASDAS, by also incorporating the CRP, was considered more representative of disease activity than the BASDAI alone, gender-attributable differences in disease activity were not explored further by multivariable analysis. 

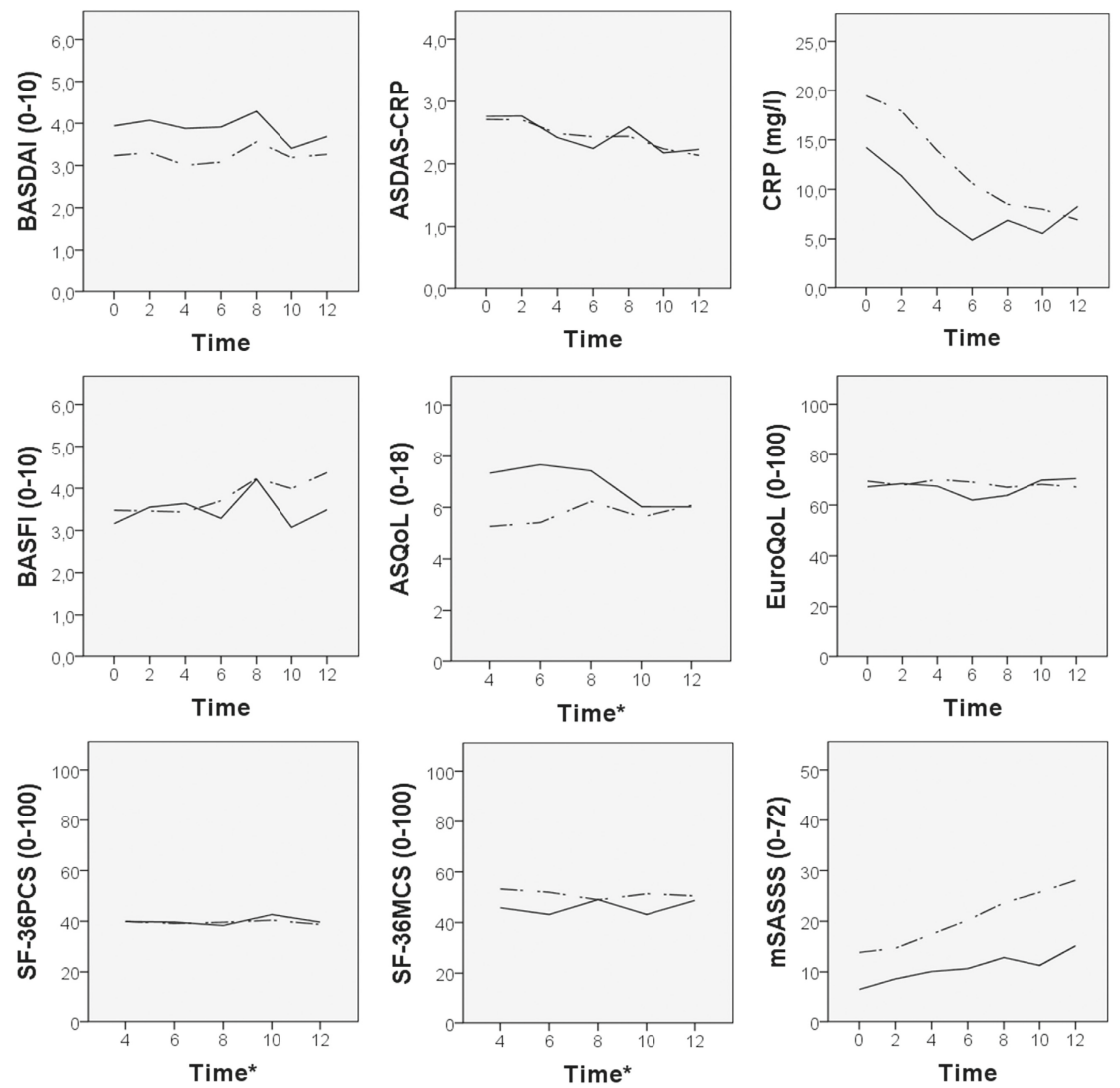

- Female - - - Male

Figure 2.1. Longitudinal course of several outcomes in patients with AS stratified for gender. Time represents follow-up duration, expressed in years. *The ASQoL, SF-36PCS and SF-36MCS were first used at 4 years of follow-up. ASDAS, Ankylosing Spondylitis Disease Activity Score; ASQoL, Ankylosing Spondylitis Quality of Life score; BASDAI, Bath Ankylosing Spondylitis Disease Activity Index; BASFI, Bath Ankylosing Spondylitis Functional Index; CRP, C-reactive protein; EuroQoL, European Quality Of Life scale; mSASSS, modified Stoke Ankylosing Spondylitis Spine Score; SF-36MCS, Short Form 36 Mental Component Summary score; SF-36PCS, Short Form 36 Physical Component Summary score.

\section{Quality of Life}

Over time, male patients seemed to experience a better QoL, especially when assessed with the ASQoL (Figure 2.1). This was univariably reflected by a trend towards an association between male gender and a lower (= better) ASQoL over time $(B=-1.15,95 \% \mathrm{Cl}-2.50$ to $0.20, p=0.09)$, which was statistically significant in a fully adjusted multivariable model $(\mathrm{B}=-1.18,95 \% \mathrm{Cl}-2.17$ to $-0.20, \mathrm{p}=0.02$ ) (Table 2.2). Also, a trend towards an association 
between male gender and a higher (= better) EuroQoL over time was found by univariable analysis ( $\mathrm{B}=2.75,95 \% \mathrm{Cl}-1.29$ to $6.79, \mathrm{p}=0.18)$, but in a fully adjusted model this was not statistically significant (Table 2.3). Regarding SF-36, male gender was univariably associated with a higher (= better) mental component score of the SF-36 ( $B=4.39,95 \%$ $\mathrm{Cl} 1.17$ to $7.61, \mathrm{p}<0.01)$, but not with a higher physical component score $(\mathrm{B}=1.07,95 \% \mathrm{Cl}$ -2.00 to $4.14, p=0.50)$. In the fully adjusted model, the association between male gender and better SF-36 Mental Component Summary score remained statistically significant (B $=5.84,95 \%$ Cl 2.21 to $9.48, p<0.01)$ (Table 2.4 ).

\section{Radiographic damage}

Univariable analysis showed an association between male gender and a higher mSASSS over time ( $B=10.05,95 \%$ Cl 5.50 to $14.59, p<0.01$ ) (Table 2.5 ), which was also statistically significant in the fully adjusted model $(B=8.24,95 \% \mathrm{Cl} 4.38$ to $12.09, p<0.01)$. 
Table 2.2. Univariable and multivariable analysis exploring determinants of $A S Q$ o in patients with AS over time

\begin{tabular}{|c|c|c|c|c|c|c|}
\hline \multirow[b]{2}{*}{ Variable } & \multicolumn{3}{|c|}{ Univariable analysis } & \multicolumn{3}{|c|}{ Multivariable analysis } \\
\hline & B & $95 \% \mathrm{Cl}$ & $\mathbf{p}$ & B & $95 \% \mathrm{Cl}$ & $\mathbf{p}$ \\
\hline Gender, male & -1.15 & -2.50 to 0.20 & 0.09 & -1.18 & -2.17 to -0.20 & 0.02 \\
\hline Age at baseline, years & 0.05 & 0.00 to 0.10 & 0.06 & -0.04 & -0.09 to 0.00 & $0.05^{\star}$ \\
\hline Symptom duration, years & 0.02 & -0.02 to 0.07 & 0.30 & & & \\
\hline HLA-B27, positive & -0.22 & -1.76 to 1.32 & 0.78 & & & \\
\hline Hip involvement, baseline & 0.71 & -0.82 to 2.24 & 0.36 & & & \\
\hline IBD, ever & 0.83 & -0.59 to 2.25 & 0.25 & & & \\
\hline Psoriasis, ever & -0.79 & -1.78 to 0.21 & 0.12 & & + & \\
\hline Anterior uveitis, ever & 0.28 & -0.67 to 1.23 & 0.56 & & & \\
\hline Smoking, current & -0.27 & -1.40 to 0.85 & 0.63 & & & \\
\hline NSAID use & 0.45 & -0.20 to 1.10 & 0.18 & & + & \\
\hline NSAID index & 0.00 & -0.01 to 0.01 & 0.63 & & & \\
\hline DMARD use & 1.09 & 0.06 to 2.12 & 0.04 & & + & \\
\hline Biologic use & 0.14 & -0.71 to 0.99 & 0.75 & & & \\
\hline CRP & 0.00 & -0.01 to 0.02 & 0.88 & & & \\
\hline ESR & 0.02 & 0.01 to 0.04 & $<0.01$ & & $\ddagger$ & \\
\hline ASDAS-CRP & 1.40 & 1.07 to 1.74 & $<0.01$ & 0.49 & 0.13 to 0.85 & $<0.01$ \\
\hline BASDAI & 1.19 & 1.04 to 1.34 & $<0.01$ & & $\ddagger$ & \\
\hline BASFI & 1.15 & 0.99 to 1.31 & $<0.01$ & 0.89 & 0.71 to 1.07 & $<0.01^{*}$ \\
\hline Back pain & 0.71 & 0.58 to 0.85 & $<0.01$ & 0.21 & 0.04 to 0.39 & $0.02 *$ \\
\hline Swollen joint count & -0.05 & -0.13 to 0.03 & 0.20 & & + & \\
\hline Tender joint count & 0.03 & 0.00 to 0.06 & 0.04 & & $\dagger$ & \\
\hline Enthesitis & 0.82 & 0.16 to 1.48 & 0.02 & & + & \\
\hline mSASSS & 0.00 & -0.03 to 0.03 & 0.98 & & & \\
\hline
\end{tabular}

${ }^{*}$ Confounder in this model. ${ }^{\dagger}$ Variable not significant and no confounder. ${ }^{\ddagger}$ Not entered in the multivariable model, because the ASDAS-CRP was preferred over the BASDAI/ESR. ASDAS, Ankylosing Spondylitis Disease Activity Score; ASQoL, Ankylosing Spondylitis Quality of Life score; BASDAI, Bath Ankylosing Spondylitis Disease Activity Index; BASFI, Bath Ankylosing Spondylitis Functional Index; CRP, C-reactive protein; DMARD, disease-modifying antirheumatic drug; ESR, erythrocyte sedimentation rate; HLA-B27, human leucocyte antigen B27; IBD, inflammatory bowel disease; mSASSS, modified Stoke Ankylosing Spondylitis Spine Score; NSAID, non-steroidal antiinflammatory drug; $95 \% \mathrm{Cl}, 95 \%$ confidence interval. 
Table 2.3. Univariable and multivariable analysis exploring determinants of EuroQoL in patients with AS over time

\begin{tabular}{|c|c|c|c|c|c|c|}
\hline \multirow[b]{2}{*}{ Variable } & \multicolumn{3}{|c|}{ Univariable analysis } & \multicolumn{3}{|c|}{ Multivariable analysis } \\
\hline & B & $95 \% \mathrm{Cl}$ & $\mathbf{p}$ & B & $95 \% \mathrm{CI}$ & $\mathbf{p}$ \\
\hline Gender, male & 2.75 & -1.29 to 6.79 & 0.18 & 1.61 & -1.07 to 4.30 & 0.24 \\
\hline Age at baseline, years & -0.12 & -0.27 to 0.04 & 0.14 & 0.11 & 0.01 to 0.21 & $0.03^{*}$ \\
\hline Symptom duration, years & -0.12 & -0.24 to 0.00 & 0.05 & & $\dagger$ & \\
\hline HLA-B27, positive & 1.03 & -4.03 to 6.09 & 0.69 & & & \\
\hline Hip involvement, baseline & -5.66 & -10.65 to -0.67 & 0.03 & & $\ddagger$ & \\
\hline IBD, ever & -6.27 & -12.33 to -0.21 & 0.04 & & $\ddagger$ & \\
\hline Psoriasis, ever & -2.30 & -8.80 to 4.20 & 0.49 & & & \\
\hline Anterior uveitis, ever & -1.70 & -4.87 to 1.46 & 0.29 & & & \\
\hline Smoking, current & 0.82 & -1.91 to 3.55 & 0.56 & & & \\
\hline NSAID use & -1.87 & -3.53 to -0.21 & 0.03 & -2.61 & -4.44 to -0.79 & $<0.01^{\star}$ \\
\hline NSAID index & -0.01 & -0.03 to 0.01 & 0.53 & & & \\
\hline DMARD use & -1.95 & -5.21 to 1.30 & 0.24 & & & \\
\hline Biologic use & 0.97 & -2.30 to 4.24 & 0.56 & & & \\
\hline CRP & -0.14 & -0.22 to -0.07 & $<0.01$ & & $\S$ & \\
\hline ESR & -0.23 & -0.31 to -0.16 & $<0.01$ & & $\S$ & \\
\hline ASDAS-CRP & -7.50 & -8.77 to -6.24 & $<0.01$ & -3.34 & -4.95 to -1.73 & $<0.01^{\star}$ \\
\hline BASDAI & -4.16 & -4.77 to -3.55 & $<0.01$ & & $\S$ & \\
\hline BASFI & -4.25 & -4.79 to -3.72 & $<0.01$ & -2.94 & -3.59 to -2.29 & $<0.01 *$ \\
\hline Back pain & -2.75 & -3.23 to -2.27 & $<0.01$ & -0.73 & -1.40 to -0.06 & $0.03^{*}$ \\
\hline Swollen joint count & -0.23 & -0.47 to 0.01 & 0.06 & & $\ddagger$ & \\
\hline Tender joint count & -0.21 & -0.33 to -0.10 & $<0.01$ & & $\ddagger$ & \\
\hline Enthesitis & -4.62 & -6.42 to -2.82 & $<0.01$ & 1.01 & -0.77 to 2.80 & $0.26^{*}$ \\
\hline mSASSS & -0.08 & -0.16 to 0.00 & 0.05 & 0.03 & -0.05 to 0.11 & $0.46^{*}$ \\
\hline
\end{tabular}

${ }^{\star}$ Confounder in this model. ${ }^{\dagger}$ Not entered in the multivariable model, because of collinearity with age. $¥$ Variable not significant and no confounder. \$Not entered in the multivariable model, because the ASDAS-CRP was preferred over the BASDAI/ CRP/ESR. ASDAS, Ankylosing Spondylitis Disease Activity Score; BASDAI, Bath Ankylosing Spondylitis Disease Activity Index; BASFI, Bath Ankylosing Spondylitis Functional Index; CRP, C-reactive protein; DMARD, disease-modifying antirheumatic drug; ESR, erythrocyte sedimentation rate; EuroQoL, European Quality of Life scale; HLA-B27, human leucocyte antigen B27; IBD, inflammatory bowel disease; mSASSS, modified Stoke Ankylosing Spondylitis Spine Score; NSAID, non-steroidal anti-inflammatory drug; $95 \% \mathrm{Cl}$, 95\% confidence interval. 
Table 2.4. Univariable and multivariable analysis exploring determinants of SF-36MCS in patients with AS over time

\begin{tabular}{|c|c|c|c|c|c|c|}
\hline \multirow[b]{2}{*}{ Variable } & \multicolumn{3}{|c|}{ Univariable analysis } & \multicolumn{3}{|c|}{ Multivariable analysis } \\
\hline & B & $95 \% \mathrm{Cl}$ & $\mathbf{p}$ & B & $95 \% \mathrm{Cl}$ & $\mathbf{p}$ \\
\hline Gender, male & 4.39 & 1.17 to 7.61 & $<0.01$ & 5.84 & 2.21 to 9.48 & $<0.01$ \\
\hline Age at baseline, years & 0.09 & -0.03 to 0.21 & 0.15 & 0.16 & 0.01 to 0.30 & $0.04^{\star}$ \\
\hline Symptom duration, years & 0.03 & -0.08 to 0.14 & 0.57 & & & \\
\hline HLA-B27, positive & 3.13 & -1.00 to 7.26 & 0.14 & & + & \\
\hline Hip involvement, baseline & 0.60 & -3.14 to 4.34 & 0.75 & & & \\
\hline IBD, ever & -1.56 & -5.34 to 2.22 & 0.42 & & & \\
\hline Psoriasis, ever & -2.06 & -4.88 to 0.76 & 0.15 & & + & \\
\hline Anterior uveitis, ever & 2.27 & -1.34 to 5.89 & 0.22 & & & \\
\hline Smoking, current & -0.43 & -2.90 to 2.04 & 0.73 & & & \\
\hline NSAID use & -0.37 & -2.56 to 1.81 & 0.74 & & & \\
\hline NSAID index & 0.00 & -0.03 to 0.03 & 0.92 & & & \\
\hline DMARD use & -1.39 & -4.20 to 1.42 & 0.33 & & & \\
\hline Biologic use & -2.60 & -4.95 to -0.25 & 0.03 & -3.50 & -6.35 to -0.65 & 0.02 \\
\hline CRP & 0.03 & -0.05 to 0.11 & 0.44 & & & \\
\hline ESR & -0.07 & -0.13 to -0.01 & 0.03 & & $\ddagger$ & \\
\hline ASDAS-CRP & -1.60 & -2.73 to -0.46 & $<0.01$ & -2.06 & -3.23 to -0.88 & $<0.01 *$ \\
\hline BASDAI & -1.24 & -1.81 to -0.68 & $<0.01$ & & $\ddagger$ & \\
\hline BASFI & -0.66 & -1.16 to -0.16 & 0.01 & & + & \\
\hline Back pain & -0.44 & -0.85 to -0.04 & 0.03 & & $\dagger$ & \\
\hline Swollen joint count & 0.11 & -0.09 to 0.30 & 0.28 & & & \\
\hline Tender joint count & -0.09 & -0.20 to 0.03 & 0.15 & & + & \\
\hline Enthesitis & -1.05 & -3.19 to 1.10 & 0.34 & & & \\
\hline mSASSS & 0.04 & -0.05 to 0.13 & 0.36 & & & \\
\hline
\end{tabular}

${ }^{*}$ Confounder in this model. ${ }^{\dagger}$ Variable not significant and no confounder. ${ }^{\ddagger}$ Not entered in the multivariable model, because the ASDAS-CRP was preferred over the BASDAI/ESR. ASDAS, Ankylosing Spondylitis Disease Activity Score; BASDAI, Bath Ankylosing Spondylitis Disease Activity Index; BASFI, Bath Ankylosing Spondylitis Functional Index; CRP, C-reactive protein; DMARD, diseasemodifying antirheumatic drug; ESR, erythrocyte sedimentation rate; EuroQoL, European Quality of Life scale; HLA-B27, human leucocyte antigen B27; IBD, inflammatory bowel disease; mSASSS, modified Stoke Ankylosing Spondylitis Spine Score; NSAID, non-steroidal anti-inflammatory drug; SF-36MCS, Short Form 36 Mental Component Summary score; 95\% Cl, 95\% confidence interval. 
Table 2.5. Univariable and multivariable analysis exploring determinants of mSASSS progression in patients with AS over time

\begin{tabular}{|c|c|c|c|c|c|c|}
\hline \multirow[b]{2}{*}{ Variable } & \multicolumn{3}{|c|}{ Univariable analysis } & \multicolumn{3}{|c|}{ Multivariable analysis } \\
\hline & B & $95 \% \mathrm{Cl}$ & p & B & $95 \% \mathrm{Cl}$ & $\mathbf{p}$ \\
\hline Gender, male & 10.05 & 5.50 to 14.59 & $<0.01$ & 8.24 & 4.38 to 12.09 & $<0.01$ \\
\hline Age at baseline, years & 0.61 & 0.42 to 0.80 & $<0.01$ & 0.55 & 0.36 to 0.73 & $<0.01 *$ \\
\hline Symptom duration, years & 0.88 & 0.72 to 1.04 & $<0.01$ & - & - & + \\
\hline HLA-B27, positive & 4.87 & -1.54 to 11.28 & 0.14 & 1.58 & -3.82 to 6.99 & $0.57 *$ \\
\hline Hip involvement, baseline & 17.94 & 10.22 to 25.66 & $<0.01$ & 13.65 & 6.32 to 20.98 & $<0.01^{\star}$ \\
\hline IBD, ever & 9.08 & 4.20 to 13.96 & $<0.01$ & 5.47 & 1.60 to 9.33 & $<0.01$ \\
\hline Psoriasis, ever & 1.41 & -5.01 to 7.83 & 0.67 & & & \\
\hline Anterior uveitis, ever & 6.23 & 2.18 to 10.28 & $<0.01$ & & $\ddagger$ & \\
\hline Smoking, current & -3.76 & -6.90 to -0.61 & 0.02 & & $\ddagger$ & \\
\hline NSAID use & -0.98 & -3.08 to 1.11 & 0.36 & & & \\
\hline NSAID index & -0.02 & -0.05 to 0.01 & 0.19 & & $\ddagger$ & \\
\hline DMARD use & -0.62 & -2.95 to 1.70 & 0.60 & & & \\
\hline Biologic use & 10.88 & 7.67 to 14.09 & $<0.01$ & 8.77 & 5.68 to 11.87 & $<0.01$ \\
\hline CRP & -0.09 & -0.15 to -0.03 & $<0.01$ & & $\S$ & \\
\hline ESR & -0.01 & -0.08 to 0.06 & 0.78 & & & \\
\hline ASDAS-CRP & -1.48 & -2.55 to -0.40 & $<0.01$ & -1.54 & -2.42 to -0.67 & $<0.01$ \\
\hline BASDAI & -0.09 & -0.51 to 0.33 & 0.67 & & & \\
\hline BASFI & 1.26 & 0.72 to 1.80 & $<0.01$ & 0.94 & 0.42 to 1.45 & $<0.01$ \\
\hline Back pain & -0.25 & -0.62 to 0.11 & 0.17 & & $\ddagger$ & \\
\hline BAS-G & -0.14 & -0.55 to 0.27 & 0.50 & & & \\
\hline Swollen joint count & 0.15 & 0.00 to 0.30 & 0.05 & & $\ddagger$ & \\
\hline Tender joint count & 0.08 & 0.01 to 0.16 & 0.03 & & $\ddagger$ & \\
\hline Enthesitis & -2.40 & -4.26 to -0.55 & 0.01 & & $\ddagger$ & \\
\hline
\end{tabular}

${ }^{*}$ Confounder in this model. ${ }^{\dagger}$ Not entered in the multivariable model, because of collinearity with age.

$\neq$ Variable not significant and no confounder. $\$$ Not entered in the multivariable model, because the ASDAS-CRP was preferred over CRP. ASDAS, Ankylosing Spondylitis Disease Activity Score; BASDAI, Bath Ankylosing Spondylitis Disease Activity Index; BASFI, Bath Ankylosing Spondylitis Functional Index; CRP, C-reactive protein; DMARD, disease-modifying antirheumatic drug; ESR, erythrocyte sedimentation rate; EuroQoL, European Quality of Life scale; HLA-B27, human leucocyte antigen B27; IBD, inflammatory bowel disease; mSASSS, modified Stoke Ankylosing Spondylitis Spine Score; NSAID, non-steroidal anti-inflammatory drug; SF-36MCS, Short Form 36 Mental Component Summary score; $95 \% \mathrm{Cl}$, 95\% confidence interval. 


\section{Discussion}

The aim of this study was to investigate potential gender-attributable differences with respect to disease activity, physical function, QoL and radiographic damage in patients with AS, both cross-sectionally and over time, using data from a 12-year follow-up period. We showed that male compared with female patients had significantly more radiographic damage and, separately, a better QoL over time. No gender-attributable differences in disease activity and physical function over time were found.

Interestingly, in this study diverging results with respect to gender-attributable differences in disease activity were found. Female patients had higher scores on BASDAI, whereas male patients had higher CRP levels, both at baseline and over time. These results are in line with reports from several cross-sectional studies. ${ }^{9,1,13}$ However, the ASDAS which consists of some questions from the BASDAI and the CRP - was similar in male and female patients, likely as a consequence of averaging these opposing scores. The ASDAS has been shown to have a better discriminatory capacity and sensitivity to change than either the BASDAI or CRP, ${ }^{33}$ which is why we decided up front that the ASDAS-CRP was to be preferred over the BASDAI and acute phase reactants in the analyses. The current findings also add to the validity of the ASDAS as a measure of disease activity. For clinical practice, it should be noted that the underlying mechanism of disease could be different between male and female patients.

Previous studies have shown that health-related QoL (HRQoL) is lower in patients with AS compared with the general population. ${ }^{34-36}$ Although impairments are most severe in the physical domains of HRQoL, ${ }^{34,36}$ mental and social domains can also be affected by AS. ${ }^{37}$ Studies investigating gender-attributable differences with respect to HRQoL in AS have shown that female gender is associated with a lower QoL.13,15,38 However, these studies were cross-sectional in design. Our study showed a lower QoL in females compared with males in the disease-specific ASQoL and in the generic Short Form 36 Mental Component Summary (SF-36MCS) score over time, but no gender-attributable differences were found in the generic EuroQoL and Short Form (36) Physical Component Summary (SF-36PCS) over time. The ASQoL has been specifically designed for AS and could therefore be more sensitive to detect differences in QoL in these patients. Moreover, several factors might explain the lower ASQoL in female patients. Fatigue and pain (factors associated with lower QoL in AS) might be more prominent in female patients. . $11,13,14,39$ Female patients have also reported a reduction of vitality.11,38 However, even after correcting for disease activity and back pain, female patients in our study still experienced lower QoL, as measured by the ASQoL and SF-36MCS. Another explanation could be that male and female patients with AS differ in the way they cope with illness and disability. ${ }^{39}$ The possible mechanisms explaining gender-attributable differences regarding pain perception in general are largely unknown, although catastrophizing has been pointed out as an important factor in, for example, 
patients with OA. ${ }^{40}$ The finding that, at baseline, the Mander Enthesitis Index and tender joint count were almost twice as high in female patients compared with male patients, while the (physician-assessed) swollen joint count was similar between both groups, might support the theory of differences in pain perception between gender. Females with AS also perceive more impairment in their activities and participation in life compared with males. ${ }^{38}$ It is likely that gender-attributable differences regarding QoL in AS are not only determined by biologic factors, but also by psychological factors. Our finding that the SF-36MCS, a measure specifically aimed at investigating mental QoL, is worse in female patients may support this hypothesis.

Several studies have investigated gender-attributable differences with respect to radiographic damage and its progression in patients with AS. It has been shown, both in populations with early as well as with long-standing disease, that male gender is associated with more severe radiographic damage. $.12,17,41$ Other factors associated with radiographic damage and/or progression are the presence of syndesmophytes, disease activity and smoking. ${ }^{16-18,41-44}$ It has been hypothesized that, besides inflammation, mechanical factors can also contribute to radiographic damage in AS. ${ }^{45}$ Physically demanding occupational activities have been shown to be associated with more radiographic damage in patients with long-standing AS. ${ }^{46,47}$

There are some limitations in this study that need to be addressed. First, at 12 years of follow-up, 98 patients were present from the original cohort of 216 patients. Although loss to follow-up is usually inevitable in a long-standing cohort study, this might have led to selection bias. However, the results for 12-year completers were similar for the total study population (data not shown). Second, a relatively low number of females were included in the study population: 62 at baseline, of which 31 completed 12 years of followup. As a result, statistical power to detect gender-attributable differences might have been insufficient. Third, although OASIS is a prevalence cohort with a wide representation of patients with AS in daily clinical practice, on average the study population consisted of patients with long-standing disease with a (relatively) high level of baseline radiographic damage. Results may, therefore, not be applicable to patients in an earlier disease stage. The main strength of this study was the prospective study design, with a mean follow-up duration of 8.3 years, and all relevant outcomes were systematically measured at regular intervals in a standardized way with validated instruments.

In conclusion, in this prospective cohort study, no gender-attributable differences were found for disease activity (measured with ASDAS) or physical function over time. However, male patients had more severe radiographic damage over time. Furthermore, and independently of radiographic damage, male patients had a better QoL over time, suggesting that other determinants like psychological factors may contribute to QoL in AS. 


\section{References}

1. Braun J, Sieper J. Ankylosing spondylitis. Lancet 2007;369:1379-1390.

2. Polley HF, Slocumb CH. Rheumatoid spondylitis: a study of 1,035 cases. Ann Intern Med 1947;26:240-249.

3. West HF. Aetiology of Ankylosing Spondylitis. Ann Rheum Dis 1949;8:143-148.

4. Feldtkeller E, Bruckel J, Khan MA. Scientific contributions of ankylosing spondylitis patient advocacy groups. Curr Opin Rheumatol 2000;12:239-247.

5. Hill HF, Hill AG, Bodmer JG. Clinical diagnosis of ankylosing spondylitis in women and relation to presence of HLA-B27. Ann Rheum Dis 1976;35:267-270.

6. Kennedy LG, Will R, Calin A. Sex ratio in the spondyloarthropathies and its relationship to phenotypic expression, mode of inheritance and age at onset. J Rheumatol 1993;20:1900-1904.

7. Lee W, Reveille JD, Weisman MH. Women with ankylosing spondylitis: a review. Arthritis Rheum 2008;59:449-454.

8. Jung YO, Kim I, Kim S, Suh CH, Park HJ, Park W, et al. Clinical and radiographic features of adultonset ankylosing spondylitis in Korean patients: comparisons between males and females. $J$ Korean Med Sci 2010;25:532-535.

9. Roussou E, Sultana S. Spondyloarthritis in women: differences in disease onset, clinical presentation, and Bath Ankylosing Spondylitis Disease Activity and Functional indices (BASDAI and BASFI) between men and women with spondyloarthritides. Clin Rheumatol 2011;30:121-127.

10. van der Horst-Bruinsma IE, Zack DJ, Szumski A, Koenig AS. Female patients with ankylosing spondylitis: analysis of the impact of gender across treatment studies. Ann Rheum Dis 2013;72:1221-1224.

11. Ibn Yacoub Y, Amine B, Laatiris A, Hajjaj-Hassouni N. Gender and disease features in Moroccan patients with ankylosing spondylitis. Clin Rheumatol 2012;31:293-297.

12. Lee W, Reveille JD, Davis JC, Jr., Learch TJ, Ward MM, Weisman MH. Are there gender differences in severity of ankylosing spondylitis? Results from the PSOAS cohort. Ann Rheum Dis 2007;66:633-638.

13. Tournadre A, Pereira B, Lhoste A, Dubost JJ, Ristori JM, Claudepierre P, et al. Differences between women and men with recent-onset axial spondyloarthritis: results from a prospective multicenter French cohort. Arthritis Care Res (Hoboken) 2013;65:1482-1489.

14. Slobodin G, Reyhan I, Avshovich N, Balbir-Gurman A, Boulman N, Elias M, et al. Recently diagnosed axial spondyloarthritis: gender differences and factors related to delay in diagnosis. Clin Rheumatol 2011;30:1075-1080.

15. de Carvalho HM, Bortoluzzo AB, Goncalves CR, da Silva JA, Ximenes AC, Bertolo MB, et al. Gender characterization in a large series of Brazilian patients with spondyloarthritis. Clin Rheumatol 2012;31:687-695. 
16. Ramiro S, Stolwijk C, van Tubergen A, van der Heijde D, Dougados $M$, van den Bosch F, et al. Evolution of radiographic damage in ankylosing spondylitis: a 12 year prospective follow-up of the OASIS study. Ann Rheum Dis 2015;74:52-59.

17. Rudwaleit M, Haibel H, Baraliakos X, Listing J, Marker-Hermann E, Zeidler H, et al. The early disease stage in axial spondylarthritis: results from the German Spondyloarthritis Inception Cohort. Arthritis Rheum 2009;60:717-727.

18. van Tubergen A, Ramiro S, van der Heijde D, Dougados M, Mielants H, Landewe R. Development of new syndesmophytes and bridges in ankylosing spondylitis and their predictors: a longitudinal study. Ann Rheum Dis 2012;71:518-523.

19. van der Linden S, Valkenburg HA, Cats A. Evaluation of diagnostic criteria for ankylosing spondylitis. A proposal for modification of the New York criteria. Arthritis Rheum 1984;27:361-368.

20. Garrett S, Jenkinson T, Kennedy LG, Whitelock H, Gaisford P, Calin A. A new approach to defining disease status in ankylosing spondylitis: the Bath Ankylosing Spondylitis Disease Activity Index. J Rheumatol 1994;21:2286-2291.

21. Lukas C, Landewe R, Sieper J, Dougados M, Davis J, Braun J, et al. Development of an ASASendorsed disease activity score (ASDAS) in patients with ankylosing spondylitis. Ann Rheum Dis 2009;68:18-24.

22. Calin A, Garrett S, Whitelock H, Kennedy LG, O'Hea J, Mallorie P, et al. A new approach to defining functional ability in ankylosing spondylitis: the development of the Bath Ankylosing Spondylitis Functional Index. J Rheumatol 1994;21:2281-2285.

23. Doward LC, Spoorenberg A, Cook SA, Whalley D, Helliwell PS, Kay LJ, et al. Development of the ASQoL: a quality of life instrument specific to ankylosing spondylitis. Ann Rheum Dis 2003;62:20-26.

24. McHorney CA, Ware JE, Jr., Raczek AE. The MOS 36-Item Short-Form Health Survey (SF-36): II. Psychometric and clinical tests of validity in measuring physical and mental health constructs. Med Care 1993;31:247-263.

25. Ware JE, Jr., Sherbourne CD. The MOS 36-item short-form health survey (SF-36). I. Conceptual framework and item selection. Med Care 1992;30:473-483.

26. EuroQol G. EuroQol--a new facility for the measurement of health-related quality of life. Health Policy 1990;16:199-208.

27. Jones SD, Steiner A, Garrett SL, Calin A. The Bath Ankylosing Spondylitis Patient Global Score (BAS-G). Br J Rheumatol 1996;35:66-71.

28. Mander M, Simpson JM, McLellan A, Walker D, Goodacre JA, Dick WC. Studies with an enthesis index as a method of clinical assessment in ankylosing spondylitis. Ann Rheum Dis 1987;46:197-202.

29. Jenkinson TR, Mallorie PA, Whitelock HC, Kennedy LG, Garrett SL, Calin A. Defining spinal mobility in ankylosing spondylitis (AS). The Bath AS Metrology Index. J Rheumatol 1994;21:1694-1698.

30. Creemers MC, Franssen MJ, van't Hof MA, Gribnau FW, van de Putte LB, van Riel PL. Assessment of outcome in ankylosing spondylitis: an extended radiographic scoring system. Ann Rheum Dis 2005;64:127-129. 
31. Ramiro S, van Tubergen A, Stolwijk C, Landewe R, van de Bosch F, Dougados M, et al. Scoring radiographic progression in ankylosing spondylitis: should we use the modified Stoke Ankylosing Spondylitis Spine Score (mSASSS) or the Radiographic Ankylosing Spondylitis Spinal Score (RASSS)? Arthritis Res Ther 2013;15:R14.

32. Dougados M, Simon P, Braun J, Burgos-Vargas R, Maksymowych WP, Sieper J, et al. ASAS recommendations for collecting, analysing and reporting NSAID intake in clinical trials/ epidemiological studies in axial spondyloarthritis. Ann Rheum Dis 2011;70:249-251.

33. Machado P, van der Heijde D. How to measure disease activity in axial spondyloarthritis? Curr Opin Rheumatol 2011;23:339-345.

34. Ariza-Ariza R, Hernandez-Cruz B, Navarro-Sarabia F. Physical function and health-related quality of life of Spanish patients with ankylosing spondylitis. Arthritis Rheum 2003;49:483-487.

35. Dagfinrud H, Mengshoel AM, Hagen KB, Loge JH, Kvien TK. Health status of patients with ankylosing spondylitis: a comparison with the general population. Ann Rheum Dis 2004;63:1605-1610.

36. Davis JC, van der Heijde D, Dougados M, Woolley JM. Reductions in health-related quality of life in patients with ankylosing spondylitis and improvements with etanercept therapy. Arthritis Rheum 2005;53:494-501.

37. Martindale J, Smith J, Sutton CJ, Grennan D, Goodacre L, Goodacre JA. Disease and psychological status in ankylosing spondylitis. Rheumatology (Oxford) 2006;45:1288-1293.

38. Dagfinrud H, Kjeken I, Mowinckel P, Hagen KB, Kvien TK. Impact of functional impairment in ankylosing spondylitis: impairment, activity limitation, and participation restrictions. $J$ Rheumatol 2005;32:516-523.

39. Ward MM. Health-related quality of life in ankylosing spondylitis: a survey of 175 patients. Arthritis Care Res 1999;12:247-255.

40. Keefe FJ, Lefebvre JC, Egert JR, Affleck G, Sullivan MJ, Caldwell DS. The relationship of gender to pain, pain behavior, and disability in osteoarthritis patients: the role of catastrophizing. Pain 2000;87:325-334.

41. Ward MM, Hendrey MR, Malley JD, Learch TJ, Davis JC, Jr., Reveille JD, et al. Clinical and immunogenetic prognostic factors for radiographic severity in ankylosing spondylitis. Arthritis Rheum 2009;61:859-866.

42. Baraliakos X, Listing J, Rudwaleit M, Haibel H, Brandt J, Sieper J, et al. Progression of radiographic damage in patients with ankylosing spondylitis: defining the central role of syndesmophytes. Ann Rheum Dis 2007;66:910-915.

43. Poddubnyy D, Haibel H, Listing J, Marker-Hermann E, Zeidler H, Braun J, et al. Baseline radiographic damage, elevated acute-phase reactant levels, and cigarette smoking status predict spinal radiographic progression in early axial spondylarthritis. Arthritis Rheum 2012;64:1388-1398.

44. Ramiro S, van der Heijde D, van Tubergen A, Stolwijk C, Dougados M, van den Bosch F, et al. Higher disease activity leads to more structural damage in the spine in ankylosing spondylitis: 12-year longitudinal data from the OASIS cohort. Ann Rheum Dis 2014;73:1455-1461. 
45. Lories RJ, Luyten FP, de Vlam K. Progress in spondylarthritis. Mechanisms of new bone formation in spondyloarthritis. Arthritis Res Ther 2009;11:221.

46. Ramiro S, van Tubergen A, Landewé R, Boonen A, Stolwijk C, Dougados M, et al. OP0262 A Physically Demanding Job May Amplify the Effect of Disease Activity on the Development of Syndesmophytes in Patients with AS. Ann Rheum Dis 2014;73:160-161.

47. Ward MM, Reveille JD, Learch TJ, Davis JC, Jr., Weisman MH. Occupational physical activities and long-term functional and radiographic outcomes in patients with ankylosing spondylitis. Arthritis Rheum 2008;59:822-832. 


\section{Chapter 3}

Depression in ankylosing spondylitis and the role of disease-related and contextual factors: a crosssectional study

Casper Webers, Laura Vanhoof, Carsten Leue, Annelies Boonen, Sebastian Köhler Arthritis Res Ther 2019;21:215 


\section{Abstract}

\section{Background}

Patients with ankylosing spondylitis (AS) have a higher prevalence of depression compared to the general population. Comorbid depression in AS likely has a multifactorial origin. While several disease-related and contextual factors have been associated with depressive symptoms in AS, a comprehensive model of their interrelations is currently lacking. Such a model could help understand the mechanisms leading to, or maintaining, depression in AS. The objectives of the current study were to determine which factors are associated with depressive symptoms in AS and to understand their underlying relationships.

\section{Methods}

Data from a cross-sectional survey-based multicentre study were used. Potential determinants included both contextual and disease-related factors. Depressive symptoms were assessed by the Hospital Anxiety and Depression Subscale (HADS-D). Direct and indirect associations between risk factors and the latent depressive symptom outcome were explored using structural equation modelling. A final model was selected based on model fit criteria and clinical plausibility.

\section{Results}

Among 245 patients, median HADS-D score was 3 (interquartile range 1-6), and 44 patients (18\%) had a HADS-D score $\geq 8$, indicating possible depression. In the final model, contextual factors significantly associated with depressive symptoms were male gender, being employed, lower income, lower mastery and worse satisfaction with social role participation. Bath AS Disease Activity Index (BASDAI) was the only disease-related factor that was associated with depressive symptoms, acted only indirectly via mastery, and its standardized total effect on depressive symptoms was smaller than that of several contextual factors. Mastery had a central role in the path diagram and mediated the effects of BASDAI, income and satisfaction with social role participation on depressive symptoms. The final model explained $64 \%$ of the variance in the depression outcome.

\section{Conclusion}

Both contextual and disease-related factors are associated with depressive symptoms in AS. Mastery, the extent to which one feels in control over life and disease, has a key role in this process. Results support a relevance of self-efficacy in disease management and patient education. In order to improve patients' mental health, research is warranted whether mastery and its relation with depression can be modified. 


\section{Background}

Ankylosing spondylitis (AS) is a rheumatic disorder leading to significant impairment in functioning and health. ${ }^{1}$ Several studies have shown that mental health is affected in AS, including an increased risk of depression and anxiety compared to the general population. ${ }^{2,3}$ Next to its impact on patients' well-being, comorbid depression in AS and other inflammatory rheumatic diseases has been linked to higher rates of hospital admissions and work disability, leading to further economic burden. 4,5 Prevention, timely diagnosis and appropriate management of depression in AS therefore deserve attention in clinical practice. In line with this, a recent European League Against Rheumatism (EULAR) recommendation proposed screening for depression, among other comorbidities, in patients with chronic inflammatory rheumatic diseases. ${ }^{6}$

Depression in AS likely has a multifactorial origin, with several non-mutually exclusive pathways. ${ }^{2}$ For instance, living with the symptoms and consequences of AS, such as impaired physical functioning, pain and fatigue, could induce a depression. On the other hand, depression might also be a direct consequence of disease activity and inflammation. Research has shown that depressed individuals have higher plasma levels of C-reactive protein (CRP) and tumour necrosis factor alpha compared to non-depressed individuals, which has contributed to the so-called inflammatory/cytokine hypothesis of depression suggesting that inflammation contributes to the pathophysiology of depression. ${ }^{8}$

Studies investigating factors associated with depression in axial spondyloarthritis (axSpA), or AS in particular, have generally focused on disease-related factors. Factors commonly associated with depressive symptoms in axSpA are higher disease activity (Bath Ankylosing Spondylitis Disease Activity Index [BASDAI] or AS Disease Activity Score [ASDAS]), ${ }^{9-16}$ worse physical function (Bath Ankylosing Spondylitis Functional Index [BASFI]), ${ }^{10-}$ $13,15,17,18$ (widespread) pain ${ }^{10,13}$ and worse overall health state. ${ }^{18}$ Contextual factors, such as education, employment and coping skills have received less attention, but female gender, ${ }^{15,19}$ a lower level of education, ${ }^{12,13}$ lower income ${ }^{15}$ and lower self-efficacy ${ }^{13}$ have been reported to be related to depression. In AS, a model of both disease-related and contextual determinants contributing to depression, and their interrelationships, is lacking. Unravelling these intricate relationships between determinants remains challenging. For this purpose, some studies investigating depression in other chronic diseases used structural equation modelling, which allows testing complex relations between both disease-related and contextual factors and thus providing insight into underlying pathways. These studies have shown that generic risk factors, and not disease-specific factors, are the major contributors of depression in these diseases. ${ }^{20,21}$ In AS, such a model could help understand the mechanisms leading to, or maintaining, depression and help identify patients with AS that are at an increased risk for depression and potentially require additional or different treatment. 
Therefore, the objective of the current study was to explore factors associated with depressive symptoms in AS in order to develop a comprehensive model of their interrelations, including direct and indirect (i.e. mediated) effects using structural equation modelling. We hypothesized that, compared to disease-related factors, contextual factors would contribute more to depressive symptoms in AS.

\section{Patients and methods}

\section{Study population}

Data from the Social Participation in AS Study (SPASS) were used for this analysis. SPASS is a survey-based and cross-sectional multicentre study including patients with AS from six hospitals in the Netherlands. ${ }^{22}$ Patients with a diagnosis of AS in 2011 were eligible if they were at least 18 years old and fulfilled the modified New York criteria for AS according to the treating rheumatologist. ${ }^{23}$ Exclusion criteria were insufficient ability to read/understand Dutch, no internet access and the presence of life-threatening comorbidities. The study was approved by the ethics committee of the Maastricht University Medical Center, and all participants provided informed consent.

\section{Assessment of generic, contextual and disease-related factors}

Participants completed an online survey with questions on their socio-demographic context, including the level of educational attainment (four categories), being employed (yes/no), income (four categories), work disability (yes/no) and being in a relationship (yes/ no). Lifestyle was assessed by questions on smoking (yes/no), alcohol use (yes/no) and body mass index (BMI). The Short-Form 36 (SF-36) was used to capture generic health state across eight domains and summarized into a Physical Component Summary (SF36PCS) and Mental Component Summary (SF-36MCS). ${ }^{24}$ Personal contextual assessments included satisfaction with performance across six social roles as determined using the shortened version of Social Role Participation Questionnaire (SRPQ), with a range of 1 (worst) to 5 (best), ${ }^{25,26}$ and the 7-item Pearlin's mastery scale to measure the extent to which individuals perceived themselves in control of stressors that significantly impact their lives, with a score range of 7 (lowest level of perceived control) to 28 (highest level of perceived control). ${ }^{27}$ Disease-specific assessments included disease duration and medication use; presence and impact of comorbidities as assessed with the modified Self-Administered Comorbidity Questionnaire (SCQ); ${ }^{28}$ presence of extra-articular manifestations (EAMs; psoriasis, uveitis and inflammatory bowel disease); scores on the BASDAI and BASFI to assess disease activity and physical function, respectively; ${ }^{29,30}$ and spinal pain during the past week as measured using a numerical rating scale (0-10). 


\section{Assessment of depressive symptoms}

The outcome of the current study, severity of depressive symptoms, was assessed using the depression subscale of the Hospital Anxiety and Depression Scale (HADS-D). ${ }^{31}$ The HADS-D contains seven items, each scored on a Likert scale ranging from 0 to 3 (answering options differ per question), resulting in a range of 0 (no depressive symptoms) to 21 (high depressive symptoms). A HADS-D score $\geq 8$ indicates possible depression (see Supplementary File S3.1 for the HADS-D questionnaire).

\section{Statistical analysis}

We worked towards our final model in a pre-specified stepwise manner. Independent variables were first tested in univariable analyses. For this, negative binomial regression was used as HADS-D scores showed a positive skew and overdispersion. Variables used were socio-demographic context (age, gender, education, income, being employed, being in a relationship), lifestyle (BMI, current smoking, current alcohol use), history of depression, somatic comorbidity, generic physical health (SF-36PCS, vitality domain of SF36), disease-specific health characteristics (disease duration, spinal pain, BASDAI, BASFI, EAMs) and finally the personal contextual factors satisfaction with social role participation and mastery. Education and income were converted into dichotomous variables (higher education/university versus other levels, annual income $>€ 40,000$ versus $\leq € 40,000$, respectively). Variables were considered for further analysis if they were associated at an alpha level of $p<0.20$ with HADS-D in univariable analyses. We chose to be most inclusive at this stage before selecting out variables while working towards the parsimonious model.

To develop an explanatory model, structural equation modelling (SEM) was used. The objective was to set up a model that explained a substantial part of the variance in the outcome and had clinical plausibility, while being as parsimonious as possible (reflected by both number of included parameters and model fit indices). The SEM has a measurement and a structural part. For the measurement part, we regressed the seven manifest (observed) items of the HADS-D questionnaire on a continuous latent (unobserved) variable, which was called 'depression' and used to reflect depressive symptoms. The advantage of this method, compared to simply using the observed HADS-D score, is that only the individual items' shared variance contributes to the factor 'depression'. In contrast, each item's unique variance is considered nuisance/measurement error and does not contribute to the factor 'depression'. As a result, the depression construct is represented more accurately by this factor 'depression'. We used a weighted least squares means and variance-adjusted estimator as the individual HADS items were measured on an ordinal Likert scale.

The structural component consisted of direct and indirect paths between variables which were thought to be associated with depression. Direct paths go directly from a variable to depression, while indirect paths go from a variable via another variable (or multiple variables) to depression. We tested two approaches: a theory-driven and a data- 
driven approach. First, a pure theoretical model was specified based on existing evidence and clinical plausibility. Then, its model fit was compared to a simple 'baseline' model with only direct paths to depression. In subsequent data-driven steps, paths in this baseline model that did not contribute substantially $(p<0.10)$ were eliminated one by one using manual backward selection. Subsequently, possible improvement of the model by specifying indirect paths between variables was explored based on modification indices (MIs) and substantive interpretation of results, finally leading to a data-driven model. Only indirect paths that were deemed to be clinically plausible were explored. Models were evaluated by absolute and incremental fit indices, notably the root mean square error of approximation (RMSEA; value $<0.05$ indicates good fit), comparative fit index (CFl; value $\geq 0.95$ indicating good fit) and Tucker-Lewis fit index (TLI; value $\geq 0.95$ indicating good fit). ${ }^{32}$ The latter two are incremental fit indices and can also be used to compare fit across different models. Statistical analyses were performed with Stata Release 14 (StataCorp LP, USA) and Mplus version 8 (Muthén \& Muthén, USA).

\section{Results}

Table 3.1 shows the characteristics of the study population. In total, 246 patients completed the SPASS surveys. HADS-D scores were missing for one patient. In the remaining 245 patients, the mean HADS-D score was 4.1 (median = 3, interquartile range $=1-6$ ). Fortyfour patients $(18 \%)$ had an increased HADS-D score $(\geq 8)$ indicating possible depression.

\section{Identification of candidate variables for SEM}

In univariable analyses, male gender, being employed, lower income, not being in a relationship, no current alcohol use, higher BMI, comorbidity, history of depression, history of EAMs, longer disease duration, higher BASDAI, higher BASFI, more back pain, lower SF36PCS, lower SF-36 vitality domain score, lower mastery and less satisfaction with role performance (SRPQ) were associated with increased depressive symptoms at $p<0.20$ (Supplementary Table S3.1). Hence, these variables were retained in the next modelling step. 
Table 3.1. Characteristics of the study population

\begin{tabular}{|c|c|}
\hline Variable & Total $(n=245)^{\star}$ \\
\hline Age, years & $51.2(12.3)$ \\
\hline Male gender, $\mathrm{n}(\%)$ & $153(62.4)$ \\
\hline High education, $\mathrm{n}(\%)^{+}$ & $80(32.7)$ \\
\hline Currently employed, n (\%) & $139(56.7)$ \\
\hline High income, $\mathrm{n}(\%)^{\ddagger}$ & $95(38.8)$ \\
\hline SRPQ (satisfaction, 1-5) & $3.2(0.8)$ \\
\hline Mastery (7-28) & $20.7(3.9)$ \\
\hline Comorbidity (SCQ) & $3.1(4.3)$ \\
\hline History of depression, n (\%) & $9(3.7)$ \\
\hline Disease duration, years & $23.6(13.3)$ \\
\hline History of any EAM, n (\%) & $78(31.8)$ \\
\hline History of psoriasis, n (\%) & $20(8.2)$ \\
\hline History of IBD, n (\%) & $33(13.5)$ \\
\hline History of uveitis, n (\%) & $44(18.0)$ \\
\hline NSAID use, n (\%) & $134(54.7)$ \\
\hline Biological use, n (\%) & $125(51.0)$ \\
\hline BASDAI (0-10) & $4.4(2.3)$ \\
\hline BASFI $(0-10)$ & $4.2(2.6)$ \\
\hline Patient global (0-10) & $4.8(2.7)$ \\
\hline SF-36PCS (0-100) & $38.8(10.8)$ \\
\hline SF-36MCS (0-100) & $49.2(12.8)$ \\
\hline HADS-depression $(0-21)$ & $4.1(3.7)$ \\
\hline
\end{tabular}

Values are expressed as mean (SD) unless otherwise stated. *One out of 246 patients did not complete the HADS questionnaire and is therefore excluded. ${ }^{+}$Higher education/university. ${ }^{\ddagger}$ Annual income > $€ 40,000$. BASDAI, Bath Ankylosing Spondylitis Disease Activity Index; BASFI, Bath Ankylosing Spondylitis Functional Index; EAM, extra-articular manifestation; HADS, Hospital Anxiety and Depression Scale; IBD, inflammatory bowel disease; NSAID, non-steroidal anti-inflammatory drug; SCQ, Self-Administered Comorbidity Questionnaire; SF-36PCS, Short-Form 36 Physical Component Summary; SF-36MCS, Short-Form 36 Mental Component Summary; SRPQ, Social Role Participation Questionnaire.

\section{SEM of the theoretical model}

The theoretical model is shown in Figure 3.1 and further specified in Table 3.2. Next to the factors identified above, we included age and education based on existing evidence. As we preferred disease-specific outcome measures over generic outcome measures, SF-36PCS (correlated with BASFI), SF-36 vitality domain and spinal pain (both correlated with BASDAI) were excluded due to collinearity. In addition, disease duration (correlated with age) and relationship status (correlated with SRPQ) were excluded. Age was preferred over disease duration, as the latter was self-reported and might be inaccurate. SRPQ was preferred over being in a relationship as the former was considered to capture a broader range of social roles. Contextual factors finally retained comprised age, gender, education, income $>€ 40,000$, employment, alcohol use, history of depression, SRPQ and mastery. Disease- 
related factors were BASDAI, BASFI, comorbidity and presence of any EAM. The theorydriven model had insufficient fit to the data (RMSEA $=0.058, \mathrm{CFI}=0.878, \mathrm{TFI}=0.849$ ). In comparison, the baseline model including only direct paths between independent variables and the depression outcome showed moderate fit $(\mathrm{RMSEA}=0.041, \mathrm{CFI}=0.932$, $T F I=0.918)$. Therefore, the theoretical model was rejected.

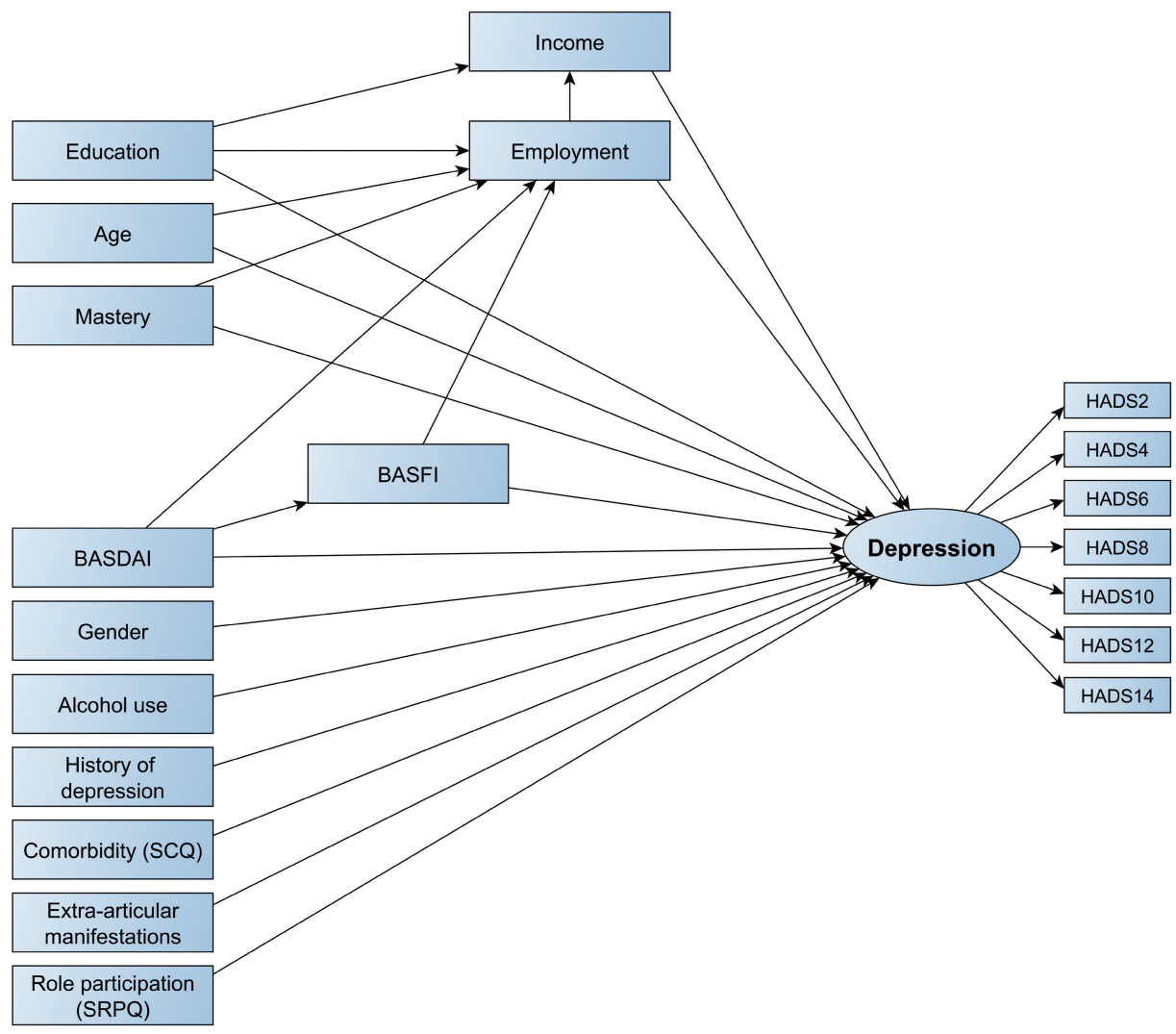

Figure 3.1. Initial (theoretical) model of depression in ankylosing spondylitis. This model was the initial, hypothesized model of depression in AS, based on biological plausibility and existing evidence. Standardized regression coefficients are presented in Table 3.2. The numbered HADS items represent the individual corresponding items on the HADS questionnaire. BASDAI, Bath Ankylosing Spondylitis Disease Activity Index; BASFI, Bath Ankylosing Spondylitis Functional Index; HADS, Hospital Anxiety and Depression Scale; SCQ, Self-Administered Comorbidity Questionnaire; SRPQ, Social Role Participation Questionnaire. 
Table 3.2. Standardized estimates of associations between variables, theoretical model

\begin{tabular}{llccc}
\hline Variable & Dependent & B & SE & p \\
\hline Age & Depression & 0.023 & 0.064 & 0.715 \\
Male gender & Depression & 0.186 & 0.057 & 0.001 \\
Education, high* & Depression & 0.090 & 0.061 & 0.143 \\
Income, high $^{+}$ & Depression & -0.088 & 0.070 & 0.206 \\
Employed, yes & Depression & 0.178 & 0.073 & 0.014 \\
Alcohol use, yes & Depression & 0.015 & 0.059 & 0.803 \\
Mastery (7-28) & Depression & -0.495 & 0.070 & $<0.001$ \\
SRPQ (1-5) & Depression & -0.351 & 0.072 & $<0.001$ \\
History of depression & Depression & 0.060 & 0.066 & 0.361 \\
Comorbidity score (SCQ, 0-39) & Depression & 0.015 & 0.068 & 0.830 \\
BASDAI (0-10) & Depression & 0.052 & 0.079 & 0.510 \\
BASFI (0-10) & Depression & 0.023 & 0.063 & 0.716 \\
EAM, any & Depression & -0.033 & 0.058 & 0.571 \\
Age & Employed, yes & -0.530 & 0.061 & $<0.001$ \\
Education, high & Employed, yes & 0.031 & 0.086 & 0.717 \\
Mastery (7-28) & Employed, yes & 0.115 & 0.114 & 0.314 \\
BASDAI (0-10) & Employed, yes & 0.152 & 0.114 & 0.185 \\
BASFI (0-10) & Employed, yes & -0.210 & 0.092 & 0.022 \\
BASDAI (0-10) & BASFI (0-10) & 0.676 & 0.041 & $<0.001$ \\
Education, high & Income, high & 0.410 & 0.068 & $<0.001$ \\
Employed, yes & Income, high & 0.131 & 0.098 & 0.181 \\
\hline
\end{tabular}

Standardized regression coefficients can be interpreted as the change in y (dependent variable) in y standard deviation units for a standard deviation change in $\mathrm{x}$ (independent variable). *Higher education/ university. ${ }^{\dagger}$ Annual income > $€ 40,000$. BASDAI, Bath Ankylosing Spondylitis Disease Activity Index; BASFI, Bath Ankylosing Spondylitis Functional Index; EAM, extra-articular manifestation; SCQ, Self-Administered Comorbidity Questionnaire; SE, standard error; SRPQ, Social Role Participation Questionnaire.

\section{SEM of the data-driven model}

The baseline model (model 1) as mentioned above was then subject to further specification. First, non-significant paths were removed in a backward fashion (age, alcohol use, BASFI, presence of comorbidities, EAM). This model had good fit (model 2; RMSEA $=0.034$, $\mathrm{CFI}=0.970, \mathrm{TFI}=0.963$ ). Then, indirect paths between contextual factors (education, employment, income, satisfaction with social role participation and mastery) and diseaserelated factors (such as BASDAI) were explored step-by-step to see whether this would improve the explanatory power of the model further. To avoid capitalization on spurious associations in the data, paths were foremost added based on clinical plausibility. During this modelling step, the non-significant path from education to depression was dropped, and indirect paths from BASDAI, income and social role participation to depression via mastery were added. This model (model 3) had good absolute fit according to RMSEA (0.038) and better incremental fit according to CFI (0.980) and TFI (0.975) than model 2. After careful consideration, and in light of model fit, explained variance in the outcome 
and model parsimony, model 3 was considered the final model. The model is presented in Figure 3.2 and specified in Tables 3.3 and 3.4.

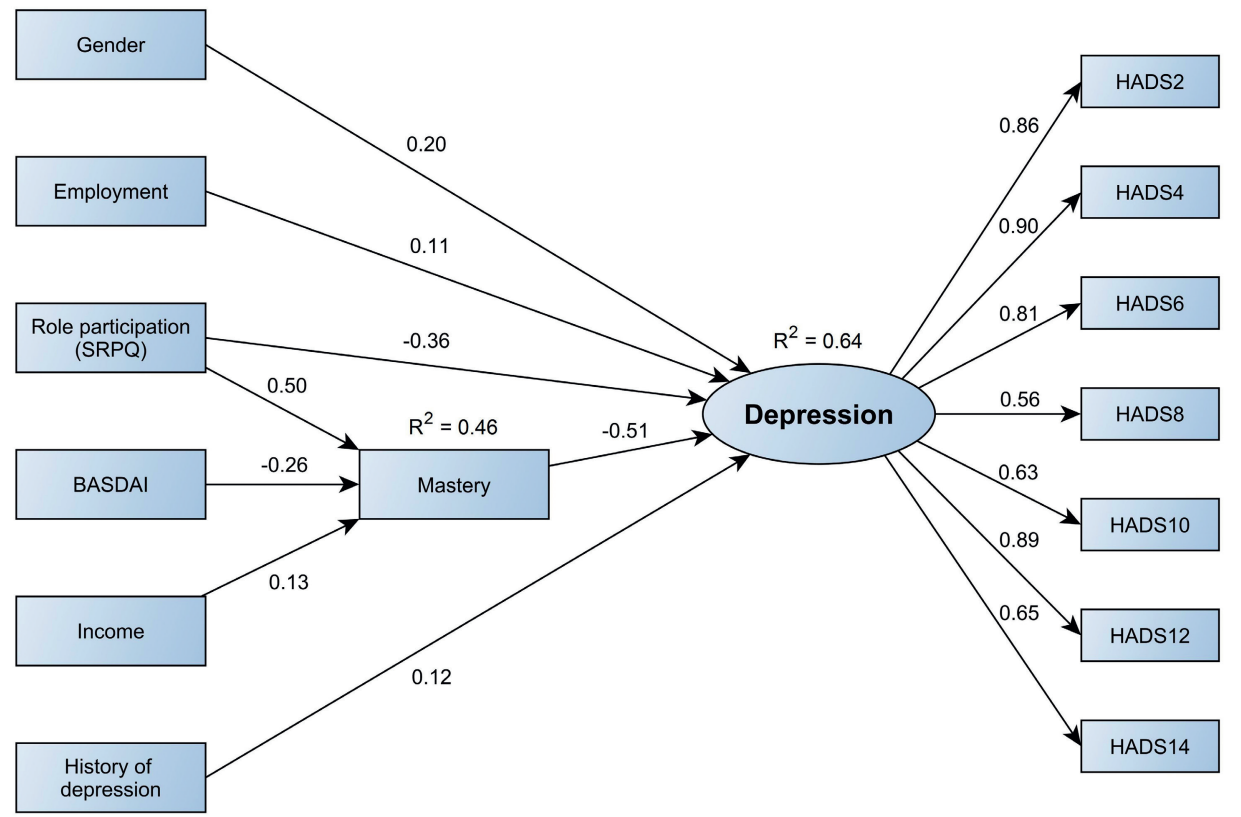

Figure 3.2. Final model of depression in ankylosing spondylitis. This model is the final model of depression in AS, based on model fit criteria. Numbers above the arrows represent the standardized regression coefficients of direct paths. Standardized regression coefficients can be interpreted as the change in y (dependent variable) in y standard deviation units for a standard deviation change in $\mathrm{x}$ (independent variable). Standardized coefficients of indirect effects are presented in Table 3.4. The numbered HADS items represent the individual corresponding items on the HADS questionnaire. BASDAI, Bath Ankylosing Spondylitis Disease Activity Index; HADS, Hospital Anxiety and Depression Scale; SRPQ, Social Role Participation Questionnaire. 
Table 3.3. Standardized estimates of associations between variables, final model

\begin{tabular}{llccc}
\hline Variable & Dependent & B & SE & p \\
\hline Male gender & Depression & 0.197 & 0.061 & 0.001 \\
Employed, yes & Depression & 0.107 & 0.060 & 0.076 \\
SRPQ (1-5) & Depression & -0.363 & 0.066 & $<0.001$ \\
Mastery (7-28) & Depression & -0.507 & 0.064 & $<0.001$ \\
History of depression, yes & Depression & 0.121 & 0.072 & 0.092 \\
SRPQ (1-5) & Mastery & 0.495 & 0.044 & $<0.001$ \\
BASDAI (0-10) & Mastery & -0.262 & 0.060 & $<0.001$ \\
Income, high* & Mastery & 0.133 & 0.059 & 0.025 \\
\hline
\end{tabular}

Standardized regression coefficients can be interpreted as the change in y (dependent variable) in $y$ standard deviation units for a standard deviation change in $\mathrm{x}$ (independent variable). ${ }^{*}$ Annual income $>€ 40,000$. BASDAI, Bath Ankylosing Spondylitis Disease Activity Index; SE, standard error; SRPQ, Social Role Participation Questionnaire.

Table 3.4. Standardized direct and indirect effects of mediated paths on depression, final model

\begin{tabular}{llccc}
\hline Variable & Direct/indirect & B & SE & p \\
\hline SRPQ (1-5) & Direct & -0.363 & 0.066 & $<0.001$ \\
& Indirect (via Mastery) & -0.251 & 0.037 & $<0.001$ \\
& Total & -0.614 & 0.053 & $<0.001$ \\
BASDAI (0-10) & $\mathrm{N} / \mathrm{A}$ & & \\
& Direct & 0.133 & 0.037 & $<0.001$ \\
& Indirect (via Mastery) & 0.133 & 0.037 & $<0.001$ \\
Income, high* & Total & $\mathrm{N} / \mathrm{A}$ & & \\
& Direct & -0.067 & 0.032 & 0.033 \\
& Indirect (via Mastery) & -0.067 & 0.032 & 0.033 \\
\hline
\end{tabular}

Standardized regression coefficients can be interpreted as the change in y (dependent variable) in y standard deviation units for a standard deviation change in $x$ (independent variable). ${ }^{*}$ Annual income > €40,000. BASDAI, Bath Ankylosing Spondylitis Disease Activity Index; N/A, not applicable; SE, standard error; SRPQ, Social Role Participation Questionnaire.

\section{Contextual and disease-related factors in the final model}

Model 3 explained $64.2 \%$ of the variance in the latent depression outcome. Male gender, history of depression, being employed and decreased mastery were directly associated with increased depressive symptoms. In addition, higher BASDAI, lower satisfaction with role participation and an annual income $\leq € 40,000$ were indirectly associated with increased depressive symptoms (all via mastery, Table 3.4). Notably, BASDAI was the only disease-related factor in the model. Its standardized total effect on depression $(B=0.133)$ was smaller than that of SRPQ $(B=-0.614)$ and male gender $(B=0.197)$, comparable to that of a history of depression $(B=0.121)$ and being employed $(B=0.107)$ and greater than that of income $(B=-0.067)$ (Tables 3.3 and 3.4). 


\section{Sensitivity analyses}

Several post hoc sensitivity analyses were conducted to test the robustness of results. First, the association between being employed and depressive symptoms could have been confounded by age. To exclude a possible effect of age, the final model was applied to the population aged 65 or younger (65 was the legal age of retirement in the Netherlands in 2011). This led to similar results: being employed was still associated with more depressive symptoms $(p=0.03)$. Second, history of depression was dropped from the final model (as we could not exclude that those with a previous diagnosis of depression never recovered and were still in the same depressive episode). The associations between other determinants and depressive symptoms remained similar, but model fit worsened. Third, we investigated whether BASFI could (a) substitute BASDAI, (b) should be included next to BASDAI or (c) mediated the association between BASDAI and mastery. All scenarios resulted in lower model fit, lower explained proportion of the variance in the outcome or non-significant paths from BASFI to depression $(p=0.30)$.

\section{Discussion}

In this cross-sectional study of a representative cohort of Dutch AS patients, both contextual and disease-related factors were related to depressive symptoms in AS and together explained a substantial proportion of its variance. Higher mastery, a personal contextual factor, was particularly associated with lower depressive symptoms and an important mediator for several other factors. Regarding disease-related factors, BASDAI was the only determinant in the final explanatory model. Its association with depression was mediated by mastery and weaker than that of several contextual factors.

Our study suggests that mastery plays a central role for the presence of depressive symptoms in AS. A higher sense of mastery, or perceived control over things that happen to an individual in life, has been associated with better employment status in AS and with better mental and physical well-being in other chronic diseases. ${ }^{33-35}$ In line with our results, the related construct of lower self-efficacy has previously been associated with depression in AS. ${ }^{13,36}$ Importantly, our data show that mastery not only has a direct relation with depression, but also is a strong mediator for other factors as a sort of final common (psychological) pathway. More specifically, higher disease activity, being unable to satisfactorily perform social roles and lower income are associated with decreased feelings of control (mastery), which in turn is associated with increased depressive symptoms. These findings could have important implications for the prevention and treatment of depressive symptoms by increasing patients' sense of mastery. The central role of mastery supports the focus on increasing self-management skills of patients with AS. Available education programmes for patients with inflammatory arthritis nowadays not only focus on 
transferring knowledge, but also aim to improve cognitive and behavioural coping. ${ }^{37}$ Such interventions might affect directly mastery, which is considered to be a main determinant or precedent of coping, but they might also help patients with lower levels of mastery cope with specific stressors associated with being chronically ill, without affecting mastery as a personality trait.

In contrast, disease-related factors (BASDAI) had a more modest association and only indirectly so through mastery. This is in line with previous research in a general population sample showing that mastery mediates the relationship between functional limitations and depressive symptoms. ${ }^{38}$ Unfortunately, we did not have data on direct measures of inflammation, e.g. CRP or erythrocyte sedimentation rate (ESR), leaving uncertainty on a direct role of inflammation in patients with auto-inflammatory disease, independent of their experience of stiffness and fatigue. The relationship between inflammation and depression is complex. ${ }^{8}$ While increased self-reported disease activity (possibly a proxy of inflammation) has consistently been associated with depressive symptoms in several studies, results vary for the relation between CRP/ESR and depressive symptoms. ${ }^{39}$ Of note, sensitivity analyses showed BASDAI likely is a better determinant of depressive symptoms than BASFI. Possibly, BASDAI reflects inflammation more appropriately (in line with the inflammation hypothesis). ${ }^{40}$ Alternatively, the symptoms as reflected by the BASDAI (pain, stiffness, fatigue) might have a greater impact on the affective state than functional impairments. Finally, it could be that the effect of functional impairments was already represented by other variables in the model, such as being employed or role participation.

Besides mastery, three other contextual factors, namely male gender, employment and a history of depression, were directly associated with depressive symptoms. While it is known that female patients with AS report worse quality of life, male patients have higher inflammatory markers, ${ }^{41}$ suggesting our findings are consistent with the neuroinflammatory hypothesis of depression. ${ }^{8,42}$ Nonetheless, increased depressive symptoms in male patients are in contrast with studies in the general population. ${ }^{43}$ Moreover, a study investigating the risk of depression in patients with AS and controls found no substantial interaction between AS and gender, ${ }^{3}$ while another recent study did find no association between gender and depressive symptoms in multivariable analysis. ${ }^{15}$ Obviously, confirmation of gender differences in depression from clinical studies of AS is needed, including insight into gender-specific pathways in depression. ${ }^{44}$

Being employed is generally considered beneficial for physical and mental health. ${ }^{45}$ Surprisingly, we found that being employed was associated with increased depressive symptoms, even after adjusting for satisfaction with work performance as captured by the SRPQ. ${ }^{22}$ It should be noted, however, that the SRPQ assesses satisfaction with role participation, which is subject to personal interpretation and does not necessarily reflect objective difficulties with role performance. One could speculate that, despite a (potential) 
positive effect of employment on well-being, employment may also lead to role overload, role conflict and role strain in patients with chronic disease. ${ }^{46}$

A past history of depression has been shown to be an important risk factor in both the

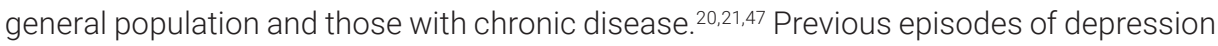
likely mark an underlying vulnerability. However, few patients reported a history of depression (4\%), which might reflect under-detection of affective states in patients with complex somatic and psychiatric comorbidities. ${ }^{48}$ Also, it is unknown whether patients who reported a history of depression had recovered from this, or had an ongoing depression at the time that the survey was conducted.

The study has some notable strengths. From an etiological perspective, development of depression should be considered a multifaceted process, in which factors can have both direct and indirect effects. ${ }^{47}$ SEM allowed us to investigate the dependencies between both observed variables and the latent construct by using a path model. Other strengths were the participation of six centres within the Netherlands with different settings (academic and private hospitals) and from various geographical regions, which increases generalizability, and the availability of data on multiple contextual factors.

The current study also has some limitations. First, although the HADS-D is a validated instrument to assess depressive symptoms, it is a self-reported screening tool. ${ }^{49} \mathrm{Abnormal}$ HADS-D scores do not necessarily correspond to a diagnosis of major depressive disorder and should not be considered as such. Of note, the HADS-D does compare favourably to other measures of depressive symptoms with regard to predictive value. ${ }^{49}$ Second, due to the cross-sectional design of this study, no firm conclusions regarding causality can be drawn. Although the good fit of the final model supports the relationships between variables as specified in our model, these need to be replicated in a longitudinal study. Third, the mean disease duration of patients in SPASS was high, limiting the generalizability to patients with recent onset of disease.

Almost one fifth of the patients in this cohort had a HADS-D score that indicates 'possible depression'. In other studies, these rates are even higher. ${ }^{39}$ Apparently, depressive symptoms (and likely depression) are common in AS, which supports screening for depressive symptoms in practice. ${ }^{6}$ Based on the current study, it cannot be stated whether mastery can be improved (nor whether an improvement in mastery would lead to improvement of psychological health). However, patients with low mastery might be at increased risk of depression in AS. As such, screening for low mastery might be helpful to identify those who need additional support. In addition, patient education could be tailored to the individual patient's context, including their level of mastery. 


\section{Conclusions}

In summary, the current study showed that both contextual and disease-related factors are associated with depressive symptoms in AS. Mastery, the extent to which one feels in control over life and disease, likely has a key role in this process.

Timely diagnosis and management of depression in AS will improve patients' health and likely save societal costs. Future studies should investigate how mastery can be enhanced, and whether this results in better mental well-being in AS.

\section{Funding}

This work was supported by AbbVie. AbbVie sponsored the data collection but had no role in the study design, the analysis or interpretation of the data or the writing of the manuscript. Publication of this article was not contingent upon approval by AbbVie. 


\section{References}

1. Braun J, Sieper J. Ankylosing spondylitis. Lancet 2007;369:1379-1390.

2. Shen CC, Hu LY, Yang AC, Kuo BI, Chiang YY, Tsai SJ. Risk of Psychiatric Disorders following Ankylosing Spondylitis: A Nationwide Population-based Retrospective Cohort Study. J Rheumatol 2016;43:625-631.

3. Meesters JJ, Bremander A, Bergman S, Petersson IF, Turkiewicz A, Englund M. The risk for depression in patients with ankylosing spondylitis: a population-based cohort study. Arthritis Res Ther 2014;16:418.

4. Lowe B, Willand L, Eich W, Zipfel S, Ho AD, Herzog W, et al. Psychiatric comorbidity and work disability in patients with inflammatory rheumatic diseases. Psychosom Med 2004;66:395-402.

5. Sundquist K, Li X, Hemminki K, Sundquist J. Subsequent risk of hospitalization for neuropsychiatric disorders in patients with rheumatic diseases: a nationwide study from Sweden. Arch Gen Psychiatry 2008;65:501-507.

6. Baillet A, Gossec L, Carmona L, Wit M, van Eijk-Hustings $Y$, Bertheussen $H$, et al. Points to consider for reporting, screening for and preventing selected comorbidities in chronic inflammatory rheumatic diseases in daily practice: a EULAR initiative. Ann Rheum Dis 2016;75:965-973.

7. Dowlati Y, Herrmann N, Swardfager W, Liu H, Sham L, Reim EK, et al. A meta-analysis of cytokines in major depression. Biol Psychiatry 2010;67:446-457.

8. Miller $\mathrm{AH}$, Raison $\mathrm{CL}$. The role of inflammation in depression: from evolutionary imperative to modern treatment target. Nat Rev Immunol 2016;16:22-34.

9. Brionez TF, Assassi S, Reveille JD, Green C, Learch T, Diekman L, et al. Psychological correlates of self-reported disease activity in ankylosing spondylitis. J Rheumatol 2010;37:829-834.

10. Durmus D, Sarisoy G, Alayli G, Kesmen H, Cetin E, Bilgici A, et al. Psychiatric symptoms in ankylosing spondylitis: their relationship with disease activity, functional capacity, pain and fatigue. Compr Psychiatry 2015;62:170-177.

11. Martindale J, Smith J, Sutton CJ, Grennan D, Goodacre L, Goodacre JA. Disease and psychological status in ankylosing spondylitis. Rheumatology (Oxford) 2006;45:1288-1293.

12. Baysal O, Durmus B, Ersoy Y, Altay Z, Senel K, Nas K, et al. Relationship between psychological status and disease activity and quality of life in ankylosing spondylitis. Rheumatol Int 2011;31:795-800.

13. Meesters JJ, Petersson IF, Bergman S, Haglund E, Jacobsson LT, Bremander A. Sociodemographic and disease-related factors are associated with patient-reported anxiety and depression in spondyloarthritis patients in the Swedish SpAScania cohort. Clin Rheumatol 2014;33:1649-1656.

14. Godfrin-Valnet M, Prati C, Puyraveau M, Toussirot E, Letho-Gyselink H, Wendling D. Evaluation of spondylarthritis activity by patients and physicians: ASDAS, BASDAI, PASS, and flares in 200 patients. Joint Bone Spine 2013;80:393-398. 
15. Redeker I, Hoffmann F, Callhoff J, Haibel H, Sieper J, Zink A, et al. Determinants of psychological well-being in axial spondyloarthritis: an analysis based on linked claims and patient-reported survey data. Ann Rheum Dis 2018;77:1017-1024.

16. Kilic G, Kilic E, Ozgocmen S. Relationship between psychiatric status, self-reported outcome measures, and clinical parameters in axial spondyloarthritis. Medicine (Baltimore) 2014;93:e337.

17. Brionez TF, Assassi S, Reveille JD, Learch TJ, Diekman L, Ward MM, et al. Psychological correlates of self-reported functional limitation in patients with ankylosing spondylitis. Arthritis Res Ther 2009;11:R182.

18. Hakkou J, Rostom S, Aissaoui N, Berrada KR, Abouqal R, Bahiri R, et al. Psychological status in Moroccan patients with ankylosing spondylitis and its relationships with disease parameters and quality of life. J Clin Rheumatol 2011;17:424-428.

19. Barlow JH, Macey SJ, Struthers GR. Gender, depression, and ankylosing spondylitis. Arthritis Care Res 1993;6:45-51.

20. Leentjens AF, Aben I, Lodder J, Verhey FR. General and disease-specific risk factors for depression after ischemic stroke: a two-step Cox regression analysis. Int Psychogeriatr 2006;18:739-748.

21. Leentjens AF, Moonen AJ, Dujardin K, Marsh L, Martinez-Martin P, Richard IH, et al. Modeling depression in Parkinson disease: disease-specific and nonspecific risk factors. Neurology 2013;81:1036-1043.

22. van Genderen S, Plasqui G, Landewe R, Lacaille D, Arends S, van Gaalen F, et al. Social Role Participation in Patients With Ankylosing Spondylitis: A Cross-Sectional Comparison With Population Controls. Arthritis Care Res (Hoboken) 2016;68:1899-1905.

23. van der Linden $\mathrm{S}$, Valkenburg HA, Cats A. Evaluation of diagnostic criteria for ankylosing spondylitis. A proposal for modification of the New York criteria. Arthritis Rheum 1984;27:361368.

24. Ware JE, Jr., Sherbourne CD. The MOS 36-item short-form health survey (SF-36). I. Conceptual framework and item selection. Med Care 1992;30:473-483.

25. Gignac MA, Backman CL, Davis AM, Lacaille D, Mattison CA, Montie P, et al. Understanding social role participation: what matters to people with arthritis? J Rheumatol 2008;35:1655-1663.

26. Oude Voshaar M, van Onna M, van Genderen S, van de Laar M, van der Heijde D, Heuft L, et al. Development and Validation of a Short Form of the Social Role Participation Questionnaire in Patients with Ankylosing Spondylitis. J Rheumatol 2016;43:1386-1392.

27. Pearlin LI, Schooler C. The structure of coping. J Health Soc Behav 1978;19:2-21.

28. Sangha O, Stucki G, Liang MH, Fossel AH, Katz JN. The Self-Administered Comorbidity Questionnaire: a new method to assess comorbidity for clinical and health services research. Arthritis Rheum 2003;49:156-163.

29. Calin A, Garrett S, Whitelock H, Kennedy LG, O'Hea J, Mallorie P, et al. A new approach to defining functional ability in ankylosing spondylitis: the development of the Bath Ankylosing Spondylitis Functional Index. J Rheumatol 1994;21:2281-2285. 
30. Garrett S, Jenkinson T, Kennedy LG, Whitelock H, Gaisford P, Calin A. A new approach to defining disease status in ankylosing spondylitis: the Bath Ankylosing Spondylitis Disease Activity Index. J Rheumatol 1994;21:2286-2291.

31. Zigmond AS, Snaith RP. The hospital anxiety and depression scale. Acta Psychiatr Scand 1983;67:361-370.

32. Byrne BM. Structural Equation Modeling with Mplus: Basic Concepts, Applications, and Programming. New York: Routledge/Taylor \& Francis Group; 2012.

33. Taylor SE, Stanton AL. Coping resources, coping processes, and mental health. Annu Rev Clin Psychol 2007;3:377-401.

34. Ross CE, Mirowsky J. The Sense of Personal Control: Social Structural Causes and Emotional Consequences. In: Aneshensel CS, Phelan JC, Bierman A. Handbook of the Sociology of Mental Health. Dordrecht: Springer Netherlands 2013: 379-402.

35. Webers C, Vanhoof L, van Genderen S, Heuft L, van de Laar M, Luime J, et al. Employment and the role of personal factors among patients with ankylosing spondylitis: a Dutch cross-sectional case-control study. RMD Open 2018;4:e000680.

36. Meesters J, Bergman S, Haglund E, Jacobsson L, Petersson IF, Bremander A. Prognostic factors for change in self-reported anxiety and depression in spondyloarthritis patients: data from the population-based SpAScania cohort from southern Sweden. Scand J Rheumatol 2018;47:185-193.

37. Zangi HA, Ndosi M, Adams J, Andersen L, Bode C, Bostrom C, et al. EULAR recommendations for patient education for people with inflammatory arthritis. Ann Rheum Dis 2015;74:954-962.

38. Backe IF, Patil GG, Nes RB, Clench-Aas J. The relationship between physical functional limitations, and psychological distress: Considering a possible mediating role of pain, social support and sense of mastery. SSM Popul Health 2018;4:153-163.

39. Zhao S, Thong D, Miller N, Duffield SJ, Hughes DM, Chadwick L, et al. The prevalence of depression in axial spondyloarthritis and its association with disease activity: a systematic review and meta-analysis. Arthritis Res Ther 2018;20:140.

40. Nerurkar L, Siebert S, Mclnnes IB, Cavanagh J. Rheumatoid arthritis and depression: an inflammatory perspective. The Lancet Psychiatry 2019;6:164-173.

41. Webers C, Essers I, Ramiro S, Stolwijk C, Landewe R, van der Heijde D, et al. Gender-attributable differences in outcome of ankylosing spondylitis: long-term results from the Outcome in Ankylosing Spondylitis International Study. Rheumatology (Oxford) 2016;55:419-428.

42. Nusslock R, Miller GE. Early-Life Adversity and Physical and Emotional Health Across the Lifespan: A Neuroimmune Network Hypothesis. Biol Psychiatry 2016;80:23-32.

43. Seedat S, Scott KM, Angermeyer MC, Berglund P, Bromet EJ, Brugha TS, et al. Cross-national associations between gender and mental disorders in the World Health Organization World Mental Health Surveys. Arch Gen Psychiatry 2009;66:785-795.

44. Kendler KS, Gardner CO. Sex differences in the pathways to major depression: a study of opposite-sex twin pairs. Am J Psychiatry 2014;171:426-435.

45. Waddell G, Burton AK, Great Britain. Department for Work and Pensions. Is work good for your health and well-being? London: TSO; 2006. 
46. Gignac MA, Backman CL, Kaptein S, Lacaille D, Beaton DE, Hofstetter C, et al. Tension at the borders: perceptions of role overload, conflict, strain and facilitation in work, family and health roles among employed individuals with arthritis. Rheumatology (Oxford) 2012;51:324-332.

47. Kendler KS, Gardner CO, Prescott CA. Toward a comprehensive developmental model for major depression in women. Am J Psychiatry 2002;159:1133-1145.

48. Leue C, Driessen G, Strik JJ, Drukker M, Stockbrugger RW, Kuijpers PM, et al. Managing complex patients on a medical psychiatric unit: an observational study of university hospital costs associated with medical service use, length of stay, and psychiatric intervention. J Psychosom Res 2010;68:295-302.

49. Smarr KL, Keefer AL. Measures of depression and depressive symptoms: Beck Depression Inventory-II (BDI-II), Center for Epidemiologic Studies Depression Scale (CES-D), Geriatric Depression Scale (GDS), Hospital Anxiety and Depression Scale (HADS), and Patient Health Questionnaire-9 (PHQ-9). Arthritis Care Res (Hoboken) 2011;63 Suppl 11:S454-466. 


\section{Chapter 4}

Infliximab treatment reduces depressive symptoms in patients with ankylosing spondylitis: an ancillary study to a randomized controlled trial (ASSERT)

Casper Webers, Carmen Stolwijk, Olga Schiepers, Thea Schoonbrood, Astrid van Tubergen, Robert Landewé, Désirée van der Heijde, Annelies Boonen

Arthritis Res Ther 2020;22:225 


\section{Abstract}

\section{Background}

Patients with ankylosing spondylitis (AS) are at increased risk of depression. This increased risk has been hypothesized to be solely secondary due to AS-related symptoms, or additionally due to a common inflammatory pathway. From a clinical perspective, it is important to know whether treatment with tumor necrosis factor alpha inhibitors reduces depressive symptoms, while from a pathophysiological point of view, it would be insightful to understand whether such an effect would be a direct result of reduced inflammation, the result of reduced AS-related symptoms, or both. The objective of this study was to evaluate the effect of infliximab on depressive symptoms in patients with AS in a randomizedcontrolled trial setting.

\section{Methods}

Data were retrieved from a subgroup of patients from the AS Study for the Evaluation of Recombinant Infliximab Therapy (ASSERT). Patients were randomly allocated to infliximab $(n=16)$ or placebo $(n=7)$ until week 24 , after which all received infliximab until week 54 . Associations between treatment group and depressive symptoms, measured with the Center for Epidemiological Studies Depression scale (CES-D, range 0-60 [best-worst]) at baseline and over time, were explored with generalized estimating equations (GEE).

\section{Results}

Mean CES-D score at baseline was 15.5 (SD 9.3) in the infliximab group and 17.3 (SD 5.7) in the placebo group. Twelve patients (52\%) had a CES-D score $\geq 16$, suggestive for clinical depression. After 24 weeks, mean CES-D had decreased to 9.5 (SD 11.4) in the infliximab group, but was 18.0 (SD 6.9) in the placebo group. GEE revealed larger improvements in depressive symptoms ( $\mathrm{B}=-6.63,95 \% \mathrm{Cl}-13.35$ to 0.09 ) and odds of possible depression $(\mathrm{OR}=0.02,95 \% \mathrm{Cl} 0.00$ to 0.72$)$ in the infliximab group, compared to the placebo group. Both associations largely disappeared when adjusted for self-reported disease activity and/or physical function. Additional adjustment for C-reactive protein (CRP) did not change results.

\section{Conclusion}

Depressive symptoms are common in patients with AS and active disease. Infliximab improves these depressive symptoms in AS when compared to placebo by improving disease symptoms. We did not find an indication for a direct link between CRP-mediated inflammation and depressive symptoms. 


\section{Background}

Ankylosing spondylitis (AS) affects not only the patients' physical health, but also their mental well-being. A systematic review showed that patients with AS have an increased prevalence of depressive symptoms, with rates ranging between $11 \%$ and $64 \%$. $^{1}$ Comorbid depression in AS impacts the individual, and has societal relevance, as it has been associated with work disability in inflammatory arthritis. ${ }^{2}$

Different possible pathways might explain the increased prevalence of depressive symptoms in AS. Depressive symptoms could be secondary to disease-related impairments such as pain and limitations in physical functioning, or to psychological consequences such as worrying about the future. ${ }^{3}$ But AS and depressive symptoms may also share a common pathophysiological pathway as both may be the result of an auto-inflammatory biological process; pro-inflammatory biomarkers, such as C-reactive protein (CRP) and tumor necrosis factor (TNF)- $a$, have been found to be higher in depressed individuals compared to non-depressed individuals, leading to the 'inflammatory/cytokine hypothesis of depression'. ${ }^{4}$ Also, a randomized controlled trial revealed that TNF-a inhibitors (TNFi) can improve depressive symptoms in patients with treatment-resistant depression and increased inflammatory markers. ${ }^{5}$

From a clinical perspective, it is of importance to understand whether treatment with TNFi can reduce depressive symptoms in patients with AS. From a pathophysiological point of view, it might be interesting to understand if such an effect would be the result of a reduction of AS-related symptoms, inflammation, or both. Previously, several studies have reported improvements in depressive symptoms in patients with AS after treatment with infliximab. ${ }^{6-8}$ Interestingly, observations on the mechanism behind this (potential) effect of infliximab were not equivocal, as correlations of depressive symptoms with either AS-related symptoms (self-reported disease activity) ${ }^{8}$ or inflammatory biomarkers ${ }^{6}$ have been reported. None of these studies was placebo-controlled or blinded, however, and the observed improvements could have been the result of regression to the mean. In two randomized controlled trials (RCTs), etanercept improved depressive symptoms in patients with AS and non-radiographic axial spondyloarthritis (nr-axSpA), although reported effects were small, and the nature of the effect of TNFi on depressive symptoms was not further explored.9,10

The objectives of the present study were to evaluate in patients with AS the effect of infliximab on depressive symptoms compared to placebo and to explore the association between depressive symptoms and AS-related symptoms (experienced disease activity and physical functioning) and inflammation over time. 


\section{Patients and methods}

Data were retrieved from a sub-study of the Ankylosing Spondylitis Study for the Evaluation of Recombinant Infliximab Therapy (ASSERT), which originally randomized 279 patients. Patients from ASSERT that had been included in the Maastricht University Medical Centre were considered eligible for the current sub-study, and asked to complete a questionnaire on depressive symptoms in parallel to the protocol-required assessments of ASSERT. The ancillary study population consisted of 23 patients, 16 patients randomly assigned to infliximab and 7 to placebo.

\section{Study design}

The design of the ASSERT RCT has been previously reported. ${ }^{11}$ Briefly, patients were included in ASSERT if they were 18 years or older and classified as AS according to the modified New York criteria. Patients had to have a Bath AS Disease activity index (BASDAI) score $\geq 4$ and a spinal pain assessment score $\geq 4$ on a visual analog scale. ${ }^{12}$ Patients were randomly assigned (3:8 ratio) to receive infusions of $5 \mathrm{mg} / \mathrm{kg}$ infliximab or placebo at weeks $0,2,6,12$, and 18 . From week 24 until week 54 , all patients received infliximab therapy. The study protocol was reviewed and approved by the independent ethics committee (METC azM/UM). All patients provided written informed consent.

\section{Study outcomes}

Depressive symptoms were assessed with the Center for Epidemiologic Studies Depression scale (CES-D). ${ }^{13,14}$ This validated instrument was chosen since it contains fewer somatic items than other instruments. ${ }^{15}$ The CES-D consists of 20 items on perceived mood and level of functioning during the past week. Every item is scored on a 4-point scale, where $0=$ rarely or none of the time, 1 = some or little of the time, $2=$ occasionally or a moderate amount of time, and $3=$ most of the time. The total CES-D score is the sum of all items (range 0 [best] to 60 [worst]). In addition, four CES-D subscales have been defined ('Somatic-retarded activity' [range 0-21], 'Depressed affect' [range 0-15], 'Positive affect' [range 0-12] and 'Interpersonal affect' [range 0-6]), reflecting combinations of varying individual items. ${ }^{16} \mathrm{~A}$ total CES-D score of $\geq 16$ is employed as a cutoff suggestive for clinical depression (i.e. 'possible depression') and would warrant a referral for a diagnostic evaluation. ${ }^{14}$ Self-reported disease activity and physical function were measured with the BASDAI and Bath AS Functional Index (BASFI), respectively. ${ }^{17}$ Inflammation was assessed with the serum CRP. Study outcomes were assessed at weeks 0, 6, 12, 24, and 54. Both patients and assessors were blinded until week 24 . The main interest of the study was the (between-group difference in) change from baseline CES-D at week 24, in line with ASSERT, in which the main outcome was assessed at the same point in follow-up. 


\section{Statistical analysis}

Differences in baseline characteristics between groups were explored with independent t-test, Mann Whitney test or chi-square test, depending on level of measurement and distribution. Fisher's exact test was preferred over chi-square test for small samples (expected count < 5). Chi-square tests (or Fisher's exact tests) and Mann-Whitney $U$ tests were used to respectively compare the proportion of patients with a CES-D score $\geq 16$ and the mean CES-D scores between groups at the different time points.

The course of CES-D scores between groups over time (until week 24, as thereafter both groups were on infliximab) was compared using generalized estimating equation (GEE) analyses. GEE can take into account the within-subject correlation in a longitudinal study, i.e. the dependency that exists between assessments within the same subject. ${ }^{18,19}$ GEE is focused on estimating the average outcome in the population (population-averaged model), and the model estimates reflect both within-subject and between-subject effects. It requires an a priori defined 'working correlation structure'. For this analysis, an 'exchangeable' correlation structure was chosen, based on the similar correlations of CES-D scores between time points. ${ }^{19}$

First, separate GEE analyses were carried out with either continuous CES-D scores, or dichotomized CES-D score (normal [<16] vs increased [ $\geq 16]$ ), as the outcome (dependent variable). Considering the small sample size, only a limited number of variables could be included in the GEE. Group (infliximab versus placebo) and time (categorical) were included as independent variables, as was as an interaction between group and time (group*time), to test whether there was a difference in the outcome (change from baseline CES-D [continuous] or change from baseline odds of increased CES-D [dichotomized]) between the groups after the first 24 weeks. The GEE analyses were adjusted for baseline CES-D. Second, as we were specifically interested in the mechanism behind (improvement of) depressive symptoms in AS, we explored whether a potential association between infliximab and reduced depressive symptoms remained after adjustment for time-varying AS-specific variables of disease symptoms (BASDAI or BASFl; added as independent variables to the initial model with group, time, group*time and baseline CES-D as independent variables), as well as inflammation (CRP; added as independent variable to the initial model with group, time, group *time and baseline CES-D as independent variables), or both. Of note, BASDAI and BASFI were added in separate models due to collinearity. In ASSERT, treatment allocation was stratified by CRP (within or above 3 times the upper limit of normal); for the current sub-study, we did not adjust for this stratification, as CRP was one of our variables of interest and in light of the sample size. For all analyses, $p<0.05$ was considered statistically significant. Analyses were performed with R, version 3.5.3. ${ }^{20}$ 


\section{Results}

At baseline, the groups were largely comparable in terms of demographics and disease characteristics, although the placebo group contained only male patients and had slightly (though statistically non-significant) higher mean BASFI and Patient Global (Table 4.1).

Table 4.1. Baseline characteristics separately for patients in the infliximab and placebo arm

\begin{tabular}{lccc}
\hline & $\begin{array}{c}\text { Infliximab } \\
(\mathbf{n}=\mathbf{1 6})\end{array}$ & $\begin{array}{c}\text { Placebo } \\
(\mathbf{n = 7})\end{array}$ & $\mathbf{p}$ \\
\hline Male gender, $\mathrm{n}(\%)$ & $11(68.8)$ & $7(100.0)$ & 0.27 \\
Age, years & $38.6(11.6)$ & $44.9(5.8)$ & 0.19 \\
Disease duration, years & $8.3(8.2)$ & $11.5(7.4)$ & 0.37 \\
HLA-B27 positive, $\mathrm{n}(\%)$ & $14(87.5)$ & $5(71.4)$ & 0.56 \\
History of uveitis, $\mathrm{n}(\%)$ & $6(37.5)$ & $1(14.3)$ & 0.37 \\
History of psoriasis, $\mathrm{n}(\%)$ & $0(0.0)$ & $0(0.0)$ & - \\
History of IBD, $\mathrm{n}(\%)$ & $2(12.5)$ & $1(14.3)$ & 1.00 \\
BASDAl score (0-10) & $7.0(1.3)$ & $7.1(0.7)$ & 0.55 \\
BASFI score (0-10) & $6.3(1.5)$ & $7.2(1.3)$ & 0.21 \\
Patient's global assessment (0-10 VAS) & $6.8(1.4)$ & $7.8(1.2)$ & 0.15 \\
Mander enthesis index (0-90) & $7.7(8.6)$ & $12.8(14.6)$ & 0.69 \\
Swollen joint index (0-44) & $2.9(3.7)$ & $3.0(3.9)$ & 0.86 \\
Chest expansion, cm & $2.0(0.9)$ & $2.5(2.0)$ & 0.87 \\
Night pain, (0-10 VAS) & $6.4(2.0)$ & $7.4(1.0)$ & 0.11 \\
CRP level, mg/l & $26.0(24.4)$ & $15.4(16.0)$ & 0.22 \\
Increased CRP, $\mathrm{n}(\%)^{\star}$ & $13(81.3)$ & $6(85.7)$ & 1.00 \\
CES-D score (0-60) & $15.5(9.3)$ & $17.3(5.7)$ & 0.66 \\
Increased CES-D, $\mathrm{n}(\%)^{\dagger}$ & $9(56.3)$ & $3(42.9)$ & 0.67 \\
\hline
\end{tabular}

Values expressed as mean (SD), unless otherwise indicated. *Defined as CRP $>5 \mathrm{mg} / \mathrm{l}$. ${ }^{\dagger}$ Defined as a score $\geq 16$, indicating possible depression. BASDAI, Bath Ankylosing Spondylitis Disease Activity Index; BASFI, Bath Ankylosing Spondylitis Functional Index; CES-D, Center for Epidemiologic Studies Depression Scale; CRP, C-reactive protein; HLA-B27, human leucocyte antigen B27; IBD, inflammatory bowel disease; VAS, visual analog scale.

At weeks 6, 12, 24 and 54, a CES-D score was missing for 1, 2, 0 and 2 patients, respectively; none of the patients had more than 1 missing CES-D score. The mean CES-D score at baseline was 15.5 (SD 9.3) in the infliximab group and 17.3 (SD 5.7) in the placebo group. Fiftysix percent (9 of 16) of the patients in the infliximab group and $43 \%$ (3 of 7 ) in the placebogroup had a CES-D score $\geq 16$ at baseline, suggestive for clinical depression. The scores on the four CES-D subscales did not differ between groups at baseline (see Supplementary Table S4.1 and Supplementary Figure S4.1). When comparing the current sub-study population $(n=23)$ to those who did participate in ASSERT but not part of this sub-study $(n=256)$, the ancillary study patients had slightly higher scores on BASDAI (7.0 [SD 1.1] versus 6.4 [SD 1.6]) and BASFI (6.6 [SD 1.5] versus 5.7 [SD 2.0]) (see Supplementary Table S4.2). 


\section{Course of CES-D over time}

In the first 24 weeks after baseline, CES-D in the infliximab group decreased substantially compared to the placebo group (Figure 4.1A). Within groups, the mean (SD) [change from baseline $(\triangle)$, number of patients who completed the CES-D at that time point] CES-D score at week 6 had decreased to 10.3 (SD 7.7) $[\Delta-5.2, n=16]$ in the infliximab group and 15.9 (SD 6.0) $[\Delta-2.5, n=6]$ in the placebo-group ( $p=0.03$ for comparison of absolute CES-D). At 24 weeks, mean CES-D scores were 9.5 (SD 11.4) $[\Delta-6.0, n=16]$ in the infliximab group and 18.0 (SD 6.9) $[\triangle+0.6, n=7]$ in the placebo group ( $p=0.02$ for comparison of absolute CES-D). At week 54, 30 weeks after the original placebo group had switched to infliximab, the mean CES-D score in the original placebo group had decreased to the same degree as the infliximab group (9.5 [SD 13.1] [ $\triangle-9.3, n=5]$ vs 8.6 [SD 8.4] [ $\triangle-6.9, n=16], p=0.90$ for comparison of absolute CES-D). Similar changes over time were observed in both groups for BASDAI (Figure 4.1B).

Exploration of the CES-D subscales showed scores in the infliximab group had improved strongest in the first 24 weeks after baseline for the subscale 'Somatic-retarded activity' and to a lesser extent for the subscale 'Depressed affect', when compared to the placebo group (see Supplementary Table S4.1 and Supplementary Figure S4.1).

At week $6,25 \%$ (4 of 16) of the infliximab group had a CES-D score $\geq 16$ suggestive for clinical depression, compared to $50 \%$ (3 of 6) in the placebo group ( $p=0.33$ ) (Figure 4.2). After 24 weeks, these proportions were 13\% (2 of 16) and $71 \%$ (5 of 7), respectively $(p=0.01$ ). At week 54 , when all patients received infliximab, $20-25 \%$ (1 of 5 of the original placebo group, 4 of 16 of the original infliximab group) had a CES-D score $\geq 16$.

\section{GEE analysis of factors associated with CES-D over time}

Differences in disease course between treatment groups over time were explored by GEE. As expected, BASDAI scores in the first 24 weeks were significantly lower in the infliximab group compared to the placebo group $\left(B_{\text {group } \star \text { time }(24)}=-2.97,95 \% \mathrm{Cl}-4.51\right.$ to $\left.-1.42, \mathrm{p}<0.01\right)$. This effect was partially explained by a reduction in inflammation (reflected by CRP) in the infliximab group, as observed in separate models in which CRP was included in addition to treatment (data not shown).

Further exploration of depressive symptoms by GEE revealed a (borderline nonsignificant) larger improvement in CES-D scores in the infliximab group compared to the placebo group after the first 24 weeks (model $1 \mathrm{~A}$ : $\mathrm{B}_{\text {group*time }(24)}=-6.63,95 \% \mathrm{Cl}-13.35$ to $0.09, p=0.05$ ). After adjustment for BASDAI, no association was observed anymore between infliximab and change in CES-D scores over time (model 1B: $\mathrm{B}_{\text {group*time(24) }}=-2.66$, $95 \% \mathrm{Cl}-9.44$ to $4.11, \mathrm{p}=0.44$ ), while BASDAl itself was significantly associated with CES-D scores (model 1B: $B_{\text {BASDAI }}=1.34,95 \% \mathrm{Cl} 0.53$ to 2.15, $\mathrm{p}<0.01$ ) (Table 4.2). Adjustment for CRP instead of BASDAI had a notably smaller effect on the association between infliximab treatment and CES-D scores (model 1C: $\mathrm{B}_{\text {group*time(24) }}=-5.71,95 \% \mathrm{Cl}-12.53$ to $1.12, \mathrm{p}=0.10$ ). 
Finally, when both BASDAI and CRP were included, BASDAI remained associated with CES-D scores, while CRP was not (model 1D, Table 4.2).
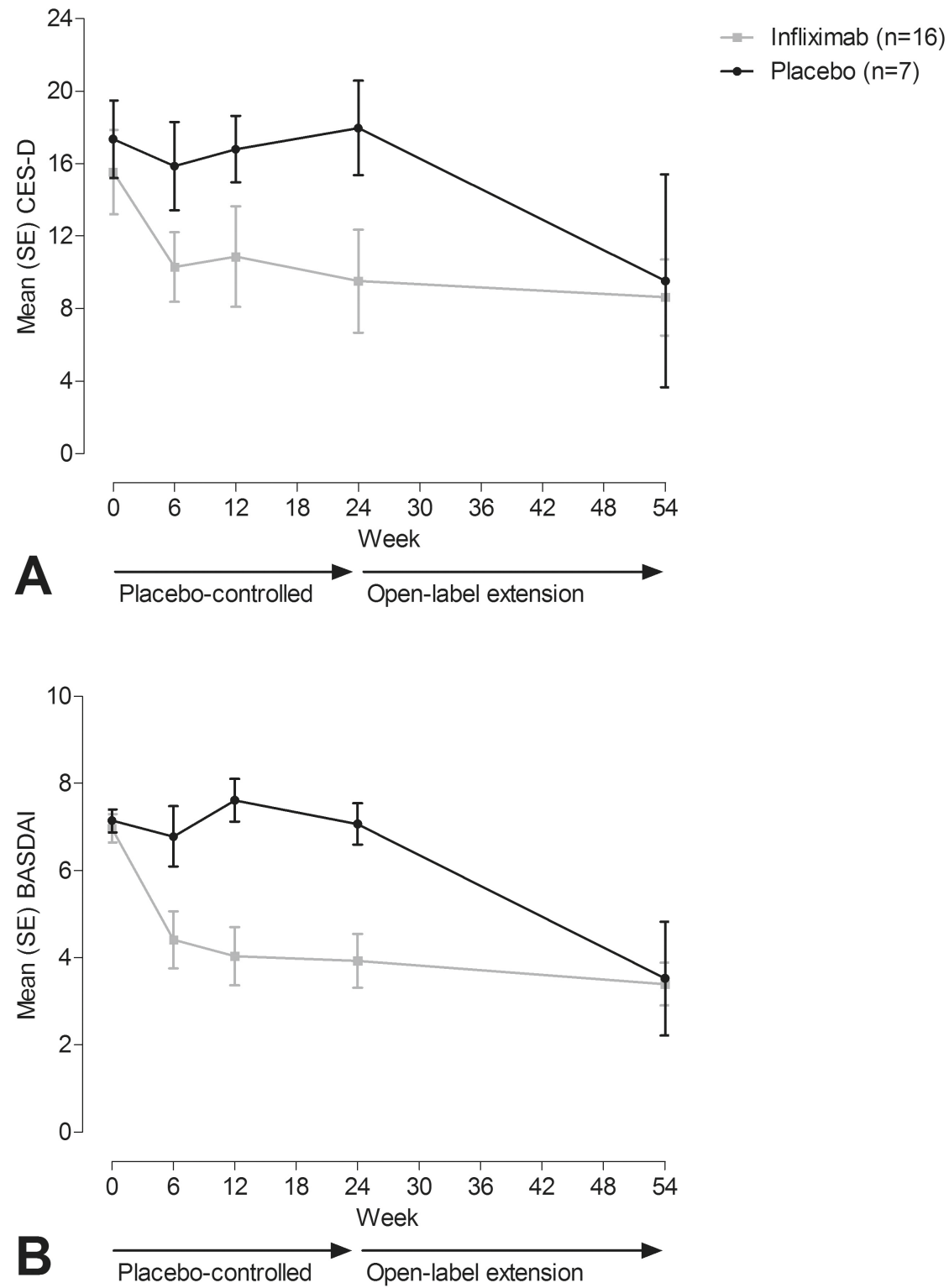

Figure 4.1. CES-D (A) and BASDAI (B) scores over time according to treatment group. During the open-label extension, all patients received infliximab. BASDAI, Bath Ankylosing Spondylitis Disease Activity Index; CES-D, Center for Epidemiologic Studies Depression Scale; SE, standard error. 


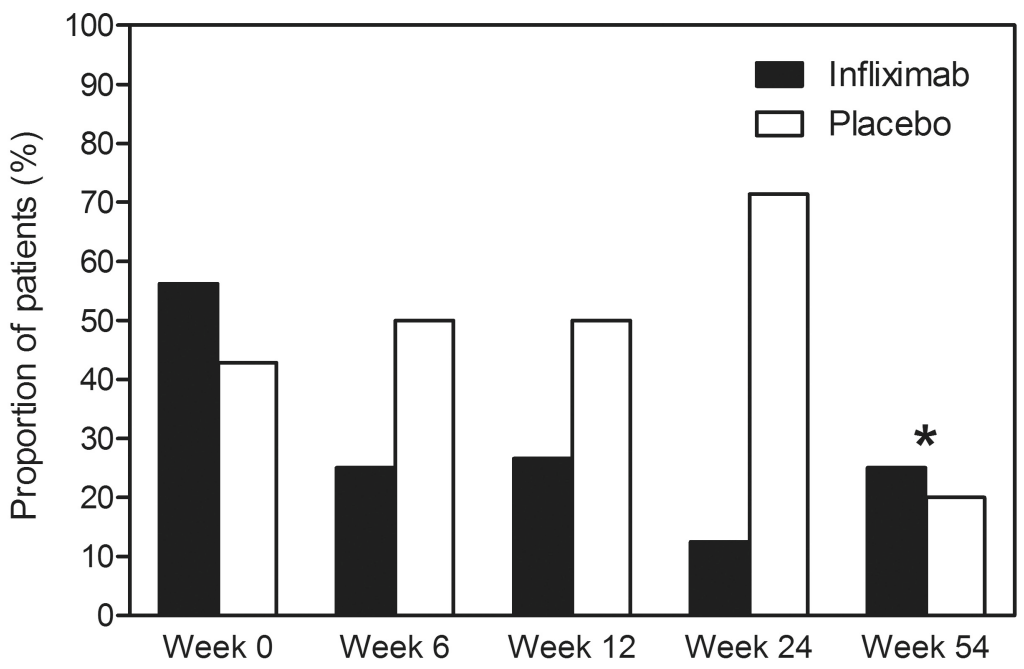

Figure 4.2. Proportion of patients with CES-D score $\geq 16$ over time according to treatment group. *From Week 24 onwards, all patients received infliximab. CES-D, Center for Epidemiologic Studies Depression Scale.

When exploring the odds of possible depression (CES-D score $\geq 16$ ) as the outcome, while adjusting for baseline CES-D status (increased [ $\geq 16]$ vs normal $[<16]$ ), findings were similar: infliximab treatment was associated with a larger reduction in odds of having an increased CES-D after 24 weeks (model 2A: $\mathrm{OR}_{\text {group*time(24) }}=0.02,95 \% \mathrm{Cl} 0.00$ to $0.72, \mathrm{p}=0.03$ ), but after adjustment for BASDAl, this association was no longer significant (model 2B: $\mathrm{OR}_{\text {group }}=0.03,95 \% \mathrm{Cl} 0.00$ to 1.32, $\mathrm{p}=0.07$ ) (Table 4.2). After adjustment for CRP instead of BASDAl, a similar observation was made (model 2C: $\mathrm{OR}_{\text {group } * \text { ime }(24)}=0.03,95 \% \mathrm{Cl} 0.00$ to 1.30, $p=0.07$ ) (Table 4.2). Adjustment for both BASDAI and CRP resulted in none of these (treatment or BASDAI or CRP) being significantly associated with increased CES-D scores (model 2D, Table 4.2).

Analyses using BASFI instead of BASDAI led to similar results: after adjustment for BASFI, the initial association between treatment group and CES-D scores was no longer observed, and when both BASFI and CRP were included, BASFI was associated with CES-D, while CRP was not (models 3A-3D, Table 4.3). Using the odds of possible depression (CES-D score $\geq 16$ ) as outcome yielded similar results, although BASFI remained associated with possible depression, also after adjustment for CRP (models 4A-4D, Table 4.3). 


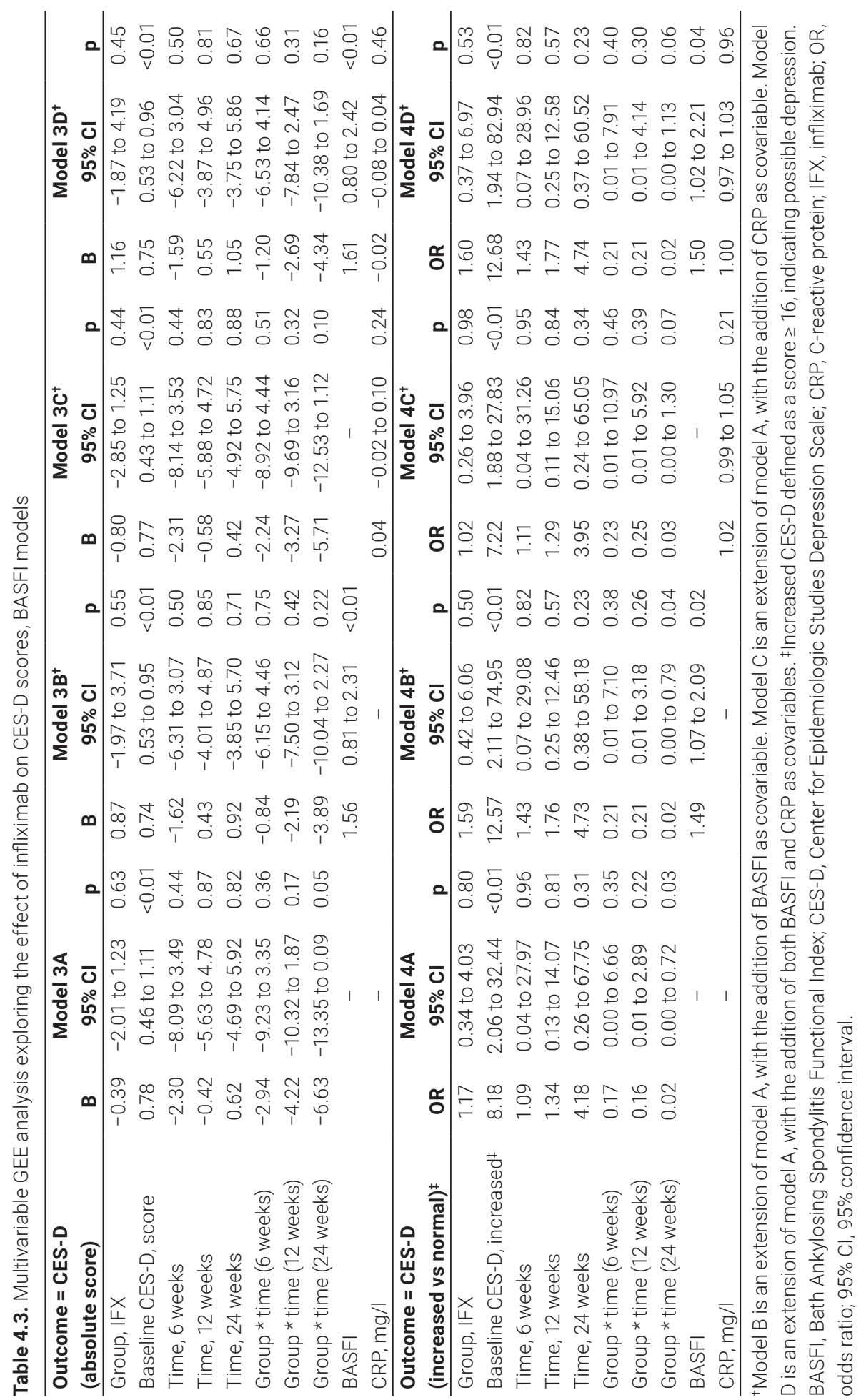




\section{Discussion}

This study showed that depressive symptoms are common in patients with AS that have high disease activity. Infliximab improved depressive symptoms in patients with AS after 24 weeks of treatment. This effect could largely be explained by the effect of infliximab on self-reported symptoms of AS.

Over half of the patients with AS and active disease had a CES-D score $\geq 16$ at baseline, indicative for possible depression. This high proportion seems to be on the upper end of the prevalence range as reported in the literature, but is likely the result of the inclusion criteria for ASSERT, which required patients to have active disease. ' For comparison, in control populations in the Netherlands, a possible depression as measured by increased CES-D score has been reported in 5-22\%. ${ }^{21-23}$

The reduction in depressive symptoms in the infliximab group occurred already within the first weeks and was maintained during the remainder of follow-up. Importantly, treatment with infliximab was not only associated with a decrease in depressive symptoms, but also with decreased odds of CES-D scores above the threshold for (probable) depression. The substantial reduction (an estimated $98 \%$ reduction in odds of having an increased CES-D after 24 weeks of weeks of infliximab compared to placebo), although certainly an overestimation of the effect of infliximab on true clinical depression, seems clinically relevant. This implicates that, at least in a population of patients with active AS, infliximab not only decreases the severity of depressive symptoms and odds of probable depression, but potentially even lowers the odds of true clinical depression. Of note, even after up to 54 weeks of treatment, $20-25 \%$ of both groups still had CES-D scores suggestive of possible depression.

Comparing our results with other studies that investigated the effect of TNFi on depressive symptoms in AS is difficult, because other study designs and/or instruments were used to assess depressive symptoms (in none the CES-D was used). ${ }^{6-10}$ Two RCTs assessed the effect of etanercept on depressive symptoms as a secondary outcome or in post hoc analysis. The first study, comparing sulfasalazine to etanercept among 566 patients with AS, reported significant improvements in depressive symptoms after 16 weeks in both treatment arms, with larger improvements in the etanercept group. ${ }^{9}$ In the second study, where 215 patients with nr-axSpA were treated with etanercept or placebo for 12 weeks followed by etanercept for all subjects for another 12 weeks, depressive symptoms did not differ between groups after 12 weeks or 24 weeks, but had improved from baseline after 24 weeks in both groups. ${ }^{10}$ In addition, three observational studies on the effect of infliximab on depressive symptoms in AS were published, with a total of 52 patients and all of limited duration (6-12 weeks). ${ }^{6-8}$ In line with our findings, in these observational studies similar proportions of patients with depression scores above the threshold for the respective depression instrument used at baseline and over time were 
observed. ${ }^{7,8}$ Also, improvements in depressive symptoms occurred already within the first weeks after initiation of infliximab. Of note, none of these studies explored whether these improvements can be fully explained by improvements in symptoms or inflammation.

It remains challenging whether our results can help to understand if AS has a direct (inflammatory) or indirect (through pain and limitations) effect on depressive symptoms. The association between treatment with infliximab and improvement of depressive symptoms largely disappeared after adjustment for AS-specific symptoms, i.e. selfreported disease activity and physical function, suggesting the change in depressive symptoms in these patients is (at least partially) secondary to changes in their AS-related symptoms. Of note, the relationship between self-reported depressive symptoms and selfreported AS-related symptoms could (partially) be bidirectional. In rheumatoid arthritis, for example, the patient visual analog scale component of the Disease Activity Score (DAS28) has been strongly associated with depression. ${ }^{24}$ Likewise, in the current study, responses on BASDAI or BASFI could be influenced by the patient's emotional state. Additionally, it is known some covariance exists between all self-reported measures, which likely adds to some overestimation of the observed associations. Notwithstanding, when considering an alternative explanation for the improvements in depressive symptoms, i.e. a reduction in inflammation, CRP did not seem to independently/directly contribute to the effect of infliximab treatment on depressive symptoms: adjustment for CRP did have a minor impact on the association between infliximab and depressive symptoms when compared to the effect of BASDAI or BASFI, suggesting little mediation of the effect of infliximab via CRP-mediated inflammation. This further suggests the mechanism behind depressive symptoms in these patients is mainly based on the impact of AS-related symptoms. It should be noted, however, that due to the small sample size, these secondary analyses were only exploratory and no elaborate path analyses could be conducted. Nonetheless, the association between CRP and depressive symptoms, compared with BASDAI or BASFI, was not only statistically non-significant but also very small numerically, suggesting a direct effect of CRP-mediated inflammation would be little (if any) in a larger sample. Overall, it remains challenging to unravel the intricate relationships between the inflammatory pathophysiological process behind AS, AS-related symptoms, and depression. While CRP is commonly used as inflammatory biomarker in axSpA, we cannot rule out CRP is not appropriate as a biomarker to identify a potential link between inflammation and depression in this disease. While the current results do not allow us to draw firm conclusions regarding these associations between markers of inflammation and depression, our data suggests other inflammatory biomarkers are likely more interesting to further explore than CRP.

In addition, two other interesting observations can be made. First, while all patients had high BASDAI and BASFI scores at baseline, only half of these patients had CES-D scores above the threshold for possible depression, indicating the relation between experienced pain or functional limitations and depression is not an absolute one. Second, 
baseline CES-D remained strongly associated with the course of CES-D over time, even when accounting for BASDAI or BASFI. This suggests that, while the effect of infliximab on depressive symptoms seems to be mostly mediated by improvement in pain and functional limitations, depressive symptoms as measured with the CES-D are additional and distinct phenomena rather than only a reflection of these pain and limitations. It would be interesting to further explore which patients with active disease have an increased susceptibility to depression, for example as a result of genetic predisposition or personality and coping traits. ${ }^{25}$ On this line, it has recently been shown that illness perceptions have an important role in the relationship between back pain and mental health outcomes. ${ }^{26}$ Further, in axSpA, patients with comorbid depression are much more likely to suffer from other mental health and substance abuse disorders, also suggesting an underlying vulnerability. ${ }^{27}$

The main limitation of this study is the small number of patients restricting the power to detect significant changes and limiting the number of covariables that could be included in the models. However, strong and clinically relevant absolute changes and improvements in depressive symptoms were observed. Further, we should realize that the CES-D is a screening questionnaire which cannot be used to diagnose depression, for which the gold standard still is psychiatric interviewing and examination. On this line it should be noted the questions in the CES-D refer to the past week, which might further reflect reactive depressive symptoms (instead of clinical depression/chronic depression), overestimating the proportion with actual depression. The associations as observed in the analyses of the current study are possibly an overestimation (numerically), and the effect of infliximab on true (physician-diagnosed) clinical depression might be smaller in daily practice. Finally, we did not have data available on the individual BASDAI items, precluding analysis of the contribution of each item.

The findings in the present study have several implications. Rheumatologists should be aware of the high prevalence of depressive symptoms in patients with AS and active disease, while considering that these symptoms are not strictly a result of pain and loss of functioning. In addition, our results suggest that treatment with a TNFi is beneficial for depressive symptoms in the majority of this population. Still, a proportion of patients seem to maintain clinically significant depressive symptoms despite TNFi treatment, which might require specialized treatment.

\section{Conclusions}

The prevalence of depressive symptoms was high among this patient population with active AS. TNFi treatment improved the depressive symptoms of AS patients; our data suggest that this benefit seems an indirect effect of TNFi treatment on AS-related symptoms. Appropriate management of depression in AS deserves attention in clinical practice. 


\section{Funding}

ASSERT was sponsored by Janssen Biologics. This sub-study of the ASSERT trial was performed without any financial support. Janssen Biologics had no role in the study design or in the collection, analysis, or interpretation of the data, the writing of the manuscript, or the decision to submit the manuscript for publication. Publication of this article was not contingent upon approval by Janssen Biologics. 


\section{References}

1. Zhao S, Thong D, Miller N, Duffield SJ, Hughes DM, Chadwick L, et al. The prevalence of depression in axial spondyloarthritis and its association with disease activity: a systematic review and meta-analysis. Arthritis Res Ther 2018;20:140.

2. Lowe B, Willand L, Eich W, Zipfel S, Ho AD, Herzog W, et al. Psychiatric comorbidity and work disability in patients with inflammatory rheumatic diseases. Psychosom Med 2004;66:395-402.

3. Martindale J, Smith J, Sutton CJ, Grennan D, Goodacre L, Goodacre JA. Disease and psychological status in ankylosing spondylitis. Rheumatology (Oxford) 2006;45:1288-1293.

4. Miller AH, Raison CL. The role of inflammation in depression: from evolutionary imperative to modern treatment target. Nat Rev Immunol 2016;16:22-34.

5. Raison CL, Rutherford RE, Woolwine BJ, Shuo C, Schettler P, Drake DF, et al. A randomized controlled trial of the tumor necrosis factor antagonist infliximab for treatment-resistant depression: the role of baseline inflammatory biomarkers. JAMA Psychiatry 2013;70:31-41.

6. Arisoy O, Bes C, Cifci C, Sercan M, Soy M. The effect of TNF-alpha blockers on psychometric measures in ankylosing spondylitis patients: a preliminary observation. Rheumatol Int 2013;33:1855-1864.

7. Ertenli I, Ozer S, Kiraz S, Apras SB, Akdogan A, Karadag O, et al. Infliximab, a TNF-alpha antagonist treatment in patients with ankylosing spondylitis: the impact on depression, anxiety and quality of life level. Rheumatol Int 2012;32:323-330.

8. Ersozlu-Bozkirli ED, Keskek SO, Bozkirli E, Yucel AE. The effect of infliximab on depressive symptoms in patients with ankylosing spondylitis. Acta Reumatol Port 2015;40:262-267.

9. van der Heijde D, Braun J, Dougados M, Sieper J, Pedersen R, Szumski A, et al. Sensitivity and discriminatory ability of the Ankylosing Spondylitis Disease Activity Score in patients treated with etanercept or sulphasalazine in the ASCEND trial. Rheumatology (Oxford) 2012;51:1894-1905.

10. Dougados M, Tsai WC, Saaibi DL, Bonin R, Bukowski J, Pedersen R, et al. Evaluation of Health Outcomes with Etanercept Treatment in Patients with Early Nonradiographic Axial Spondyloarthritis. J Rheumatol 2015;42:1835-1841.

11. van der Heijde D, Dijkmans B, Geusens P, Sieper J, DeWoody K, Williamson P, et al. Efficacy and safety of infliximab in patients with ankylosing spondylitis: results of a randomized, placebocontrolled trial (ASSERT). Arthritis Rheum 2005;52:582-591.

12. Garrett S, Jenkinson T, Kennedy LG, Whitelock H, Gaisford P, Calin A. A new approach to defining disease status in ankylosing spondylitis: the Bath Ankylosing Spondylitis Disease Activity Index. J Rheumatol 1994;21:2286-2291.

13. Radloff LS. The CES-D Scale: A Self-Report Depression Scale for Research in the General Population. Appl Psychol Meas 1977;1:385-401. 
14. Smarr KL, Keefer AL. Measures of depression and depressive symptoms: Beck Depression Inventory-II (BDI-II), Center for Epidemiologic Studies Depression Scale (CES-D), Geriatric Depression Scale (GDS), Hospital Anxiety and Depression Scale (HADS), and Patient Health Questionnaire-9 (PHQ-9). Arthritis Care Res (Hoboken) 2011;63 Suppl 11:S454-466.

15. Blalock SJ, DeVellis RF, Brown GK, Wallston KA. Validity of the Center for Epidemiological Studies Depression Scale in arthritis populations. Arthritis Rheum 1989;32:991-997.

16. Ensel WM. 4 - Measuring Depression: The CES-D Scale. In: Lin N, Dean A, Ensel WM. Social Support, Life Events, and Depression. Orlando: Academic Press 1986: 51-70.

17. Calin A, Garrett S, Whitelock H, Kennedy LG, O'Hea J, Mallorie P, et al. A new approach to defining functional ability in ankylosing spondylitis: the development of the Bath Ankylosing Spondylitis Functional Index. J Rheumatol 1994;21:2281-2285.

18. Zeger SL, Liang KY, Albert PS. Models for longitudinal data: a generalized estimating equation approach. Biometrics 1988;44:1049-1060.

19. Twisk JW. Longitudinal data analysis. A comparison between generalized estimating equations and random coefficient analysis. Eur J Epidemio/ 2004;19:769-776.

20. R Core Team. R: A language and environment for statistical computing. Vienna: R Foundation for Statistical Computing, 2019. URL: http://www.R-project.org.

21. Bouma J, Ranchor A, Sanderman R, Van Sonderen E. Het meten van symptomen bij depressie met de CES-D, een handleiding [Measurement of depressive symptoms with the CES-D, a manual]. Groningen, Noordelijk Centrum voor Gezondheidsvraagstukken, Rijksuniversiteit Groningen 19952-24.

22. Pouwer F, Beekman AT, Nijpels G, Dekker JM, Snoek FJ, Kostense PJ, et al. Rates and risks for co-morbid depression in patients with Type 2 diabetes mellitus: results from a communitybased study. Diabetologia 2003;46:892-898.

23. Schroevers MJ, Sanderman R, van Sonderen E, Ranchor AV. The evaluation of the Center for Epidemiologic Studies Depression (CES-D) scale: Depressed and Positive Affect in cancer patients and healthy reference subjects. Qual Life Res 2000;9:1015-1029.

24. Cordingley L, Prajapati R, Plant D, Maskell D, Morgan C, Ali FR, et al. Impact of psychological factors on subjective disease activity assessments in patients with severe rheumatoid arthritis. Arthritis Care Res (Hoboken) 2014;66:861-868.

25. Webers C, Vanhoof L, Leue C, Boonen A, Kohler S. Depression in ankylosing spondylitis and the role of disease-related and contextual factors: a cross-sectional study. Arthritis Res Ther 2019;21:215.

26. van Lunteren M, Scharloo M, Ez-Zaitouni Z, de Koning A, Landewe R, Fongen C, et al. The Impact of Illness Perceptions and Coping on the Association Between Back Pain and Health Outcomes in Patients Suspected of Having Axial Spondyloarthritis: Data From the SPondyloArthritis Caught Early Cohort. Arthritis Care Res (Hoboken) 2018;70:1829-1839.

27. Zhao SS, Solomon DH, Goodson NJ. Comment on: Comorbidity burden in axial spondyloarthritis: a cluster analysis: reply. Rheumatology (Oxford) 2020;59:692-693. 


\section{Chapter 5}

Sick leave and its predictors in ankylosing spondylitis: long-term results from the Outcome in Ankylosing Spondylitis International Study

Casper Webers, Sofia Ramiro, Robert Landewé, Désirée van der Heijde, Filip van den Bosch, Maxime Dougados, Astrid van Tubergen, Annelies Boonen

RMD Open 2018;4:e000766 


\section{Abstract}

\section{Objective}

To investigate the occurrence of ankylosing spondylitis (AS)-related sick leave (SL) over 6-12 years and explore factors predicting first and recurrent SL.

\section{Methods}

Data from employed patients from the Outcome in Ankylosing Spondylitis International Study were used. At each visit, patients indicated the occurrence of SL (yes/no) in the previous inter-assessment period. Cox regressions predicted a first episode of SL. Generalised estimating equations (GEE) explored the association between SL and (timelagged) predictors. To investigate whether SL predicts new SL, SL in the first year was included as covariate in a separate analysis.

\section{Results}

139 patients (76\% males, mean age 38.7 [SD 10.0] years) were at risk for SL for an average period of 7.9 years, of whom 88 (63\%) reported any SL. In both the Cox baseline predictors model (HR) and the time-varying GEE models (OR), AS Disease Activity Score ( $H R=1.67$, 95\% Cl 1.23 to 2.28; OR =1.48, 95\% Cl 1.07 to 2.03); Bath AS Disease Activity Index $(\mathrm{HR}=1.33,95 \% \mathrm{Cl} 1.18$ to $1.51 ; \mathrm{OR}=1.31,95 \% \mathrm{Cl} 1.15$ to 1.49$)$, Bath AS Functional Index $(\mathrm{HR}=1.17,95 \% \mathrm{Cl} 1.02$ to $1.34 ; \mathrm{OR}=1.31,95 \% \mathrm{Cl} 1.16$ to 1.47$)$ and comorbidity at baseline (GEE only, OR $=1.52,95 \% \mathrm{Cl} 1.00$ to 2.29 ) were associated with SL in separate models, but only in patients with low educational attainment. SL in the first year was an independent predictor of SL over time (OR 2.62 to 8.37 in different models, all $p<0.05$ ).

\section{Conclusion}

Disease activity and physical function predicted first and recurrent $S L$, but only in patients with low educational attainment. Prior SL results in future SL, and SL should therefore be a signal for support to prevent future adverse work outcome. 


\section{Introduction}

Symptoms of ankylosing spondylitis (AS) usually arise in young adulthood, thereby affecting patients' ability to pursue their professional career and participate sustainably in the labour force. ${ }^{1-6}$ Previous observational research on worker participation in AS mainly focused on the magnitude and determinants of work disability. ${ }^{3-5}$ However, understanding sick leave (SL) might be even more important. First, sick leave is in itself a relevant outcome. For society, the indirect costs associated with sick leave and work disability due to AS have been shown to be at least as high as direct costs. ${ }^{7}$ Besides, patients with a musculoskeletal disease indicated absenteeism had a negative effect on psychological well-being and self-esteem. ${ }^{8}$ Second, recurrent and/or prolonged sick leave may serve as an indicator of future adverse work outcomes such as reduced career prospects or eventually work loss.

Only few studies have investigated determinants of sick leave in AS.1,-13 Biomedical factors that have been identified include higher self-reported active disease and depressive symptoms, ${ }^{11}$ worse functional status, ${ }^{1,13}$ concomitant peripheral joint disease ${ }^{10}$ and higher level of pain. ${ }^{13}$ In addition, contextual factors, defined by the WHO as factors that are outside the disease, can influence outcomes such as sick leave. These can be personal (e.g. sex, age, education) and environmental factors (e.g. relationships with others, health services, social security). ${ }^{14}$ Previous studies showed that lower educational attainment, helplessness, job type (physical load) and social security regulations are associated with sick leave.,10,12 However, a recent review concluded that evidence was weak, as only few studies were available. ${ }^{15}$ Finally, the role of sick leave itself as a potential predictor of recurrent sick leave has never been explored in AS. If such an association is found, both patients and society could benefit from this signal, reducing repeated or long-term sick leave and perhaps work disability.

In order to support a causal role of potential factors in relation to sick leave, longitudinal data are mandatory, especially when it allows time-dependent variation of potential predictors. This is particularly relevant as some factors (such as disease activity) might have short-term influence on the occurrence of sick leave, while other factors (such as contextual factors) are rather long-term determinants.

The aim of the present study was to investigate patterns in AS-related sick leave over an extended follow-up period and to investigate which factors, disease-related and contextual, can predict or explain sick leave over time. We hypothesised that contextual factors, specifically education, job type and country of residence, predict and explain sick leave independently of disease characteristics, and that the association between disease activity and sick leave would emerge when exploring shorter time-intervals between clinical assessment and the occurrence of sick leave. Furthermore, we expected sick leave to be an independent predictor for future sick leave. 


\section{Methods}

\section{Patient population}

Data from the Outcome in AS International Study (OASIS) were used. OASIS is a multinational prevalence cohort, initiated in 1996 and concluded in 2015. In total, 217 consecutive patients with AS who met the modified New York Criteria were recruited from the Netherlands, Belgium and France from September 1996 through March 1997.16 All patients were treated by their rheumatologists according to standard care. Biological treatment was available on indication since 2002. All patients signed informed consent.

\section{Demographic characteristics and outcome assessment}

Information about age, gender, highest level of education attained (dichotomised as higher professional/university versus any other [lower] educational level), human leucocyte antigen B27 (HLA-B27) status, duration of symptoms, presence of physician-confirmed extra-articular manifestations (EAMs: psoriasis, inflammatory bowel disease [IBD] and anterior uveitis) and radiographic hip involvement was collected at baseline. Using clinical records, the Rheumatic Disease Comorbidity Index (RDCI) at baseline was calculated with a theoretical score of $0-9$, representing a weighted sum score of common comorbidities. ${ }^{17,18}$

Clinical outcomes were assessed every 6 months during the first 2 years of followup, every year until 6 years of follow-up, and every 2 years thereafter. Disease activity was measured with the Bath AS Disease Activity Index (BASDAI), ${ }^{19}$ the AS Disease Activity Score with C-reactive protein (ASDAS-CRP), ${ }^{20}$ and laboratory tests (erythrocyte sedimentation rate [ESR] and CRP). Physical function was assessed by the Bath AS Functional Index (BASFI). ${ }^{21}$ Severity of axial- and peripheral pain experienced during the last week was assessed with two single item globals (0-10; higher being worse). The Bath AS Global Score (BAS-G) was used for global assessment of the patient's well-being. ${ }^{22}$ Physician's global assessment of disease activity was assessed by a single item global (0-10; higher being worse). The Bath AS Metrology Index (BASMI, linear algorithm) was used to assess spinal mobility. ${ }^{23,24}$ Radiographic damage of the spine was evaluated every 2 years with the modified Stoke AS Spine Score (mSASSS), ${ }^{25,26}$ and scores represent the average of two trained readers. ${ }^{27}$ Information about pharmacological treatment (use of non-steroidal anti-inflammatory drugs [NSAIDs], conventional synthetic disease-modifying antirheumatic drugs [csDMARDs] and biologicals) was retrieved at every visit. Use of NSAIDs was converted into the Assessment of SpondyloArthritis international Society (ASAS) NSAID score. ${ }^{28}$

\section{Work-related outcome and job type}

Patients completed questionnaires assessing work status, and in those employed job type (eight categories) and work hours per week every 6 months during the first 2 years of follow-up, every year until 6 years of follow-up, and every 2 years thereafter, until year 
12. Working 33 hours or more per week was considered full-time work. Job type was dichotomised into two types: white-collar worker (administrative, scientific and managerial professions) and blue-collar workers (industrial, commercial, servicing, transportation and agricultural professions). ${ }^{29,30}$ No other data on work contextual factors were collected. Patients with paid work could indicate whether they had experienced AS-related sick leave, without a minimum duration, since last visit and this happened every 2 months during the first 2 years of follow-up, annually until 6 years of follow-up, and every 2 years thereafter.

\section{Statistical analysis}

Analyses included only patients 'at risk for sick leave', that is, patients working at baseline as well as those who started or resumed work during follow-up. Patients were considered to be 'at risk for sick leave' from the first assessment they reported to be working (which was not necessarily the baseline assessment of OASIS), and this assessment was used as baseline in all analyses. Patients were censored if they stopped working, became fully work disabled, retired or at the end of follow-up. Patients with evidence of long-term sick leave at entry into the cohort, based on their response to the questionnaire, were excluded from all analyses.

\section{Baseline characteristics and description of sick leave}

Baseline characteristics of patients with work were described and compared between those reporting 'ever' or 'never' sick leave during follow-up using independent t-test, MannWhitney test or chi-square test, as appropriate. For small samples (expected count < 5), Fisher's exact test was used.

\section{Factors associated with sick leave over time}

Both time-to-first-event and recurrent event analyses were performed. Eventually, three models were computed (Supplementary Figure S5.1). Model 1 is a baseline predictor model exploring time-dependent risk for the first event of sick leave (using Cox regression). Model 2 is a 'time-varying predictor' model, allowing explanatory factors to vary over time and exploring association with recurrent events of sick leave (using generalised estimating equations [GEE]). Given the number of missing data on sick leave, GEE (which can handle missing data without losing the entire patient from the analysis) with discrete time points was preferred over Cox recurrent event regression. ${ }^{31}$ Model 3 was an extension of model 2 , with the aim of investigating whether sick leave predicts recurrent sick leave. In this model, the baseline was shifted to the assessment after 1 year of being at risk for sick leave, and sick leave in the first year of being at risk was included as a dichotomised covariate.

In the base-case of the time-varying models, a 1-year time-lag period was chosen for the time-varying variables, as any longer period was considered less plausible to influence sick leave. Consequently, only data for the first 6 years could be used as further 
assessments took place every 2 years. To check the possible influence of a shorter or longer time-lag period, two additional (sensitivity) analyses were carried out. First, a 6-month time-lag period was used, in which only data for the first 2 years could be used and second, a 2-year time-lag period was used using all available follow-up data, that is, 12 years. Of note, for the main time-lagged analyses, the 2-monthly sick leave assessments during the first 2 years of follow-up were aggregated into periods of 1 year (1-year time-lag analysis) to harmonise with later assessment periods.

Modelling strategy and variable selection

Variables that could potentially explain or predict sick leave were categorised into four variable groups ('blocks'): (1) sociodemographics (age, gender [male], country of origin, education, job type, part-time work status), (2) disease characteristics (symptom duration, HLA-B27 positivity, presence of each EAM, RDCl, smoking, ASAS NSAID score, csDMARD use), (3) disease activity (BASDAI, CRP, ESR, ASDAS-CRP, physician global, axial pain, peripheral pain) and (4) function and damage (BASFI, BASMI, mSASSS). Exploratory analysis revealed that the number of observations with time-lagged biological use over time was low (less than 1\%). Biological use was therefore not included as potential predictor.

Variables in the final models were selected in steps. All variables of interest were first analysed individually, while adjusting for age and gender. Variables with $p<0.20$ or confounding variables, which changed the coefficient of sex and/or age $>10 \%$ on inclusion in the model, were retained and subsequently analysed within their variable block using a manual forward method. Variables significantly associated with the outcome $(p<0.05)$ within each variable block were retained and finally all variable blocks were tested together. Variables that lost significance on inclusion of variables from other blocks were removed from the model using a backward manual method, except for age and gender which were always retained in the model. Collinearity between covariates was checked for in each step, and relevant interactions between the variables were explored both within and between variable blocks ( $p<0.10$ used as threshold for interactions). If analyses had to be stratified due to significant interactions, variables as selected in the total sample were used in the strata. This ensured comparability of results between strata. Analyses were performed using SPSS V.23.0 (IBM, Armonk, New York, USA) and Stata SE Release 14.0 (StataCorp, College Station, Texas, USA). 


\section{Results}

\section{Description of sick leave and baseline characteristics}

Of the 216 valid patients in OASIS, 141 (65\%) were at risk for sick leave, of which 2 were excluded due to self-reported long-term sick leave at baseline. In the remaining 139 patients, the average age was 38.7 (SD 10.0) years and average symptom duration 16.4 (SD 8.9) years. At inclusion in OASIS, 121 (87\%) patients were employed, while 18 (13\%) started or resumed work during follow-up.

The median time at risk for (recurrent) sick leave among the 139 patients was 84 (IQR 48-144) months. On average, a patient completed $77 \%$ of the assessments for sick leave during the period at risk. Among the 88 patients (63\%) who ever reported sick leave, 62 (70\%) reported sick leave at more than one assessment and 35 (40\%) reported sick leave at more than three assessments. The majority of first sick leave events (62/88 [70\%]) occurred during the first 2 years of being at risk for sick leave. The number of patients at risk for SL after 2, 4, 6, 8, 10 and 12 years was 137, 108, 88, 68, 63 and 56, respectively. Figure 5.1 shows the number of patients at risk for sick leave and the occurrence of first and recurrent sick leave over time during the first 6 years.

Compared with patients who never reported sick leave during follow-up, those who ever reported sick leave were more likely to be lower educated and more likely to have a blue-collar job type (Table 5.1). There were no other significant differences in baseline characteristics or time at risk for sick leave between these two groups.

Table 5.1. Baseline* characteristics of the total study population at risk for sick leave and for the patients with and without sick leave separately

\begin{tabular}{|c|c|c|c|c|}
\hline Variable & $\begin{array}{c}\text { Total group } \\
(\mathrm{n}=139)\end{array}$ & $\begin{array}{l}\text { Ever sick leave }^{+} \\
\quad(\mathrm{n}=88)\end{array}$ & $\begin{array}{c}\text { Never sick leave }{ }^{\dagger} \\
(n=51)\end{array}$ & $\mathbf{p}^{\ddagger}$ \\
\hline Age, years & $38.7(10.0)$ & $37.9(9.6)$ & $40.3(10.6)$ & 0.18 \\
\hline Male gender, $\mathrm{n}(\%)$ & $105(75.5)$ & $68(77.3)$ & $37(72.5)$ & 0.53 \\
\hline Country of origin & & & & 0.23 \\
\hline The Netherlands, n (\%) & $74(53.2)$ & $51(58.0)$ & $23(45.1)$ & \\
\hline Belgium, n (\%) & $45(32.4)$ & $24(27.3)$ & $21(41.2)$ & \\
\hline France, n (\%) & $20(14.4)$ & $13(14.8)$ & $7(13.7)$ & \\
\hline Education, high, n (\%) & $49(36.0)$ & $23(27.1)$ & $26(51.0)$ & $<0.01$ \\
\hline Job type, white collar, n (\%) & $71(55.9)$ & $38(48.1)$ & $33(68.8)$ & 0.02 \\
\hline Part-time worker, n (\%) & $22(15.9)$ & $11(12.6)$ & $11(21.6)$ & 0.17 \\
\hline Partial work disability, n (\%) & $19(13.8)$ & $14(16.1)$ & $5(9.8)$ & 0.30 \\
\hline Age at onset symptoms, years & $22.1(7.5)$ & $21.5(7.4)$ & $23.1(7.7)$ & 0.25 \\
\hline Duration of symptoms, years & $16.4(8.9)$ & $16.2(8.3)$ & $16.7(10.1)$ & 0.79 \\
\hline HLA-B27 positive, n (\%) & $112(83.6)$ & $70(81.4)$ & $42(87.5)$ & 0.36 \\
\hline Comorbidity index $(\mathrm{RDCl})^{\S}$ & $0.2(0.5)$ & $0.2(0.5)$ & $0.1(0.3)$ & 0.11 \\
\hline Cardiovascular disease, n (\%) & $7(5.0)$ & $6(6.8)$ & $1(2.0)$ & \\
\hline
\end{tabular}


Table 5.1. Continued.

\begin{tabular}{|c|c|c|c|c|}
\hline Variable & $\begin{array}{l}\text { Total group } \\
(n=139)\end{array}$ & $\begin{array}{l}\text { Ever sick leave }^{\dagger} \\
(n=88)\end{array}$ & $\begin{array}{l}\text { Never sick leave }{ }^{\dagger} \\
(n=51)\end{array}$ & $\mathbf{p}^{\ddagger}$ \\
\hline Diabetes mellitus, n (\%) & $1(0.7)$ & $1(1.1)$ & $0(0.0)$ & \\
\hline Fracture, n (\%) & $5(3.6)$ & $4(4.5)$ & $1(2.0)$ & \\
\hline Depression, n (\%) & $1(0.7)$ & $1(1.1)$ & $0(0.0)$ & \\
\hline Gastrointestinal disease, n (\%) & $6(4.3)$ & $5(5.7)$ & $1(2.0)$ & \\
\hline History of IBD, n (\%) & $7(5.1)$ & $5(5.7)$ & $2(4.0)$ & 1.00 \\
\hline History of psoriasis, n (\%) & $8(5.8)$ & $6(6.8)$ & $2(4.0)$ & 0.71 \\
\hline History of AAU, n (\%) & $22(15.9)$ & $14(15.9)$ & $8(16)$ & 0.99 \\
\hline Hip involvement, n (\%)§ & $26(18.8)$ & $16(18.4)$ & $10(19.6)$ & 0.86 \\
\hline \multicolumn{5}{|l|}{ Medication use, current ${ }^{\#}$} \\
\hline NSAID, n (\%) & $101(72.7)$ & $66(75)$ & $35(68.6)$ & 0.42 \\
\hline ASAS NSAID score & $62.5(53.8)$ & $64.6(53.2)$ & $58.6(55.3)$ & 0.45 \\
\hline csDMARD, n (\%) & $15(10.8)$ & $8(9.1)$ & $7(13.7)$ & 0.40 \\
\hline Smoking, current, n (\%) & $41(39.4)$ & $27(39.7)$ & $14(38.9)$ & 0.94 \\
\hline $\mathrm{CRP}, \mathrm{mg} / \mathrm{l}$ & $15.3(19.5)$ & $16.2(17.6)$ & $13.9(22.3)$ & 0.07 \\
\hline Elevated CRP (>10 mg/L), n (\%) & $48(36.1)$ & $33(40.2)$ & $15(29.4)$ & 0.21 \\
\hline ESR, mm/hour & $12.3(12.1)$ & $11.3(10.1)$ & $14.0(14.7)$ & 0.42 \\
\hline ASDAS-CRP & $2.5(0.9)$ & $2.6(0.9)$ & $2.3(1.0)$ & 0.06 \\
\hline BASDAI (0-10) & $2.9(1.8)$ & $3.0(1.9)$ & $2.7(1.7)$ & 0.27 \\
\hline BASFI (0-10) & $2.4(2.0)$ & $2.6(2.1)$ & $2.1(1.9)$ & 0.22 \\
\hline Back pain $(0-10)$ & $3.2(2.2)$ & $3.4(2.1)$ & $2.9(2.2)$ & 0.16 \\
\hline BAS-G (0-10) & $3.4(2.4)$ & $3.4(2.3)$ & $3.5(2.6)$ & 0.84 \\
\hline Swollen joint count $(0-44)$ & $0.5(1.5)$ & $0.4(1.5)$ & $0.5(1.5)$ & 0.60 \\
\hline Tender joint count $(0-53)$ & $1.8(3.3)$ & $2.0(3.5)$ & $1.5(2.9)$ & 0.19 \\
\hline BASMI (0-10) & $3.4(1.5)$ & $3.5(1.5)$ & $3.2(1.5)$ & 0.27 \\
\hline mSASSS (0-72) & $7.0(11.0)$ & $7.5(12.0)$ & $6.0(9.3)$ & 0.87 \\
\hline
\end{tabular}

Values expressed as mean (SD) unless otherwise stated. *Data from the first assessment in which patients reported to be working were used as baseline variables. ${ }^{\dagger}$ Ever sick leave; patients who reported sick leave at least once during up to 12 years of follow-up. Never sick leave; patients who never reported sick leave during up to 12 years of follow-up. Note that some of these patients became lost to follow-

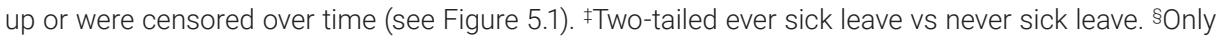
assessed at OASIS baseline. \#No patients used biologicals at baseline (first assessment in which they reported to be working). AAU, acute anterior uveitis; AS, ankylosing spondylitis; ASAS, Assessment of SpondyloArthritis international Society; ASDAS, AS Disease Activity Score; BASDAI, Bath AS Disease Activity Index; BASFI, Bath AS Functional Index; BAS-G, Bath AS Global Score; BASMI, Bath AS Metrology Index; CRP, C-reactive protein; csDMARD, conventional synthetic disease-modifying antirheumatic drug; ESR, erythrocyte sedimentation rate; HLA-B27, human leucocyte antigen B27; IBD, inflammatory bowel disease; mSASSS, modified Stoke Ankylosing Spondylitis Spine Score; NSAID, non-steroidal anti-inflammatory drug; RDCl, Rheumatic Diseases Comorbidity Index. 


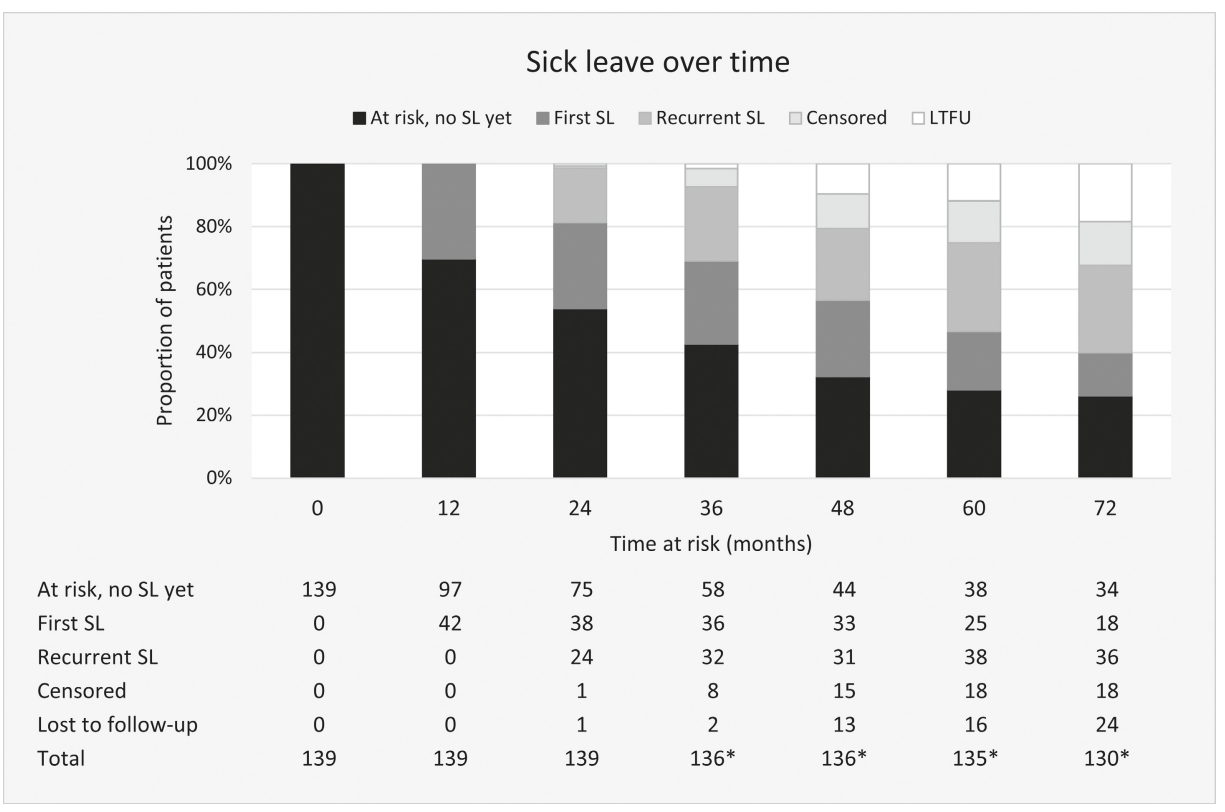

Figure 5.1. Distribution of first and recurrent sick leave episodes over time in the study population at risk. No SL yet = those who are at risk for sick leave, but have not incurred any sick leave (yet). First SL = those who reported $S L$ for the first time during follow-up, in the previous interval or before. Recurrent $S L=$ those who reported $S L$ for the second time during follow-up, in the previous interval or before. Censored $=$ censored from analyses due to reasons of job loss, unemployment, work disability, retirement. Lost to follow-up = patients that were lost to follow-up. *Due to the design of OASIS (annual assessments until month 72 , thereafter every 2 years), annual assessments were not always available for those who became at risk for SL during follow-up. AS, ankylosing spondylitis; LTFU, lost to follow-up; OASIS, Outcome in Ankylosing Spondylitis International Study; SL, ankylosing spondylitis-related sick leave.

\section{Factors associated with sick leave}

Tables 5.2, 5.3 and 5.4 present the results of the multivariable models predicting or explaining SL over time. The results of univariable analyses are shown in Supplementary Tables S5.1 and S5.2. Correlation/collinearity was found between education and job type (variables belonging to group 1), between ASDAS, BASDAI and BASFI (groups 3/4) and between education and BASDAI/ASDAS/BASFI (groups 1/3/4). For the final models, education was selected over job type because of robustness of the association with the outcome. For ASDAS, BASDAI and BASFI, it was decided to perform three separate analyses. As an interaction was observed between education and ASDAS, BASDAI and BASFI, all models were stratified for low and high educational attainment.

In the Cox regression baseline prediction model (model 1, using 12 years of follow-up), an additional interaction between gender and disease activity entailed further stratification for gender (Table 5.2). In view of small sample size of the female subgroups ( $n=20$ for 
low education, $n=14$ for high education), only the results for male subgroups (with high vs low education) are presented. While in male patients with a low level of education, higher baseline ASDAS ( $\mathrm{HR}=1.67,95 \% \mathrm{Cl} 1.23$ to 2.28), BASDAI ( $\mathrm{HR}=1.33,95 \% \mathrm{Cl} 1.18$ to 1.51 ) and BASFI ( $H R=1.17,95 \% \mathrm{CI} 1.02$ to 1.34$)$ were associated with increased hazard for first sick leave, in male patients with high level of education, no significant associations with any predictor were observed.

The 1-year time-lag time-varying GEE analyses (model 2, using 6 years of follow-up) revealed for patients with low education an association over time between higher ASDAS ${ }_{\text {lag- }}$ 1yr $\left(\mathrm{OR}=1.48,95 \% \mathrm{Cl} 1.07\right.$ to 2.03), higher $\mathrm{BASDAl}_{\text {lag-1yr }}(\mathrm{OR}=1.31,95 \% \mathrm{Cl} 1.15$ to 1.49$)$ or higher $\mathrm{BASFI}_{\text {lag-1yr }}(\mathrm{OR}=1.31,95 \% \mathrm{Cl} 1.16$ to 1.47$)$ and odds of sick leave during the next year, all in separate analyses (Table 5.3). In addition, in the BASDAI model, higher comorbidity scores at baseline predicted sick leave at any future time point $(\mathrm{OR}=1.52,95 \% \mathrm{Cl} 1.00$ to 2.29). In contrast, in those with high education, no association between either disease activity or physical function and sick leave was seen (Table 5.3). Sensitivity analyses using a 6-month time-lag (using 2 years of follow-up) or 2-year time-lag (using 12 years of followup) yielded similar results. Of note, the effect of the association between ASDAS (and to a lesser extent BASDAI and BASFI) and sick leave was stronger when using a shorter (6-month) time-lag and weaker when using a longer (2-year) time-lag (Supplementary Tables S5.3 and S5.4).

When including sick leave during the first year at risk $\left(\mathrm{SL}_{\text {|st-year }}\right)$ as a covariate in the GEE (model 3, using 6 years of follow-up), $\mathrm{SL}_{\text {lst-year }}$ was consistently associated with sick leave over time, both in those with low and with high educational attainment. The strength of this association was not significantly different between both educational groups ( $p$-value interaction $\mathrm{SL}_{\text {1st-year }}$ * education $=0.63$ ). In addition, only in those with low education,

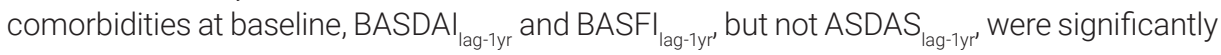
associated with future sick leave (Table 5.4). Of note, in the ASDAS model, BAS-G emerged as a significant variable associated with future sick leave, while ASDAS itself was excluded due to non-significance.

As the associations observed between those with low and high educational attainment and sick leave might still be explained by job type (patients with low educational attainment more often were blue-collar workers [62-67\% of the lower educated considered in the GEE analyses], with physically demanding jobs), this was explored in an additional analysis. After adjustment for job type, higher ASDAS/BASDASI/BASFI remained independently associated with sick leave in patients with low educational attainment, while job type itself was not significantly associated with sick leave (data not shown). 


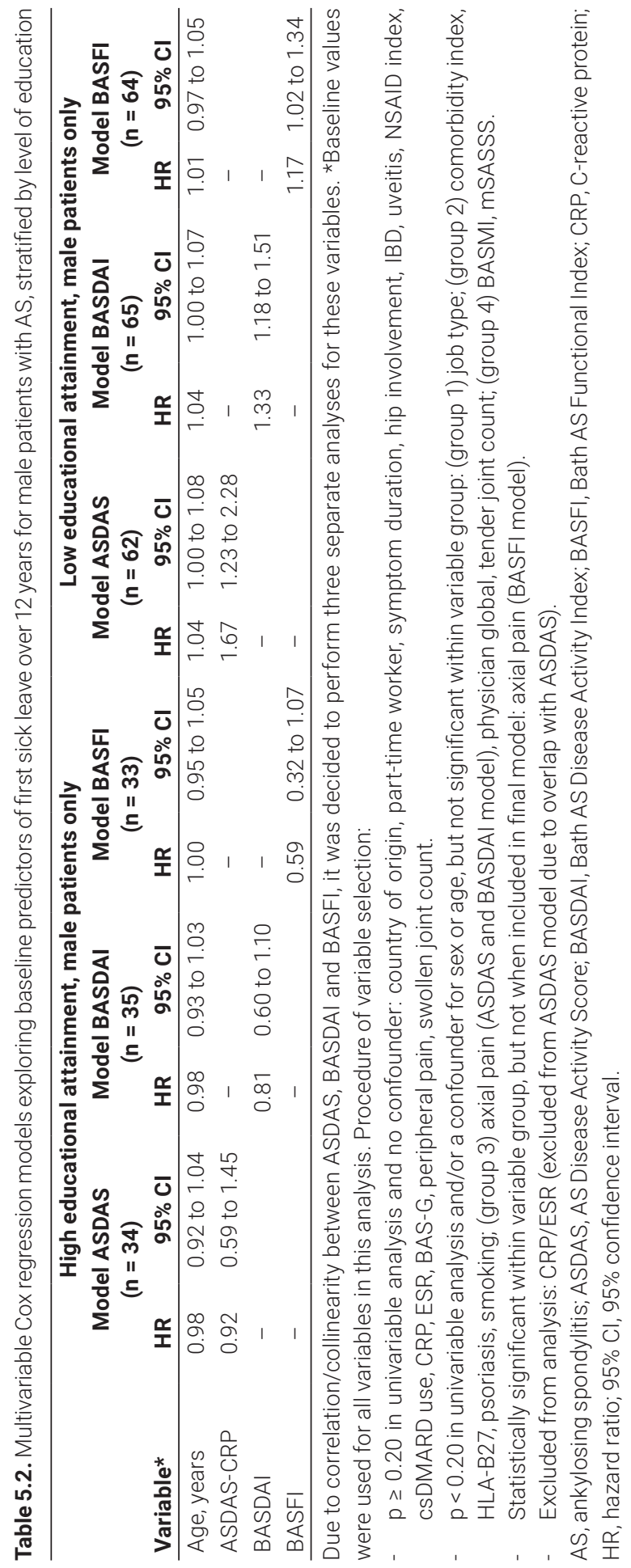




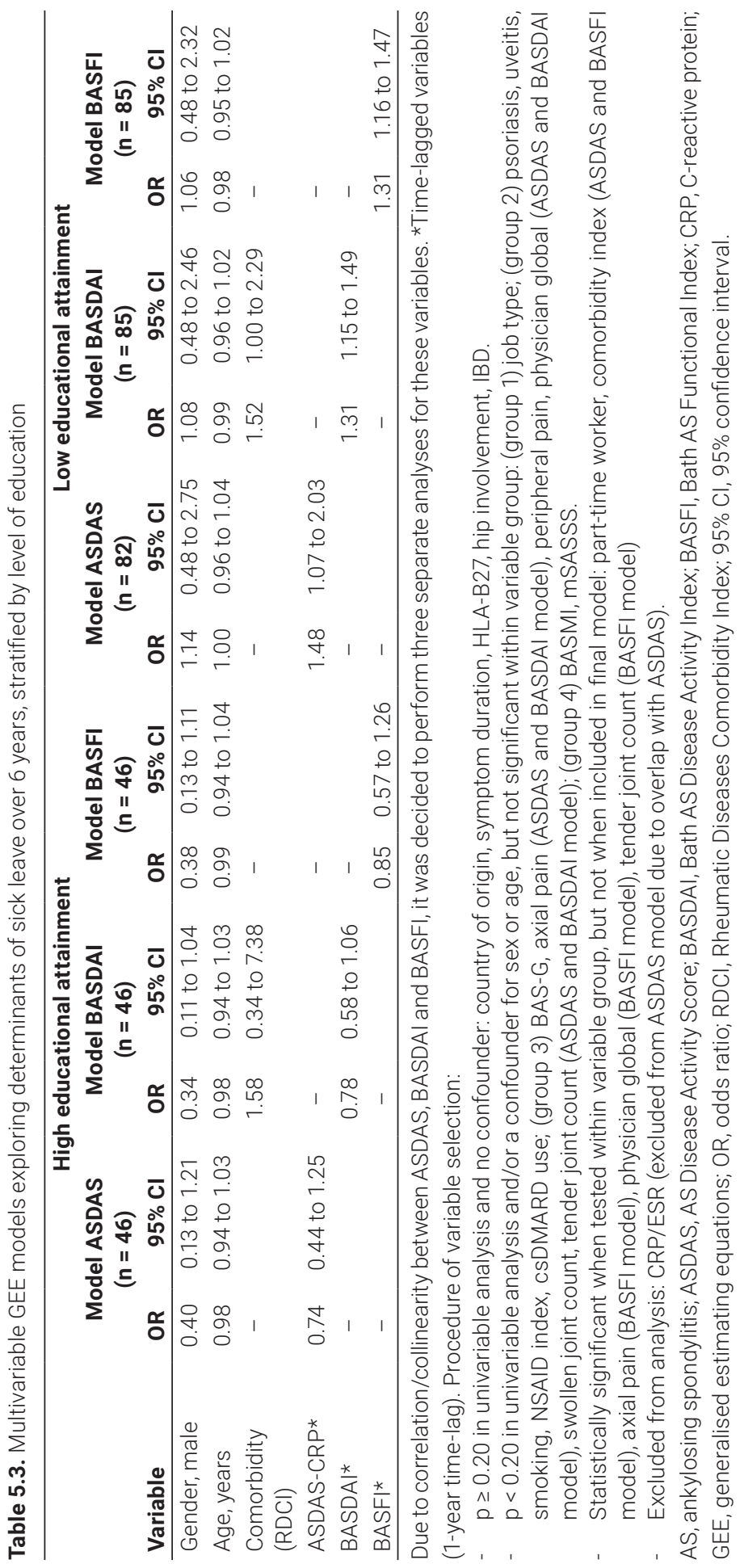




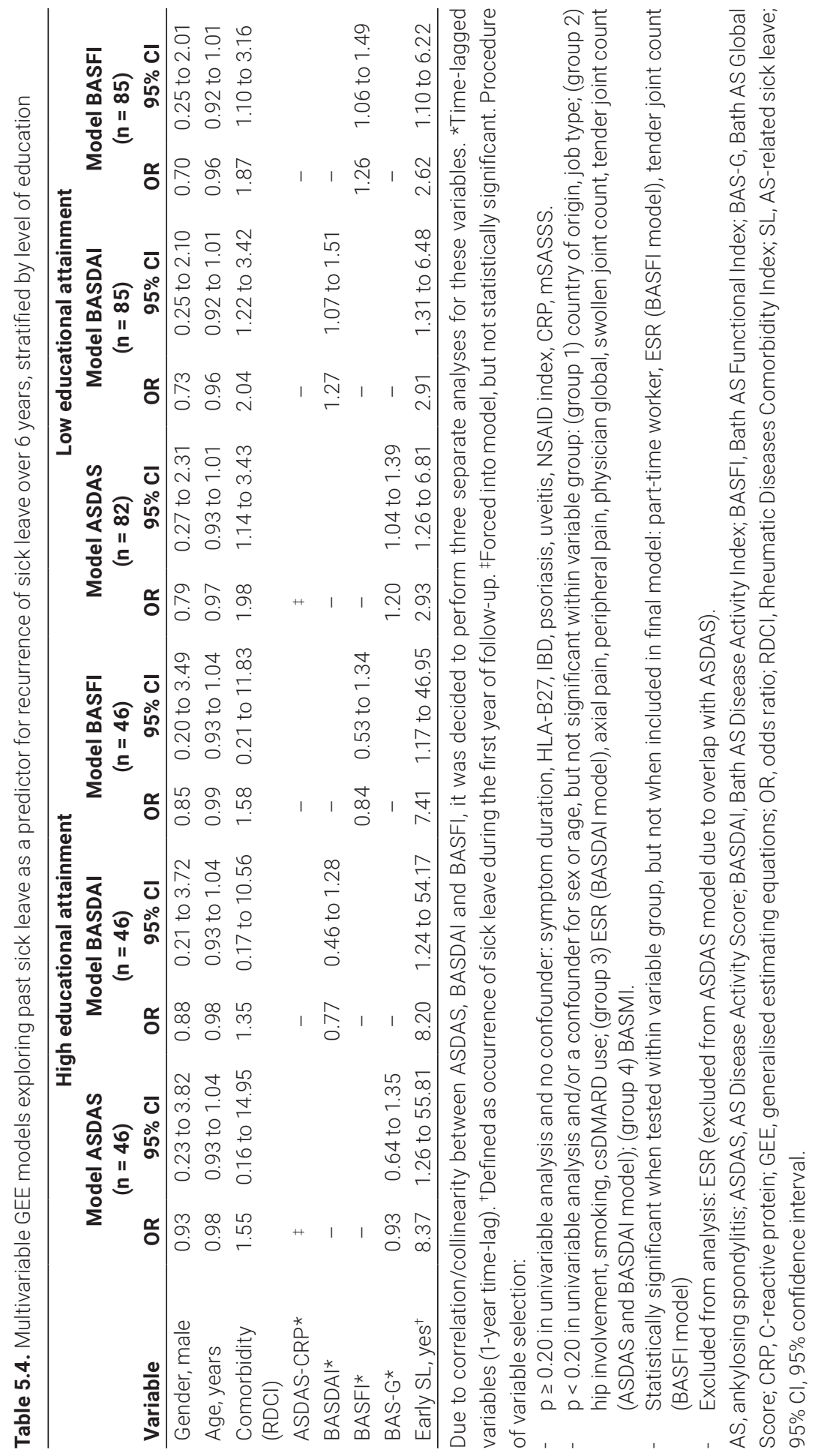




\section{Discussion}

Among a large number of factors explored, higher disease activity, worse physical function and, to a varying extent, the presence of comorbidities played a role in predicting or explaining sick leave over time. Importantly, most of these effects were dependent on educational level. In addition, the occurrence of sick leave independently of other factors predicts recurrent sick leave.

The association between educational level and sick leave in AS has been investigated previously in one cross-sectional study, which found that a lower educational level was associated with the length of sick leave, but not with the likelihood of incurring any sick leave. ${ }^{9}$ Our study revealed that education actually modified the association between disease activity or physical function and sick leave. More specifically, only in those with a low level of education higher disease activity or worse physical function increased the risk of sick leave. This role of education is likely multifactorial and might relate to job type, coping ability and self-management skills. While those with lower educational attainment more often were blue-collar worker (about 65\%), adjustment for job type did not alter our results and job type did not contribute. As such, educational attainment might reflect more adequate coping with stressors related to disease as well as work, and it is likely that such self-management skills are more important than a specific job type.

The association between higher disease activity and/or worse physical function and sick leave was already highlighted in previous research.1,11,13 As we showed an association in the Cox regression (for male patients with low education attainment) between baseline disease activity and a first episode of sick leave over a period of 12 years, disease activity must have an extended influence on the risk of sick leave. However, the short median time from baseline to first sick leave (1.2 years) should be noted. Results from additional analyses with time-varying models suggest that, in patients with low educational attainment, the effect size of disease activity is clearly larger when time-lag is shorter. Such temporal effect was less clear for BASFI. This suggests that the sick leave in patients with low educational attainment is more sensitive to variation in disease activity over time, while BASFI reflects both underlying disease activity and (irreversible) structural damage, ${ }^{32}$ therefore being both a short-term and long-term predictor of sick leave in these patients. Neither disease activity nor physical function predicted SL in patients with high educational attainment.

Comorbidities (but not EAMs) at baseline were associated with sick leave over time in the time-varying models. Again, this was only significant in those with low education attainment. Apparently, comorbidities have a long-lasting effect with negative impact on absenteeism in AS. Those with lower educational attainment might be less capable to cope with AS and also with comorbidities. As we used AS-related sick leave as outcome, these results imply that patients attribute the influence of comorbidity on sick leave to AS. It should be noted that, at baseline, only 16 (12\%) patients had at least one comorbidity. 
This is likely the result of the relatively young age at baseline (38.7 years) and also a healthy worker effect (those still working are likely to have a better health state compared with those not working anymore and thus not at risk for SL). In addition, lack of screening for comorbidities in these patients in clinical practice could also have played a role (as awareness of the importance of collecting this was limited at the time of OASIS baseline). The limited number of patients with comorbidities at baseline precluded analysis of the impact of specific comorbidities.

Several studies in AS indicated that country of residence is associated with work disability, and also in the 12-year follow-up study of withdrawal from work in OASIS, a significant influence of country of residence was seen. ${ }^{5}$ However, in the current analyses of sick leave, no influence of country was observed. This is in line with the analyses of the first 2 years in OASIS, which revealed that the risk of having an episode of sick leave did not depend on country (while length of sick leave did). ${ }^{33}$ Apparently, the patient's decision to take sick leave is independent of the social security system or cultural aspects related to country of residence but stronger related to health-related and personal factors.

To our best knowledge, this was the first study to investigate whether disease-related sick leave in patients with AS independently predicts recurrent disease-related sick leave, which was confirmed. Previous studies have shown similar results in workers with nonspecific musculoskeletal complaints and in general, non-disease specific samples. ${ }^{34-36}$ Our results emphasise the importance of adequate support for patients who incur sick leave. Prevention of sick leave in AS might reduce short-term costs (for the current period of sick leave) and is likely to prevent future sick leave as well, thereby reducing long-term costs.

The current study had several limitations that need to be addressed. First, the patients in OASIS at risk for SL had long-standing disease with an average symptom duration of 16 years at baseline, thereby limiting the generalisability of the results to patients with short-lasting disease manifestations. Next, a 'healthy worker effect' might exist in our study population, as patients with severe disease might have been excluded from the labour force (i.e. fully work disabled) before the start of OASIS and would therefore not be included in the analyses. As a result, the population at risk for sick leave in OASIS might be healthier than the overall age-adjusted and gender-adjusted AS population. Third, attrition bias might have occurred. After 12 years, only 56 (40\%) patients were still at risk for (recurrent) sick leave. It is unknown whether those who became unemployed or work disabled, or were simply lost to follow-up, would have reported sick leave had they remained. Fourth, although information on the length of sick leave was gathered, this was frequently missing or unreliably reported. Moreover, as longer recall periods are associated with imprecision of the length of self-reported sick leave, we decided not to use the length of sick leave as outcome, limiting the interpretation of our analysis. ${ }^{37}$ Fifth, the temporal relationship between variables was ensured using time-lagged variables, but the actual period between predictor and sick leave could vary considerably. In sensitivity analyses, 
we used shorter time-lag periods of 6 months in order to minimise this uncertainty. Finally, as biologicals first became available after several years of follow-up, the number of observations with biological use was low and the effect of biological use on SL over time could not be explored.

The main strength of the current study was the prospective study design, and the length of follow-up allowing to investigate whether sick leave was a predictor for recurrent sick leave. Additionally, all relevant outcomes were systematically measured at regular intervals in a standardised way using validated instruments.

While our findings can be relevant for clinical practice, as we identified factors that could warn rheumatologists a patient is at risk for (upcoming or recurrent) sick leave, it should be noted that occurrence of sick leave is not an outcome with only negative connotations: sick leave could be appreciated as a signal for impending work disability, but it could also serve as a means to recover (thereby preventing work disability in the long term). Even then, AS-related sick leave is still a signal that some form of support is necessary. However, it would be worthwhile to investigate if sick leave should always, and at all costs, be prevented. Further research to determine the exact role of sick leave in sickness and recovery in AS is warranted. Also, we should be careful to not stigmatise patients with chronic disease for having sick leave.

In conclusion, in this prospective cohort study, disease-specific factors (higher disease activity, worse functioning and/or comorbidity) increased the risk for recurrent AS-related sick leave in those with lower education. In addition, AS-related sick leave was an independent and strong predictor of recurrent AS-related sick leave over time. Sick leave seems a signal that support is warranted to prevent future adverse work outcome. 


\section{References}

1. Boonen A, Brinkhuizen T, Landewe R, van der Heijde D, Severens JL. Impact of ankylosing spondylitis on sick leave, presenteeism and unpaid productivity, and estimation of the societal cost. Ann Rheum Dis 2010;69:1123-1128.

2. Webers $C$, Vanhoof $L$, van Genderen S, Heuft L, van de Laar M, Luime J, et al. Employment and the role of personal factors among patients with ankylosing spondylitis: a Dutch cross-sectional case-control study. RMD Open 2018;4:e000680.

3. Verstappen SM, Watson KD, Lunt M, McGrother K, Symmons DP, Hyrich KL, et al. Working status in patients with rheumatoid arthritis, ankylosing spondylitis and psoriatic arthritis: results from the British Society for Rheumatology Biologics Register. Rheumatology (Oxford) 2010;49:1570-1577.

4. Bakland G, Gran JT, Becker-Merok A, Nordvag BY, Nossent JC. Work disability in patients with ankylosing spondylitis in Norway. J Rheumatol 2011;38:479-484.

5. Castillo-Ortiz JD, Ramiro S, Landewe R, van der Heijde D, Dougados M, van den Bosch F, et al. Work Outcome in Patients With Ankylosing Spondylitis: Results From a 12-Year Followup of an International Study. Arthritis Care Res (Hoboken) 2016;68:544-552.

6. Strombeck B, Jacobsson LT, Bremander A, Englund M, Heide A, Turkiewicz A, et al. Patients with ankylosing spondylitis have increased sick leave--a registry-based case-control study over 7 yrs. Rheumatology (Oxford) 2009;48:289-292.

7. Strombeck B, Englund M, Bremander A, Jacobsson LT, Kedza L, Kobelt G, et al. Cost of illness from the public payers' perspective in patients with ankylosing spondylitis in rheumatological care. J Rheumatol 2010;37:2348-2355.

8. Floderus B, Goransson S, Alexanderson K, Aronsson G. Self-estimated life situation in patients on long-term sick leave. J Rehabil Med 2005;37:291-299.

9. Gordeev VS, Maksymowych WP, Schachna L, Boonen A. Understanding presenteeism in patients with ankylosing spondylitis: contributing factors and association with sick leave. Arthritis Care Res (Hoboken) 2014;66:916-924.

10. Guillemin F, Briancon S, Pourel J, Gaucher A. Long-term disability and prolonged sick leaves as outcome measurements in ankylosing spondylitis. Possible predictive factors. Arthritis Rheum 1990;33:1001-1006.

11. Healey EL, Haywood KL, Jordan KP, Garratt A, Packham JC. Impact of ankylosing spondylitis on work in patients across the UK. Scand J Rheumatol 2011;40:34-40.

12. Meyer K, Niedermann K, Tschopp A, Klipstein A. Is the work ability index useful to evaluate absence days in ankylosing spondylitis patients? A cross-sectional study. BMJ Open 2013;3.

13. Ward MM, Kuzis S. Risk factors for work disability in patients with ankylosing spondylitis. $J$ Rheumatol 2001;28:315-321.

14. World Health Organization. International classification of functioning, disability and health: ICF. Geneva: World Health Organization; 2001. 
15. Stolwijk C, Castillo-Ortiz JD, Gignac M, Luime J, Boonen A, Group OWP. Importance of Contextual Factors When Measuring Work Outcome in Ankylosing Spondylitis: A Systematic Review by the OMERACT Worker Productivity Group. Arthritis Care Res (Hoboken) 2015;67:1316-1327.

16. van der Linden S, Valkenburg HA, Cats A. Evaluation of diagnostic criteria for ankylosing spondylitis. A proposal for modification of the New York criteria. Arthritis Rheum 1984;27:361-368.

17. Michaud K, Wolfe F. Comorbidities in rheumatoid arthritis. Best Pract Res Clin Rheumatol 2007;21:885-906.

18. Stolwijk C, van Tubergen A, Ramiro S, Essers I, Blaauw M, van der Heijde D, et al. Aspects of validity of the self-administered comorbidity questionnaire in patients with ankylosing spondylitis. Rheumatology (Oxford) 2014;53:1054-1064.

19. Garrett S, Jenkinson T, Kennedy LG, Whitelock H, Gaisford P, Calin A. A new approach to defining disease status in ankylosing spondylitis: the Bath Ankylosing Spondylitis Disease Activity Index. J Rheumatol 1994;21:2286-2291.

20. Lukas C, Landewe R, Sieper J, Dougados M, Davis J, Braun J, et al. Development of an ASASendorsed disease activity score (ASDAS) in patients with ankylosing spondylitis. Ann Rheum Dis 2009;68:18-24.

21. Calin A, Garrett S, Whitelock H, Kennedy LG, O'Hea J, Mallorie P, et al. A new approach to defining functional ability in ankylosing spondylitis: the development of the Bath Ankylosing Spondylitis Functional Index. J Rheumatol 1994;21:2281-2285.

22. Jones SD, Steiner A, Garrett SL, Calin A. The Bath Ankylosing Spondylitis Patient Global Score (BAS-G). Br J Rheumatol 1996;35:66-71.

23. van der Heijde D, Landewe R, Feldtkeller E. Proposal of a linear definition of the Bath Ankylosing Spondylitis Metrology Index (BASMI) and comparison with the 2-step and 10-step definitions. Ann Rheum Dis 2008;67:489-493.

24. Jenkinson TR, Mallorie PA, Whitelock HC, Kennedy LG, Garrett SL, Calin A. Defining spinal mobility in ankylosing spondylitis (AS). The Bath AS Metrology Index. J Rheumatol 1994;21:1694-1698.

25. Creemers MC, Franssen MJ, van't Hof MA, Gribnau FW, van de Putte LB, van Riel PL. Assessment of outcome in ankylosing spondylitis: an extended radiographic scoring system. Ann Rheum Dis 2005;64:127-129.

26. Ramiro S, van Tubergen A, Stolwijk C, Landewe R, van de Bosch F, Dougados M, et al. Scoring radiographic progression in ankylosing spondylitis: should we use the modified Stoke Ankylosing Spondylitis Spine Score (mSASSS) or the Radiographic Ankylosing Spondylitis Spinal Score (RASSS)? Arthritis Res Ther 2013;15:R14.

27. Ramiro S, Stolwijk C, van Tubergen A, van der Heijde D, Dougados M, van den Bosch F, et al. Evolution of radiographic damage in ankylosing spondylitis: a 12 year prospective follow-up of the OASIS study. Ann Rheum Dis 2015;74:52-59.

28. Dougados M, Simon P, Braun J, Burgos-Vargas R, Maksymowych WP, Sieper J, et al. ASAS recommendations for collecting, analysing and reporting NSAID intake in clinical trials/ epidemiological studies in axial spondyloarthritis. Ann Rheum Dis 2011;70:249-251. 
29. Gaudette LA, Richardson A, Huang S. Which workers smoke? Health Rep 1998;10:35-45 (ENG); 35-47 (FRE).

30. Schreuder KJ, Roelen CA, Koopmans PC, Groothoff JW. Job demands and health complaints in white and blue collar workers. Work 2008;31:425-432.

31. Twisk JW, Smidt N, de Vente W. Applied analysis of recurrent events: a practical overview. J Epidemiol Community Health 2005;59:706-710.

32. Machado P, Landewe R, Braun J, Hermann KG, Baraliakos X, Baker D, et al. A stratified model for health outcomes in ankylosing spondylitis. Ann Rheum Dis 2011;70:1758-1764.

33. Boonen A, van der Heijde D, Landewe R, Spoorenberg A, Schouten H, Rutten-van Molken M, et al. Work status and productivity costs due to ankylosing spondylitis: comparison of three European countries. Ann Rheum Dis 2002;61:429-437.

34. Lotters F, Hogg-Johnson S, Burdorf A. Health status, its perceptions, and effect on return to work and recurrent sick leave. Spine (Phila Pa 1976) 2005;30:1086-1092.

35. Koopmans PC, Roelen CA, Groothoff JW. Risk of future sickness absence in frequent and longterm absentees. Occup Med (Lond) 2008;58:268-274.

36. Roelen CA, Koopmans PC, Schreuder JA, Anema JR, van der Beek AJ. The history of registered sickness absence predicts future sickness absence. Occup Med (Lond) 2011;61:96-101.

37. Severens JL, Mulder J, Laheij RJ, Verbeek AL. Precision and accuracy in measuring absence from work as a basis for calculating productivity costs in The Netherlands. Soc Sci Med 2000;51:243-249. 


\section{Chapter 6}

\section{Employment and the role of personal factors among}

patients with ankylosing spondylitis: a Dutch crosssectional case-control study

Casper Webers, Laura Vanhoof, Simon van Genderen, Liesbeth Heuft, Mart van de Laar, Jolanda Luime, Désirée van der Heijde, Floris van Gaalen, Anneke Spoorenberg, Annelies Boonen RMD Open 2018;4:e000680 


\section{Abstract}

\section{Objective}

To update the knowledge on employment and the role of mastery, a personal factor reflecting the level of control over life and disease, among Dutch patients with ankylosing spondylitis (AS) compared to general population subjects.

\section{Methods}

Data of persons $\leq 65$ years participating in a Dutch cross-sectional multicentre study on social participation in AS were used. Being employed was the main outcome. Standardised employment ratios (SERs) were calculated using indirect standardisation after adjusting for age, gender and education and repeated after stratification by symptom duration tertiles. Modified Poisson regressions were performed to understand the role of mastery (Pearlin's scale) independent of sociodemographic and health-related factors.

\section{Results}

214 patients and 470 controls (127 [59.3\%] and 323 [68.7\%] males; mean age 48.3 [SD 10.4] and 39.3 [SD 12.7] years, respectively) completed an online questionnaire. SER (95\% CI) in patients was 0.83 (0.69 to 0.98); 0.84 (0.67 to 1.04) in males; 0.83 (0.59 to 1.07) in females. Adjusted absolute employment of patients compared to controls was $69 \%$ versus $84 \% ; 73 \%$ versus $86 \%$ for males; $62 \%$ versus $78 \%$ for females. In multivariable analyses stratified for patients and controls, mastery was associated with being employed in patients, but only in those with low education. In controls, not mastery but higher education was associated with being employed.

\section{Conclusion}

Our study reveals that patients suffering from AS compared to population controls are less likely to be employed. Mastery is an important personal factor associated with employment in patients but not in controls. Interventions aimed at improving employment of patients with AS should likely account for mastery. 


\section{Introduction}

For patients with ankylosing spondylitis (AS), employment ranks among the three most important social roles. ${ }^{1}$ Preceding studies showed that patients with AS encounter difficulties to remain employed. ${ }^{2}$ When compared with population controls, a Dutch study from 2001 revealed that age-adjusted and gender-adjusted employment in patients with established AS was $11 \%$ lower. ${ }^{3}$ Moreover, a decrease in employment was already seen early in the disease. ${ }^{4}$ In the same period, other European studies confirmed reduced employment of patients compared with the general population. 5,6 Since then, efforts have been made to improve timely diagnosis and treatment of AS. Importantly, biological disease-modifying antirheumatic drugs (bDMARDs) have been introduced, which had overall beneficial effect on presenteeism and sick leave in patients with higher disease activity.? Given this progress, it would be expected that employment rates in AS are improving and possibly even become similar to those of the general population. This would be especially expected in patients with short symptom duration, as the effects of improvement in care over the last decade would be expected to be most pronounced in this subgroup.

Participation in labour force of patients with a chronic disease is a complex outcome, and several theoretical frameworks are available to help understand the complex interplay between biomedical and different personal and environmental factors. ${ }^{8,9}$ Disease-related determinants, such as disease activity and physical function, can only partially explain the impact of AS on work. ${ }^{10}$ Past studies provided empirical evidence that lack of control, reflected by passive coping, self-efficacy or helplessness were strongly associated with adverse work outcome, independent of disease specific impairments. ${ }^{4,11,12}$ However, it remains unclear whether the effect of personal attitudes or beliefs has a generic (ubiquitous) effect on work participation, or plays a different role in patients compared with general population subjects. Such information would be relevant to emphasise the role of self-management specifically in persons with a chronic disease, and would support reinforcing the role of self-efficacy in patient education programmes for employed patients with AS for whom continuation in the workforce is an important goal. ${ }^{13}$

In the current study, the first objective was to update the current knowledge on employment of patients with AS in comparison to the general population in the Netherlands, also in relation to symptom duration. The second objective was to understand whether mastery, reflecting level of control over life and disease, would have a similar association with employment in patients as in controls. 


\section{Methods}

\section{Study population}

Data from the Social Participation in AS Study (SPASS), a multicentre cross-sectional survey-based study including patients with AS in the Netherlands, were used for this analysis. ${ }^{1}$ Patients were recruited from six hospitals during a 6-month period in 2011. Patients were eligible if at least 18 years of age and if the treating rheumatologist confirmed fulfilment of the modified New York criteria for AS. ${ }^{14}$ Exclusion criteria were insufficient ability to read/understand the Dutch language, no access to a computer with online connection and severe immediate life-threatening comorbidities according to the treating physician. A control population was recruited in parallel by Ipsos, an ISOcertified independent company specialised in population surveys for global market, policy and research purposes. Population controls were sampled to yield an age and gender distribution as expected from previously published observational studies in AS (mean age 42 years, male to female ratio 3:1).15 The study was approved by the ethical committee of the Maastricht University Medical Center and all participants provided informed consent.

\section{Assessments}

All participants completed a similar online survey, with questions on sociodemographics including income (four categories), education (primary school, lower [professional] education, secondary [vocational] education, higher education/university) and a question on employment (currently employed, yes/no). Lifestyle was assessed using questions on smoking and drinking behaviour. Generic health status was assessed using the Short Form 36 (SF-36), providing a Physical Component Summary (SF-36PCS) and Mental Component Summary (SF-36MCS). ${ }^{16}$ Disease-related questions included questions on symptom duration (defined as time in years since symptom onset) and medication use. Disease activity and functioning were measured among patients using the Bath AS Disease Activity Index (BASDAI) and Bath AS Functional Activity Index (BASFI), respectively.17,18 Presence, treatment and functional impact of comorbidities and extra-articular manifestations (psoriasis, uveitis and inflammatory bowel disease [IBD]), were assessed using the SelfAdministered Comorbidity Questionnaire (SCQ). ${ }^{19}$ Mastery, the extent to which one feels their life chances as being under their personal control, was assessed using the 7-item Pearlin's mastery scale. ${ }^{20}$ This instrument measures the extent to which individuals perceive themselves in control of forces that significantly impact their lives. Each item can be scored on a 1 to 4 scale (1: strongly disagree; 2 : disagree; 3: agree; 4: strongly agree) resulting in a score range of 7 (worst) to 28 (best). The individual items of Pearlin's mastery scale are presented in Supplementary File S6.1. 


\section{Statistical analysis}

Being employed (yes/no) was the main outcome for the current analyses, which is why the study sample was restricted to those aged $\leq 65$ years (the legal age of retirement in the Netherlands in 2011). Differences in demographic and health characteristics between patients and population controls were explored with independent t-test, Mann Whitney test or chi-square test, depending on level of measurement and distribution. If appropriate (expected count < 5), Fisher's exact test was preferred over chi-square test.

\section{Standardized Employment Ratios}

The impact of AS on work participation when compared with population controls was assessed for the total group and subsequently for three strata of symptom duration (tertiles: $0-14,15-27$ and 28-50 years), by computing standardised employment ratios (SERs) with 95\% Cl using indirect standardisation methods. Standardisation accounted for gender, age (categorised: $<35,35-<50$ and 50-65 years of age) and education (university/ college level versus no/lower/secondary education). The SER can be interpreted as the relative chance of patients with AS having a paid job compared with the control group (set as reference, value $=1.00$ ). To investigate the effect of disease activity on employment, SERs were also presented for patients with a BASDAI $\geq 4$ and patients with a BASDAI $<4$ separately. Using the SER, the adjusted absolute employment rate for patients was computed by multiplying the SER for patients by the absolute employment rate of controls.

\section{Differential effect of contributory factors in patients and controls}

To assess the differential impact of mastery on employment in patients or controls, a regression model was developed with employment (yes/no) as dependent variable. As incidence rate ratios (IRRs, generated by modified Poisson regression) more accurately reflect risks than ORs (generated by logistic regression) when the prevalence of the outcome is $>10 \%$, modified Poisson regression was preferred over logistic regression. ${ }^{21}$ Exploratory analysis revealed that patients on TNFi were in a worse health state compared with patients not on TNFi. Likely, these patients had even worse disease at the start of TNFi, and the role of TNFI at the individual level cannot further be explored as this covariate is subject to confounding by indication. Consequently, TNFi use was not included in the multivariable models to prevent biased results. Also, as the aim of this analysis was to compare the differential effect of factors in patients and controls, generic variables (such as SF-36PCS) were preferred over disease-specific factors (such as BASDAI). Variables of interest were thus education (dichotomised, higher education/university versus other), smoking, alcohol use, body mass index, comorbidity, health status (SF-36PCS, SF-36MCS) and mastery. These were first explored in univariable analysis, correcting for gender and age. Next, a basic multivariable model was computed in the total sample including age, gender and group-membership (patient versus control). Subsequently, demographic variables and 
health variables (SF-36PCS, comorbidity) that were associated with being employed in univariable analyses $(p<0.20)$ were added using a manual forward method, after ruling out collinearity between variables. Variables were retained if significantly associated with the outcome $(p<0.05)$ and/or a confounder (changed the IRR of included variables $>10 \%)$. As a final step, mastery was added.

Interactions between group-membership and all variables in the model were tested, and $p<0.10$ was considered sufficient reason to explore stratified analyses. As significant interactions were found between group-membership and mastery $(p=0.02)$ as well as SF-36PCS ( $p=0.08)$, further analyses were carried out in patients and controls separately. As an additional interaction was observed between education and mastery in the patient group ( $p=0.08)$, the final analyses were carried out in three separate subsamples: controls, patients with lower education and patients with higher education. All statistical analyses were performed with SPSS V.23.0 (IBM, Armonk, New York, USA) and Stata Release 14 (Stata, College Station, Texas, USA).

\section{Results}

\section{Comparison of patients with AS versus controls}

In total, 214 subjects diagnosed with AS and 470 controls of 65 years or younger participated. Against expectations, patients were significantly older than controls (48.3 vs 39.3 years, $p$ $<0.01$ ) and less frequently male (59.3\% vs $68.7 \%, p=0.02)$. Patients more frequently had low income and low education. Further, comorbidity score was higher and SF-36PCS and mastery were worse in patients with AS compared with population controls (Table 6.1).

\section{Standardised employment ratios}

The SER $(95 \% \mathrm{CI})$ in patients with AS, having controls as reference (value 1.00), was 0.83 (0.69 to 0.98 ) overall; 0.84 (0.67 to 1.04) for males and 0.80 (0.59 to 1.07) for females (Figure 6.1A). The adjusted absolute employment rates for patients and controls were $69 \%$ vs $84 \%$ in the total population; $73 \%$ vs $86 \%$ for males and $62 \%$ vs $78 \%$ for females. Although not statistically significant, SERs in males were lowest in the tertile of those with longest symptom duration. This was not observed in females. Along the same line, SERs were slightly (but not significantly) lower in females than in males, except for the subgroup with a symptom duration of 15-27 years (Figure 6.1A). It should be noted that also absolute (adjusted) employment was somewhat lower in females compared with males (Figure 6.1B). The SER in patients with a BASDAI $\geq 4$ was significantly lower compared with controls. In contrast, in patients with a BASDAI $<4$, the SER was almost similar to controls (Figure 6.2). 
Table 6.1. Characteristics of the patients with AS and population controls aged $\leq 65$ years

\begin{tabular}{|c|c|c|c|}
\hline Variable & $\begin{array}{c}\text { AS } \\
(n=214)\end{array}$ & $\begin{array}{l}\text { Controls } \\
(n=470)\end{array}$ & $\mathrm{p}^{*}$ \\
\hline Age, years & $48.3(10.4)$ & $39.3(12.7)$ & $<0.01$ \\
\hline Male, n (\%) & $127(59.3)$ & $323(68.7)$ & 0.02 \\
\hline Education, n (\%) & & & $<0.01^{\dagger}$ \\
\hline Primary school & $2(0.9)$ & $0(0.0)$ & \\
\hline Lower (professional) education & $36(16.8)$ & $30(6.4)$ & \\
\hline Secondary education & $107(50.0)$ & $207(44.0)$ & \\
\hline Higher education/university & $69(32.2)$ & $233(49.6)$ & \\
\hline Current smoker, n (\%) & $43(20.1)$ & $90(19.2)$ & 0.78 \\
\hline Alcohol use (yes), n (\%) & $168(78.5)$ & $389(82.8)$ & 0.18 \\
\hline $\mathrm{BMI}, \mathrm{kg} / \mathrm{m}^{2}$ & $26.3(4.4)$ & $25.3(4.3)$ & $<0.01$ \\
\hline Currently employed, n (\%) & $139(65.0)$ & $393(83.6)$ & $<0.01$ \\
\hline Work disability, n (\%) & $58(27.1)$ & $17(3.6)$ & $<0.01$ \\
\hline Annual income, n (\%) & & & $<0.01$ \\
\hline$\leq € 20,000$ & $64(29.9)$ & $44(11.3)$ & \\
\hline$>€ 20,000$ and $\leq € 40,000$ & $65(30.4)$ & $113(29.0)$ & \\
\hline$>€ 40,000$ and $\leq € 60,000$ & $39(18.2)$ & $123(31.5)$ & \\
\hline$>€ 60,000$ & $46(21.5)$ & $110(28.2)$ & \\
\hline Symptom duration, years & $21.4(11.2)$ & $\mathrm{N} / \mathrm{A}$ & $\mathrm{N} / \mathrm{A}$ \\
\hline Time since diagnosis, years & $15.5(10.7)$ & N/A & $\mathrm{N} / \mathrm{A}$ \\
\hline Current medication use, $\mathrm{n}(\%)$ & & & $\mathrm{N} / \mathrm{A}$ \\
\hline NSAID & $117(54.7)$ & $\mathrm{N} / \mathrm{A}$ & \\
\hline Anti-TNF & $119(55.6)$ & $\mathrm{N} / \mathrm{A}$ & \\
\hline $\operatorname{SCQ}(0-39)^{\ddagger}$ & $2.7(4.1)$ & $1.0(1.7)$ & $<0.01$ \\
\hline History of psoriasis, n (\%) & $18(8.4)$ & N/A & N/A \\
\hline History of uveitis, n (\%) & $38(17.8)$ & N/A & $\mathrm{N} / \mathrm{A}$ \\
\hline History of IBD, n (\%) & $31(14.5)$ & $\mathrm{N} / \mathrm{A}$ & $\mathrm{N} / \mathrm{A}$ \\
\hline BASDAI & $4.3(2.2)$ & $N / A$ & N/A \\
\hline BASFI & $4.1(2.5)$ & $\mathrm{N} / \mathrm{A}$ & N/A \\
\hline SF-36PCS (0-100) & $39.5(10.6)$ & $53.9(8.4)$ & $<0.01$ \\
\hline SF-36MCS (0-100) & $49.2(12.8)$ & $49.4(11.7)$ & 0.32 \\
\hline Mastery (7-28) & $20.8(4.0)$ & $22.4(3.9)$ & $<0.01$ \\
\hline
\end{tabular}

Values expressed as mean (SD) unless otherwise stated. *Two-tailed patients versus controls. Continuous data: independent t-tests for normally distributed variables and Mann-Whitney tests for non-normally distributed variables. Categorical data: chi-square tests and Fisher's exact tests (latter for small samples, expected count $<5$ ). ${ }^{+}$Result of chi-square test, $4 \times 2$ table. Post hoc test for difference in level of education (high vs other) between groups was significant $(p<0.001)$. ${ }^{\ddagger}$ Modified SCQ, excluding questions on back pain, chronic rheumatic disease and osteoarthritis. AS, ankylosing spondylitis; BASDAI, Bath Ankylosing Spondylitis Disease Activity Index; BASFI, Bath Ankylosing Spondylitis Functional Index; BMI, body mass index; IBD, inflammatory bowel disease; N/A, not applicable; NSAID, non-steroidal anti-inflammatory drug; SCQ, Self-Administered Comorbidity Questionnaire; SF-36PCS, Short Form 36 Physical Component Summary; SF-36MCS, Short Form 36 Mental Component Summary; TNF, tumour necrosis factor. 


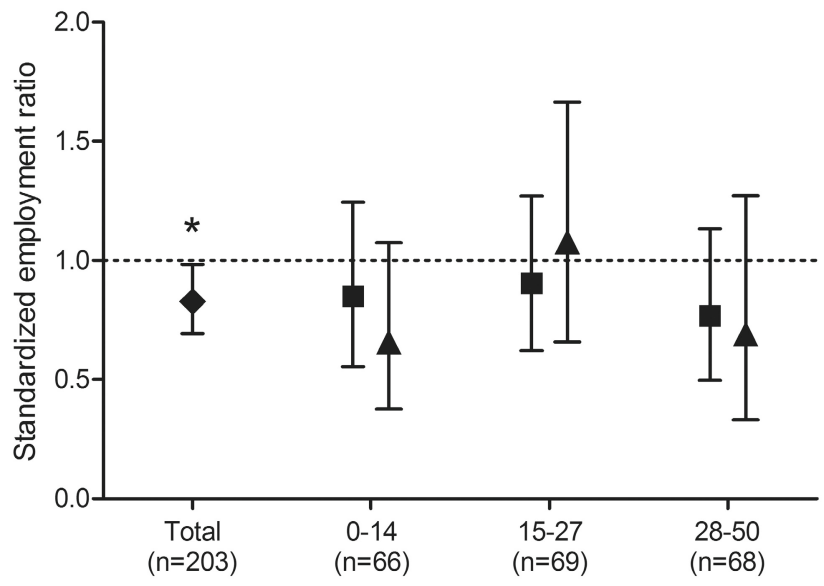

AS, total group

- AS, males

$\Delta$ AS, females

A Tertiles of symptom duration, years

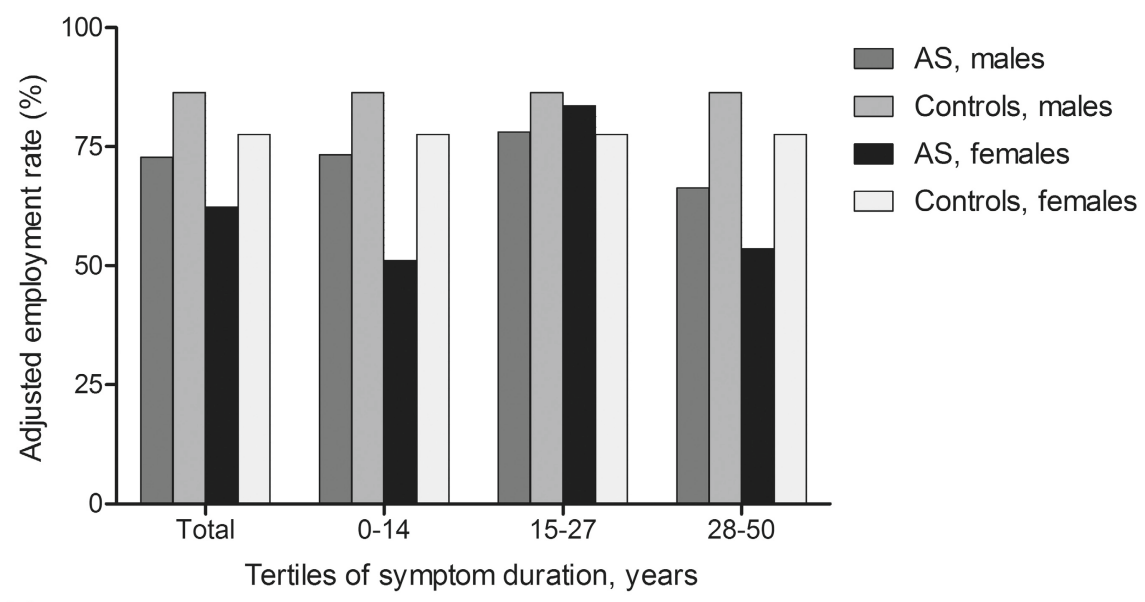

B

Figure 6.1. Employment of patients with AS compared to controls. SERs with $95 \% \mathrm{Cls}$ of patients with AS with controls set as reference (dotted line, 1A) and adjusted absolute employment rates for patients with AS and controls (1B), stratified by symptom duration and gender. Calculation of adjusted absolute employment $=S_{\text {SER }} \times$ employment rate of controls. Due to missing data, 203 (of 214) patients were included in this analysis. ${ }^{*} p<0.05$ compared to controls. AS, ankylosing spondylitis; SERs, standardised employment ratios. 


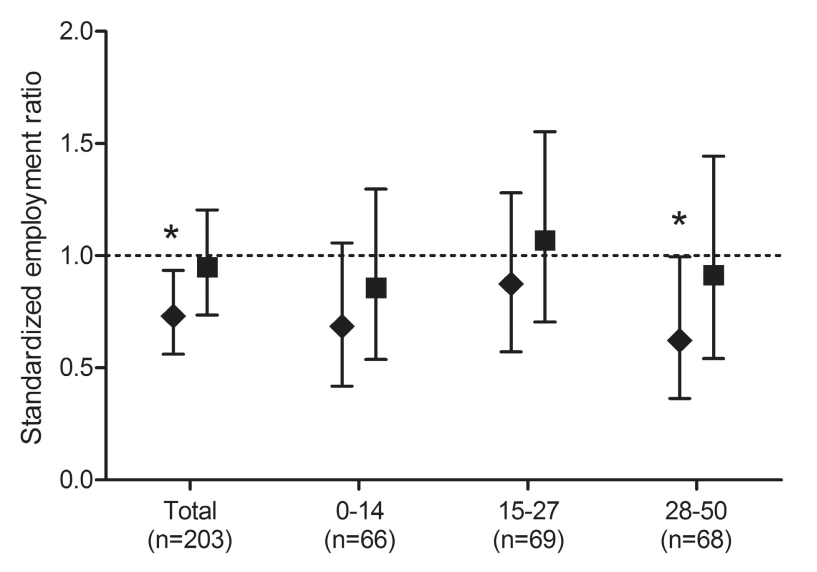

Tertiles of symptom duration, years

Figure 6.2. Employment of patients with AS compared to controls, by BASDAI. SERs with $95 \% \mathrm{Cls}$ of patients with AS with controls set as reference (dotted line), stratified by symptom duration and BASDAI. Due to missing data, 203 (of 214) patients were included in this analysis. ${ }^{*} p<0.05$ compared to controls. AS, ankylosing spondylitis; BASDAI, Bath Ankylosing Spondylitis Disease Activity Index; SERs, standardised employment ratios.

\section{Differential effect of mastery in patients and controls}

The results of univariable analyses are shown in Table 6.2. Multivariable stratified analyses by group-membership and further by education in patients are presented in Table 6.3. Among controls, better SF-36PCS and higher educational attainment were associated with increased employment rates (IRR $=1.01,95 \% \mathrm{Cl} 1.00$ to 1.02 for SF-36PCS; IRR $=1.09,95 \%$ $\mathrm{Cl} 1.01$ to 1.18 for higher education). No association between mastery and employment was observed in controls. However, in patients with AS with lower education a significant association was seen between mastery and employment (IRR $=1.04,95 \% \mathrm{Cl} 1.01$ to 1.08), while this was not observed in those with higher education (mastery forced into multivariable model: $\mathrm{IRR}=1.01,95 \% \mathrm{Cl} 0.98$ to 1.04). In addition to education, higher age was associated with a decreased employment, while better SF-36PCS with an increased chance of being employed (Table 6.3).

To confirm the role of mastery in patients with a low level of education, a scenario analysis was carried out for which BASDAI or BASFI (separate models due to collinearity between these variables) was used in the models instead of SF-36PCS. This analysis led to similar results (Table 6.4). Of note, mastery was not significant nor a confounder in patients with a high level of education, and if forced into the models, its effect size was small to none (data not shown). 


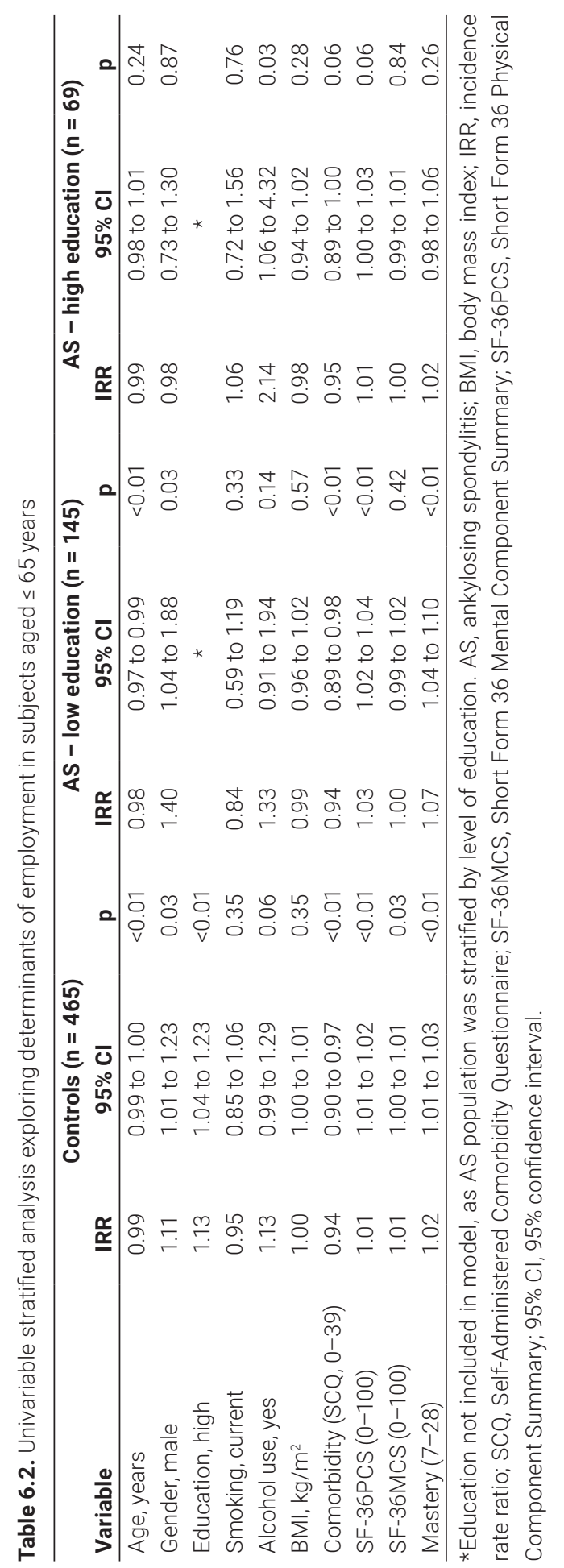




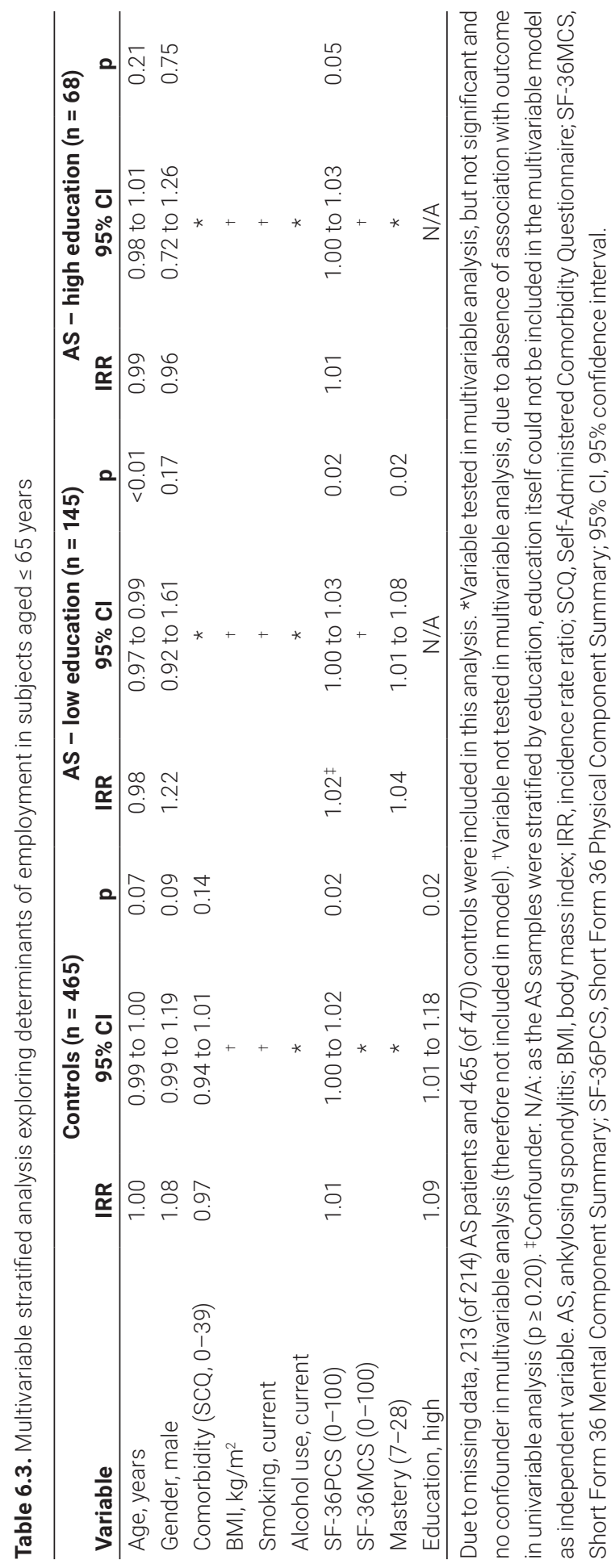




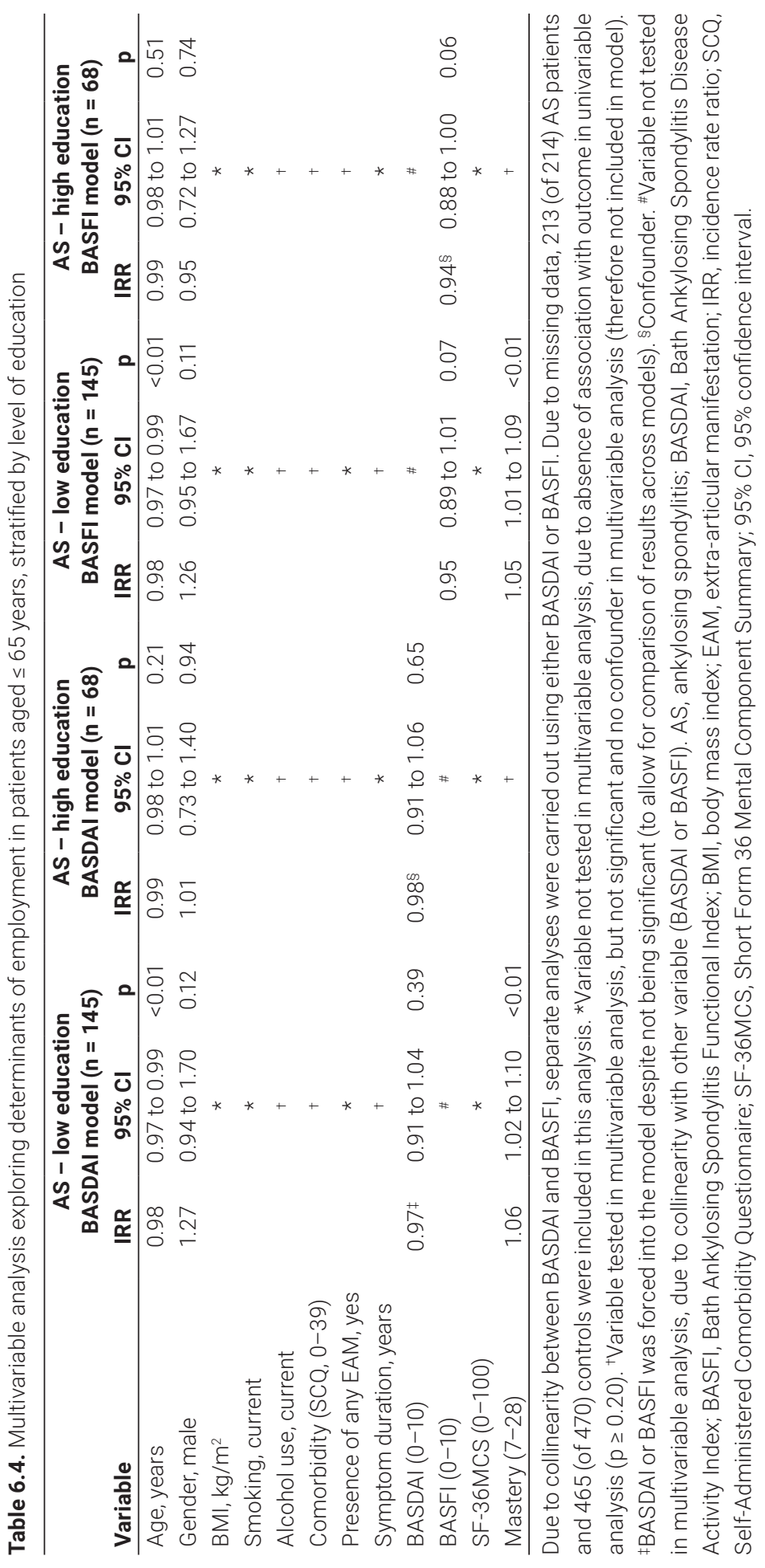




\section{Discussion}

Employment among patients with AS in the Netherlands was $14.4 \%$ lower than in a general population sample after adjustment for age, gender and education. Although this adverse effect on employment was also observed in patients with AS with shorter symptom duration, the impact seemed stronger in those with longest symptom duration. Mastery, a personal factor assessing level of control over life and disease, was associated with employment in patients with AS who had a lower educational level, but not in controls.

Considering the innovations in diagnosis and biomedical management of patients with AS over the last two decades, one would expect the difference in employment between patients and general population to have become smaller. Instead, almost 15 years after a comparable study among Dutch AS patients (data from 1997) which reported a reduction in employment of $11 \%$, our findings were of similar magnitude. ${ }^{3}$ It should be emphasised that overall employment in the general population increased substantially over this 15-year period. While employment rate for the general population in the previous study was $66 \%$ ( $54 \%$ in AS, adjusted), this was $84 \%$ in the current study (69\% in AS, adjusted). Likely the concurrent increase in employment in the general population, but also the higher work load in times of economic austerity that likely affects patients more severely, attenuates the expected improvement on work participation of patients when compared with controls. A recent study from Germany investigating employment (among other outcomes) in a mixed prevalence and incidence cohort of patients with AS in the period 2000-2012 revealed overall employment ratios comparable to our results. ${ }^{22}$ Somewhat contrary to our study, they found that the overall difference in employment rates between patients with AS and general population was decreasing, and even non-existent in the younger subgroups. When stratifying our sample for symptom duration, employment rates were even decreased in those with less than 15 years' symptom duration. This suggests that employment remains challenging despite improved medical treatment. Notwithstanding, the decrease in employment was somewhat stronger in those with a longer symptom duration. This may reflect that patients diagnosed in the last 15 years have benefitted from the availability of biologicals.

Although previous studies in AS pointed towards a greater reduction in work participation among men than women, the current study suggests no gender difference. ${ }^{3,6}$ The non-significant higher employment ratio of 1.08 in women with a symptom duration between 16 and 30 years was unexpected. Of note, the sample size of this subgroup was small ( $n=25$ patients, of which 8 were with higher education), as reflected by the large confidence interval surrounding the IRR and chance likely played a role.

An adverse impact of comorbidities on employment in spondyloarthritis has recently been described in a cross-sectional international study. ${ }^{23}$ In the current study, comorbidities were associated with employment in univariable analysis in both controls and patients 
with AS, but such association was not confirmed in multivariable analysis in either of the populations. Possible explanations for this discrepancy could be the differences in study populations and instruments used to assess comorbidity. Also, the influence of comorbidities on outcome might not be similar across countries. ${ }^{24}$

The current analyses confirm the role of personal contextual factors in relation to employment among patients with AS. Specifically, lower mastery was associated with not being employed. Importantly, mastery was only relevant in patients with lower education, another personal contextual factor. Apparently, in lower educated persons low mastery is a barrier to overcome challenges to remain active in the labour force. To the best of our knowledge this is the first study to reveal that mastery is not a 'generic' determinant of work outcome, as clearly mastery played no role in employment outcome among controls. It seems that persons with a chronic disease are more vulnerable to the effect of lower mastery.

In addition to the role of context, physical health (SF-36PCS) remains suboptimal in patients compared with controls and contributes importantly to the lower employment. Although biologicals were widespread available in 2011, active disease was present in a significant number of patients in SPASS (BASDAI $\geq 4$ in $57.5 \%$ of patients). Within the limits of interpretability in a cross-sectional study, subgroup analysis of the data also suggested employment in patients is particularly reduced in those with BASDAI $\geq$ 4. Currently, the treat-to-target principle is being investigated in axial spondyloarthritis (axSpA). It is important that studies on treat-to-target in axSpA also consider work participation as an outcome. If treat-to-target (i.e. to low disease activity) for axSpA turns out to be effective, the difference in employment between patients with AS and the general population should become smaller.

Strengths of our study were inclusion of a general population sample, participation of centres with different settings (academic and private hospitals) and from various geographical regions and availability of all predictors in patients as well as controls. Nevertheless, there are some limitations. First, it should be emphasised that the current observations apply only to patients under care of a rheumatologist. Further, matching of patients to control subjects was less successful than intended, but extensive adjustment was performed in all analyses. Also, given our retrospective approach, reverse causality (loss of employment or unable to become employed having negative influence on mastery) cannot be excluded. Comparison with the 1997 Dutch data, while insightful, should be done with some caution as data collection was not similar (for 1997 aggregated data from the Central Bureau of Statistics was used for standardization, while for the current study direct sampling allowed to collect more patient level characteristics). ${ }^{3}$ Next, as cultural, societal and legal provisions are likely to influence employment status in both patients and the general population, generalisability of our results to other countries is limited. Finally, although we had information on use of TNFi medication (55\% users in AS group), the 
effect of TNFi medication on employment could not be investigated, due to confounding by indication. It should be noted that data on the health state and disease activity of these patients before TNFi initiation were not available. Consequently, no conclusions regarding the benefits of TNFi use regarding employment can be drawn. Note that this limitation does not impact our primary analysis of employment rates in patients versus controls.

In summary, our findings showed that despite the widespread availability of bDMARDs, employment of Dutch patients with AS was decreased when compared with general population controls. Not only biomedical but also contextual factors explain employment. Higher mastery was associated with better employment in patients only, especially those with lower educational level. Programmes aimed at work participation in AS might need to focus on self-management skills to be effective. Further research is necessary to develop interventions and confirm their effectiveness.

\section{Funding}

This work was supported by AbbVie. AbbVie sponsored the data collection but had no role in the study design, the analysis or interpretation of the data or the writing of the manuscript. Publication of this article was not contingent upon approval by AbbVie. 


\section{References}

1. van Genderen S, Plasqui G, Landewe R, Lacaille D, Arends S, van Gaalen F, et al. Social Role Participation in Patients With Ankylosing Spondylitis: A Cross-Sectional Comparison With Population Controls. Arthritis Care Res (Hoboken) 2016;68:1899-1905.

2. Boonen A. A review of work-participation, cost-of-illness and cost-effectiveness studies in ankylosing spondylitis. Nat Clin Pract Rheumatol 2006;2:546-553.

3. Boonen A, Chorus A, Miedema H, van der Heijde D, van der Tempel H, van der Linden S. Employment, work disability, and work days lost in patients with ankylosing spondylitis: a cross sectional study of Dutch patients. Ann Rheum Dis 2001;60:353-358.

4. Chorus AM, Boonen A, Miedema HS, van der Linden S. Employment perspectives of patients with ankylosing spondylitis. Ann Rheum Dis 2002;61:693-699.

5. Boonen A, van der Heijde D, Landewe R, Spoorenberg A, Schouten H, Rutten-van Molken M, et al. Work status and productivity costs due to ankylosing spondylitis: comparison of three European countries. Ann Rheum Dis 2002;61:429-437.

6. Mau W, Listing J, Huscher D, Zeidler H, Zink A. Employment across chronic inflammatory rheumatic diseases and comparison with the general population. J Rheumatol 2005;32:721-728.

7. van der Burg LR, Ter Wee MM, Boonen A. Effect of biological therapy on work participation in patients with ankylosing spondylitis: a systematic review. Ann Rheum Dis 2012;71:1924-1933.

8. Stolwijk C, Castillo-Ortiz JD, Gignac M, Luime J, Boonen A, Group OWP. Importance of Contextual Factors When Measuring Work Outcome in Ankylosing Spondylitis: A Systematic Review by the OMERACT Worker Productivity Group. Arthritis Care Res (Hoboken) 2015;67:1316-1327.

9. Tang K, Escorpizo R, Beaton DE, Bombardier C, Lacaille D, Zhang W, et al. Measuring the impact of arthritis on worker productivity: perspectives, methodologic issues, and contextual factors. J Rheumatol 2011;38:1776-1790.

10. Dagfinrud H, Kjeken I, Mowinckel P, Hagen KB, Kvien TK. Impact of functional impairment in ankylosing spondylitis: impairment, activity limitation, and participation restrictions. J Rheumatol 2005;32:516-523.

11. Gordeev VS, Maksymowych WP, Schachna L, Boonen A. Understanding presenteeism in patients with ankylosing spondylitis: contributing factors and association with sick leave. Arthritis Care Res (Hoboken) 2014;66:916-924.

12. Healey EL, Haywood KL, Jordan KP, Garratt A, Packham JC. Impact of ankylosing spondylitis on work in patients across the UK. Scand J Rheumatol 2011;40:34-40.

13. Zangi HA, Ndosi M, Adams J, Andersen L, Bode C, Bostrom C, et al. EULAR recommendations for patient education for people with inflammatory arthritis. Ann Rheum Dis 2015;74:954-962.

14. van der Linden S, Valkenburg HA, Cats A. Evaluation of diagnostic criteria for ankylosing spondylitis. A proposal for modification of the New York criteria. Arthritis Rheum 1984;27:361-368.

15. Sieper J, Braun J, Rudwaleit M, Boonen A, Zink A. Ankylosing spondylitis: an overview. Ann Rheum Dis 2002;61 Suppl 3:iii8-18. 
16. Ware JE, Jr., Sherbourne CD. The MOS 36-item short-form health survey (SF-36). I. Conceptual framework and item selection. Med Care 1992;30:473-483.

17. Garrett S, Jenkinson T, Kennedy LG, Whitelock H, Gaisford P, Calin A. A new approach to defining disease status in ankylosing spondylitis: the Bath Ankylosing Spondylitis Disease Activity Index. J Rheumatol 1994;21:2286-2291.

18. Calin A, Garrett S, Whitelock H, Kennedy LG, O'Hea J, Mallorie P, et al. A new approach to defining functional ability in ankylosing spondylitis: the development of the Bath Ankylosing Spondylitis Functional Index. J Rheumatol 1994;21:2281-2285.

19. Sangha O, Stucki G, Liang MH, Fossel AH, Katz JN. The Self-Administered Comorbidity Questionnaire: a new method to assess comorbidity for clinical and health services research. Arthritis Rheum 2003;49:156-163.

20. Pearlin LI, Schooler C. The structure of coping. J Health Soc Behav 1978;19:2-21.

21. Zou G. A modified poisson regression approach to prospective studies with binary data. Am J Epidemiol 2004;159:702-706.

22. Huscher D, Thiele K, Rudwaleit M, Albrecht KC, Bischoff S, Krause A, et al. Trends in treatment and outcomes of ankylosing spondylitis in outpatient rheumatological care in Germany between 2000 and 2012. RMD Open 2015;1:e000033.

23. Nikiphorou E, Ramiro S, van der Heijde D, Norton S, Molto A, Dougados M, et al. Association of Comorbidities in Spondyloarthritis With Poor Function, Work Disability, and Quality of Life: Results From the Assessment of SpondyloArthritis International Society Comorbidities in Spondyloarthritis Study. Arthritis Care Res (Hoboken) 2018;70:1257-1262.

24. van der Zee-Neuen A, Putrik P, Ramiro S, Keszei AP, Hmamouchi I, Dougados M, et al. Large country differences in work outcomes in patients with RA - an analysis in the multinational study COMORA. Arthritis Res Ther 2017;19:216. 


\section{Chapter 7}

\section{Valuing treatment with infliximab for ankylosing spondylitis using a willingness-to-pay approach}

Casper Webers, Ivette Essers, Astrid van Tubergen, Jürgen Braun, Frank Heldmann, Xenofon Baraliakos, Annelies Boonen

Arthritis Care Res (Hoboken) 2018;70:608-616 


\section{Abstract}

\section{Objective}

To investigate willingness to pay (WTP) for treatment with infliximab by patients with ankylosing spondylitis (AS) and explore factors associated with WTP.

\section{Methods}

Data from 85 patients participating in the European AS Infliximab Cohort (EASIC) open-label extension of the AS Study for the Evaluation of Recombinant Infliximab Therapy (ASSERT) were used. WTP was included at baseline in EASIC and comprised a hypothetical scenario exploring whether the patient would be willing to pay for beneficial effects of infliximab and, if so, what amount they would be willing to pay per administration. Factors associated with WTP were explored using zero-inflated negative binomial (ZINB) regressions.

\section{Results}

Of the 85 patients, $63(74.1 \%)$ were willing to pay, and among these, the mean amount they were willing to pay per administration was €275 (median €100 [interquartile range $€ 50-200]$ ). Multivariable ZINB analysis showed that Assessment of SpondyloArthritis international Society criteria for $20 \%$ improvement (ASAS20) response was associated with a 7-fold lower likelihood to pay 0 euros (odds ratio [OR] 0.14, 95\% confidence interval [95\% Cl] 0.03 to 0.71$)$ and a 3 -fold increase in the amount willing to pay $(\exp (\beta)=3.32,95 \%$ $\mathrm{Cl} 1.44$ to 7.69). In addition, the country of residence was associated with a lower likelihood to pay 0 euros (OR $0.07,95 \% \mathrm{Cl} 0.02$ to 0.36 ), while increased age was associated with the amount willing to pay $(\exp (\beta)=1.05,95 \% \mathrm{Cl} 1.01$ to 1.09$)$.

\section{Conclusion}

In a hypothetical scenario, three-quarters of patients with AS receiving long-term infliximab stated that they were willing to pay an out-of-pocket contribution for this treatment. Treatment response contributed to the willingness as well as to the amount patients were willing to pay. 


\section{Introduction}

Ankylosing spondylitis (AS) is a chronic inflammatory rheumatic disease characterized by onset at relatively young age and potentially important long-term disability that can result in considerable costs. ${ }^{1}$ Treatment with anti-tumor necrosis factor (TNF) agents provides substantial and long-standing improvement in pain and function in $\mathrm{AS}^{2-4}$ and can reduce the burden-of-illness for patients and society. ${ }^{5}$ However, these agents are costly and their impact on healthcare budgets is considerable. ${ }^{6,7}$ It is therefore essential to develop a comprehensive view on the value of biologic treatments. Improvements in health in AS have traditionally been assessed using the Assessment of SpondyloArthritis international Society (ASAS) core outcome domains, which evaluate the impact of interventions on those aspects of health that are typically affected in AS, comprising pain, stiffness, fatigue, physical functioning, mobility, inflammation, and structural damage. ${ }^{8}$ Such an approach is limited in helping to understand the value for the overall improvement in health state and limits comparisons in health gain across diseases. Therefore, preference-based methods have been developed to explore the non-monetary value for (changes in) overall health state in the setting of choice and are grounded in the utility and decision-making theory. Alternatively, contingent valuation methods (CVMs) explore the monetary valuation of improvements in health state, and are grounded in welfare economic theory. Within the CVMs, a willingness-to-pay (WTP) approach asks patients (usually in hypothetical scenarios) how much they would pay for a certain improvement in health. ${ }^{9-11}$ Both preference-based valuation and contingent valuation allow comparison of improvements in health state across diseases, and results can be used in economic evaluations.

WTP has been used in a wide range of diseases to estimate improvement in overall health from the patient's perspective. ${ }^{11,12}$ WTP studies in rheumatology have been performed in rheumatoid arthritis (RA), psoriatic arthritis and gout. ${ }^{13-16}$ There is only 1 WTP study on patients with AS. It revealed, in a randomized controlled trial, that patients were willing to contribute out of pocket for improvements in health experienced following a spa treatment, and that the amount of personal contribution was influenced by the level of expected improvement, but also by the treatment environment (rehabilitation clinic versus spa resort). ${ }^{17}$ In the current study, patients receiving treatment with infliximab were asked to imagine a situation in which they should pay an out-of-pocket contribution to be able to continue treatment. The aim was to investigate the monetary value patients attach to improvements in health by infliximab, and to explore factors associated with both willingness to pay and the amount they were willing to pay. We hypothesized that almost all patients would be willing to pay, and that willingness and the amount they were willing to pay would be influenced by the level of treatment response. 


\section{Patients and Methods}

\section{Patients}

Data from the European AS Infliximab Cohort (EASIC), a 2-year open-label investigatorinitiated extension of the AS Study for the Evaluation of Recombinant Infliximab Therapy (ASSERT), was used for the current study. ${ }^{18}$ In brief, patients originally included in ASSERT had a diagnosis of AS according to the modified New York Criteria for AS, ${ }^{19}$ a Bath AS Disease Activity Index (BASDAI) score $\geq 4$ (range $0-10$ ), and spinal pain of $\geq 4$ on a visual analog scale (range 0-10 cm). ${ }^{4}$ EASIC baseline visits occurred between December 2005 and November 2006. In the period between the end of ASSERT and the start of EASIC, all patients were treated by their rheumatologist according to the local standard of care. In summary, 89 patients received continuous infliximab (on average, every 6-8 weeks at a dosage of 4-6 mg/kg body weight). Of the 14 patients who had discontinued infliximab after ASSERT, 9 patients experienced a relapse and were reintroduced to infliximab at the start of EASIC. ${ }^{18}$ The study protocols of ASSERT and EASIC were reviewed and approved by the respective institutional or independent ethics committee of each country. All patients provided written informed consent.

\section{Assessments}

Several demographics (age, sex and country of residence) and clinical outcomes were collected in ASSERT and EASIC. Disease activity was assessed using the BASDAI ${ }^{20}$ and laboratory tests, including the $\mathrm{C}$-reactive protein (CRP) level and the erythrocyte sedimentation rate. Physical function was assessed using the Bath AS Functional Activity Index (BASFI). ${ }^{21}$ Patient global well-being was assessed using the patient global (the question regarding well-being during the last week from the Bath AS Global score). ${ }^{22}$ The Bath AS Metrology Index (BASMI) was used to measure spinal mobility. ${ }^{23}$ Available data from the ASSERT baseline assessment allowed for the calculation of absolute change in BASDAI, CRP level, BASFI, BASMI and patient global between the start of ASSERT and the start of EASIC, as well as the Assessment of SpondyloArthritis international Society criteria for 20\% improvement (ASAS20) and 40\% improvement (ASAS40) response and ASAS partial remission at the start of EASIC..$^{24,25}$

\section{WTP}

A WTP self-report questionnaire was included at baseline in EASIC. Patients were asked whether they would be willing to pay a personal contribution to sustain the beneficial effect of treatment with infliximab, in the hypothetical situation that the drug treatment would not be (completely) reimbursed by the payer (health insurer/national health service) under the current conditions. If they were willing to pay, patients were asked an open-ended question regarding what amount (in euros) they would be willing to pay out of pocket 
per administration of infliximab. The full scenario presented to the patient is shown in Supplementary File S7.1. Those not willing to pay were asked to indicate whether they felt the treatment was not worth a personal contribution, whether their financial situation did not allow a personal contribution, or whether there was another reason for being unwilling to pay. To assess spending power, patients were asked how much they spend yearly on luxury (vacations) or common (shoes) products. Finally, patients were asked whether they knew the price of 1 administration of infliximab in euros, and, if yes, to state the true price. In addition, the true country-specific market price for 1 administration per patient was calculated, assuming a dosage of $5 \mathrm{mg} / \mathrm{kg}$, while adjusting the price of infliximab to the year of data collection of the WTP using the country-specific consumer price index. To better understand the possible influence of country of residence, the payment flows in different healthcare systems in 2005-2006 in the countries participating in EASIC were checked and are described in Supplementary File S7.2.

\section{Statistical analysis}

Differences in characteristics between patients willing to pay and patients not willing to pay were explored with independent t-tests, the Mann-Whitney test, or chi-square test, depending on the level of measurement and distribution. Fisher's exact test (with FreemanHalton extension, if appropriate) was preferred over the chi-square test for small samples (expected count <5). To detect possible selection bias due to non-response to the question about WTP, a subgroup analysis was performed comparing outcomes for patients who did not complete the WTP question with those who did.

As the amount of money patients would be willing to pay was non-parametrically distributed, with an excess of zeros (i.e. for patients not willing to pay), a zero-inflated negative binomial (ZINB) regression was used to investigate factors associated with WTP. This technique can be used for modeling overdispersed count variables (such as euros). Specifically, ZINB models counts of zero ('zeros') assuming these originate from different processes (i.e. patients declaring unwillingness to pay out of protest [certain/structural zeros] or patients declaring unwillingness to pay because they consider the treatment not worthy of payment [likely/sampling zeros]). ZINB regression was preferred over both ordinary negative binomial regression and zero-inflated Poisson regression based on model fit reflected by the Akaike and Bayesian information criteria (AIC and BIC, respectively). The results of ZINB analysis therefore consist of 2 components: the zero-inflated model (logistic), reflecting the variables that identify whether patients would never be willing to pay (i.e. predicting a 'certain zero'); and the expected count model (negative binomial model), reflecting the factors that contribute to the amount patients are willing to pay (including both zeros and non-zeros).

In view of small sample size and to ensure sufficient power to detect significance of possible covariates, a limited number of variables could be explored within the multivariable 
models. Therefore, the possible explanatory or confounding variables were first categorized into 4 groups that were considered to have a distinct but meaningful influence on WTP. The groups were as follows: demographics (sex, age, and disease duration), clinical characteristics reflecting improvement and/or achieved health state (such as ASAS20 response or current BASDAI), country of residence (residing in the Netherlands versus not residing in the Netherlands, as exploratory analyses showed a large difference in WTP across this variable), and spending power (each variable separately or the sum). Within each group (clinical characteristics/country of residence/spending power), the variables associated with outcome, defined as a p-value less than 0.20 in univariable analysis after adjustment for sex and age, were identified. Next, these variables were further explored in consecutive order in a multivariable model, based on a manual forward-selection method. Variables were retained when they significantly contributed to the model $(p<0.05)$. Several models were built with different combinations of variables, while at the same time we aimed to ensure representation of the variables of each of the 4 groups and avoid the inclusion of variables with collinearity. All statistical analyses were performed with SPSS, version 22.0, and Stata, version 12.

\section{Results}

Of the 216 European patients included in ASSERT, 103 (48\%) continued in EASIC. For the current study, 2 cases were excluded because of data inconsistency. Of the remaining 101 patients, 85 (84.1\%) completed the WTP question and were included in the analysis. Comparing these patients $(n=85)$ to those who did not provide data on WTP (not participating in EASIC or not completing the WTP question [ $n=129]$ ), patients included in the current analysis more frequently fulfilled the ASAS20 response criteria at the end of ASSERT (88.2\% versus 58.4\%; $p<0.01)$.

In the current sample, $67 / 85$ patients (78.8\%) were male and the mean (SD) age was 43.4 (10.3) years. The majority of the patients (85.9\%) resided in Germany, the Netherlands, or Belgium. Sixty-two patients (72.9\%) fulfilled the ASAS20 response criteria (deemed ASAS responders) at entry in EASIC after treatment with infliximab (Table 7.1).

Sixty-three of 85 patients $(74.1 \%)$ were willing to pay a personal contribution for treatment with infliximab. The amount they were willing to pay per administration ranged from $€ 10$ to $€ 2,500$ per patient, with a mean of $€ 275$ and a median of $€ 100$ (interquartile range $€ 50-200$ ). On average, this amount was $11.3 \%$ of the actual price. Of the 22 patients who were not willing to pay, $14(63.6 \%)$ indicated this was due to their financial situation and $6(27.3 \%)$ gave other reasons, e.g. 'the health insurance company should pay' and treatment with infliximab would 'reduce other current and future health expenditures.' None of the patients indicated that the treatment effects were not worth a personal contribution. 
Table 7.1. Baseline (EASIC) comparison of patients willing to pay and patients not willing to pay

\begin{tabular}{|c|c|c|c|c|}
\hline Variable & $\begin{array}{l}\text { Total group } \\
(\mathrm{n}=\mathbf{8 5})\end{array}$ & $\begin{array}{l}\text { Willing to pay } \\
(n=63)\end{array}$ & $\begin{array}{l}\text { Not willing to pay } \\
(n=22)\end{array}$ & $p^{*}$ \\
\hline Age, years & $43.4(10.3)$ & $42.9(9.5)$ & $44.7(12.3)$ & 0.48 \\
\hline Male, n (\%) & $67(78.8)$ & $49(77.8)$ & 18 (81.8) & 0.77 \\
\hline Country of residence, $n(\%)^{+}$ & & & & $<0.01$ \\
\hline Germany & $31(36.5)$ & $27(42.9)$ & $4(18.2)$ & \\
\hline The Netherlands & $21(24.7)$ & $9(14.3)$ & $12(54.5)$ & \\
\hline Belgium & $21(24.7)$ & $18(28.6)$ & $3(13.6)$ & \\
\hline United Kingdom & $9(10.6)$ & $7(11.1)$ & $2(9.1)$ & \\
\hline Finland & $2(2.4)$ & $2(3.2)$ & $0(0.0)$ & \\
\hline France & $1(1.2)$ & $0(0.0)$ & $1(4.5)$ & \\
\hline Disease duration, years & $13.5(8.3)$ & $14.3(8.3)$ & $11.4(7.8)$ & 0.16 \\
\hline Dose of infliximab, mg & $405(63)$ & $403(68)$ & $412(45)$ & 0.55 \\
\hline Market price of IFX treatment, $€$ & $2,659(876)$ & $2,718(925)$ & $2,491(709)$ & 0.24 \\
\hline BASDAI (0-10) & $3.2(2.0)$ & $2.9(1.9)$ & $4.2(2.0)$ & 0.01 \\
\hline $\mathrm{CRP}, \mathrm{mg} / \mathrm{l}^{\ddagger}$ & $7.8(11.1)$ & $7.3(10.0)$ & $9.3(14.0)$ & 0.71 \\
\hline BASFI (0-10) & $3.5(2.2)$ & $3.2(2.1)$ & $4.5(2.3)$ & 0.02 \\
\hline BASMI (0-10) & $2.2(1.6)$ & $2.0(1.5)$ & $2.8(1.9)$ & 0.06 \\
\hline Patient global (0-10) & $3.5(2.4)$ & $3.1(2.2)$ & $4.7(2.5)$ & $<0.01$ \\
\hline Change in BASDAI§ & $-3.3(2.1)$ & $-3.5(2.1)$ & $-2.5(2.1)$ & 0.05 \\
\hline Change in CRP, mg//\$ $\ddagger$ & $-20.0(24.7)$ & $-22.0(23.5)$ & $-14.2(27.6)$ & 0.05 \\
\hline Change in BASFIS & $-2.5(2.0)$ & $-2.6(2.0)$ & $-2.2(2.2)$ & 0.39 \\
\hline Change in BASMIs & $-1.9(1.5)$ & $-1.8(1.5)$ & $-2.2(1.6)$ & 0.40 \\
\hline ASAS20 response, $n(\%) \S$ & $62(72.9)$ & $50(79.4)$ & $12(54.5)$ & 0.02 \\
\hline ASAS40 response, $n(\%) \S$ & $36(44.4)$ & $31(51.7)$ & $5(23.8)$ & 0.02 \\
\hline ASAS partial remission, $\mathrm{n}(\%) \S$ & $17(30.9)$ & $15(37.5)$ & $2(13.3)$ & 0.08 \\
\hline \multicolumn{5}{|l|}{ Willingness to pay } \\
\hline $\begin{array}{l}\text { Amount willing to pay for one IFX } \\
\text { administration, } € \text { (median, IQR) }\end{array}$ & $\begin{array}{c}199 \\
(50,0-150)^{\#}\end{array}$ & $\begin{array}{c}275 \\
(100,50-200)\end{array}$ & & \\
\hline Percentage of true price willing to pay & & 11.3 & & \\
\hline \multicolumn{5}{|l|}{ Reason not willing to pay, $\mathrm{n}(\%)$ : } \\
\hline Not worthwhile & & & $0(0.0)$ & \\
\hline Personal financial situation & & & $14(70.0)$ & \\
\hline Other & & & $6(30.0)$ & \\
\hline \multicolumn{5}{|l|}{ Spending power } \\
\hline On vacations, $€ /$ person/year $(n=65)$ & $1,060(1,161)$ & $1,157(1,229)$ & $528(398)$ & 0.06 \\
\hline On shoes, $€ /$ person/year $(n=71)$ & $163(130)$ & $176(127)$ & $113(131)$ & 0.03 \\
\hline Stated to know costs IFX, n (\%) & $58(69.0)$ & $45(72.6)$ & $13(59.1)$ & 0.24 \\
\hline $\begin{array}{l}\text { Self-estimated cost per administration } \\
\text { (in those stated knowing), } €\end{array}$ & $\begin{array}{c}2,187 \\
(1,043)\end{array}$ & $\begin{array}{l}2,168 \\
(1,028)\end{array}$ & $\begin{array}{l}2,255 \\
(1,135)\end{array}$ & 0.79 \\
\hline
\end{tabular}

Values are the mean (SD) unless otherwise indicated. ${ }^{*}$ Two-tailed statistics for patients willing to pay versus patients not willing to pay. For continuous data, independent $t$-tests were used for normally distributed variables and Mann-Whitney tests for non-normally distributed variables. For categorical data, chi-square tests were used. Fisher's exact test (with Freeman-Halton extension, if appropriate) was used for small samples (expected count $<5$ ). ${ }^{\dagger}$ The percentages shown reflect the 
proportion of patients from the country in the total, willing, or not willing to pay group. ${ }^{\ddagger}$ CRP level considered $1.0 \mathrm{mg} / \mathrm{l}$ if below limit of detection (< $1.0 \mathrm{mg} / \mathrm{l})$. \$Change in outcome between start of ASSERT (Ankylosing Spondylitis Study for the Evaluation of Recombinant Infliximab Therapy) to start of EASIC. \#Including patients that were not willing to pay (amount willing to pay equal to zero). ASAS20, Assessment of SpondyloArthritis international Society criteria for $20 \%$ improvement; ASAS40, ASAS criteria for 40\% improvement; BASDAI, Bath Ankylosing Spondylitis Disease Activity Index; CRP, C-reactive protein; BASFI, Bath Ankylosing Spondylitis Functional Index; BASMI, Bath Ankylosing Spondylitis Metrology Index; EASIC, European Ankylosing Spondylitis Infliximab Cohort; IFX, infliximab; IQR, interquartile range.

Fifty-eight patients (69.0\%) indicated knowing the true price of treatment with infliximab, which they estimated at mean (SD) €2,187 (€1,043) per administration. Forty-three of these patients were willing to pay, and the amount they were willing to pay for 1 administration was on average $16.9 \%$ of what they estimated to be the true price, and $9.9 \%$ of the actual true price in this group of patients.

\section{Comparison between patients willing to pay and patients not willing to pay}

No significant differences regarding age, sex, or disease duration, nor in the time elapsed since the start of ASSERT, were found between those willing to pay and those not willing to pay. Patients willing to pay had significantly better current BASDAI, BASFI, and patient global scores, and specifically reported less fatigue, spinal pain, and joint pain (Table 7.1). The average changes in BASDAI, BASFI, and BASMI scores since the start of treatment with infliximab were not significantly different between those willing to pay and those not willing to pay. However, patients who were willing to pay perceived significantly more change in patient global well-being and more frequently fulfilled ASAS20 and ASAS40 response criteria (Table 7.1). Finally, patients who were willing to pay indicated that they spent more money annually on common (shoes) and luxury (vacations) products. However, patients willing to pay did not differ from those not willing to pay in their stated knowledge of the price of infliximab (Table 7.1).

\section{Multivariable exploration of WTP and amount willing to pay}

The associations between each of the explanatory variables and the willingness to pay, as well as the amount they were willing to pay, after adjustment for age and sex, are shown in Supplementary Table S7.1 and Supplementary Table S7.2. Several multivariable models were explored using the variable groups (demographics, clinical characteristics, country of residence, and spending power). Of all variables explored, only ASAS20/ASAS40 response and country of residence (the Netherlands) were consistently associated with willingness and/or amount willing to pay. Although univariable analyses showed an association between spending power and willingness to pay, adding spending power in the multivariable analysis provided diverging results and unstable models. This was mainly due to a large amount of missing data on spending power: 71 patients (83.5\%) reported their 
spending on at least 1 of the products. Missing values on spending power were especially prevalent among the 22 patients not willing to pay $(n=14 / 22$ [64\%] and $n=10 / 22$ [45\%] of the spending power on common and luxury goods, respectively, missing). For this reason, we had to exclude spending power from the multivariable models.

Two final and robust multivariable models were selected: an ASAS20 and an ASAS40 model, shown in Table 7.2 and Table 7.3, respectively. In the ASAS20 model, ASAS responders had 7 times lower likelihood to pay zero compared to ASAS non-responders (odds ratio [OR] 0.14, 95\% confidence interval [95\% Cl] 0.03 to 0.71; $p<0.01$ ). Likewise, patients not residing in the Netherlands had 14 times lower likelihood to pay zero compared to those residing in the Netherlands (OR $0.07,95 \% \mathrm{Cl} 0.02$ to $0.36, \mathrm{p}<0.01)$. In addition, if prepared to pay, the expected amount that patients would be willing to pay for 1 administration of infliximab was on average 3 times higher in ASAS responders compared to non-responders $(\exp (\beta)=3.32,95 \% \mathrm{Cl} 1.44$ to $7.69, \mathrm{p}<0.01)$, and the amount willing to pay increased with increasing age $(\exp (\beta)=1.05,95 \% \mathrm{Cl} 1.01$ to $1.09, \mathrm{p}<0.01)$ (Table 7.2). The ASAS40 model showed similar results, with the exception that ASAS40 was associated with willingness to pay, but not with the amount willing to pay. In this model, none of the selected parameters were significantly associated with the amount willing to pay. As it was felt that a measure of (current or change in) disease should be included, alternative disease characteristics were explored, and BASDAI score, albeit not statistically significant, was selected in this part of the model based on effect size and model fit reflected by AIC/BIC.

\section{Predicting patients' absolute WTP}

Using the coefficients of the ASAS20 model described, WTP was predicted for several specific patient scenarios (Figure 7.1). It revealed that a hypothetical male patient of 45 years who is not residing in the Netherlands and who is likely willing to pay for infliximab (unlikely to have a count of zero), would contribute a predicted $€ 343$ per administration if he was an ASAS20 responder and €103 if he was an ASAS20 non-responder. The 3.3-fold difference (€343/€103) in the amount he was willing to pay corresponds to the $\exp (\beta)$ for ASAS20 response in the final model (Table 7.2). On the contrary, if this person was not necessarily willing to pay (could have a count of zero), the amount he was willing to pay was found to be $€ 316$ (ASAS20 responder) and €64 (ASAS20 non-responder) per administration. 
Table 7.2. Multivariable ASAS20 zero-inflated negative binomial regression model exploring determinants of willingness to pay for infliximab treatment in ankylosing spondylitis

\begin{tabular}{|c|c|c|c|}
\hline & $\beta$ & $\operatorname{Exp}(\beta)$ or $\mathrm{OR}(95 \% \mathrm{CI})^{*}$ & p \\
\hline \multicolumn{4}{|l|}{ Amount willing to pay, $\exp (\beta)^{+}$} \\
\hline Sex (male) & 0.57 & 1.76 (0.79 to 3.94$)$ & 0.17 \\
\hline Age & 0.05 & 1.05 (1.01 to 1.09$)$ & $<0.01$ \\
\hline ASAS20 response & 1.20 & $3.32(1.44$ to 7.69$)$ & $<0.01$ \\
\hline \multicolumn{4}{|l|}{ Unwillingness to pay, OR } \\
\hline Sex (male) & 0.90 & 2.45 (0.37 to 16.12$)$ & 0.35 \\
\hline Age & 0.06 & 1.06 (0.97 to 1.16$)$ & 0.17 \\
\hline ASAS20 response & -1.93 & $0.14(0.03$ to 0.71$)$ & 0.02 \\
\hline Country of residence (the Netherlands) ${ }^{\S}$ & 2.61 & $13.6(2.76$ to 66.59$)$ & $<0.01$ \\
\hline
\end{tabular}

${ }^{\star} \operatorname{Exp}(\beta)=$ factor change in expected count for unit increase in independent variable. $\mathrm{OR}=$ factor change in odds for unit increase in independent variable. ${ }^{+}$Negative binomial model, predicting expected count. ‡Logistic model, predicting unwillingness to pay (the amount willing to pay being a 'certain zero'). \$The Netherlands versus other (Belgium, Germany, Finland, France, or UK). ASAS20, Assessment of SpondyloArthritis international Society criteria for $20 \%$ improvement; OR, odds ratio; $95 \% \mathrm{Cl}, 95 \%$ confidence interval.

Table 7.3. Multivariable ASAS40 zero-inflated negative binomial regression model exploring determinants of willingness to pay for infliximab treatment in ankylosing spondylitis

\begin{tabular}{lccc}
\hline & $\boldsymbol{\beta}$ & $\operatorname{Exp}(\boldsymbol{\beta})$ or OR $(\mathbf{9 5} \% \mathbf{C l})^{*}$ & $\mathbf{p}$ \\
\hline Amount willing to pay, $\exp (\beta)^{\dagger}$ & & & \\
Sex (male) & 0.62 & $1.87(0.73$ to 4.79$)$ & 0.20 \\
Age & 0.06 & $1.06(1.02$ to 1.10$)$ & $<0.01$ \\
BASDAl & -0.19 & $0.82(0.66$ to 1.04$)$ & 0.10 \\
Unwillingness to pay, OR ${ }^{\ddagger}$ & & & \\
Sex (male) & 1.22 & $3.41(0.25$ to 47.18$)$ & 0.36 \\
Age & 0.03 & $1.03(0.96$ to 1.11$)$ & 0.40 \\
ASAS40 response & -2.41 & $0.09(0.01$ to 0.54$)$ & $<0.01$ \\
Country of residence (the Netherlands) ${ }^{\S}$ & 3.40 & $29.88(4.17$ to 214.11$)$ & $<0.01$ \\
\hline
\end{tabular}

${ }^{\star} \operatorname{Exp}(\beta)=$ factor change in expected count for unit increase in independent variable. $\mathrm{OR}=$ factor change in odds for unit increase in independent variable. ${ }^{+}$Negative binomial model, predicting expected count. ₹Logistic model, predicting unwillingness to pay (the amount willing to pay being a 'certain zero'). \$The Netherlands versus other (Belgium, Germany, Finland, France, or UK). ASAS40, Assessment of SpondyloArthritis international Society criteria for $40 \%$ improvement; BASDAI, Bath Ankylosing Spondylitis Disease Activity Index; OR, odds ratio; 95\% Cl, 95\% confidence interval. 

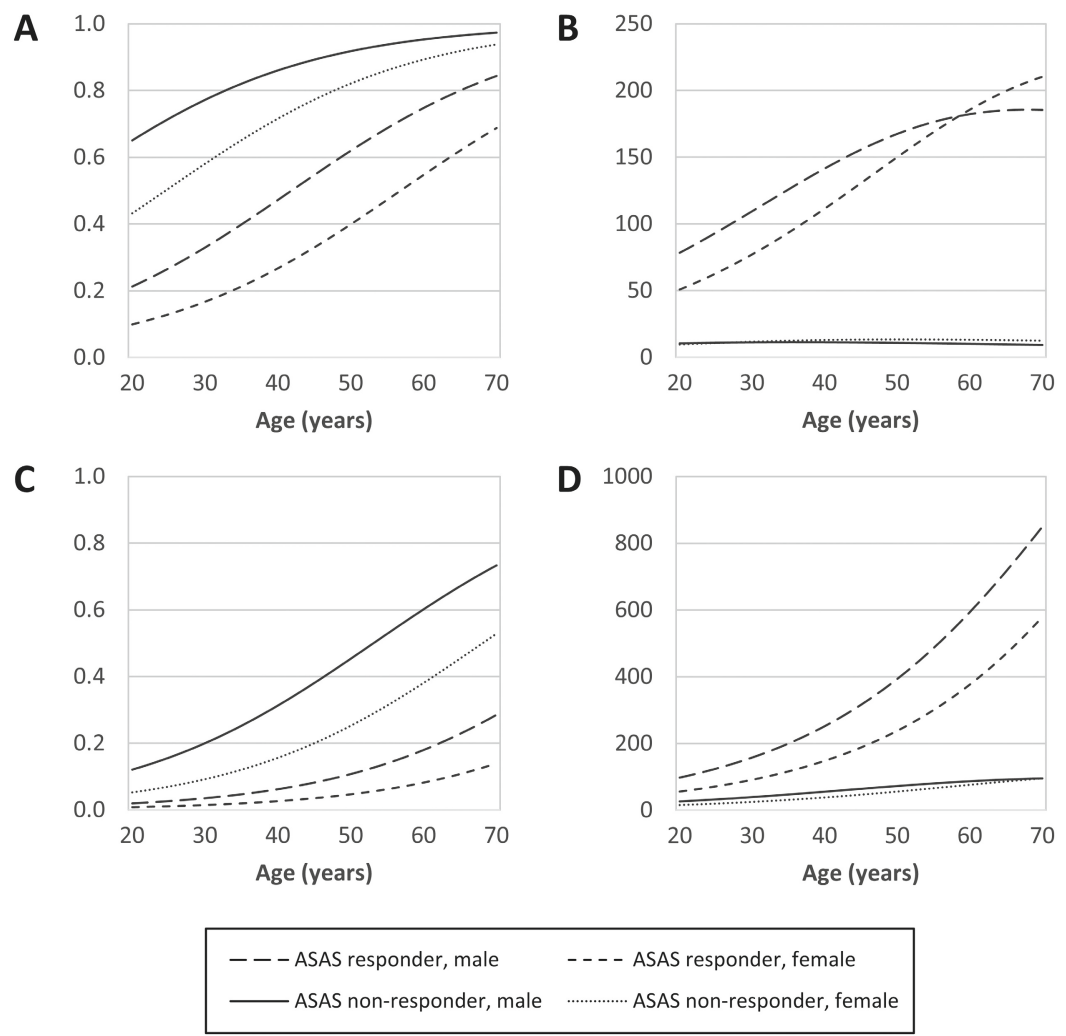

Figure 7.1. Predicted probabilities of being a certain zero (i.e. unwilling to pay) as well as the predicted amount patients are willing to pay for 1 administration of infliximab. A. Predicted probability not willing to pay for patients residing in the Netherlands; B. predicted amount willing to pay for patients residing in the Netherlands; C. predicted probability not willing to pay for patients residing in other participating countries; D. predicted amount willing to pay for patients residing in other participating countries. Note that the amount patients are willing to pay (B and D) is predicted using the ASAS20 response zero-inflated negative binomial regression model shown in Table 7.2, taking into account the predicted probability that a patient is certainly not willing to pay (being a 'certain' zero). For example, for a male patient of 45 years not residing in the Netherlands and who is an ASAS responder, the model predicts a probability of willingness to pay for infliximab of 0.92 . If he is willing to pay, the predicted amount that he is willing to pay for 1 administration is $€ 343$. Therefore, taking into account the probability of 0.08 $(1.00-0.92=0.08)$ that he was not willing to pay anything, this patient would be willing to pay $0.92 \times$ $€ 343+0.08 \times € 0=€ 316$. If the same male patient was an ASAS non-responder, our model predicts a lower probability of willingness to pay for infliximab (0.62), with a predicted amount willing to pay of $€ 103$, if he is willing to pay. Again, taking into account the probability of not willing to pay $(1.00-0.62=0.38)$, the average willing-to-pay amount is $€ 64(0.62 \times € 103+0.38 \times € 0)$. Because ASAS responder status is associated with both parts of the model (willingness to pay as well as willing-to-pay amount), ASAS response in this patient leads to an almost 5 -fold increase in the willing-to-pay amount. ASAS, Assessment of SpondyloArthritis international Society; ASAS20, ASAS criteria for $20 \%$ improvement. 


\section{Discussion}

This study showed that $74 \%$ of patients with AS receiving long-term infliximab treatment were willing to pay to continue treatment in a hypothetical situation that infliximab would not be further reimbursed and patients should pay a personal contribution for experienced benefits. Those who were not willing to pay indicated this was due to financial considerations and not due to the fact that the treatment was not worth an out-of-pocket payment. As such, this indicates the high value patients attribute to the health gains they experienced. The average price patients were willing to pay for 1 administration of infliximab was roughly $17 \%$ of the self-estimated price and $11 \%$ of the (country-specific) actual market price. ASAS20/ASAS40 response and not residing in the Netherlands were associated with willingness to pay, while ASAS20 response and increasing age were associated with a higher amount they were willing to pay. As the ASAS40 response criteria are more stringent than the ASAS20 response criteria, they are apparently less sensitive to capture the amount that patients are willing to pay (even if they are willing to pay).

When interpreting the results in light of the literature on WTP for medical interventions, the strong association that we found between treatment response and willingness to pay as well as the amount patients are willing to pay was in line with our hypothesis. Other studies also found WTP (either willingness or amount willing to pay) to be higher when more improvement in health was expected or experienced. . $15,256-28$ It should be noted, though, that most WTP studies use a hypothetical improvement in health (ex ante, nonuser perspective), whereas in the current study the improvement was truly experienced by the patients (ex post, user perspective). Although the ex ante perspective is useful from an economic point of view to understand the preparedness of potential users (or the general population) to pay for new treatments, such as biological agents, this was not our objective. We were interested in the monetary value that patients attribute to the benefits and harms of treatment. In addition, the investigated treatment (infliximab) had already been approved and was reimbursed in Europe when EASIC started. We therefore adopted an ex post perspective. It is difficult to state how the expected WTP would change if we had chosen another perspective, as studies investigating multiple perspectives are limited and report conflicting results. ${ }^{11,12}$

Conflicting results with respect to WTP and age have also been reported. ${ }^{15,16,29-31}$ More specifically, lower age has been associated with WTP in studies investigating a hypothetical cure for RA and for gout. ${ }^{15,31}$ On the other hand, higher age has been associated with WTP in a study investigating total knee replacement. ${ }^{30}$ Our analysis was able to distinguish between the willingness to pay itself and the amount patients are willing to pay. Age was not associated with the willingness to pay itself, indicating that the value for treatment was independent of age. On the other hand, the amount patients were willing to pay was 
higher in older patients, possibly because of higher lifetime earnings in older patients or less fear of long-term side effects.

In contingent valuation studies, spending power is recognized to confound or influence WTP. While theoretically this relationship seems sound, results regarding independent associations between income and WTP are not equivocal. 16,17,27,29-31 Although our univariable analyses suggest an influence of spending power on WTP, due to missing values (in an overall small sample), spending power could not be explored fully in multivariable analyses. Household income, corrected for the number of people in the household, is a more common indicator of spending power. However, it had been shown that non-response on income questions is considerable and concentrated mostly in the tails of the income distribution. ${ }^{32}$ Unfortunately, replacing income with personal or household expenditure, could not avoid non-response in the current study.

While the overall proportion of patients in our study not willing to pay (26\%) is similar compared to other studies investigating WTP for treatment for musculoskeletal or rheumatic diseases, 15,28,30,31 we found a large influence of willingness to pay depending on the country of residence. Apparently, different policies on healthcare financing influenced WTP. Willingness to pay tended to be lower in those countries in which a direct copayment is less common (the Netherlands, the UK and France). Dutch patients, paying relatively high premiums but not being accustomed to out-of-pocket expenditures including copayments, seemed especially reluctant to pay extra costs. ${ }^{33}$ Of note, at the time of the WTP questionnaire, the Dutch healthcare system had introduced a major transition to a compulsory (rather than private) premium-based insurance system. ${ }^{34}$ The public discussion on compulsory premiums might have further influenced attitudes toward copayments. Even when emphasizing the hypothetical context of the scenario that aimed to understand the value of treatment with anti-TNF, this level of abstraction is apparently difficult. For Dutch patients, 'treatment of $A S^{\prime}$ is felt to be a public right associated with paying the premium, rather than an additional commercial good (protest zeros). Interestingly, the multivariable models showed that those 'playing the game' (i.e. those willing to pay), would contribute a similar amount of money. As such, this issue also illustrates the value of zeroinflated models, which allow for the identification of the 'excess zeros' and at the same time allow for insight into factors contributing to the willingness to pay and the amount that patients are willing to pay.

There are some limitations in this study that need to be addressed. Possibly, selection bias occurred, as not all patients from ASSERT participated in EASIC and not all patients within EASIC responded to the WTP questionnaire. As patients from ASSERT not included in EASIC were less frequently ASAS20 responders, treatment responders were probably overrepresented. This possibly resulted in overestimation of the proportion of patients willing to pay and of the absolute mean amount they were willing to pay. The results mostly apply to long-term users, as those without treatment response might be 
expected to discontinue treatment and not be interested in continuing in EASIC. The relatively small sample size (85 patients) limited the number of explanatory factors in the multivariable models, thereby reducing the statistical power to detect true effects, or possibly overestimating the effect size. The use of open-ended questions, as in this study, has been associated with response effect bias (i.e. patients giving strategic, socially desirable, or protest answers) and with non-response bias. ${ }^{11}$ The participants in this study had experienced benefits and/or harms from treatment (ex post). Although this could be a strength with regard to the evaluation of treatment effects, it could also increase the risk of response bias. This likely occurred in our study, as not all patients 'played the game' (as mentioned above). However, alternative elicitation methods, such as bidding games or payment cards, are also associated with forms of bias.11,35

Despite the limitations of the WTP method, ${ }^{10,11,35}$ this technique has strong theoretical grounds and is a valuable approach to assess treatment benefits using a different but additional perspective. Also, it should be acknowledged that common approaches to assess outcome have advantages and disadvantages, but are so generally accepted that these disadvantages are almost no longer noticed. The relevance of the current study is that it sheds additional light on the value of biologic agents for the treatment of AS.

In summary, $74 \%$ of patients with AS who received long-term treatment with infliximab were willing to pay a (hypothetical) out-of-pocket contribution for treatment with infliximab. Treatment response contributed to the willingness to pay as well as to the amount that patients were willing to pay. The WTP method seems to be a valuable addition to the common approaches used for investigating treatment benefits in AS.

\section{Funding}

This work was supported by Janssen Biologics and Merck. Janssen Biologics and Merck had no role in the study design or in the collection, analysis, or interpretation of the data, the writing of the manuscript, or the decision to submit the manuscript for publication. Publication of this article was not contingent upon approval by Janssen Biologics or Merck. 


\section{References}

1. Braun J, Sieper J. Ankylosing spondylitis. Lancet 2007;369:1379-1390.

2. Braun J, Baraliakos X, Brandt J, Listing J, Zink A, Alten R, et al. Persistent clinical response to the anti-TNF-alpha antibody infliximab in patients with ankylosing spondylitis over 3 years. Rheumatology (Oxford) 2005;44:670-676.

3. Braun J, Baraliakos X, Listing J, Fritz C, Alten R, Burmester G, et al. Persistent clinical efficacy and safety of anti-tumour necrosis factor alpha therapy with infliximab in patients with ankylosing spondylitis over 5 years: evidence for different types of response. Ann Rheum Dis 2008;67:340-345.

4. van der Heijde D, Dijkmans B, Geusens P, Sieper J, DeWoody K, Williamson P, et al. Efficacy and safety of infliximab in patients with ankylosing spondylitis: results of a randomized, placebocontrolled trial (ASSERT). Arthritis Rheum 2005;52:582-591.

5. van der Burg LR, Ter Wee MM, Boonen A. Effect of biological therapy on work participation in patients with ankylosing spondylitis: a systematic review. Ann Rheum Dis 2012;71:1924-1933.

6. Reveille JD, Ximenes A, Ward MM. Economic considerations of the treatment of ankylosing spondylitis. Am J Med Sci 2012;343:371-374.

7. Sorensen J, Andersen LS. The case of tumour necrosis factor-alpha inhibitors in the treatment of rheumatoid arthritis: a budget impact analysis. Pharmacoeconomics 2005;23:289-298.

8. Sieper J, Rudwaleit M, Baraliakos X, Brandt J, Braun J, Burgos-Vargas R, et al. The Assessment of SpondyloArthritis international Society (ASAS) handbook: a guide to assess spondyloarthritis. Ann Rheum Dis 2009;68 Suppl 2:ii -44.

9. Diener A, O'Brien B, Gafni A. Health care contingent valuation studies: a review and classification of the literature. Health Econ 1998;7:313-326.

10. Klose T. The contingent valuation method in health care. Health Policy 1999;47:97-123.

11. O'Brien B, Gafni A. When do the "dollars" make sense? Toward a conceptual framework for contingent valuation studies in health care. Med Decis Making 1996;16:288-299.

12. Sach TH, Smith RD, Whynes DK. A 'league table' of contingent valuation results for pharmaceutical interventions: a hard pill to swallow? Pharmacoeconomics 2007;25:107-127.

13. Slothuus U, Brooks RG. Willingness to pay in arthritis: a Danish contribution. Rheumatology (Oxford) 2000;39:791-799.

14. Tuominen R, Azbel M, Hemmila J, Mottonen T. Willingness to pay for improvement of physical function among rheumatoid arthritis patients as measured by Health Assessment Questionnaire. Rheumatol Int 2011;31:347-352.

15. Khanna D, Ahmed M, Yontz D, Ginsburg SS, Tsevat J. Willingness to pay for a cure in patients with chronic gout. Med Decis Making 2008;28:606-613.

16. Hu SW, Holt EW, Husni ME, Qureshi AA. Willingness-to-pay stated preferences for 8 healthrelated quality-of-life domains in psoriatic arthritis: a pilot study. Semin Arthritis Rheum 2010;39:384-397. 
17. Boonen A, Severens JL, van Tubergen A, Landewe R, Bonsel G, van der Heijde D, et al. Willingness of patients with ankylosing spondylitis to pay for inpatient treatment is influenced by the treatment environment and expectations of improvement. Ann Rheum Dis 2005;64:1650-1652.

18. Heldmann F, Brandt J, van der Horst-Bruinsma IE, Landewe R, Sieper J, Burmester GR, et al. The European ankylosing spondylitis infliximab cohort (EASIC): a European multicentre study of long term outcomes in patients with ankylosing spondylitis treated with infliximab. Clin Exp Rheumatol 2011;29:672-680.

19. van der Linden S, Valkenburg HA, Cats A. Evaluation of diagnostic criteria for ankylosing spondylitis. A proposal for modification of the New York criteria. Arthritis Rheum 1984;27:361-368.

20. Garrett S, Jenkinson T, Kennedy LG, Whitelock H, Gaisford P, Calin A. A new approach to defining disease status in ankylosing spondylitis: the Bath Ankylosing Spondylitis Disease Activity Index. J Rheumatol 1994;21:2286-2291.

21. Calin A, Garrett S, Whitelock H, Kennedy LG, O'Hea J, Mallorie P, et al. A new approach to defining functional ability in ankylosing spondylitis: the development of the Bath Ankylosing Spondylitis Functional Index. J Rheumatol 1994;21:2281-2285.

22. Jones SD, Steiner A, Garrett SL, Calin A. The Bath Ankylosing Spondylitis Patient Global Score (BAS-G). Br J Rheumatol 1996;35:66-71.

23. Jenkinson TR, Mallorie PA, Whitelock HC, Kennedy LG, Garrett SL, Calin A. Defining spinal mobility in ankylosing spondylitis (AS). The Bath AS Metrology Index. J Rheumatol 1994;21:1694-1698.

24. Anderson JJ, Baron G, van der Heijde D, Felson DT, Dougados M. Ankylosing spondylitis assessment group preliminary definition of short-term improvement in ankylosing spondylitis. Arthritis Rheum 2001;44:1876-1886.

25. Brandt J, Listing J, Sieper J, Rudwaleit M, van der Heijde D, Braun J. Development and preselection of criteria for short term improvement after anti-TNF alpha treatment in ankylosing spondylitis. Ann Rheum Dis 2004;63:1438-1444.

26. Zillich AJ, Blumenschein K, Johannesson M, Freeman P. Assessment of the relationship between measures of disease severity, quality of life, and willingness to pay in asthma. Pharmacoeconomics 2002;20:257-265.

27. Kartman $B$, Andersson $F$, Johannesson $M$. Willingness to pay for reductions in angina pectoris attacks. Med Decis Making 1996;16:248-253.

28. Thompson MS. Willingness to pay and accept risks to cure chronic disease. Am J Public Health 1986;76:392-396.

29. Ramsey SD, Sullivan SD, Psaty BM, Patrick DL. Willingness to pay for antihypertensive care: evidence from a staff-model HMO. Soc Sci Med 1997;44:1911-1917.

30. Cross MJ, March LM, Lapsley HM, Tribe KL, Brnabic AJ, Courtenay BG, et al. Determinants of willingness to pay for hip and knee joint replacement surgery for osteoarthritis. Rheumatology (Oxford) 2000;39:1242-1248.

31. Fautrel B, Clarke AE, Guillemin F, Adam V, St-Pierre Y, Panaritis T, et al. Valuing a hypothetical cure for rheumatoid arthritis using the contingent valuation methodology: the patient perspective. $J$ Rheumatol 2005;32:443-453. 
32. Schrapler JP. Respondent behavior in panel studies - A case study for income nonresponse by means of the German Socio-Economic Panel (SOEP). Sociological Methods \& Research 2004;33:118-156.

33. World Health Organization. Global Health Expenditure Database (2016). [cited 2016 December 22nd]; Available from: http://apps.who.int/nha/database.

34. Daley C, Gubb J, Clarke E, Bidgood E. Healthcare Systems: The Netherlands. London: Civitas Health Unit 2013.

35. Bayoumi AM. The measurement of contingent valuation for health economics. Pharmacoeconomics 2004;22:691-700. 


\section{Chapter 8}

Cost-effectiveness of diagnostic algorithms for axial spondyloarthritis in the Netherlands: a model-based economic evaluation

Casper Webers, Sabine Grimm, Astrid van Tubergen, Floris van Gaalen, Désirée van der Heijde, Manuela Joore, Annelies Boonen

Submitted for publication 


\section{Chapter 9}

Development, usability and acceptability of an integrated eHealth system for spondyloarthritis in the Netherlands (SpA-Net)

Casper Webers, Esther Beckers, Annelies Boonen, Yvonne van Eijk-Hustings, Harald Vonkeman, Mart van de Laar, Astrid van Tubergen

RMD Open 2019;5:e000860 


\section{Abstract}

\section{Objective}

To develop and test the usability and acceptability of a disease-specific integrated electronic health (eHealth) system for spondyloarthritis (SpA) in the Netherlands ('SpA-Net').

\section{Methods}

SpA-Net was developed in four phases. First, content and design were discussed with experts on SpA and patients. Second, the database, electronic medical record (EMR) and quality management system were developed. Third, multiple rounds of testing were performed. Fourth, the eHealth system was implemented in practice and feasibility was tested among patients through semistructured focus interviews ( $n=16$ patients) and among care providers through feedback meetings ( $\mathrm{n}=11$ rheumatologists/fellows and 5 nurses).

\section{Results}

After completion of the first three steps of development in 2015, SpA-Net was implemented in 2016. All patients included have a clinical diagnosis of SpA. Information on domains relevant to clinical record-keeping is prospectively collected at routine outpatient consultations and readily available to care providers, presented in a clear dashboard. Patients complete online questionnaires prior to outpatient visits. In February 2019, 1,069 patients were enrolled (mean age 54.9 [SD 14.1] years, 52.4\% men). Patients interviewed $(n=16)$ considered SpA-Net an accessible system that was beneficial to disease insight and patient-physician communication, and had additional value to current care. Care providers appreciated the additional information for (preparing) consultations. Barriers were the initial time required to adopt the EMR and the quantity of data entry.

\section{Conclusion}

SpA-Net enables monitoring of patients with SpA and real-life data collection, and could help improve knowledge and optimise communication between patients and care providers. Both considered SpA-Net a valuable addition to current care. 


\section{Introduction}

Spondyloarthritis $(\mathrm{SpA})$ is a chronic inflammatory rheumatic disease with a heterogeneous clinical presentation. It may follow a disabling disease course, leading to substantial impairment of health-related quality of life (HRQoL), and to substantial costs for society due to healthcare utilisation and work productivity loss. ${ }^{1-3}$

From the care provider's perspective, regular and personalised monitoring of disease activity, physical functioning, medication use, side effects and comorbidities is essential to improve and maintain patients' HRQoL. Patient-reported outcome measures (PROMs) could further support this process and may also directly contribute to patient-centred care. ${ }^{4}$ Measuring outcomes that matter to patients is becoming increasingly important, as a way to learn and improve healthcare, to support shared-decision making and to secure sustainable healthcare. ${ }^{5}$ However, regular monitoring using PROMs has not yet been widely implemented into clinical practice. Barriers against use are time constraints, administrative burden, lack of a digital system to capture PROMs, lack of training, motivation and reluctance to change. ${ }^{6}$ In addition, it is unknown whether routine collection of PROMs leads to improved outcome for the individual patient in clinical practice.

From the patient's perspective, access to results of regular monitoring using PROMs could provide insight into their own health state. Patient empowerment and shared decision making are advocated as essential elements of high quality clinical practice. ${ }^{7}$ The patient and the rheumatologist decide together on the best possible management and define personal treatment goals, taking into account patient-specific context regarding comorbidities, adverse events, patient preference and preferred role, frequency of monitoring, and personal circumstances. To be involved in this process, patients need to be informed about their disease and management options, and vice versa, the patient's voice needs to be heard. Good mutual communication is therefore essential. Furthermore, regular monitoring using PROMs can also be done electronically (ePROMS), which allows for telemonitoring with the potential to decrease the number of visits and reduce the burden for the patient.

From the payer's perspective, governments and insurers increasingly demand transparency on outcomes, safety and efficiency/costs of care. The concept of value-based healthcare (VBHC) delivery, that is, a healthcare system where the health outcomes achieved per euro spent (value) are maximised, was introduced more than a decade ago. ${ }^{8}$ Regular and comprehensive measurement of relevant health outcomes is one of the core principles of $\mathrm{VBHC} .{ }^{8,9}$ On a related note, variations in medical practice were already acknowledged 50 years ago but have recently been gaining attention. ${ }^{10}$ The extent to which this variation is 'unwarranted', i.e. the consequence of a complex interaction between several medical and non-medical factors finally resulting in underuse or overuse of healthcare, should be minimised. Benchmarking and performance evaluation, as well as transparency on the 
results, can support this process. This requires an integrated, supported and cyclic process of improvement with a sufficient number of centres and patients.

Within the field of electronic health (eHealth, i.e. healthcare supported by information technology), new developments such as online monitoring tools could support high-quality, personalised and efficient care for patients with SpA. Most electronic medical records (EMRs) in their current form are not fit for chronic disease management, as relevant disease measures are often not available and ways to monitor the course of disease over time are lacking. ${ }^{11}$ A disease-specific, integrated eHealth system, that is, a system that is central in the organisation of daily care, linked with existing EMRs and accessible for patients, can serve the needs of care providers, patients, payers and society. 8,12-18 In addition, from a scientific perspective, it would capture data for research. While some aspects, such as regular collection of (e)PROMs, have been successfully implemented in SpA, to our knowledge, a system for comprehensive disease management was not yet available in the Netherlands.

In order to facilitate integration of the patient's and the healthcare provider's perspective on quality of care, we aimed (1) to develop and implement an integrated eHealth system for (tele)monitoring and reporting of health-related data of patients with SpA in the Netherlands ('SpA-Net'), including an EMR and real-time quality management system, and (2) to test the usability and acceptability of this system among patients and care providers.

\section{Patients and methods}

\section{Development of SpA-Net}

The development of SpA-Net was carried out according to an iterative process of four phases: (1) content and design, (2) technical development of database and EMR, (3) internal and external testing, and (4) implementation. Rheumatologists, nurses experienced with care for patients with SpA and trained patient research partners were involved during various phases of development. Detailed information on the development of SpA-Net and the roles of the stakeholders is described in Supplementary File S9.1. SpA-Net is registered in the Netherlands Trial Registry.

\section{Content and design}

In 2014 and 2015, rheumatologists (experts in the field of SpA), nurses and two experienced patient research partners were consulted on the design and content of SpA-Net. To ensure that SpA-Net would capture all domains essential for clinical record-keeping in SpA, a 'core set' was defined. Based on evidence from literature review and expert opinion, domains and instruments were selected from existing Assessment of SpondyloArthritis international Society/Outcome Measures in Rheumatology (ASAS/OMERACT) and Group 
for Research and Assessment of Psoriasis and Psoriatic Arthritis/OMERACT (GRAPPA/ OMERACT) sets, ${ }^{19,20}$ and several other disease-specific as well as generic domains and instruments were added. Also, indicators of quality of care and patient experience of care were included. In order to prevent abundant and unnecessary data collection, intervals were set per questionnaire (Table 9.1). Whenever possible, use of free-text fields was avoided to allow for standardised and structured data capture.12 Altogether, we aimed for an inclusive, efficient core set with domains that were relevant for daily practice (as opposed to research registries, which usually have extensive sets of questionnaires and are less efficient in daily practice). We further decided that aggregated data on quality indicators from participating centres should become available in SpA-Net to gain insight into practice variation. As SpA-Net aimed to closely follow the patient in daily practice, we decided that visits to the rheumatologist using SpA-Net should not be according to a predefined schedule but instead left to the discretion of the care provider.

Table 9.1. Domains, instruments and questionnaires included in SpA-Net

\begin{tabular}{|c|c|c|c|}
\hline Domain & Reported by & Instrument & Interval (minimum)* \\
\hline $\begin{array}{l}\text { Demographic } \\
\text { characteristics }\end{array}$ & Patient & $\begin{array}{l}\text { Questionnaire (education, } \\
\text { marital state, employment, } \\
\text { alcohol, smoking) }\end{array}$ & 1 year \\
\hline Work, productivity & Patient & WPAI ${ }^{21}$ & 6 months \\
\hline $\begin{array}{l}\text { Quality of life, health } \\
\text { state }\end{array}$ & Patient & $\begin{array}{l}\text { SF-36, }{ }^{22} \text { EQ-5D, }{ }^{23} \text { ASAS } \\
\text { Health Index }{ }^{24}\end{array}$ & $\begin{array}{l}1 \text { month (SF-36), } \\
6 \text { months (EQ-5D, } \\
\text { ASAS Health Index) }\end{array}$ \\
\hline Physical function & Patient & $\mathrm{BASFI},{ }^{25} \mathrm{HAQ}-\mathrm{S}^{26}$ & 6 months \\
\hline Patient global & Patient & $\begin{array}{l}\text { NRS (global disease activity } \\
\text { last week) }\end{array}$ & 1 month \\
\hline Fatigue & Patient & Fatigue question of BASDAl ${ }^{27}$ & Every visit \\
\hline Pain & Patient & VAS & 1 month \\
\hline Experience with care & Patient & Modified PREM ${ }^{28}$ & 1 year \\
\hline $\begin{array}{l}\text { Medical history, } \\
\text { comorbidity }\end{array}$ & Physician & $N / A$ & Updated every visit \\
\hline Medication use & Physician & $\mathrm{N} / \mathrm{A}$ & Updated every visit \\
\hline Adverse events & Physician, patient & $\mathrm{N} / \mathrm{A}$ & Updated every visit \\
\hline SpA manifestations & Physician & $\begin{array}{l}\text { Checklist: inflammatory } \\
\text { back pain, peripheral } \\
\text { arthritis, enthesitis, } \\
\text { dactylitis, psoriasis, uveitis, } \\
\text { IBD, elevated CRP, NSAID } \\
\text { response, recent GI or } \\
\text { urogenital infection, positive } \\
\text { family history, sacroiliitis on } \\
\text { X-ray/MRI, HLA-B27 status }\end{array}$ & Updated every visit \\
\hline Disease activity & Physician, patient & $\begin{array}{l}\text { ASDAS, }{ }^{29} \text { BASDAl, }{ }^{27} \text { CRP, } \\
\text { ESR }\end{array}$ & Every visit \\
\hline
\end{tabular}


Table 9.1. Continued.

\begin{tabular}{|c|c|c|c|}
\hline Domain & Reported by & Instrument & Interval (minimum)* \\
\hline Physician global & Physician & VAS (disease activity) & Every visit \\
\hline Spinal mobility & Physician & $\begin{array}{l}\text { Chest expansion, occiput } \\
\text { to wall, modified Schober, } \\
\text { cervical rotation, lateral } \\
\text { spinal flexion }\end{array}$ & On indication \\
\hline Peripheral symptoms & Physician & $\begin{array}{l}\text { SJC66, TJC68, presence } \\
\text { and location of dactylitis, } \\
\text { presence and location of } \\
\text { enthesitis in } 65 \text { sites }\end{array}$ & Every visit \\
\hline Skin/Nail involvement & Physician & $\begin{array}{l}\text { Body surface area, presence } \\
\text { of nail psoriasis }\end{array}$ & On indication \\
\hline Laboratory results & Physician & $\begin{array}{l}\text { Haemoglobin, white blood } \\
\text { cell count, platelet count, } \\
\text { liver/renal function }\end{array}$ & On indication \\
\hline
\end{tabular}

*Minimum interval between assessments of the domain. Visits to the rheumatologist are not predefined, but scheduled according to the opinion of the care provider. Consequently, the interval between assessments of domains can vary among patients but will never be shorter than the minimum interval reported here. ASAS, Assessment of SpondyloArthritis International Society; ASDAS, Ankylosing Spondylitis Disease Activity Score; BASDAI, Bath Ankylosing Spondylitis Disease Activity Index; BASFI, Bath Ankylosing Spondylitis Functional Index; CRP, C-reactive protein; EQ-5D, EuroQoL-5D; ESR, erythrocyte sedimentation ratio; GI, gastrointestinal; HAQ-S, Health Assessment Questionnaire for Spondyloarthropathies; HLA-B27, human leucocyte antigen B27; IBD, inflammatory bowel disease; N/A, not applicable; NRS, Numerical Rating Scale; NSAID, non-steroidal antiinflammatory drug; PREM, patient-reported experience measure; SF-36, Short Form 36 Health Survey; SJC, swollen joint count; SpA, spondyloarthritis; TJC, tender joint count; VAS, Visual Analogue Scale; WPAI, Work Productivity and Activity Impairment.

\section{Technical development and infrastructure}

The technical system behind SpA-Net was developed by Transparency in Healthcare $(\mathrm{TiH}$, www.tihealthcare.nl) in 2015, specialised in the development of software for collecting and monitoring clinical and patient-reported data. The SpA-Net registry is incorporated within DREAM (Dutch Rheumatoid Arthritis Monitoring), a collaboration of Dutch rheumatology practices that aims to improve the quality of patient care, to provide transparency on treatment results and costs, and to produce data for scientific research. For the purpose of collecting, storing and using comprehensive data on patient outcomes, a web-based data acquisition and storage system was developed, which can be linked to, and integrated with, the EMRs of patients in local hospitals. Information on laboratory markers of inflammation can be extracted from the hospital information management system. Data storage and maintenance in SpA-Net meet all Dutch and European legal requirements, and is in line with regulations on the protection of personal data (NEN7510, ISO2700 and the EU General Data Protection Regulation). 
Testing

After the initial development phase, SpA-Net was evaluated in a test environment during multiple rounds of internal and external testing in 2015 and 2016. These rounds were aimed at both improving different aspects of the system and bug-testing. Results from testing were reported monthly to the development team to ensure rapid cycles of improvement.

Implementation

After identification of barriers and facilitators for successful implementation, a multifaceted implementation strategy was developed. ${ }^{30,31} \mathrm{SpA}-\mathrm{Net}$ was initially implemented into clinical practice in two centres, followed by an extension to other centres. Part of the implementation strategy was engaging those who have to record data. ${ }^{32}$ To motivate rheumatologists and stimulate dynamic refinement of SpA-Net, staff meetings were organised every 2 months to evaluate the usability of SpA-Net in practice, discuss bugs encountered, demonstrate updated system features and provide feedback to care providers on the use of SpA-Net. After every meeting, feedback from staff was communicated to the development team. Care providers thus helped shape SpA-Net and embed it into clinical practice.

As part of the implementation strategy, patients were informed about SpA-Net on an individual basis during outpatient visits and accompanied by a demonstration of SpA-Net.

\section{Usability and acceptability of SpA-Net}

A usability and acceptability study was planned to evaluate satisfaction, accessibility and experiences with SpA-Net in clinical practice from the users' perspective (patients and care providers).

In November and December 2017, a sample of patients with SpA were recruited from the Maastricht University Medical Center to participate in focus group interviews (see Supplementary File S9.2 for a detailed description of the methodology). Interviews were planned with approximately five patients each, until data saturation was reached. Inclusion criteria were a clinical SpA diagnosis, age $\geq 18$ years, at least two visits to the rheumatology clinic since implementation of SpA-Net and mastery of the Dutch language. Eligibility for inclusion was considered on a case-by-case basis, aiming for a sample that reflected the full spectrum of the SpA population. To prevent selection bias, patients did not have to actively participate in SpA-Net. Prior to the interviews, SpA-Net was briefly demonstrated to any patients in the focus groups that had no experience with the system. In semistructured focus group interviews, the accessibility and usability of SpA-Net, and whether patients perceived SpA-Net had an effect on disease understanding and on quality of care in daily practice, were assessed. In the same period, rheumatologists and nurses were interviewed in multiple group sessions on the usability of SpA-Net, the role of SpA-Net in (preparing) consultations and the perceived effect of SpA-Net on the quality of care. 


\section{Data analysis}

Descriptive statistics were used to summarise the characteristics of the total population in SpA-Net and the participants in the focus group interviews. Patient interviews were audiotaped and transcribed verbatim. Using NVivo V.11 software, transcripts were coded and meaningful quotes were structurally classified into themes and subthemes for analysis (see Supplementary File S9.2). ${ }^{33}$ All statistical analyses were performed using R V.3.1.4.

\section{Results}

In order to serve its purpose as an integrated (tele)monitoring system, SpA-Net was designed and developed as a secure web page (http://www.mijnreumacentrum.nl) compatible with tablet devices. TiH provides technical support to care providers and patients.

\section{Development: content}

SpA-Net is meant to provide a comprehensive view of the patient. Domains captured by PROMs include disease activity, physical function, pain, global assessment of disease activity, work participation and HRQoL. These data are complemented with clinical measures on spinal mobility and peripheral joint involvement, physician's global assessment of disease, laboratory values and imaging data. In addition, demographic and socioeconomic status, medical history, comorbidities and extra-articular manifestations, lifestyle factors, medication use, and adverse events are collected (Table 9.1). Of note, data on all medications, prescribed for SpA or another condition, are collected. A patientreported experience measure is included to assess patient experiences with care. Finally, individual treatment goals can be registered and monitored.

\section{Development: design}

SpA-Net was designed to replace the existing EMR for patients with SpA, thereby also avoiding double entry. For care providers, SpA-Net is split into three tabs: (1) Dashboard, (2) Visit and (3) Data Input \& Reporting. The Dashboard provides an overview, and includes patients' personal information, presence of SpA features, current medication use, summary of recent visits, patients' notes and graphical representations (graphs) of disease activity, HRQoL and functioning (Figure 9.1). The disease activity graph is colour-coded to aid quick interpretation, using the cut-offs as defined by ASAS (Figure 9.2). ${ }^{34}$ The Visit tab allows care providers to enter a new outpatient visit, and includes a selection of items relevant for clinical record-keeping, such as a manikin for joint involvement and enthesitis. These items are completed on indication. Adverse events are recorded for record-keeping, and are also automatically reported to the Netherlands Pharmacovigilance Centre (Lareb). The Data Input \& Reporting tab includes all items of SpA-Net and can be used to complete missing 
items outside of visits. Besides these three tabs, there is an additional dashboard where care providers can access aggregated data on clinical indicators for quality improvement, comparing their centre with other centres (Figure 9.3). Patients can also access SpA-Net (Figure 9.1). After being introduced to SpA-Net, they receive a login and password. Two-factor verification is mandatory for all patients. For them, all clinical information is accompanied by clickable pop-ups with understandable explanations in lay language. The clinical information includes the diagnosis, a list of current and past medication, recent laboratory results, graphs of disease activity, HRQoL and functioning, and care provider's notes of recent outpatient visits. Patients can report possible side effects to medication and leave notes for their care provider, for example on topics they wish to discuss during their next visit. For urgent matters, such as serious suspected side effects, patients are explicitly instructed to contact the outpatient clinic by phone or email. Questionnaires are available for the patient to complete prior to each consultation. In between visits, patients can complete questionnaires for selfmonitoring, depending on the minimum interval (see Table 9.1).

\section{Development: testing}

A multitude of bugs and errors were encountered during 10 rounds of testing. These included error screens, incomplete questionnaires, errors in formulas used to calculate composite scores and accepting extreme values. All bugs and errors were fixed. The most recent version (V.1.11.0) of SpA-Net was launched in June 2018. 


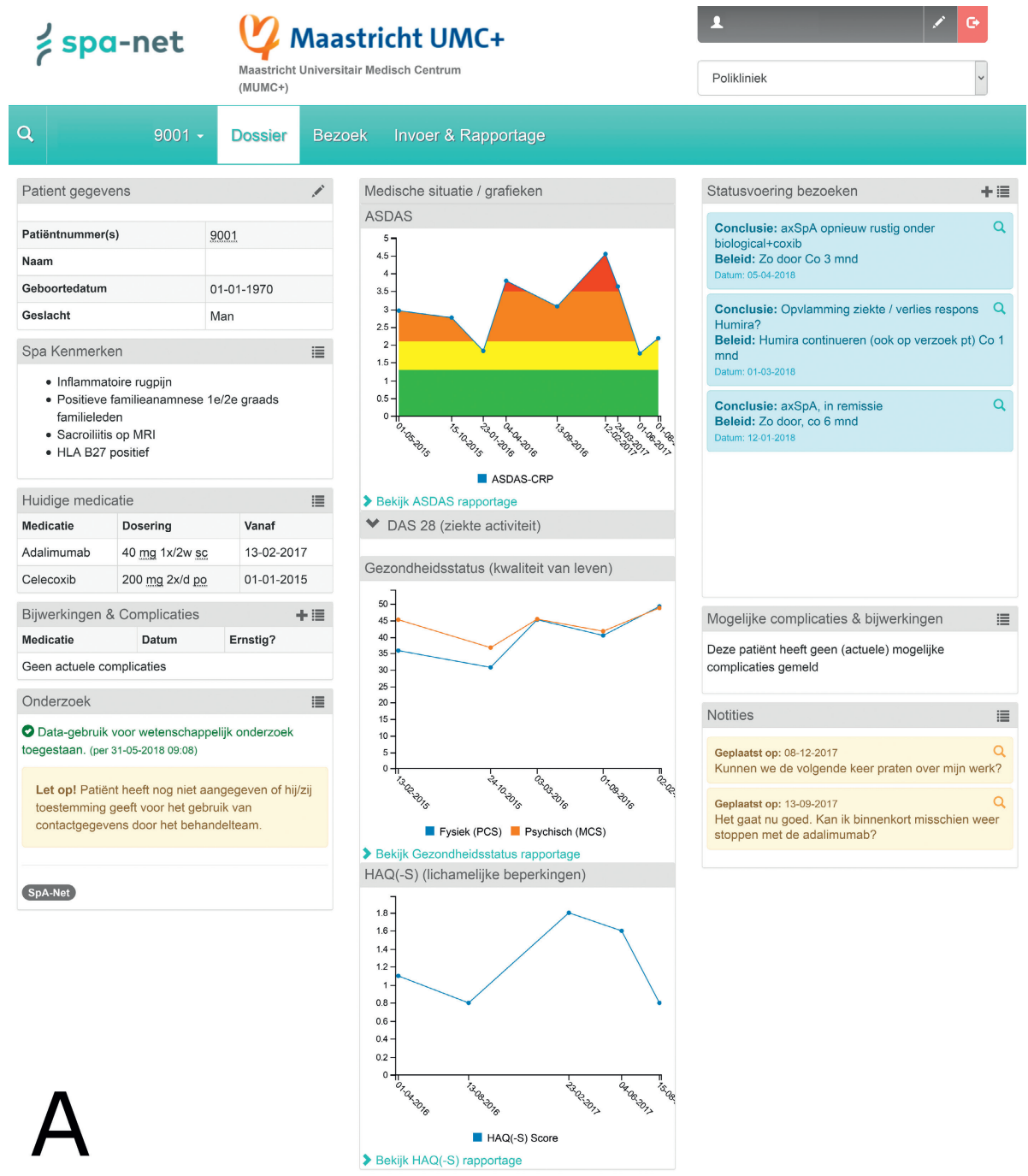

Figure 9.1. Side-by-side view of the care provider's dashboard (A) and the patient's dashboard (B) in SpA-Net. The care provider's dashboard (A) includes the patient's personal information, (past) presence of SpA features, current medication use, summary of most recent visits, patient's notes, and graphical representations of ASDAS, SF-36 and HAQ-S. 


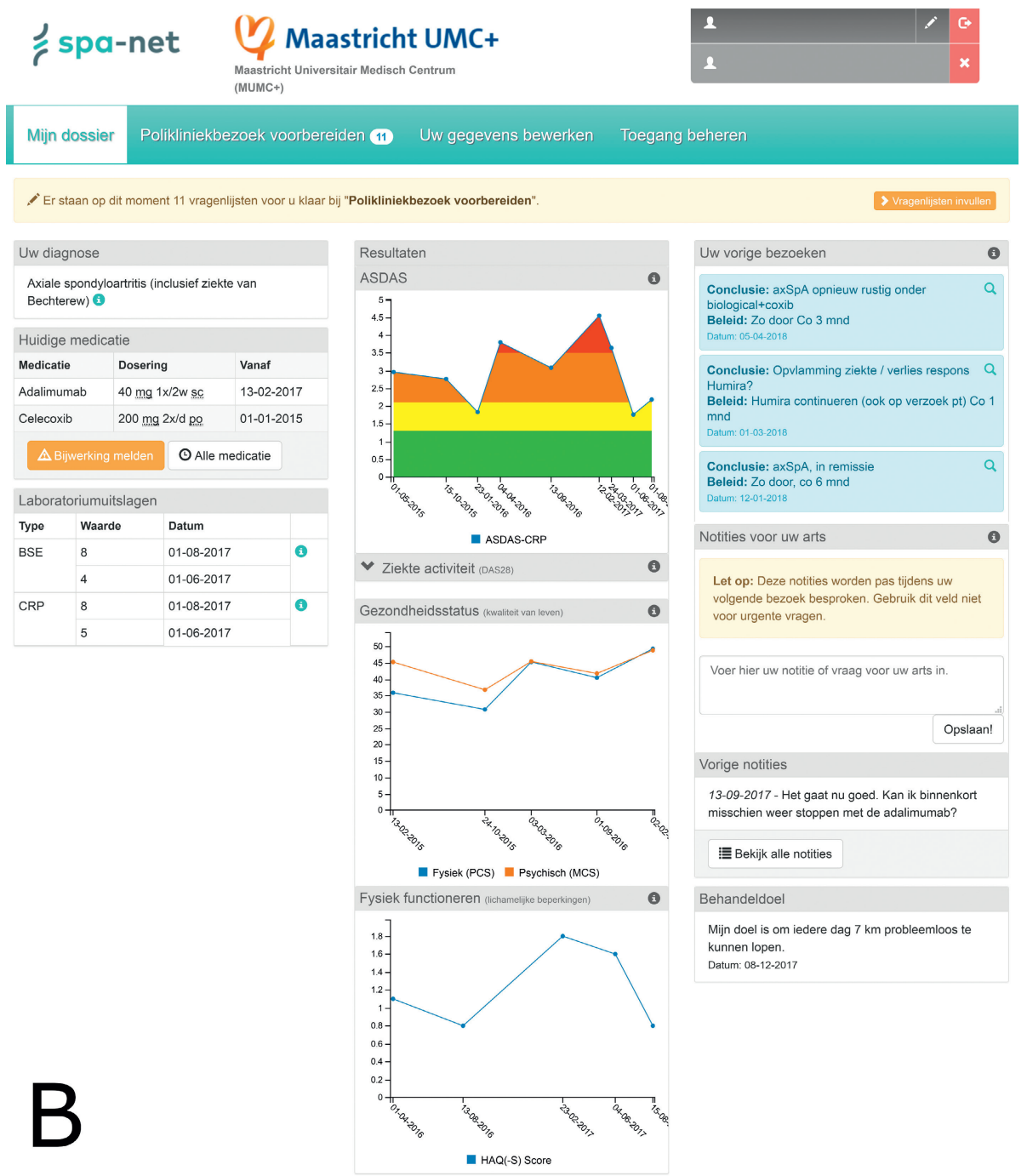

Figure 9.1. (Continued). The patient's dashboard (B) presents an excerpt of their EMR, which contains information regarding diagnosis, recent laboratory results, results from questionnaires, current medication and most recent outpatient visits. In addition, patients have the option to report possible side effects and can leave notes for their care provider. For patients, all items are accompanied by understandable explanations and information is presented in graphs whenever possible. ASDAS, Ankylosing Spondylitis Disease Activity Score; EMR, electronic medical record; HAQ-S, Health Assessment Questionnaire for Spondyloarthropathies; SF-36, Short Form 36 Health Survey; SpA, spondyloarthritis. 


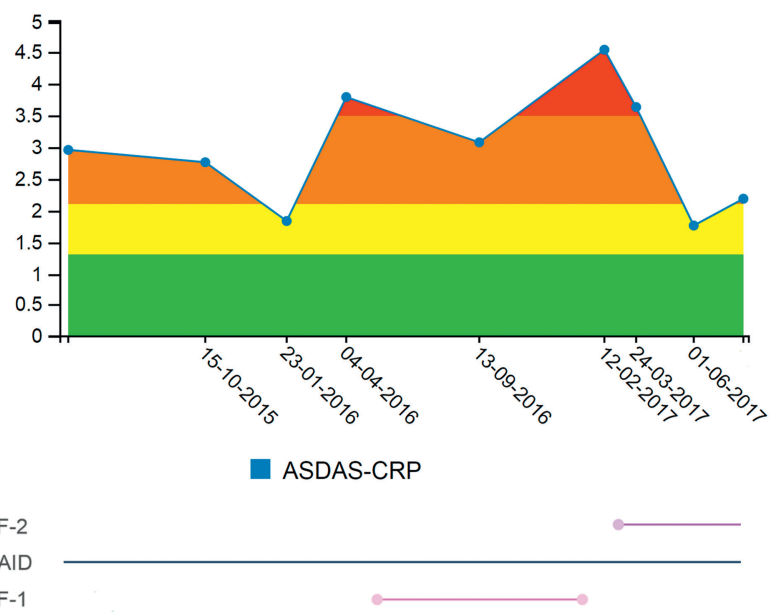

Figure 9.2. Graph in SpA-Net reporting the evolution of ASDAS in relation to medication use over time, care provider's perspective. In SpA-Net, detailed graphs of ASDAS (shown), SF-36 (not shown) and HAQ-S (not shown) are presented together with the patient's medication use over time. The ASDAS graph is colour-coded (traffic light, using the cut points as recommended by the ASAS) to aid quick interpretation. ASAS, Assessment of SpondyloArthritis international Society; ASDAS, Ankylosing Spondylitis Disease Activity Score; CRP, C-reactive protein; HAQ-S, Health Assessment Questionnaire for Spondyloarthropathies; NSAID, non-steroidal anti-inflammatory drug; SF-36, Short Form 36 Health Survey; TNF, tumour necrosis factor.

\section{Development: implementation and use in practice}

SpA-Net was launched into practice in May 2016 in two rheumatology centres. All rheumatologists and nurses were trained with a manual and practised in a test environment before use in practice. Use of SpA-Net was not mandatory for care providers in participating centres, but strongly encouraged through motivational interviewing and peer pressure. Some care providers quickly adopted SpA-Net, whereas others were more hesitant. Personal assistance for care providers was available, if needed.

Outpatients with a clinical diagnosis of SpA were consecutively included in SpA-Net and prospectively monitored. On inclusion, patients were educated on SpA-Net, received an information booklet and were instructed to prepare each visit by completing the PROMs in the week prior to the consultation date.

A number of additional actions were taken to increase participation in SpA-Net. First, a dedicated nurse was tasked with assisting those who need help with logging in or using SpA-Net. Second, we introduced a touch-screen tablet PC at the clinic, for those without internet access or who have forgotten to complete the questionnaires at home. Third, monthly open evenings were organised for patients with questions and general information meetings for patients twice a year. Of note, the open evenings had very low attendance, likely due to the availability of the dedicated nurse at the time of outpatient visits (a more 
feasible option for patients). Internal and external benchmarking is done annually and summarised results are published in an annual report.

Once SpA-Net was successfully implemented in the two initial adopting centres, steps were undertaken to increase awareness on SpA-Net among Dutch rheumatologists by presentations at the annual meeting of the Dutch Rheumatology Society, local hospital visits with demonstrations and written information in the Dutch Rheumatology journal. In February 2019, 1,069 patients from five centres had been enrolled in SpA-Net (Table 9.2), and inclusion is ongoing.

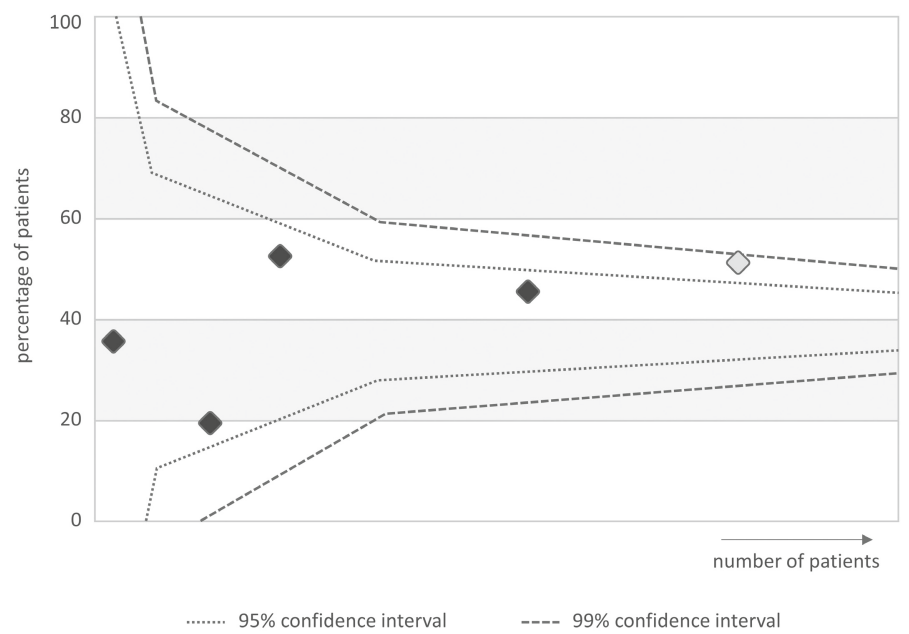

Figure 9.3. Example of graph of aggregated data on clinical indicators for quality improvement in SpA-Net, care provider's perspective. In order to stimulate performance evaluation and benchmarking, aggregated data on relevant clinical indicators of care are presented in a separate dashboard in SpA-Net. For illustrative purposes, an example is shown presenting the proportion of patients with an ASDAS < 2.1 For the care provider's centre (light grey dot) in comparison with other participating centres (dark grey dots). ASDAS, Ankylosing Spondylitis Disease Activity Score.

\section{Usability and acceptability study}

Accessibility, usability, satisfaction of use and experiences with SpA-Net in clinical practice from the perspective of both patients and care providers were assessed through focus group interviews and feedback meetings, respectively. Sixteen patients were interviewed (4 groups, 3-5 patients per interview), after which information saturation was reached. Included patients had axial, peripheral, or combined axial and peripheral SpA with or without concomitant psoriasis, inflammatory bowel disease and/or anterior uveitis (Table 9.3). Fifteen of these 16 patients (94\%) had been introduced to SpA-Net before, and 8 (50\%) considered themselves to actively and consistently use SpA-Net. Patients considered the layout of SpA-Net to be clear, well accessible and intuitive. They felt SpA-Net was a valuable addition to current care, and improved communication and patient involvement. 
Patients appreciated having access to their EMR with lay-term explanations. In addition, they valued the increased insight into their disease over time and the option to add notes. Points of improvement were the login process and providing insight into the conclusion and plan from the care provider after each visit. Patients not actively using SpA-Net did so because of either long-term stable disease or because they did not want to be occupied with their disease in their spare time. Of note, patients who were initially not enthusiastic about SpA-Net became interested when they learnt about the possibilities. A member check was carried out, and interviewed patients had no comments on the summarised results of the interviews.

Furthermore, seven rheumatologists, four residents in rheumatology and five nurses were interviewed during group meetings on the use of SpA-Net in daily practice. Care providers appreciated the additional information for (preparing) their consultations, the insight gained into the evolution of important outcomes such as disease activity and HRQoL over time in relation to medication use, and the ease of prescribing medication. Barriers against use were the initial time required to adopt the EMR, the number of 'clicks' and the quantity of data entry during consultations. Rheumatologists felt the latter could be at the expense of patient-clinician interaction, especially for patients who did not complete the questionnaires prior to their visit. Of note, rheumatologists supported by nurses during visits experienced less barriers when using SpA-Net. All remarks were converted into action plans for further improvement. During subsequent interviews, rheumatologists stated they used SpA-Net more frequently and consistently. 
Table 9.2. Characteristics of patients included in SpA-Net as of February 2019

\begin{tabular}{|c|c|c|}
\hline Variable & $\begin{array}{c}\text { Total group } \\
(n=1,069)\end{array}$ & Completed, n (\%) \\
\hline Age, years & $54.9(14.1)$ & $1,069(100.0)$ \\
\hline Male, n (\%) & $560(52.4)$ & $1,069(100.0)$ \\
\hline Symptom duration, years & $16.0(11.3)$ & $528(49.4)$ \\
\hline HLA-B27 positive, n (\%) & $300(46.2)$ & $650(60.8)$ \\
\hline Diagnosis* & & $1,069(100.0)$ \\
\hline Axial SpA, n (\%) & $339(31.7)$ & \\
\hline Peripheral SpA, n (\%) & $96(9.0)$ & \\
\hline Axial and peripheral SpA, n (\%) & $55(5.1)$ & \\
\hline Psoriatic arthritis, n (\%) & $510(47.7)$ & \\
\hline Reactive arthritis, n (\%) & $5(0.5)$ & \\
\hline IBD-associated arthritis, n (\%) & $28(2.6)$ & \\
\hline Undifferentiated SpA, n (\%) & $36(3.4)$ & \\
\hline ASDAS-CRP & $2.3(1.0)$ & $500(46.8)$ \\
\hline BASDAI & $4.3(2.2)$ & $640(59.9)$ \\
\hline BASFI & $3.3(2.5)$ & $550(51.4)$ \\
\hline HAQ-S & $0.7(0.6)$ & $465(43.5)$ \\
\hline VAS pain & $3.9(2.6)$ & $706(66.0)$ \\
\hline Patient global & $4.0(2.6)$ & $674(63.0)$ \\
\hline Physician global & $1.6(1.7)$ & $693(64.8)$ \\
\hline SJC & $0.5(1.3)$ & $606(56.7)$ \\
\hline TJC & $1.1(3.1)$ & $606(56.7)$ \\
\hline SF-36PCS & $39.9(10.0)$ & $551(51.5)$ \\
\hline SF-36MCS & $48.8(11.3)$ & $549(51.4)$ \\
\hline$E Q-5 D$ & $0.8(0.2)$ & $382(35.7)$ \\
\hline ASAS-HI & $5.7(3.4)$ & $382(35.7)$ \\
\hline Medication use, current ${ }^{\dagger}$ & & $1,021(95.5)$ \\
\hline NSAID, n (\%) & $554(54.3)$ & \\
\hline csDMARD, n (\%) & $418(40.9)$ & \\
\hline bDMARD, n (\%) & 391 (38.3) & \\
\hline tsDMARD, n (\%) & $2(0.2)$ & \\
\hline
\end{tabular}

Values expressed as mean (SD) unless stated otherwise. If a patient had multiple scores on an instrument, the first score since enrolment in SpA-Net was used. *Clinical diagnosis as made by the rheumatologist. ${ }^{\dagger}$ Percentages apply to population with registered medication. In 48 patients (4.5\%), no medication was registered. ASAS-HI, Assessment of SpondyloArthritis International Society Health Index; ASDAS, Ankylosing Spondylitis Disease Activity Score; BASDAI, Bath Ankylosing Spondylitis Disease Activity Index; BASFI, Bath Ankylosing Spondylitis Functional Index; bDMARD, biological disease-modifying antirheumatic drug; CRP, C-reactive protein; CSDMARD, conventional synthetic disease-modifying antirheumatic drug; EQ-5D, EuroQoL-5D; HAQ-S, Health Assessment Questionnaire for Spondyloarthropathies; HLA-B27, human leucocyte antigen B27; IBD, inflammatory bowel disease; MCS, Mental Component Summary; NSAID, non-steroidal anti-inflammatory drug; PCS, Physical Component Summary; SF-36, Short Form 36 Health Survey; SJC, swollen joint count; SpA, spondyloarthritis; TJC, tender joint count; tsDMARD, targeted synthetic disease-modifying antirheumatic drug; VAS, Visual Analogue Scale. 
Table 9.3. Characteristics of patients participating in the focus group interviews

\begin{tabular}{|c|c|}
\hline Variable & $\begin{array}{c}\text { Total group } \\
(\mathrm{n}=16)\end{array}$ \\
\hline Age, years & $62.6(41-78)$ \\
\hline Male, n (\%) & $6(37.5)$ \\
\hline \multicolumn{2}{|l|}{ Household composition } \\
\hline Living alone, n (\%) & $2(12.5)$ \\
\hline Partner without children, n (\%) & $10(62.5)$ \\
\hline Partner with children, $\mathrm{n}(\%)$ & $3(16.7)$ \\
\hline Other family member(s), n(\%) & $1(6.3)$ \\
\hline \multicolumn{2}{|l|}{ Educational attainment } \\
\hline Low, n (\%) & $3(18.8)$ \\
\hline Middle, n (\%) & $8(50)$ \\
\hline High, n (\%) & 5 (31.3) \\
\hline \multicolumn{2}{|l|}{ Employment } \\
\hline Full-time/part-time, n (\%) & $3(16.7)$ \\
\hline Retired/house-keeping/caregiver, n (\%) & $9(50)$ \\
\hline Unemployed, n (\%) & $2(11.1)$ \\
\hline Work disabled, n (\%) & $4(22.2)$ \\
\hline \multicolumn{2}{|l|}{ Smoking status } \\
\hline Never, n (\%) & $7(43.8)$ \\
\hline Current, n (\%) & $3(18.8)$ \\
\hline Former, n (\%) & $6(37.5)$ \\
\hline Alcohol consumption, yes, n (\%) & $11(68.8)$ \\
\hline \multicolumn{2}{|l|}{ Phenotype } \\
\hline Axial SpA, n (\%) & $5(31.3)$ \\
\hline Peripheral SpA, n (\%) & $5(31.3)$ \\
\hline Axial and peripheral SpA, n (\%) & $6(37.5)$ \\
\hline Symptom duration, years & $17.5(1-66)$ \\
\hline \multicolumn{2}{|l|}{ Extra-articular manifestations } \\
\hline Psoriasis, n (\%) & $7(43.8)$ \\
\hline Anterior uveitis, n (\%) & $4(25.0)$ \\
\hline Inflammatory bowel disease, n (\%) & $3(18.8)$ \\
\hline Any extra-articular manifestation, $\mathrm{n}(\%)$ & $11(68.8)$ \\
\hline
\end{tabular}

Values expressed as median (range) unless stated otherwise. SpA, spondyloarthritis. 


\section{Discussion}

Here, we described the successful development and implementation in daily practice of an integrated eHealth system and quality registry for patients with SpA in the Netherlands. Both patients and care providers considered SpA-Net feasible and acceptable for use in clinical care.

Over the last two decades, a multitude of cohorts and registries have been developed for SpA. While patients registries can technically be considered to be cohorts, registries such as SpA-Net have an important advantage over typical cohort studies ${ }^{32,35}$ as they provide a real-world view of all aspects of clinical practice and can be used to evaluate care as it is actually provided. ${ }^{35}$ What sets SpA-Net apart from most existing registries is its full integration in daily care as an EMR, inclusion of all subtypes of SpA, and the key role for the patient. In the Netherlands, SpA-Net is the first quality registry for all subtypes of SpA. Similar quality registries have been successfully operating in Denmark and Sweden. ${ }^{36-38}$

Increasingly, healthcare is shifting from physician-centred to patient-centred. Patients feel the need to be informed and involved. ${ }^{39}$ PROMs are considered essential in patientcentred care. Sharing PROM results with patients in a comprehensible way can improve the patient's knowledge, communication and trust. ${ }^{40}$ ePROMs have several advantages over paper-based assessments. ${ }^{18}$ Remote collection of questionnaires is usually faster ${ }^{41}$ and results in better data capture with less missings. ${ }^{42}$ Furthermore, ePROMs are accepted, and even preferred, by patients with rheumatic disease in routine practice. ${ }^{41,43,44}$ ePROMs and paper-based PROMs lead to comparable results in most studies. ${ }^{45} \mathrm{SpA}-\mathrm{Net}$ combines these facets, by remote collection and presentation of PROMs over time in relation to the treatments provided, to the care provider and patient in an understandable way. Notwithstanding, it has yet to be shown whether regular collection of PROMs in daily practice really leads to improved outcome for the individual patient. Personalised monitoring systems such as SpA-Net will play a pivotal role in this regard.

As became evident during the current study, most patients who were interviewed appreciated SpA-Net, especially the way it improved communication, stimulated patient involvement and provided the opportunity to monitor their own health state. These findings are in line with previous studies on eHealth in rheumatology. 14,46 In a pretest-posttest study investigating an online portal in rheumatoid arthritis (RA), a relevant proportion of patients felt that using the web portal increased their involvement in disease management (44\%) and understanding of care providers' explanation (24\%). ${ }^{14}$ Another study supported the potential benefits of eHealth for quality of care, as the use of a newly developed, diseasespecific eHealth system in patients with RA was associated with achieving low disease activity over time while at the same time maintaining patient satisfaction and improving physicians' productivity. ${ }^{11}$ 
SpA-Net was usable and acceptable in clinical practice. At the same time, several barriers were found. From the care provider's perspective, especially time constraints and burden of data entry during consultations were frequently reported. The burden of data registration is a factor that hinders how a quality registry can lead to quality improvement, as the time spent on data registration could instead be spent on other improvement efforts. ${ }^{47}$ In this regard, integration in daily care is necessary. ${ }^{15,16}$ By using SpA-Net as an EMR, data collection by care providers has become part of the standard clinical workflow. In order to further ease this burden for both care providers and patients, we strived towards a simple, yet comprehensive and intuitive system, and developed a core set of domains with a limited number of instruments. Also, the rheumatologists in this study reported that the burden of data entry decreased over time, and thus at least partly could be attributed to the initial transition period. Additionally, support by a dedicated nurse seemed to lower the burden for rheumatologists.

About half of the interviewed patients did not feel the need to actively use SpA-Net. These patients provided us insight into possible barriers to becoming an active user. Two previous studies showed that, if online access was provided, about half of the respondents accessed their EMR. ${ }^{14,48}$ Reasons for not using the portal were lack of internet access, lack of spare time or not being interested. Furthermore, patients who are older, lower educated, have lower health literacy and/or lower computer literacy could be less likely to use eHealth systems such as SpA-Net. 14,42,43,48 It is essential that systems meant to assess and improve quality of care are inclusive, especially as those patients who are less likely to participate might be those who would benefit most from improvements in care delivery. ${ }^{7}$ In $2017,97 \%$ and $88 \%$ of Dutch residents aged 12 years or older and 65 years or older, respectively, had internet access. ${ }^{49}$ With the support of a nurse, we strived to involve as many patients as possible in SpA-Net. It should be noted that currently no data on the actual usage of the system by patients are available, and a future study will address this.

In order to successfully implement and maintain integrated monitoring and quality managements systems, overcoming barriers of change is essential. Besides a strong commitment of both care providers and patients as discussed above, the social (culture, current practice), organisational (resources, support) and economical (financing of care) context are relevant. ${ }^{30,31}$ For SpA-Net, a bottom-up approach was chosen, meaning that participation for centres is voluntary. The successful implementation of SpA-Net in both academic and general hospitals supports the transferability of this system within the Netherlands. As long as regular monitoring of outcome relevant to patients is not mandatory, full implementation of quality management systems will be difficult, if not impossible. Bundle payments, or payment for the care of a patient's medical condition across the entire care cycle, will stimulate implementation of quality management systems and acceptance of PROMs and other outcomes relevant to patients. In this regard, decreasing the administrative and reporting burden of process quality indicators 
to increase transparency on outcome could prove beneficial. ${ }^{5}$ Systems such as SpA-Net will be necessary to capture those indicators relevant for high-quality care.

In conclusion, we developed and implemented an integrated eHealth system and quality registry (SpA-Net) for patients with SpA in the Netherlands. SpA-Net enables regular monitoring of patients with SpA and could help optimise knowledge and communication between patients and care providers, facilitate treatment decisions, stimulate patient empowerment, support VBHC and provide data for patient-centred research. Both patients and care providers considered SpA-Net a valuable addition to current care for SpA.

\section{Funding}

SpA-Net was financially supported by grants from ZonMw (project number 836042001) and the Dutch Arthritis Society, and was sponsored by AbbVie, Biogen, Celgene, JanssenCilag, MSD, Novartis, Pfizer and UCB. None of these parties had a role in the study design or in the collection, analysis or interpretation of the data, the writing of the manuscript, or the decision to submit the manuscript for publication. Publication of this article was not contingent upon approval by any of these parties. 


\section{References}

1. Boonen A, Brinkhuizen T, Landewe R, van der Heijde D, Severens JL. Impact of ankylosing spondylitis on sick leave, presenteeism and unpaid productivity, and estimation of the societal cost. Ann Rheum Dis 2010;69:1123-1128.

2. Strombeck B, Englund M, Bremander A, Jacobsson LT, Kedza L, Kobelt G, et al. Cost of illness from the public payers' perspective in patients with ankylosing spondylitis in rheumatological care. J Rheumatol 2010;37:2348-2355.

3. Castillo-Ortiz JD, Ramiro S, Landewe R, van der Heijde D, Dougados M, van den Bosch F, et al. Work Outcome in Patients With Ankylosing Spondylitis: Results From a 12-Year Followup of an International Study. Arthritis Care Res (Hoboken) 2016;68:544-552.

4. El Miedany Y. Adopting patient-centered care in standard practice: PROMs moving toward disease-specific era. Clin Exp Rheumatol 2014;32:S-40-46.

5. Porter ME, Larsson S, Lee TH. Standardizing Patient Outcomes Measurement. N Engl J Med 2016;374:504-506

6. Locklear T, Miriovsky BJ, Willig JH, Staman K, Bhavsar N, Weinfurt K, et al. Strategies for Overcoming Barriers to the Implementation of Patient-Reported Outcomes Measures. [cited 2018 March 3rd]; Available from: https://www.nihcollaboratory.org/Products/Strategies-forOvercomingBarriers-to-PROs.pdf.

7. Smolen JS, Schols M, Braun J, Dougados M, FitzGerald O, Gladman DD, et al. Treating axial spondyloarthritis and peripheral spondyloarthritis, especially psoriatic arthritis, to target: 2017 update of recommendations by an international task force. Ann Rheum Dis 2018;77:3-17.

8. Porter ME, Teisberg EO. How physicians can change the future of health care. JAMA 2007;297:1103-1111.

9. Porter ME. A strategy for health care reform--toward a value-based system. N Engl J Med 2009;361:109-112.

10. Wennberg JE. Time to tackle unwarranted variations in practice. BMJ 2011;342:d1513.

11. Newman ED, Lerch V, Billet J, Berger A, Kirchner HL. Improving the quality of care of patients with rheumatic disease using patient-centric electronic redesign software. Arthritis Care Res (Hoboken) 2015;67:546-553.

12. Richter JG, Chehab G, Schneider M. Electronic health records in rheumatology: emphasis on automated scoring and additional use. Clin Exp Rheumatol 2016;34:S62-S68.

13. Coates LC. Implementing the findings of the TICOPA trial in clinical practice: challenges in implementation and how information technology can bridge the gap. Clin Exp Rheumatol 2016;34:S73-S74.

14. van der Vaart R, Drossaert CH, Taal E, Drossaers-Bakker KW, Vonkeman HE, van de Laar MA. Impact of patient-accessible electronic medical records in rheumatology: use, satisfaction and effects on empowerment among patients. BMC Musculoskelet Disord 2014;15:102.

15. Sokka T. Go, go, GoTreatIT! Clin Exp Rheumatol 2016;34:S91-S95. 
16. Catarinella FS, Bos WH. Digital health assessment in rheumatology: current and future possibilities. Clin Exp Rheumatol 2016;34:S2-S4.

17. Sargious A, Lee SJ. Remote collection of questionnaires. Clin Exp Rheumatol 2014;32:S-168-172.

18. Kiltz U, Boonen A, Braun J, Richter JG. Electronic assessment of disease activity and functioning in patients with axial spondyloarthritis: challenges and unmet needs. Clin Exp Rheumatol 2016;34:S57-S61.

19. Landewe R, van Tubergen A. Clinical Tools to Assess and Monitor Spondyloarthritis. Curr Rheumatol Rep 2015;17:47.

20. Gladman DD, Mease PJ, Strand V, Healy P, Helliwell PS, Fitzgerald O, et al. Consensus on a core set of domains for psoriatic arthritis. J Rheumatol 2007;34:1167-1170.

21. Reilly MC, Gooch KL, Wong RL, Kupper H, van der Heijde D. Validity, reliability and responsiveness of the Work Productivity and Activity Impairment Questionnaire in ankylosing spondylitis. Rheumatology (Oxford) 2010;49:812-819.

22. Ware JE, Jr., Sherbourne CD. The MOS 36-item short-form health survey (SF-36). I. Conceptual framework and item selection. Med Care 1992;30:473-483.

23. EuroQol G. EuroQol--a new facility for the measurement of health-related quality of life. Health Policy 1990;16:199-208.

24. Kiltz U, van der Heijde D, Boonen A, Cieza A, Stucki G, Khan MA, et al. Development of a health index in patients with ankylosing spondylitis (ASAS HI): final result of a global initiative based on the ICF guided by ASAS. Ann Rheum Dis 2015;74:830-835.

25. Calin A, Garrett S, Whitelock H, Kennedy LG, O'Hea J, Mallorie P, et al. A new approach to defining functional ability in ankylosing spondylitis: the development of the Bath Ankylosing Spondylitis Functional Index. J Rheumatol 1994;21:2281-2285.

26. Daltroy LH, Larson MG, Roberts NW, Liang MH. A modification of the Health Assessment Questionnaire for the spondyloarthropathies. J Rheumatol 1990;17:946-950.

27. Garrett S, Jenkinson T, Kennedy LG, Whitelock H, Gaisford P, Calin A. A new approach to defining disease status in ankylosing spondylitis: the Bath Ankylosing Spondylitis Disease Activity Index. J Rheumatol 1994;21:2286-2291.

28. Bosworth A, Cox M, O'Brien A, Jones P, Sargeant I, Elliott A, et al. Development and Validation of a Patient Reported Experience Measure (PREM) for Patients with Rheumatoid Arthritis (RA) and other Rheumatic Conditions. Curr Rheumatol Rev 2015;11:1-7.

29. Lukas C, Landewe R, Sieper J, Dougados M, Davis J, Braun J, et al. Development of an ASASendorsed disease activity score (ASDAS) in patients with ankylosing spondylitis. Ann Rheum Dis 2009;68:18-24.

30. Grol R, Wensing M. What drives change? Barriers to and incentives for achieving evidence-based practice. Med J Aust 2004;180:S57-60.

31. Grol R, Grimshaw J. From best evidence to best practice: effective implementation of change in patients' care. Lancet 2003;362:1225-1230.

32. Gliklich R, Dreyer N, Leavy M. Registries for Evaluating Patient Outcomes: A User's Guide. Third edition. Rockville, MD: Quality AfHRa, 2014. 
33. Polit DF, Beck CT. Essentials of nursing research: appraising evidence for nursing practice. 7th ed. Philadelphia: Wolters Kluwer Health/Lippincott Williams \& Wilkins; 2010.

34. Machado P, Landewe R, Lie E, Kvien TK, Braun J, Baker D, et al. Ankylosing Spondylitis Disease Activity Score (ASDAS): defining cut-off values for disease activity states and improvement scores. Ann Rheum Dis 2011;70:47-53.

35. Inman R, Sieper J. Oxford textbook of axial spondyloarthritis. First edition. ed2016.

36. Eriksson JK, Askling J, Arkema EV. The Swedish Rheumatology Quality Register: optimisation of rheumatic disease assessments using register-enriched data. Clin Exp Rheumatol 2014;32:S-147-149.

37. de Thurah A, Stengaard-Pedersen K, Axelsen M, Fredberg U, Schougaard LMV, Hjollund NHI, et al. Tele-Health Followup Strategy for Tight Control of Disease Activity in Rheumatoid Arthritis: Results of a Randomized Controlled Trial. Arthritis Care Res (Hoboken) 2018;70:353-360.

38. Hetland ML. DANBIO: a nationwide registry of biological therapies in Denmark. Clin Exp Rheumatol 2005;23:S205-207.

39. Segan JD, Briggs AM, Chou L, Connelly KL, Seneviwickrama M, Sullivan K, et al. Patientperceived health service needs in inflammatory arthritis: A systematic scoping review. Semin Arthritis Rheum 2018;47:765-777.

40. El Miedany Y, El Gaafary M, Palmer D. Assessment of the utility of visual feedback in the treatment of early rheumatoid arthritis patients: a pilot study. Rheumatol Int 2012;32:3061-3068.

41. Salaffi F, Gasparini S, Ciapetti A, Gutierrez M, Grassi W. Usability of an innovative and interactive electronic system for collection of patient-reported data in axial spondyloarthritis: comparison with the traditional paper-administered format. Rheumatology (Oxford) 2013;52:2062-2070.

42. Wilson AS, Kitas GD, Carruthers DM, Reay C, Skan J, Harris S, et al. Computerized informationgathering in specialist rheumatology clinics: an initial evaluation of an electronic version of the Short Form 36. Rheumatology (Oxford) 2002;41:268-273.

43. MacKenzie H, Thavaneswaran A, Chandran V, Gladman DD. Patient-reported outcome in psoriatic arthritis: a comparison of Web-based versus paper-completed questionnaires. $J$ Rheumatol 2011;38:2619-2624.

44. Richter JG, Becker A, Koch T, Nixdorf M, Willers R, Monser R, et al. Self-assessments of patients via Tablet PC in routine patient care: comparison with standardised paper questionnaires. Ann Rheum Dis 2008;67:1739-1741.

45. Campbell N, Ali F, Finlay AY, Salek SS. Equivalence of electronic and paper-based patientreported outcome measures. Qual Life Res 2015;24:1949-1961.

46. van der Vaart R, Drossaert CH, Taal E, van de Laar MA. Patient preferences for a hospital-based rheumatology Interactive Health Communication Application and factors associated with these preferences. Rheumatology (Oxford) 2011;50:1618-1626.

47. Eldh AC, Fredriksson M, Halford C, Wallin L, Dahlstrom T, Vengberg S, et al. Facilitators and barriers to applying a national quality registry for quality improvement in stroke care. BMC Health Serv Res 2014;14:354. 
48. Koevoets R, de Glas NA, le Bourlout C, Huizinga TW, Allaart CF, Dougados M, et al. Autonomous online health assessment questionnaire registry in daily clinical practice. Rheumatology (Oxford) 2013;52:883-887.

49. Internet: access, use and facilities [database on the Internet]. Central Bureau Statistics, StatLine. [cited March 9th 2018]. Available from: http://statline.cbs.nl/Statweb/publication/?VW=T\&DM $=S L N L \& P A=83429 N E D \& D 1=0 \& D 2=0,3-6 \& D 3=0 \& D 4=a \& H D=180308-1235 \& S T B=G 1, G 2, T, G 3$. 
Chapter 10

Summary and general discussion 
In this chapter, the main findings of the studies that were part of this thesis are presented, followed by a discussion of common themes across these studies. Consistent with Chapter 1 and the outline of the thesis, we distinguish two sections, one addressing the patient perspective and the other addressing the societal perspective. Of note, the studies on work participation are primarily discussed in the section representing the societal perspective, in order to capture the broader impact of work and productivity. Obviously, these outcomes are also relevant for patients, as exemplified by their inclusion in the social level of the ICF model of functioning and disability. In the discussion of the societal perspective, the consequences of work outcomes for patients are also considered, when appropriate.

Also, at the time of initiation of this thesis, the term ankylosing spondylitis (AS) was still commonly used for those axial spondyloarthritis (axSpA) patients with signs of structural damage to the sacroiliac joints on conventional radiographs. This is why 'AS' was used when discussing the literature and research questions in Chapter 1. Over time, 'radiographic axSpA' (r-axSpA) has become the preferred term, and it has recently been demonstrated that these terms are interchangeable. ${ }^{2}$ In line with these developments, in the current chapter ' $r$-axSpA' is used instead of 'AS'.

\section{Summary of main findings}

In Chapter 2, we presented a longitudinal analysis of the influence of gender, a contextual factor, on several outcomes relevant for patients with r-axSpA participating in the Outcome in Ankylosing Spondylitis International Study (OASIS). At baseline, male patients had lower self-reported disease activity, tender joint count and enthesitis scores, but higher CRP levels and more radiographic damage than female patients. Of various clinical outcomes investigated (disease activity, physical function, health-related quality of life [HRQoL], radiographic damage), only HRQOL and radiographic damage differed significantly between male and female patients over time: compared to female patients, male patients had better HRQoL (AS Quality of Life score: $B=-1.18,95 \%$ confidence interval $[95 \% \mathrm{CI}]-2.17$ to -0.20 ) but more radiographic damage over time (modified Stoke AS Spine Score: B $=8.24$, $95 \% \mathrm{Cl} 4.38$ to 12.09). As this difference in HRQoL between male and female patients was independent of disease activity, physical function and radiographic damage, it was hypothesized that this observation mainly stems from gender differences in psychological factors, and not biologic factors.

Chapters $\mathbf{3}$ and $\mathbf{4}$ focused on 'depression' and its mechanisms in r-axSpA. In Chapter 3, we assessed depressive symptoms and their determinants in a Dutch cross-sectional cohort of patients with relatively longstanding r-axSpA (Social Participation in Ankylosing Spondylitis Study, SPASS). We applied a structural equation modelling approach, which allowed us to explore of direct and indirect associations between potential determinants 
and depressive symptoms, integrated in a single model. In this patient population, one in five patients had depressive symptoms suggestive of possible depression. When exploring potential determinants of possible depression, several contextual factors were associated with depression. In contrast, only one disease-related factor (self-reported disease activity) was associated with depression, and this factor acted indirectly and with a standardized effect that was smaller than several of the contextual factors. Notably, mastery (a personal contextual factor reflecting the level of perceived control over life and disease) had a central role in the path diagram, acting as a mediator for several of the determinants. This finding supports the focus on improving self-management skills in the management of patients with r-axSpA. In Chapter 4, we described an analysis of the effect of the biological drug infliximab, a tumor necrosis factor alpha inhibitor (TNFi), on depressive symptoms in patients with r-axSpA. For this analysis, data were used from a subgroup of patients participating in a trial investigating the effect of infliximab in r-axSpA (Ankylosing Spondylitis Study for the Evaluation of Recombinant Infliximab Therapy, ASSERT). Patients received infliximab or placebo for 24 weeks, followed by infliximab in all. At baseline, approximately half of the patients had a possible depression, underscoring the impact of active disease on mental health and the importance of this research topic. After 24 weeks, patients on infliximab had a substantially larger reduction in depressive symptoms compared to placebo (Center for Epidemiological Studies Depression [CESD] scale: $\mathrm{B}=-6.63,95 \% \mathrm{Cl}-13.35$ to 0.09 ), as well as a marked reduction in the odds of possible depression ( $\mathrm{OR}=0.02,95 \% \mathrm{Cl} 0.00$ to 0.72 ). Interestingly, when exploring the possible mechanisms behind this effect, the treatment effect of infliximab was largely explained by improvements in r-axSpA-related symptoms. In contrast, there was no indication that a decrease in CRP-mediated inflammation contributed to the improvement in depressive symptoms. After 54 weeks, when all patients had received infliximab for at least 30 weeks, $24 \%$ of patients still reported depressive symptoms of such severity that it indicated a possible depression. This suggests that TNFi do not improve depressive symptoms in all patients with active r-axSpA (similar to the observation that TNFi do not reduce symptoms of axSpA in all patients). For some patients with axSpA and depression, referral and specialized treatment might be warranted.

The studies in Chapters $\mathbf{5}$ and $\mathbf{6}$ were focused on work participation as an outcome of r-axSpA. In Chapter 5, the occurrence of r-axSpA-related sick leave was investigated in patients with r-axSpA participating in OASIS, and the factors predicting both first and recurrent sick leave in these patients were explored. Over a period of up to 12 years, the majority of patients at risk (63\%) experienced at least one episode of r-axSpA-related sick leave, and almost half (45\%) reported recurrent sick leave. Disease-related factors, in particular disease activity and physical function, and comorbidity predicted r-axSpArelated sick leave. Strikingly, this was only observed in patients with low educational attainment, indicating that education acted as an effect modifier in the association between 
disease activity or physical function and sick leave. In addition, sick leave in the first year independently and strongly predicted future sick leave in all patients (OR ranged from 2.62 to 8.37 in different models, all $p<0.05$ ). Interestingly, job type, categorised as white-collar or blue-collar depending on physical workload, was not associated with sick leave. This led to the hypothesis that educational attainment does not merely reflect the working conditions but also the level of coping with stressors related to disease and work, which is likely to be more important in the context of sick leave. Sick leave itself was concluded to be a signal that support is warranted to prevent future adverse work outcome. In Chapter 6, we investigated employment rates and the association between mastery and employment in patients with r-axSpA and compared with general population controls, using data from a Dutch cross-sectional study (SPASS). Employment rates were lower in patients with r-axSpA compared to controls (standardized employment ratio [SER] $=0.83,95 \% \mathrm{Cl} 0.69$ to 0.98), especially in patients with longer symptom duration and higher self-reported disease activity. When investigating the role of mastery, it was observed that mastery was associated with employment in patients with r-axSpA who had a lower educational attainment (incidence rate ratio $[\mathrm{IRR}]=1.04,95 \% \mathrm{Cl} 1.01$ to 1.08 ), but not in patients with higher educational attainment or controls. The difference in employment between patients and general population in this study (14\%) was of similar magnitude as in older studies, which we attributed to substantial increases in overall employment in the general population, but also to increasing pressure on productivity in times of economic austerity, hampering patients to catch up on employment.

In Chapter 7, we assessed how patients with r-axSpA value treatment with infliximab, by asking them whether they would hypothetically be willing to pay for this drug to sustain its effects. This approach was used as an alternative to understand how patients value the health benefits of infliximab. In addition, the factors associated with patients' willingness to pay were explored. We used data from a European open-label extension (European Ankylosing Spondylitis Infliximab Cohort, EASIC) of the previously mentioned trial of infliximab in r-axSpA (ASSERT). Three in four patients would be willing to pay to sustain the beneficial effect of infliximab, on average $€ 275$ per administration (approximately $11 \%$ of the actual price at that time). The majority of those not willing to pay indicated this was because of financial reasons, and not because the treatment effects were not worth a personal contribution. Treatment response lowered the likelihood to pay zero euros $(\mathrm{OR}=0.14,95 \% \mathrm{Cl} 0.03$ to 0.71$)$ and increased the amount willing to pay $(\exp (\beta)=3.32$, $95 \% \mathrm{Cl} 1.44$ to 7.69 ). In addition, country of residence was associated with willingness to pay (but not the amount willing to pay). Our hypothesis was that this could be explained by differences between countries regarding policies on healthcare financing, as patients from countries in which direct copayments were less common also had lower willingness to pay. The willingness-to-pay method confirmed a different but additional view on the 
benefits of infliximab and how patients value these, but also suggested that these drugs might have been too expensive (at the time).

In Chapter 8, we reported an investigation of the lifetime cost-effectiveness of currently available diagnostic algorithms (Berlin algorithm [BER] and Modification 1 [M1] and 2 [M2]) for axSpA. In addition to the diagnostic algorithms, the value of a perfect diagnosis, and of acknowledging nr-axSpA (compared to neither acknowledging nor treating nr-axSpA, i.e. only acknowledging and treating $r$-axSpA) were also assessed. We developed a costeffectiveness model that estimates the long-term costs and effects of (mis)diagnosis and subsequent treatment of axSpA and chronic low back pain (CLBP) in a population referred to the rheumatologist. The model estimated that $M 2$, the most sensitive algorithm, was cost-effective when compared to BER (the most specific algorithm) and M1, regardless of the adopted perspective (societal incremental net monetary benefit $=-€ 7,412$ for BER $v s$ M2, -€2,569 for M1 vs M2). In addition, acknowledging nr-axSpA was cost-effective, as it resulted in more quality-adjusted life-years - as expected - but also reduced costs. Finally, when compared to the optimal existing algorithm (M2), a perfect diagnosis could cost up to an additional $€ 7,500$ and still be considered cost-effective. This study confirmed the importance of understanding the impact of diagnosis on long-term health benefits and costs (savings and expenditures). Most importantly, we concluded that it is worthwhile to invest in more accurate diagnosis in axSpA.

In Chapter 9, we described the need for an integrated registry and quality-management system for SpA in the Netherlands, and our efforts to develop and implement such a system. Over the course of several years and four phases of development, 'SpA-Net' was conceptualized, developed, tested and implemented in clinical practice in five centres in the Netherlands. The system was launched in May 2016, and by February 2019 over 1,000 patients had been enrolled. Its usability and acceptability, including satisfaction of use, were assessed and confirmed in four focus groups with patients and in interviews with care providers. These focus groups and interviews also helped identify barriers against use. The bottom-up approach chosen for development and implementation, as well as its integration in daily practice as an EMR, i.e. becoming part of the standard workflow, contributed to the successful implementation of SpA-Net.

\section{The patient perspective on outcome in axSpA}

\section{Mental health and psychiatric comorbidity in axSpA}

The impact of rheumatic and musculoskeletal diseases (RMDs) on mental health is substantial, and the prevalence of psychiatric comorbidity in these disorders is increased compared to the general population. ${ }^{3}$ Over the last decade, affective disorders, and in particular depression, in axSpA have been gaining attention. Symptoms of axSpA, such 
as pain and fatigue, can be expected to have an effect on mental well-being. In this regard, comorbid depression in axSpA is often regarded as secondary, i.e. a consequence of the physical symptoms associated with axSpA. ${ }^{4}$ However, with the introduction of the 'inflammatory hypothesis of depression' over a decade ago,,6 attention has shifted towards depression in axSpA as a possible primary manifestation. Comorbid depression could share a common pathophysiological (inflammatory) pathway with axSpA. The results of studies on the nature of comorbid depression have been far from equivocal, however, which can be attributed to the heterogeneity between studies with regard to the population, setting and factors that were investigated, as well as the challenges of investigating mental health and depression in RMDs. ${ }^{7-11}$ Below, first the challenges of investigating comorbid depression are discussed. In particular, it is questioned what is actually measured with current approaches to assess 'depression' in chronic disease. Next, the role of mastery as a (potentially modifiable) contextual risk factor for depression is explored. This is followed by a review of the current evidence on inflammation as a potential primary mechanism underlying depression, and the findings in this thesis on inflammation and comorbid depression in axSpA are put into perspective. Finally, several suggestions are provided on future research in this field of research.

\section{Challenges of investigating depression in axSpA}

Investigation of comorbid depression in axSpA comes with several challenges. First, it requires correct classification of depression, and accurate measurement of depressive symptoms. 'Depressed' cases in studies on depression are often defined by their score on a screening instrument (questionnaire) for depression, which is not fit for the purpose of diagnosis or classification. Furthermore, the thresholds used to define possibly depressed cases ('cut-offs') vary across studies. ${ }^{3}$ In both of the studies on depression in axSpA in this thesis, we used screening instruments for depression (Depression subscale of the Hospital Anxiety and Depression Scale [HADS-D] in Chapter 3, and the CES-D in Chapter 4). These studies focused mainly on the severity of depressive symptoms (and not 'possible depression' as defined by these instruments), as classification of cases as 'depressed' or 'not depressed' would introduce the risk of misclassification. In addition, depressive symptoms themselves would be relevant for patients, even in the absence of clinical depression. Even so, using the scores on such instruments as a measure of the severity of symptoms assumes that the relation between these scores and the meaning (burden) of depressive symptoms to the patient largely linear, which seems debatable. As an alternative approach, in Chapter 3, the individual (observed) HADS-D items were regressed on a latent (unobserved) variable. This latent variable 'depression' was based on the shared variance of the individual HADS-D items, thereby reducing the contribution of measurement error in these items and resulting in a more accurate representation of the depression construct. 
More importantly, it remains uncertain to what extent these instruments, usually designed to screen for depression in general populations, actually measure 'depression' or 'depressive symptoms' when used in axSpA. The overlap in some of the manifestations of depression and axSpA forms a challenge when investigating comorbid depression using questionnaires. Issues with sleep and fatigue can occur in both depression and axSpA. The inclusion of such symptoms in screening questionnaires for depression could result in false positives when applied in a population of patients with axSpA. The impact in arthritis populations seems limited, however, as shown in studies that assessed the impact of excluding items from the CES-D or investigated differential CES-D responses in individuals with and without arthritis. ${ }^{12,13}$ Modification of the screening instruments (excluding certain items), or calculation of subscales for specific domains, could theoretically help separating somatic from mental aspects and provide additional insight. The CES-D, for example, has separate subscales on somatic complaints and depressed affect. ${ }^{14}$ However, the validity and reliability of such subscales is not always clear, and some have changed over time. For the CES-D, over 20 different variations of subscale contents have been reported in the literature. ${ }^{15}$ This is why we used the overall scale for the main analysis in Chapter 4. Still, reporting improvements for specific domains of depression questionnaires, if done with consistency, would provide valuable data for comparison between studies. ${ }^{16}$ In addition to overlap in symptoms between axSpA and depression, there is another important issue: the association between the two is likely bidirectional. ${ }^{17,18}$ Consequently, the nature of any association between the two is uncertain. As observed in Chapter $\mathbf{4}$, even in the setting of an RCT, doubt remains to the direction of any association between the physical and (potential) mental manifestations of axSpA. This is complicated by the impact of the patient's affective state on measurement of axSpA-related symptoms. Several of the oft-used (and validated) instruments in axSpA are patient-reported outcome measures (PROMs), as they were designed to capture the patient perspective. Depression is associated with negative cognitions, however, which can affect perception of health. ${ }^{19,20}$ It is questionable to what extent these PROMs accurately reflect functional abilities and health in depressed patients. A recent meta-analysis of depression in axSpA found that differences in outcome measures between depressed and non-depressed patients were greater for subjective measures (Bath AS Disease Activity Index [BASDAI], Bath AS Functional Index [BASFI]) than for more objective measures (AS Disease Activity Score [ASDAS], Bath AS Metrology Index). ${ }^{3}$ Likewise, depression has been associated with worse scores on self-rated aspects of health in rheumatoid arthritis (RA) and fibromyalgia. 21,22 In both RA and psoriatic arthritis (PSA), depression has been associated with decreased subjective treatment response (patient/assessor global scores), but not objective domains of treatment response (swollen joint count, acute phase reactants). ${ }^{23,24}$ If depression distorts the subjective components of outcome measures in axSpA, this would mean 
that PROMs are not or less useful when investigating the mechanism behind depression in axSpA, and that alternative instruments and outcomes are necessary.

Fortunately, there are alternatives to using these screening instruments to assess depression, although these depend on the study objectives. Diagnosis of depression by physicians is likely based on more subtle nuances in patients' expressions and behavior than can be captured by questionnaires. Physician-diagnosed depression could therefore be the preferred alternative to the 'questionnaire-based' depression, and might be considered the gold standard for classification. For studies aimed at comparing depressed and nondepressed cases, this would be a suitable approach. However, for studies investigating severity of depressive symptoms, some form of scale or score would still be necessary. In addition, the limited acknowledgement (awareness) of depression as an important comorbidity in axSpA in the past limits the number of patients in axSpA with a pre-existing clinical diagnosis of depression (and self-report of such a diagnosis could also introduce misclassification in both directions). This might lead to an underrepresentation of the actual frequency of depression or clinically relevant depressive symptoms in this disease. Instead, axSpA patients could be assessed for depression by diagnostic interviews during studies on comorbid depression in RMDs. It is uncertain whether such an approach will affect patients' willingness to participate, however, and introduce selection bias. An advantage of physician-based assessment of cases would be that it overcomes some of the ethical challenges associated with depression screening in research settings. ${ }^{25}$

Even if it would be clear whether patients with increased scores on depression screening instruments actually have 'clinical depression', this would only be a small step forward. Knowledge on the mechanism behind their symptoms remains necessary, for appropriate recognition and management. Depressive symptoms do have an important impact on the individual, and do require attention in clinical practice.

The role of contextual factors - mastery as an example

Contextual factors have been gaining attention in medical research over the last decades, although the importance of context was already apparent long before. As discussed in

Chapter 1, in the ICF model contextual factors interact with manifestations of health conditions such as axSpA, resulting in disability and functioning as outcomes. ${ }^{1}$ In this thesis, the role of several contextual factors in axSpA was investigated. In our structural equation modelling (SEM) study on depressive symptoms and contributory factors in Chapter $\mathbf{3}$, in which both disease-related and contextual factors were explored, we concluded that context matters more than axSpA-related aspects when it comes to comorbid depression in axSpA. Out of a variety of contextual factors explored, gender, employment, a history of depression, social role participation, income and mastery were found to contribute indirectly and/or directly to depression. Mastery acted as mediator for several contextual and disease-related factors. 
Sense of mastery, or the perceived control over life and disease, is one of the personal resources that aid in coping with stressful events, and could act as a buffer for stress and hardships. ${ }^{26,27}$ Constructs closely related to mastery are self-efficacy, helplessness and locus of control. ${ }^{28-31}$ These share overlap, or are at least related to mastery, as they all conceptualize beliefs about control. ${ }^{28,29}$ Some of these 'labels' are used differently in psychology and sociology, or with different definitions. (Perceived) self-efficacy is often defined as the extent to which people feel confident that they can behave in ways that help achieve goals and feel in control. ${ }^{32}$ Sense of mastery may be the base for self-efficacy. ${ }^{28}$ Locus of control usually concerns controllability of circumstances in general, while mastery is specifically focused on circumstances that are important for the individual. ${ }^{30}$

Already in the 90s, mastery over disease and life was acknowledged as an important personal coping resource in RMDs. ${ }^{33,34}$ Prior to the SEM analysis of depression in r-axSpA in this thesis (Chapter 3), several studies had highlighted the importance of mastery. First, others had shown associations between mastery and both mental and physical well-being in general population samples and chronic disease. ${ }^{35-42}$ Second, its role as a potential mediator or moderator of the relationship between stress or hardships and health outcomes had been shown in multiple studies. . $^{37,41,43-47}$ Third, a positive relationship between high sense of mastery and better employment status in r-axSpA had been observed in a previous study of this thesis (Chapter 6). Fourth and finally, a related construct (selfefficacy) had been linked to depression in r-axSpA in a Swedish cohort. ${ }^{48}$ However, a model of 'depression' in axSpA, integrating both disease-related and contextual factors, and taking into account direct and indirect effects, was lacking. Our SEM study (Chapter 3) was aimed at constructing such a model. We confirmed the link between mastery and depression in axSpA, but also added an interesting notion: as mastery had a central role in the path diagram, it acted as a mediator for other determinants of depression in r-axSpA, i.e. income, satisfaction with role participation and self-reported axSpA disease activity. Although this finding needs to be interpreted in the context of a cross-sectional study, it would be of interest to know if mastery is a modifiable factor that could be improved with interventions. Effective modification of mastery would require that mastery is not stable (fixed), that purposeful and predictable changes in mastery are possible by means of intervention and that these changes in mastery result in better outcomes, such as reduced depressive symptoms.

Traditionally, mastery has been considered as a stable personal resource by some, similar to resilience. ${ }^{30}$ However, over the last decades, mastery's stability has been debated. ${ }^{31}$ Multiple studies observed signs of a life course trajectory of mastery and control, wherein these increase during adulthood, remain stable up till middle age and decrease with age thereafter. ${ }^{49,50}$ It has been hypothesized that chronic stress and life transitions can defy one's feelings of control to such an extent, that their sense of mastery will be challenged. As such, mastery would be a self-concept that develops over time, but can also 
decrease through critical experiences ('erosion of mastery'). ${ }^{26,50}$ These critical experiences are typically role strains and perceived failures or lack of success in life, which could be considered as 'evidence' of one's inability to change certain circumstances. ${ }^{30}$ Becoming chronically ill is such a critical experience. ${ }^{51,52}$ Many symptoms of RMDs are uncontrollable and unpredictable. RMDs are often associated with important losses in life, including loss of employment, leisure activities and independence. The uncertain disease course also introduces worry about the future and becoming dependent on others. Altogether, RMDs confront individuals with their inability to change unwanted circumstances in life, thereby challenging feelings of control and reducing sense of mastery. ${ }^{26,38,51}$ In line with this, in Chapter 6, mastery was significantly lower in patients with r-axSpA compared to general population controls. In addition to the medium- to long-term changes in mastery described above, there is some evidence for considerable short-term variability in mastery (more than merely measurement error or 'noise'), and for this variability to differ between individuals. ${ }^{53}$ Finally, theories of adaptation suggest that, after an initial loss of mastery, it can re-establish over time: psychological adjustment to an illness includes attempts to regain mastery. ${ }^{54}$ Altogether, these observations suggest that, rather than a fixed resource, sense of mastery develops and changes over time.

The observation that mastery changes over time does not prove that it can be changed through intervention, however. Only few studies have specifically investigated whether mastery can be improved with interventions, usually in populations not resembling those with axSpA (such as caregivers or patients with HIV). In rheumatology, evidence on the effectiveness of interventions on mastery is scarce, with one study reporting a significant effect of a psychotherapeutic intervention on both mastery and depressive symptoms in patients with musculoskeletal disease (mostly RA, effect size of intervention 0.50 for both outcomes)..$^{52}$ Instead, most other studies in this field investigated interventions on constructs related to mastery, such as self-efficacy, helplessness and (perceived effectiveness of) coping. Important examples of these type of interventions are selfmanagement programmes and cognitive behavioral therapy (CBT), which target coping strategies, psychological health and, in the case of CBT, patient beliefs on control. ${ }^{55}$ These studies have shown varying, but generally favorable, short-term results on self-efficacy, perceived control and coping in inflammatory arthritis, in particular RA. ${ }^{55-57}$ Long-term studies (follow-up >1 year) are limited in number, but also tend to show positive results. ${ }^{56,57}$ Recent guidelines support the use of these interventions among other forms of patient education in patients with inflammatory arthritis. ${ }^{58}$

Instead of directly targeting perceived control and beliefs, interventions could also be aimed at determinants of mastery or at factors that affect mastery. Based on the results of our SEM analysis (Chapter 3), self-reported axSpA disease activity, income and social role participation are factors that contribute to sense of mastery. Income is not a feasible target for intervention in itself. Governments are promoting sustainable employment 
of those with chronic disease, which will hopefully decrease the economic burden for patients and increase feelings of control. Social role participation research has shown that there are notable gaps in physical difficulties and satisfaction with role performance between patients with r-axSpA and general population controls. ${ }^{59}$ The European League Against Rheumatism (EULAR) recommendations for axSpA now specifically mention social participation as one of the goals of management of axSpA. ${ }^{60}$ Longitudinal studies are necessary to show whether improvements in social role participation, including employment, also result in better mastery.

If sense of mastery in axSpA could be improved directly or indirectly, it is important to know whether such improvements would result in better outcome, i.e. reduced depressive symptoms. The majority of studies investigating mastery or self-efficacy in RMDs also assessed psychological well-being and depression. ${ }^{56,61,62}$ Their results often show an overall improvement in all of these outcomes, but the relation between them has not been investigated. ${ }^{62}$ This matter is complicated by the observation that (perception of) pain and physical function can also improve with such interventions, and these can contribute both to mastery (Chapter 3) and depressive symptoms (Chapter 4). ${ }^{56}$ Future studies, especially longitudinal studies in which both potential determinants and depressive symptoms are repeatedly assessed, would be necessary to reveal the mechanisms at play. In addition, most of the evidence discussed above was gathered in populations with RA or mixed populations. The applicability of the findings to axSpA seems likely, but this would need to be confirmed.

In conclusion, over the years it has become clear that mastery is not a stable trait, but a personal coping resource that can change over time. Interventions that target mastery are scarce, especially in RMDs, but might be effective in improving perceived control. Interventions on related constructs have shown promising results, as they seem to both improve the targeted construct and depressive symptoms.

Inflammation and (comorbid) depression

In our study on the effect of infliximab on depressive symptoms in axSpA (Chapter 4), one of the aims was to untangle the effects of inflammation and axSpA-related symptoms on depression, and to understand the underlying mechanism in comorbid depression. Depression in general is an etiologically complex disorder, with a plethora of possible risk factors of different nature. ${ }^{63,64}$ Development of depression should be considered a multifaceted process, in which factors can have both direct and indirect effects on depression. Over the last two decades, there has been increasing evidence for a potential role of inflammation in depression. 5,6 Environmental risk factors for depression (such as psychosocial stress, diet, lifestyle, socioeconomic status, chronic disease) ${ }^{65}$ increase peripheral inflammation, which can lead to central inflammation through humoral, neural and cellular pathways. ${ }^{6}$ This central inflammation (mediated by IL-1 $\beta, I L-6$ and TNF) 
affects several neurotransmitters and neurocircuits: synaptic availability of serotonin, dopamine and noradrenalin is reduced (which is also the main mechanism behind the monoamine hypothesis of depression), ${ }^{66}$ glutamate levels are increased and neurogenesis is decreased. In addition, dopamine release is reduced, leading to decreased activation of reward circuitry, while activity in anxiety-related neurocircuitry (such as the amygdala) is increased. ${ }^{6}$ These changes in neurotransmitters and neurocircuitry have been associated with typical hallmarks of depression, such as anhedonia and fatigue. ${ }^{6}$ The potential link between inflammation and depression has also been investigated in biomarker studies. In general population samples, several peripheral inflammatory biomarkers (CRP, TNF-alpha, IL-1 and IL-6) have been linked to depression. ${ }^{67,68}$ In longitudinal studies, both unidirectional and bidirectional associations between peripheral inflammation and depression were observed. ${ }^{69-72} \mathrm{It}$ is unclear whether the hypothesized relationship between inflammation and depression in inflammatory diseases (like axSpA) differs from that in general population samples. The literature on biomarkers in relation to depressive symptoms in axSpA is limited to CRP and ESR. In a recent review and meta-analysis of studies on depression in axSpA, ESR (but not CRP) was significantly higher in patient groups with (possible) depression. ${ }^{3}$ In RA, several studies have investigated the potential link between inflammatory biomarkers and depression. ${ }^{16}$ Two studies investigating TNF-alpha levels and depressive symptoms in patients with RA, did not find an association between the two. ${ }^{73,74}$ Indirect evidence, in particular improvement of patient-reported mental health after treatment with anti-IL-6 therapy, has led to the suggestion that IL-6 is also involved in depression in $\mathrm{RA}^{75}$ although one could argue that these improvements might also be secondary due to improvement in RA symptoms such as pain and fatigue. Studies in which IL-6 levels and depressive symptoms were assessed, had contradictory results. ${ }^{74,76,77}$ More recently, one study linked elevated IL-17 to increased depressive symptoms in RA. ${ }^{77}$ All in all, these biomarker studies provide conflicting evidence regarding a role for inflammation in the pathophysiology of depression in inflammatory RMDs.

In addition to translational and biomarker studies, clinical observations could provide (indirect) evidence on a link between inflammation and depression. Multiple studies have investigated the effect of inflammation on antidepressant efficacy in depressed patients. It is important to note that the mechanism of action of conventional antidepressants is aimed at increasing synaptic availability of monoamines and stimulating neurogenesis. This suggests that the central inflammatory cytokine effects (as mentioned earlier) directly counter-act or circumvent these drugs, by decreasing synaptic availability of monoamines and reducing neurogenesis, or by increasing glutamate, which is not an antidepressant target. ${ }^{6}$ This might explain the association between inflammation and reduced effectiveness of antidepressants that has been observed in patients without RMDs. ${ }^{78,79}$ One could argue that, if comorbid depression in patients with inflammatory RMDs was primarily due to inflammation, antidepressants would show a similar lack of 
efficacy in these patients. Unfortunately, this has not been investigated in axSpA. One trial investigated the effect of amitriptyline on fatigue, pain and stiffness, but did not address depression. ${ }^{80}$ Studies of antidepressants in RA are available but dated, and the study populations and available treatments are not representative of current practice, thus limiting applicability of results. A Cochrane review and a recent meta-analysis of these studies found either no effect of antidepressants or conflicting evidence, and notable risks of bias. ${ }^{81,82}$ Another Cochrane review pooled studies of antidepressant efficacy on comorbid depression in populations with any somatic disease (44 RCTs were included for analysis, one in RA and the others in non-RMDs), and found antidepressants to be effective. ${ }^{83}$ Unfortunately, the low quality of evidence precludes any firm conclusions on the efficacy of conventional antidepressants for comorbid depression in inflammatory RMDs. Finally, the observations by some that depression precedes RA could theoretically be explained by a shared inflammatory pathophysiological pathway. ${ }^{84,85}$ However, several other factors, such as lifestyle (smoking, obesity), associated with both depression and RA could confound or mediate these longitudinal associations. The latter is supported by the observation that treatment with conventional antidepressants mitigates this increased risk of developing RA at a later time. ${ }^{85}$

There are also observations in clinical studies that challenge the concept of 'inflammatory depression' in inflammatory RMD. In RA and PsA, depressive symptoms have been associated with worse treatment response to TNFi, mainly due to reduced effects on subjective outcomes, and not on inflammatory markers or swollen joint counts. ${ }^{23,24,86-88}$ If comorbid depression in these patients would be primarily inflammation-driven, one would expect resolution of depressive symptoms and similar - or even better - response rates, especially if pre-TNFi disease state was relatively worse due to increased inflammation driving depression and PROMs. Also, in these studies the PROMs at baseline were often increased in the depressed patients, while markers of inflammation were not, which is not in line with inflammatory depression. ${ }^{23,86-88}$ In addition, in one longitudinal study, the initiation of TNFi compared to initiation of conventional disease-modifying antirheumatic drugs (DMARDs) or prednisone resulted in similar decreases in the use of antidepressants in these populations over time, despite the differences in mechanism of action of these drugs. ${ }^{89}$ This generic effect suggests that the (improvements in) axSpA-related symptoms, and not a shared inflammatory pathway, are contributing to depressive symptoms, although confounding by indication might have affected the results. Finally, although it has been reported that antidepressant use is higher in those patients initiating or switching biological DMARDs (bDMARDs) when compared to remaining on current therapy, the direction of this association is uncertain, i.e. depression could have led to increased PROMs and might have prompted initiation of bDMARDs. ${ }^{90}$ 
Depression in axSpA - only secondary?

In Chapter 4, no evidence was found for a direct link between (CRP-mediated) inflammation and depressive symptoms. Does this mean that it can be concluded that depression in axSpA is secondary, i.e. a consequence of axSpA-related symptoms? Comparison with similar studies in axSpA was difficult, as these were non-controlled or did not further investigate the possible mechanism underlying depressive symptoms. ${ }^{91-95}$ An important consideration is that the current study focused on the change in depressive symptoms following treatment with infliximab. Possibly, (CRP-mediated) inflammation had a role in the pathogenesis of the depressive symptoms in (subgroups of) patients before the trial, although in such case, it would be expected that an independent association between inflammation and depressive symptoms would persist. It should also be questioned whether CRP is an appropriate biomarker to identify such an association in axSpA. If this is not the case, it would be a notable discrepancy from observations in depressed populations without RMDs, where CRP as a peripheral biomarker of inflammation has been shown to correlate well with central immune activity, ${ }^{96}$ and CRP is considered one of the most reliable biomarkers of inflammation. ${ }^{6}$ The results in this thesis (Chapter 4), however, seem to suggest that inflammatory biomarkers other than CRP are more interesting to explore in future studies on depression in axSpA. Interestingly, a recent meta-analysis found that many of the changes in the chemokine concentrations observed in depressed individuals were only present in otherwise healthy study populations, and not in those with somatic comorbidities. ${ }^{97}$ Possibly, the inflammatory changes in depressed individuals with a comorbid inflammatory RMD are masked, complicating depression research in these diseases. ${ }^{16}$

Despite the increasing attention for inflammation in depression, it is important to note that (in depressed patients without RMDs) inflammation is present in only a subgroup of patients. ${ }^{72,98}$ Notable differences in neurotransmitter levels and neurocircuitry have been shown between depressed patients with inflammation and those without inflammation. ${ }^{99,100}$ In depressed patients without inflammatory disease, but with increased inflammatory biomarkers, bDMARDs may improve depressive symptoms. ${ }^{98}$ In such patients with normal levels of inflammatory biomarkers, however, these drugs are unlikely to show such an effect and might even be harmful, as IL-1 $\beta$ and TNF have important roles in the nervous system under physiologic conditions. ${ }^{101}$ These observations suggest there is not only substantial heterogeneity in the clinical manifestations of depression, but also in the underlying pathophysiology. ${ }^{102}$ This has several implications. First, a similar heterogeneity likely is present in comorbid depression. The lack of a direct link between CRP and depressive symptoms in this thesis (Chapter 4) might have been a direct result of this. Larger studies could help determine if there are relevant subgroups in axSpA in which different mechanisms for depression are at play, i.e. a direct effect of inflammation vs the impact of axSpA symptoms on HRQoL and functioning. Also, these mechanisms are not 
mutually exclusive, and could contribute simultaneously. Second, if there is heterogeneity in comorbid depression, not all axSpA patients with comorbid depression will respond, i.e. experience a reduction in depressive symptoms, to treatment with bDMARDs. In this thesis, $20-25 \%$ of patients still had clinically relevant depressive symptoms ('possible depression', CES-D $\geq 16$ ) after treatment with a bDMARD. Interestingly, these patients had higher BASDAI and BASFI, but not CRP, than those without clinically relevant depressive symptoms after treatment. Based on observations in RA, it seems that pharmacotherapy for axSpA alone is unlikely to treat comorbid depression in all patients, and that effects might be limited. ${ }^{103,104}$ Instead, dedicated treatment with antidepressants and/or psychological therapies might still be necessary for these patients.

\section{Concluding remarks on depression in axSpA}

Despite efforts to unravel the pathogenesis of depression in axSpA, there is still considerable uncertainty regarding the underlying mechanisms. There is definitely biological plausibility for inflammation to play a role in comorbid depression, but the complex crosstalk between body and mind, the limited transferability of observations in healthy populations, the shared inflammatory pathways of somatic and mental manifestations of RMDs, and the heterogeneity of depression pose large challenges for researchers. For research on this topic to advance, there seems to be a 'missing link': a lack of biomarkers or objective instruments to independently assess inflammation, physical symptoms and depression in axSpA. Use of alternative techniques, such as inflammatory markers in cerebrospinal fluid in addition to plasma and imaging modalities like functional MRI and PET-CT, might shed additional light on the underlying mechanisms, and distinguish inflammatory and non-inflammatory depression in studies. Studies should include depression as the primary outcome, so they are primarily designed to elucidate direct and indirect effects causing or contributing to depression. Contextual factors should be included as these can serve as important risk factors and mediators, and they need to be assessed over time to explore how they can change and whether this affects depressive symptoms.

Although knowledge on the underlying mechanism is helpful, for patients the recognition and treatment of comorbid depression and depressive symptoms counts. In line with this, depression in RMDs has been acknowledged as a prevalent comorbidity that should be screened for in routine care. ${ }^{105,106}$ Diagnosing depression in axSpA remains challenging, mainly because of overlap between disease manifestations and characteristics of depression. Yet, appropriate recognition and management of comorbid depression is necessary to optimize patients' quality of life, control of their RMD and efficiency of care for both. The evidence on management of depression in RMDs is limited, and the combination of both somatic and mental burden, as well as concomitant use of anti-inflammatory and antidepressant medication, can complicate treatment. Studies on different interventions for comorbid depression in axSpA - and RMDs in general - can help identify which strategies 
are optimal, and for which subgroups of patients. Non-pharmacological interventions, aimed at improving mastery and self-efficacy, could provide valuable tools in battling the mental burden of axSpA. Regardless of the underlying mechanism, timely recognition and management of depression deserves attention in axSpA.

\section{The societal perspective on outcome in axSpA}

\section{Estimation of productivity and costs of changes in productivity}

AxSpA can have substantial economic consequences for patients and society, and changes in productivity can play a large part in this. As a chronic disease that manifests itself in patients of (early) working age, the consequences of axSpA on work-related outcomes and associated costs can span multiple decades. ${ }^{107-112}$ The findings in this thesis on employment (Chapter 6) and sick leave (Chapter 5) in r-axSpA were in line with this: patients with r-axSpA were less often employed compared to the general population, and (recurrent) sick leave was prevalent. Productivity-associated costs are part of the economic burden of disease, and have been shown to be an important cost component in axSpA. ${ }^{113-}$ 116 This makes them relevant for inclusion in economic evaluations, especially from a societal perspective (as shown in Chapter 8). After all, if governments aim to maximize societies' health and wealth, costs outside of healthcare are as important as those inside healthcare. ${ }^{117}$ As an example, treatment of persons with axSpA is expensive, but a large part of these expenses are to be earned back because of improved work productivity. Still, productivity costs, and especially those due to reduced at-work productivity, were often not included in economic evaluations in general and in axSpA. ${ }^{118,119}$ Conceptual, ideological, theoretical and methodological considerations have likely contributed to this. Below, productivity and the challenges surrounding estimation of productivity and productivity costs are discussed. Next, it is explored how these challenges affected the studies in this thesis, with a particular focus on our economic evaluation of diagnostic algorithms for axSpA. This is followed by a brief reflection on productivity from the patient perspective, to be concluded with several suggestions on future research on productivity in axSpA.

\section{Productivity and productivity changes}

Productivity can be considered as a measure of how efficiently production inputs (labour, technology) are used to produce output. ${ }^{120}$ Productivity can be affected by many factors, such as job type, working hours, job satisfaction, support and health. ${ }^{121}$ Loss of health can have an effect on both aspects of labour input (quantity and quality) and thus directly affects productivity. Changes in productivity can generally occur in two areas, paid work and unpaid work. ${ }^{122}$ Within the area of paid work, the two types of productivity change are absenteeism (being absent from work due to health problems, i.e. sick leave and work 
disability) and presenteeism (decreased at-work productivity, i.e. reduced intensity and/or quality of labour, due to health problems). It is important to realize that there is a dependency between short-term absenteeism (sick leave) and presenteeism. ${ }^{123}$ Theoretically, if an increase of absenteeism results in increased productivity while working, total productivity could actually increase. In practice, this would depend on the characteristics of the work and workplace, which will be discussed further down below. Unpaid work concerns the production of goods and services that are not sold on the conventional market, i.e. nonmarket commodities. Common examples are household work, care work and volunteer work. ${ }^{124}$ Although these goods and services cannot be sold, they contribute to societal wealth. A recent panel on European recommendations for cost estimation in economic evaluations concluded that unpaid work might currently not be included due to the lack of standardized methods to measure this, but also stressed the relevance of this category and called for additional research in this area. ${ }^{125}$ The discussion below is mostly focused on challenges in the measurement and valuation steps of paid work.

\section{Challenges in the measurement of productivity changes}

Ideally, objective measures would be used for measurement of both absenteeism and presenteeism. The days absent from work or the proportion of time working with reduced productivity are the most frequent 'surrogates' used to (reliably) estimate changes in productivity. For absenteeism, external registries can be a reliable data source for this, but are often not available. For presenteeism, objective measures are difficult to develop, as for many job types output is difficult to quantify. ${ }^{126}$ There could also be ethical concerns with regard to sharing data on individuals' work productivity. As an alternative, absence from work and presenteeism are often elicited via retrospective questionnaires, i.e. self-reported.

For absenteeism, well-defined definitions of sick leave and work disability, and especially standardization of the assessment of self-reported sick leave, are required. Should all sick leave be reported, or only sick leave related to the disease under investigation? If so, can patients make this distinction? Should time taken off work to visit a care provider also be counted as sick leave? In OASIS, the cohort that was used for the study on sick leave in this thesis (Chapter 5), patients were asked to indicate whether they experienced any sick leave related to axSpA during the previous period (yes/no) and to report the length of sick leave in days (open question). Especially the second question led to a large variety in answers given, with patients sometimes denoting answers such as '4 months' or '50\% disabled'. Because of this, in addition to potential recall bias (see below), the analysis was focused on the occurrence of sick leave, instead of the length. Of note, OASIS was initiated in the 90s. Nowadays, use of standardized productivity instruments can prevent these issues.

Assessment of presenteeism comes with additional challenges. Whereas definitions of absenteeism are relatively well-defined for patients, definitions of presenteeism are more heterogeneous, mainly distinguishing the loss of production for the workplace or society, 
and the level of restriction experienced by the patients. To assess productivity loss while at work patients are often asked to rate the quantity and/or quality of the work done or the extent to which health problems affected their productivity compared to usual, effectively measuring the percentage of time loss. ${ }^{127-129}$ Alternatively, patients can be asked how much extra hours they would have to work to catch up on tasks. ${ }^{130}$ The instruments assessing patient's ability to perform work ask about the level of difficulty, often in different aspects of work (such as physical demands and mental demands). ${ }^{131,132}$ As a consequence, the alternative approaches provide very different results and a gold standard is lacking (so it is unclear whether they lead to under- or overestimated productivity losses). ${ }^{131,133}$ In addition, the outcomes of these instruments are usually converted directly to a productivity loss, using the best scores as reference. However, there is evidence that self-reported difficulty or productivity is not linearly related to production loss. ${ }^{134}$ Also, it is unclear whether patients would rate their productivity as unaffected on days without health problems. In fact, control populations also do not consider themselves fully productive while at work. ${ }^{133}$ Consequently, presenteeism could be overestimated in patient populations. Similar as for sick leave, issues such as recall (see below) and disease attribution further add to precision, reliability and variability between instruments.

Elicitation of absenteeism (especially sick leave) and presenteeism by questionnaires can also introduce recall bias, as patients are asked to recall events that sometimes took place months ago. Precision and accuracy of self-reported absenteeism, when compared to company-registered absenteeism, decrease with increasing length of the recall period. ${ }^{123,135}$ In addition, saliency might contribute more than recency when completing self-reported questionnaires: the most recent work-related events might not significantly affect reported presenteeism, while the most severe events do. ${ }^{136,137}$ Although shorter recall periods would generally be preferred, this has to be balanced against other factors, such as study design, costs and patient burden. In the study on sick leave in r-axSpA in this thesis (Chapter $\mathbf{5}$ ), recall periods during the later years of follow-up up were 1 year, which might have introduced bias. This is why sensitivity analyses were conducted with the data from the early years of follow-up, reducing the recall period to 2 months. These analyses led to similar results.

Although several standardized instruments have been developed for assessment of productivity, information on multiple measurement properties is lacking for several of these. ${ }^{121,138,139}$ In addition, their validity and applicability can vary depending on the intended use: is the instrument used to assess the impact of productivity changes on costs (economic/societal perspective), or the impact on the patient (patient perspective)? Despite these challenges, efforts by the Outcome Measures in Rheumatology (OMERACT) Worker Productivity Group to provide recommendations on the most appropriate instruments are ongoing. ${ }^{140,141}$ 
Challenges in the monetary valuation of productivity

Once the measurement of the natural units of productivity has been completed, changes in productivity have to be valued. For valuation of paid work, two theoretical approaches are commonly used: the human capital approach and the friction cost approach. The human capital approach considers any potential loss of productivity by the individual from the current age until the age of retirement, thus sometimes argued to be taking the perspective of the individual, quantified in terms of forgone earnings. ${ }^{142,143}$ The friction cost approach is based on the concept of replacement, taking the perspective of groups or society: an absent worker will be replaced after some time of lost production by a formerly unemployed worker, directly or indirectly through a chain of replacements. ${ }^{144}$ After a period of adaptation and potential loss of productivity (the 'friction period'), society will restore initial productivity. Any long-term absenteeism beyond the length of the friction period is considered not relevant for valuation for the friction cost approach. Estimates of productivity costs usually differ between these human capital and friction methods, which can have important consequences. ${ }^{143}$ They have been debated at length over the last decades, and there is still no consensus on the most appropriate choice. ${ }^{145,146}$ The Dutch guideline on economic evaluations recommends the friction cost approach. ${ }^{147}$ It should be noted that application of the friction cost approach requires more detailed data on absenteeism, as it requires knowledge about the number of consecutive days absent (due to sick leave or work disability) for each episode of absence.

The actual productivity costs for society will also depend on other factors. Usually, gross wage rates are used to value one hour of lost productivity. However, characteristics of the work can actually result in differences between wages and actual productivity. Examples are job type, team production, availability of substitute workers and timesensitivity of output. ${ }^{148}$ An oft-used example is a pilot (difficult to replace, works in a team), whose sick leave likely affects the whole flight crew if a flight were to be cancelled. These so-called 'multiplier effects' are expressed as wage multipliers. For some job types, wage multipliers of 2 and above have been estimated, meaning the value of one lost hour of productivity is over twice as much as the hourly wage. ${ }^{148-150}$ Similar to how multiplier effects can increase productivity losses, compensation mechanisms can reduce these. Examples are absent employees catching up on their tasks at a later moment during working hours, or colleagues taking over these tasks during short spells of sick leave. Studies have shown that accounting for these mechanisms could reduce productivity costs by more than 50\%. ${ }^{151,152}$ However, once multiplier effects were added, thus adjusting for team dependency and finding substitutes for absentees, the estimated productivity costs were actually close to the conventional (uncorrected) estimates. ${ }^{151}$

From the above, it should be clear that time loss does not necessarily equate productivity loss. There are methods to include the factors mentioned above in the valuation of changes in paid productivity. Company output could be linked to individual 
labour input, or managers could be asked to assess the productivity. ${ }^{150}$ As an alternative, questionnaires can include questions on workplace and job characteristics, such as team dependencies and compensation mechanisms. ${ }^{149,151}$ In rheumatology, several studies have now applied these methods to estimate productivity costs. ${ }^{149,153-155}$

A working example - economic evaluation of diagnostic algorithms in axSpA For our cost-effectiveness analysis of diagnostic algorithms for axSpA (Chapter 8), a societal perspective was adopted. Productivity costs of paid work were included in the analyses: the costs of absenteeism in the base-case analysis and the costs of presenteeism in a sensitivity analysis. This came with several assumptions and limitations, both for the measurement and valuation of productivity changes.

For the measurement of productivity changes, we used patient-level data from the SPondyloArthritis Caught Early (SPACE) cohort. ${ }^{156}$ In SPACE, productivity was assessed at baseline with the Work Productivity and Activity Impairment Questionnaire (WPAI, General Health version). ${ }^{127}$ The WPAI asks individuals to declare the number of hours missed due to health problems and due to other reasons, as well as the number of hours actually worked, in the past 7 days. In addition, they are asked to indicate how much health problems did affect their productivity while working on a scale from 0 (no effect) to 10 (maximum effect). The baseline WPAI measurements were used to estimate productivity in patients with axSpA and CLBP. Consequently, we had to assume that the productivity in the past 7 days would be representative for longer periods as well, thus extrapolating responses. Also, there was uncertainty regarding the reference level of patients' at-work productivity, and we assumed that this would be maximum (i.e. a score of 0 on the question on health impairments while working). Although debatable, as it could overestimate presenteeism, this would constitute a 'worst case' scenario of presenteeism costs. As such, the true estimate likely lies between the base-case analysis (no presenteeism included) and the sensitivity analysis with presenteeism. Of note, in this worst-case scenario, inclusion of presenteeism did not substantially affect results, i.e. did not alter the cost-effectiveness ranking of the algorithms.

(Temporary) absenteeism and presenteeism obviously only apply to patients in the workforce. Although employment status was collected at baseline in SPACE, data on employment in another Dutch cohort of axSpA patients (SPASS) that had a broader range of age groups were also available to us. As SPACE was limited to patients age 47 or younger due to the inclusion criterion of low back pain with an onset before age 45 and a duration of 2 years or less, SPASS was preferred over SPACE for employment data. ${ }^{156}$ This is why SPASS data were used for axSpA cases, and literature data for CLBP cases, to estimate employment rates by age and gender. Of note, in the model it was assumed that employment rates in correctly and incorrectly diagnosed cases were similar, due to lack of data. This was supported by the baseline employment rates in SPACE, which were 
similar for these diagnostic groups. However, if there is an effect of correct diagnosis on employment rates over time, this assumption might have attenuated differences in costs between diagnostic groups. Whether this favoured certain algorithms would depend on (i) the relative differences in productivity changes between axSpA and CLBP and (ii) how these change over time, combined with (iii) their dependency on being (in)correctly diagnosed, as well as (iv) the prevalence of axSpA. In an exploratory analysis, assuming employment rates in false positive and false negative cases would be 15\% lower (relative reduction, assumption based on SPASS data) when compared to correctly diagnosed cases, incremental net monetary benefits of comparisons from a societal perspective would be slightly smaller but otherwise unchanged.

For the valuation of productivity changes, we decided to use a pragmatic approach and apply both the human capital approach and the friction cost approach. The rationale for this was that the Dutch guidelines recommended the friction cost approach, while internationally the human capital approach was more common, and applying both thus helped gain acceptance and transferability of the analysis and results. In addition, this could provide insights into how the results differ. Unfortunately, the patient-level data on productivity in SPACE were limited to the baseline assessment with the WPAI, which only refers to the previous 7 days. For the friction cost approach, this meant that several assumptions had to be made regarding the occurrence of long-term absenteeism beyond the friction period, as only absenteeism with a shorter duration than the friction period should be valued. These assumptions were based on the distribution of absenteeism in the WPAI scores, separately for axSpA and CLBP. For the human capital approach, this limitation did not apply, but there were other limitations. The WPAI does not capture permanent absenteeism (work disability), which had to be derived from published data. As with the employment rates discussed above, assumptions on withdrawal from the labour force when valuating of productivity changes could have led to overestimation and underestimation of productivity costs.

No multipliers were used to account for the potential impact of multiplier effects (availability of substitutes, team work, time-sensitivity of output) on productivity, nor were adjustments made for potential compensation mechanisms in place, as no data were available on either of these and the validity of these methods is uncertain. Consequently, productivity losses could be overestimated, if compensation mechanisms dominated, or underestimated, if multiplier effects dominated.

Finally, although it was stated that this study adopted a societal perspective, we did not include unpaid work in the cost-effectiveness analysis due to lack of data, as the WPAI does not provide estimates of health impact on the quantity of health impact of unpaid tasks or the (additional) time needed to complete these. In addition, although inclusion is recommended by the Dutch guideline (using the replacement approach), ${ }^{147}$ consensus on the valuation is lacking. ${ }^{125}$ It is uncertain how exclusion of unpaid work in the analysis 
affected results. In one study that compared cost-of-illness (COI) in r-axSpA and CLBP samples, costs of paid and unpaid household help were higher in the latter (approx. $€ 700$ vs $€ 2,100$ annually, respectively). ${ }^{157}$ It should be noted that both disease samples had moderate to severe disease, so average unpaid work costs would likely be lower in more general disease populations. However, there are other types of unpaid work that were not included in this COI study, which might have resulted in an underestimation. Another study in r-axSpA did take all types of unpaid work into account, and valued unpaid work at $€ 1,900$ annually. ${ }^{124}$ Also, inability to execute unpaid household tasks could partially be covered by informal care, which was included in the analysis in this thesis. Nevertheless, in order for omission of unpaid work to affect the cost-effectiveness analysis, it is both the absolute amount and changes in unpaid work, combined with their dependency on being (in)correctly diagnosed, that would matter. Assuming that unpaid work loss is higher in CLBP, based on the COI study mentioned above, ${ }^{157}$ and that correct diagnosis leads to similar proportional improvements in unpaid work loss in axSpA and CLBP this would favour specificity over sensitivity. This, however, is a questionable scenario, as the effect of correct treatment on household productivity is likely larger in axSpA cases compared to CLBP cases. Current lack of knowledge on the unpaid work costs, especially in relation to (i) diagnostic status (correct/incorrectly diagnosed), (ii) other costs included and (iii) prevalence of axSpA in the population, limits any further speculation on the matter.

It should be emphasized that the economic evaluation in this thesis was model-based, and that it relied on external studies to estimate productivity. These studies were often not primarily designed for estimation of productivity costs. In a trial-based evaluation, several of the challenges above can be overcome by considering productivity costs as a relevant outcome during the design phase. ${ }^{158}$

\section{Productivity from the patient perspective}

The above discussion mainly focused on productivity costs from a societal perspective, for the purpose of economic evaluation. From the perspective of companies and of patients and their families, other considerations apply. In the short term, financial consequences of reduced productivity for patients and their families depend on specific legislation and regulations within the local social security regulations and company policies. In the long term, reduced productivity can affect career prospects and opportunities for promotion, resulting in future foregone earnings. ${ }^{159}$ Obviously, such costs are very difficult to estimate. Also, absenteeism and presenteeism also result in intangible costs for patients, as the inability to fulfill their work role might affect their wellbeing. Patients with reduced productivity might be feeling stressed, unaccomplished or stigmatized, or experience a negative attitude of colleagues towards them. Finally, an important consideration is that difficulties at work can also disturb the work-life balance and affect participation in other societal roles, i.e. family, caregiving and leisure. As an example, in the analysis 
of determinants of depression in r-axSpA in this thesis (Chapter 3), employment was associated with depression, which we attributed to role strain. ${ }^{160}$ While productivity could be preferred from the perspective of the employer or society, it might not be from the perspective of the patient if it comes at the cost of other activities. ${ }^{160,161}$

\section{Concluding remarks on productivity}

Assessment and valuation of productivity losses is challenging, but necessary from a societal perspective. The ethical and methodological concerns that some associate with inclusion of productivity costs in economic evaluations can be relevant in the decisionmaking process, but do not justify exclusion of these costs, as they do affect societal welfare. Looking forward, it is expected that productivity costs of chronic disease will remain an important part of economic evaluations, even with improved diagnosis and management. Although some of the challenges might discourage researchers to include presenteeism in their assessment, it could be just as important as absenteeism. ${ }^{124}$ Nowadays, presenteeism seems especially relevant, with improved disease management reducing long-term absenteeism and increasing time at work, and efforts by governments and organisations to accomplish sustainable employability for the chronically ill. Consequently, there could be a continuing shift from absenteeism to presenteeism, which requires additional research in RMDs. Future studies could help identify which measures of presenteeism most accurately reflect actual productivity loss, so that uniform measurement of presenteeism and transferability of results are improved. In addition, appropriate methods for valuation of these losses, in light of multiplier effects and compensation mechanisms, are needed. Importantly, as many presenteeism instruments are available, and information on multiple measurement properties is lacking on the majority of them, it is recommended to focus efforts on studying and improving these existing instruments that almost meet the filter of validity instead of developing additional ones. ${ }^{121,138,140}$ Finally, research is necessary on the methods for valuation of unpaid work, to gain reliable estimates and to avoid double counting. Current efforts to standardize methodology and transparent reporting will hopefully improve transferability of results and stimulate uptake of all types of productivity in economic evaluations. ${ }^{125}$

\section{Economic evaluations and diagnosis of axSpA}

New technologies can improve patients' quality of life, but often come at additional cost. In Chapter 1, the economic evaluation was introduced as a means to appraise new technologies by balancing their potential health gains against their costs. Economic evaluations are an essential part of health technology assessment (HTA), a systematic and multidisciplinary process to determine the value of health technology. ${ }^{162} \mathrm{~A}$ commonly used type of economic evaluation is cost-effectiveness analysis. These evaluations can be used to assess technologies that are ready for implementation, but also those in early 
stages of development (as part of early HTA). ${ }^{163}$ With increasing complexity of research and development, informed decisions on investment are becoming more important than ever. Early HTA could help guide these decisions and maximize returns on investment. Below, first the 'early-stage economic evaluation' is reviewed. This is followed by a discussion on how to improve diagnosis in axSpA, and the role early economic evaluation could have in this process. Finally, several suggestions are provided on future research in this area.

\section{Economic evaluation - the earlier, the better}

Economic evaluations in healthcare often include technologies that have been fully developed and are fit for implementation in their current state. ${ }^{163}$ Biological DMARDs in rheumatology could be used as an example: cost-effectiveness analyses are typically conducted when the drug has passed several phases of development and clinical research. Economic evaluations in this stage are meant to demonstrate to payer's (such as reimbursement authorities) that the technology in question provides good value for money. Over the years, dozens of these studies have been conducted, with a wide variety in methodology and results. Elsewhere, the history of economic evaluation in axSpA, with a focus on bDMARDs and how methodological choices and assumptions influence the results, has been extensively discussed. ${ }^{119}$ By now, economic evaluation, and especially cost-effectiveness analysis, has become an established methodology that is often applied in axSpA.

However, as the resources spent on research and development are increasing, it might be preferable to assess the economic viability of a new technology at an earlier stage. These assessments could be used to identify which technologies should be funded, or abandoned ('fail fast, fail cheap'). ${ }^{163}$ More important, in addition to informing go/no-go decisions, early assessment could help shape the development of the technology, guide efforts to collect additional evidence and define specifications of the technology. ${ }^{164,165}$ Such an approach would be beneficial for both public and private parties involved, as informed decisions are required to maximize return on investment. ${ }^{166}$ In this context, it should be noted that early HTA has a broad scope, and is more than early-stage economic evaluation. Early HTA can include methods for developers to manage their medical product portfolios, simulate trials, perform risk assessments and set realistic performance-price goals. ${ }^{163}$ Here, we focus mostly on early-stage health economic evaluation, and not on early HTA as a whole.

There are important conceptual differences between early-stage (technologies in development) and late-stage economic evaluations (technologies ready to enter the market). Importantly, the level of uncertainty during the early stages of development is generally higher. Some uncertainties can be resolved as development proceeds: new evidence can arise, for example, as the developer or others from the research field conduct studies. Due to this uncertainty, some elements of economic evaluation are especially important in early-stage assessments. Experts may play a larger role in informing input parameters, as clinical data are frequently lacking. ${ }^{164,167}$ Also, there is an important role for value of 
information. ${ }^{164,168,169}$ Value-of-information (VOI) analysis is a method used to estimate the value of collecting more information for the decision-maker. ${ }^{170}$ This information can reduce uncertainty and consequently the probability of making the wrong decision. In early-stage economic evaluation, VOI analysis can be used to assess which uncertainties carry the most risk (which information has the highest value), and allocate resources to resolve some of that uncertainty, if possible. ${ }^{168}$ Once new information becomes available, and uncertainty is reduced, the economic evaluation of development could (and should) be updated. As such, as opposed to late-stage economic evaluations, which are often considered as a 'one-time' assessment, early-stage evaluations are more iterative and can be conducted in parallel with the development of technology. ${ }^{164,169,171-173}$ Consequently, economic evaluations during the early stages of development can have a significant influence on the (future) clinical performance of the technology, whereas in late-stage economic evaluations the specifications and performance of the technology are final. ${ }^{165,169}$ In order to guide early economic evaluation, several frameworks have been developed. ${ }^{164,168,171,172,174}$ Frequently, the developer's perspective is adopted in these frameworks. For the developer, who usually has a technology in development, the essential factor is the foreseen application of their technology in daily practice (its role in the care pathway). ${ }^{164,175}$ Alternatively, from the societal (and clinical) perspective, there is usually a clinical problem that needs to be solved, for which one or several (competing) technologies are, or could become, available. This needs-driven approach to innovation is often overlooked in early HTA, yet the potential value of a technology largely depends on it solving a relevant problem. ${ }^{169}$

A commonly used method in early HTA is the headroom method. ${ }^{174}$ The headroom method evaluates the cost-effectiveness of a new diagnostic or intervention technology compared to/in addition to current gold standard technology, by defining a maximum cost (the headroom) acceptable to the adopter of the technology. If a new technology already has a minimum cost, the required diagnostic performance for this technology to be cost-effective could be assessed. The headroom method has already been used in rheumatology. One study investigated the early-stage cost-effectiveness of four diagnostic tests in patients with inflammatory arthritis who were suspected of having RA, from a societal perspective over a 1-year time horizon. ${ }^{176}$ Both existing (MRI of hands and feet) and new technologies (interleukin- 6 serum levels test, B cell-related gene expression and a gene assay for RA) were included. These technologies were primarily considered as add-on tests for diagnosis, i.e. used in addition to the classification criteria for RA, ${ }^{177}$ with diagnosis based on the classification criteria as comparator. The available headroom, which ranged from €151 to €369 depending on the test and the subgroup in which the test was used, was higher than the costs of some of the tests, indicating that adding these would be cost-effective. The model was later extended with a state-transition model and a time horizon of 5 years, leading to similar results. ${ }^{178}$ Currently, there are no published early-stage economic evaluations, using the headroom or other early HTA methods, in 
axSpA. Of note, matters of confidentiality and intellectual property could have prevented publication of such studies. ${ }^{163}$

\section{Early recognition and diagnosis of axSpA - room for improvement}

Timely recognition and diagnosis of axSpA is a clinical challenge, resulting in a delay between onset of symptoms and diagnosis. ${ }^{179}$ This delay in diagnosis can be attributed to a delay in referral from non-rheumatologists to rheumatologists, and to misdiagnosis by rheumatologists. Efforts to reduce this delay have resulted in referral strategies for non-rheumatologists and diagnostic algorithms for rheumatologists. ${ }^{156,180-187}$ In the costeffectiveness analysis in this thesis, which was the first economic evaluation of diagnosis of axSpA in the rheumatology setting (Chapter 8), the focus was on the diagnostic algorithms. The M2 algorithm was most cost-effective, although there was still considerable room for improvement in terms of cost-effectiveness. This is fortunate, as the M2 algorithm is far from perfect. With an axSpA subtype-weighted sensitivity of $80 \%$ and specificity of $85 \%$, 1 in 6 referred patients would be misdiagnosed if $M 2$ is applied. A perfect diagnosis could cost almost an additional $€ 7,500$ while remaining cost-effective (the headroom for a perfect test). However, the scenario of a perfect diagnosis will likely never become reality, at least not in the foreseeable future, so the question would be: in what ways can diagnosis of axSpA realistically be improved, using available and (currently) experimental technology, and how much can society afford to do so? Ideally, with several experimental diagnostic technologies in the development pipeline, only those technologies that hold promise (are expected to result in value) would be funded. These technologies could be either implemented as an 'add-on test', i.e. combined with (parts of) a diagnostic algorithm, or as a 'replacement test', effectively replacing diagnostic algorithms. As the study in this thesis revealed that either increasing sensitivity or specificity of M2 would increase value in terms of costs and/or effects, both sensitive and specific add-on tests could be worth pursuing.

For the selection and evaluation of a potential add-on test, $\mathrm{M} 2$ would be the starting point. The first step would be to identify where, in the M2 algorithm, there is a 'need' for improvement. In other words, which 'diagnostic (sub)groups' have the potential for gains in value if diagnostic accuracy is improved. The term 'diagnostic subgroup' in this context refers to a subpopulation of cases who share certain diagnostic characteristics used in the algorithm (e.g. number of axSpA features, or HLA-B27 positivity), thus following the same path in the decision tree of the algorithm. Identification of these diagnostic subgroups is essential, as it will determine where to position add-on tests. Relevant subgroup factors for this decision will be the current diagnostic accuracy in the subgroup, number of cases (volume), specific case-mix within a subgroup, the diagnostic cost incurred by the subgroup (costs of the add-on test) and the relative costs and effects of axSpA and CLBP cases in the subgroup. 
Scrutinizing M2, there are two diagnostic subgroups in particular that could be improved. First, one could consider the subgroup with no signs of sacroiliitis on conventional radiography of the sacroiliac joints (negative XRAY-SI), 2-3 SpA features and a negative HLA-B27 test. These cases are labelled by M2 as 'no axSpA', yet 15\% of these actually do have axSpA according to the rheumatologist (false negatives). This subgroup accounts for over $70 \%$ of all underdiagnosis of axSpA in M2. Alternatively, there is the subgroup with a negative XRAY-SI and at least 4 SpA features. This subgroup is labelled as 'axSpA' by M2, although around $30 \%$ actually do not have axSpA (false positives). This subgroup accounts for $50 \%$ of all overdiagnosis of axSpA in M2. Add-on tests in either of these subgroups could help reduce under- or overdiagnosis. Finally, an add-on test could be applied to multiple subgroups simultaneously, for example to all cases labelled as 'axSpA'.

The next step would be to evaluate possible add-on tests with characteristics that fit these subgroups. The headroom method could be used for this, as a means to either find the maximum acceptable cost of the test, or the required diagnostic accuracy if a minimum cost is already known. In addition, VOI analysis would be insightful to identify which aspects of possible add-on tests, and of axSpA, need additional research. As a first step, changes in the use of the currently available diagnostic tests in M2 could be evaluated. For example, MRI of the sacroiliac joints (MRI-SI) is not used in either of the subgroups described above. Addition of MRI-SI to these subgroups would increase costs, but could potentially reduce misdiagnosis. Alternatively, MRI-SI could replace, or be combined with, HLA-B27. These modifications might have already been investigated as part of the original development of this algorithm, but not from an economic perspective. On the one hand, cost-effectiveness of these types of modifications would be easy to investigate, as data on the test characteristics and the consequences of their use for the case-mix are available. On the other hand, the potential gains of this analysis might be limited, as these technologies have already been fully developed and implemented in daily practice. More interesting are new diagnostic technologies that are not yet used in M2. These technologies could be added to the algorithm as separate steps or as replacement of the diagnostics in place (XRAY-SI, HLA-B27, MRI-SI). Candidate technologies are biomarkers that are currently experimental or in development. Examples are antibody-based biomarkers, such as anti-CD74 antibodies, and genetic biomarkers (micro-RNAs). ${ }^{188,189}$ These have shown varying diagnostic accuracy in research settings, and if applied in certain subgroups could potentially add value. Such modifications would be challenging to investigate: the data on these technologies are limited, and the applicability of experimental results to practice is unclear. The potential gains (or reductions in losses) of making the right decisions on further research on these technologies would be high, however, as some of these techniques have not yet been fully developed, and none of them have been implemented in daily practice. There is always a trade-off between the level of certainty (generally higher if decision is made at a later stage) and potential gains (generally higher if decision is made 
at an earlier stage), but early economic evaluation can help direct this trade-off by focusing resources on those uncertainties that mostly affect gains. Sensitivity and scenario analyses in these evaluations could help assess the impact of uncertainty and identify impactful gaps in knowledge on these technologies. These gaps could be addressed, resolving some of these uncertainties, and the evaluation could be updated.

Instead of add-on tests, new technologies can also be evaluated as replacement tests, thus replacing $\mathrm{M} 2$ as a whole, although this approach would be mainly hypothetical. The heterogeneity of axSpA is unlikely to be captured in a singly technology, as exemplified by the current use of multiple technologies in M2. A new diagnostic test is unlikely to either be more accurate than $\mathrm{M} 2$, or be inexpensive enough to justify a lower accuracy. To illustrate the latter: if $\mathrm{M} 2$ would be replaced with a hypothetical new diagnostic test with zero cost and only $1 \%$ lower sensitivity and specificity, this test would not be cost-effective.

Above, the discussion focused on the diagnostic accuracy of the rheumatologist. As an alternative approach, patient referral from non-rheumatologists could be improved, for example by implementing a referral strategy. This would be less of an early economic evaluation, as no specific technologies are involved that are still in development, but relevant nonetheless. An important limitation in the existing evidence on referral strategies is that in most studies only the referred population was assessed for axSpA. ${ }^{181,183,184,187}$ This precludes firm conclusions on the number and characteristics of especially the false negatives, i.e. the axSpA cases missed by the referrer. Either additional studies in non-selected CLBP samples, or several assumptions on the false negative population in particular, are necessary to investigate cost-effectiveness of referral strategies. Such studies in CLBP would be costly and time-consuming. Existing studies on referral strategies rarely provide data on the total number of patients screened for referral, with some exceptions. ${ }^{185,190}$ The prevalence of axSpA in CLBP populations in primary care is often assumed to be around 5\%, although higher estimates have been reported. ${ }^{184,190-192}$ This estimate indicates that large CLBP populations would have to be included in referral studies to reach sufficient numbers of CLBP and axSpA cases. It also demonstrates the challenge of improving referral without overburdening rheumatologists.

Regardless, if referral would be optimized - by improving sensitivity, specificity or both - the referred population seen by the rheumatologist would change. Changes in the casemix could render $\mathrm{M} 2$ less accurate, a variation of the spectrum effect.193 This interplay between referral and diagnosis is highly relevant, but is yet to be investigated in axSpA. In the only economic evaluation of referral of axSpA to date, the diagnosis following referral was assumed to be perfect. ${ }^{194}$ This makes sense from a methodological perspective, as focusing the analysis on one part of the 'referral-diagnosis chain' is likely more feasible. For the cost-effectiveness analysis in this thesis, we also deemed analyzing a combination 
of referral and diagnosis too complex as a first step. However, it cannot be ignored that, in practice, referral will affect diagnosis and subsequent treatment.

Concluding remarks on early economic evaluations and diagnosis of axSpA

Currently, different opportunities to improve recognition and diagnosis of axSpA are being pursued. As funding is limited, choices have to be made. Which approaches are worth it, and which are not? Or better put: how can these approaches be changed to make them worth it? Above, it was explored how early-stage economic evaluation could be used to guide research on this topic. Although a promising tool to help guide allocation of (human and financial) resources, early-stage health economic modelling has yet to become part of 'mainstream' health economics in rheumatology. In the above review of the challenges of these studies, the matter of uncertainty was also discussed. The informative value of uncertainty for research is often neglected or even opposed. Uncertainty is often linked to relevant clinical questions, however, and insight into uncertainties can help prioritize clinical and epidemiological research and set a research agenda. Uncertainty should not be rejected, but embraced.

Although the discussion above was limited to diagnosis, similar principles would apply to other domains, such as prevention or treatment. Going forward, comparisons between potential investments do not need to be limited to one domain. For example, in axSpA, one could compare improvement in diagnosis with better prediction of bDMARD treatment response: both outcomes could be achieved with new technologies, but which of the two would result in more value for society? Such questions are highly relevant, as research budgets are limited, and funders need to make targeted investments. The public and private sector could seek to collaborate on this matter, to promote needs-driven innovation, and together try to overcome barriers (such as confidentiality) to successful early HTA. As with economic evaluations in general, transparency in the methodology and results would be essential, not only to inform the decision-makers, but also to support the credibility and acceptance of these type of studies among care providers, patients and the general public.

\section{Recommendations for future research}

In this chapter, a summary was provided of the studies in this thesis, and the findings were discussed in a broader context. These studies, on several health and economic outcomes in axSpA, have added new insights to the existing body of evidence in axSpA, but also helped identify gaps in the current knowledge and prompted new research questions. Below, the recommendations for future research are briefly summarized.

From the patient perspective, first there is a need for observational research on the performance of current screening instruments for depression in axSpA, using physician- 
diagnosed depression as the external standard to avoid misclassification with regard to such diagnosis. Such studies have been conducted in other RMDs, but not in axSpA. Currently, it remains unclear to what extent these instruments actually reflect depression and depressive symptoms in axSpA. Second, in order to further elucidate pathogenesis of comorbid depression, additional research is necessary on both contextual factors and new biomarkers (non-CRP biomarkers in peripheral blood, inflammatory markers in cerebrospinal fluid, functional MRI and PET-CT) in axSpA patients, with and without depressive symptoms or depression. Preferably, these would be longitudinal studies, so that changes in potential determinants can be linked to changes in depressive symptoms. Third and finally, there is a need for interventional studies on the efficacy of conventional antidepressants and non-pharmacological treatment (aimed at improving self-efficacy or mastery) for comorbid depression in axSpA. These studies could provide insight into the underlying mechanisms of comorbid depression, while also help guide treatment for depressed patients with axSpA in practice. The primary outcome in these studies should be depression or depressive symptoms, and essential aspects of their design include systematic collection of both axSpA-specific outcomes and psychological outcomes (depressive symptoms, mastery or similar construct) over time, pre-defined subgroup analyses for those with or without signs of inflammatory depression and proper adjustment for any concomitant use of anti-inflammatory treatments.

From the societal perspective, first there is a need for observational and interventional studies to gather information on the measurement properties of existing instruments for presenteeism, and to identify which of these most accurately measure actual changes in productivity. A better accuracy of estimates of (changes in) presenteeism would benefit both interventional studies targeting presenteeism as outcome, as well as cost-effectiveness studies. Second, the existing methods to account for multiplier and compensation effects need to be validated, using either input from employers or objective measures if available. In addition, once validated, country- and work-specific estimates of these effects are necessary. Third, research that uses unselected primary care CLBP samples to simulate referral strategies and subsequent diagnosis of axSpA would greatly inform society on the interplay between referral and diagnosis, and on the patients that are usually not assessed (false negatives). The results could guide development or finetuning of referral strategies, and serve as inputs for economic evaluations. These economic evaluations would simulate referral strategies followed by both perfect and imperfect diagnosis. Fourth and finally, biomarkers that are currently in development should be assessed as add-on or replacement tests for diagnosis of axSpA in early-stage economic evaluations. An important part of these evaluations would be uncertainty and value of information analyses. The results could help set priorities for research funding and guide development decisions. 


\section{References}

1. World Health Organization. International classification of functioning, disability and health: ICF. Geneva: World Health Organization; 2001.

2. Boel A, Molto A, van der Heijde D, Ciurea A, Dougados M, Gensler LS, et al. Do patients with axial spondyloarthritis with radiographic sacroiliitis fulfil both the modified New York criteria and the ASAS axial spondyloarthritis criteria? Results from eight cohorts. Ann Rheum Dis 2019;78:1545-1549.

3. Zhao S, Thong D, Miller N, Duffield SJ, Hughes DM, Chadwick L, et al. The prevalence of depression in axial spondyloarthritis and its association with disease activity: a systematic review and meta-analysis. Arthritis Res Ther 2018;20:140.

4. Martindale J, Smith J, Sutton CJ, Grennan D, Goodacre L, Goodacre JA. Disease and psychological status in ankylosing spondylitis. Rheumatology (Oxford) 2006;45:1288-1293.

5. Dantzer R, O'Connor JC, Freund GG, Johnson RW, Kelley KW. From inflammation to sickness and depression: when the immune system subjugates the brain. Nat Rev Neurosci 2008;9:46-56.

6. Miller $\mathrm{AH}$, Raison $\mathrm{CL}$. The role of inflammation in depression: from evolutionary imperative to modern treatment target. Nat Rev Immunol 2016;16:22-34.

7. Jiang Y, Yang M, LV Q, Qi J, Lin Z, Liao Z, et al. Prevalence of psychological disorders, sleep disturbance and stressful life events and their relationships with disease parameters in Chinese patients with ankylosing spondylitis. Clin Rheumatol 2018;37:407-414.

8. Xu X, Shen B, Zhang A, Liu J, Da Z, Liu H, et al. Anxiety and depression correlate with disease and quality-of-life parameters in Chinese patients with ankylosing spondylitis. Patient Prefer Adherence 2016;10:879-885.

9. Zou Q, Jiang Y, Mu F, Shi Y, Fang Y. Correlation of Axial Spondyloarthritis with Anxiety and Depression. Med Sci Monit 2016;22:3202-3208.

10. Baysal O, Durmus B, Ersoy Y, Altay Z, Senel K, Nas K, et al. Relationship between psychological status and disease activity and quality of life in ankylosing spondylitis. Rheumatol Int 2011;31:795-800.

11. Kilic G, Kilic E, Ozgocmen S. Relationship between psychiatric status, self-reported outcome measures, and clinical parameters in axial spondyloarthritis. Medicine (Baltimore) 2014;93:e337.

12. Blalock SJ, DeVellis RF, Brown GK, Wallston KA. Validity of the Center for Epidemiological Studies Depression Scale in arthritis populations. Arthritis Rheum 1989;32:991-997.

13. Hu J, Ward MM. Screening for depression in arthritis populations: an assessment of differential item functioning in three self-reported questionnaires. Qual Life Res 2017;26:2507-2517.

14. Ensel WM. 4 - Measuring Depression: The CES-D Scale. In: Lin N, Dean A, Ensel WM. Social Support, Life Events, and Depression. Orlando: Academic Press 1986: 51-70.

15. Carleton RN, Thibodeau MA, Teale MJ, Welch PG, Abrams MP, Robinson T, et al. The center for epidemiologic studies depression scale: a review with a theoretical and empirical examination of item content and factor structure. PLoS One 2013;8:e58067.

16. Nerurkar L, Siebert S, Mclnnes IB, Cavanagh J. Rheumatoid arthritis and depression: an inflammatory perspective. The Lancet Psychiatry 2019;6:164-173. 
17. Husted JA, Tom BD, Farewell VT, Gladman DD. Longitudinal study of the bidirectional association between pain and depressive symptoms in patients with psoriatic arthritis. Arthritis Care Res (Hoboken) 2012;64:758-765.

18. Rathbun AM, Reed GW, Harrold LR. The temporal relationship between depression and rheumatoid arthritis disease activity, treatment persistence and response: a systematic review. Rheumatology (Oxford) 2013;52:1785-1794.

19. Disner SG, Beevers CG, Haigh EA, Beck AT. Neural mechanisms of the cognitive model of depression. Nat Rev Neurosci 2011;12:467-477.

20. Gotlib IH, Joormann J. Cognition and depression: current status and future directions. Annu Rev Clin Psychol 2010;6:285-312.

21. Cordingley L, Prajapati R, Plant D, Maskell D, Morgan C, Ali FR, et al. Impact of psychological factors on subjective disease activity assessments in patients with severe rheumatoid arthritis. Arthritis Care Res (Hoboken) 2014;66:861-868.

22. Jensen KB, Petzke F, Carville S, Fransson P, Marcus H, Williams SC, et al. Anxiety and depressive symptoms in fibromyalgia are related to poor perception of health but not to pain sensitivity or cerebral processing of pain. Arthritis Rheum 2010;62:3488-3495.

23. Michelsen B, Kristianslund EK, Sexton J, Hammer HB, Fagerli KM, Lie E, et al. Do depression and anxiety reduce the likelihood of remission in rheumatoid arthritis and psoriatic arthritis? Data from the prospective multicentre NOR-DMARD study. Ann Rheum Dis 2017;76:1906-1910.

24. Kekow J, Moots R, Khandker R, Melin J, Freundlich B, Singh A. Improvements in patient-reported outcomes, symptoms of depression and anxiety, and their association with clinical remission among patients with moderate-to-severe active early rheumatoid arthritis. Rheumatology (Oxford) 2011;50:401-409.

25. Sheehan AM, McGee H. Screening for depression in medical research: ethical challenges and recommendations. BMC Med Ethics 2013;14:4.

26. Pearlin LI, Lieberman MA, Menaghan EG, Mullan JT. The stress process. J Health Soc Behav 1981;22:337-356.

27. Taylor SE, Stanton AL. Coping resources, coping processes, and mental health. Annu Rev Clin Psychol 2007;3:377-401.

28. Ross CE, Mirowsky J. The Sense of Personal Control: Social Structural Causes and Emotional Consequences. In: Aneshensel CS, Phelan JC, Bierman A. Handbook of the Sociology of Mental Health. Dordrecht: Springer Netherlands 2013: 379-402.

29. Lachman ME, Neupert SD, Agrigoroaei S. The relevance of control beliefs for health and aging. Handbook of the psychology of aging, 7th ed. San Diego, CA, US: Elsevier Academic Press 2011: 175-190.

30. Pearlin LI, Nguyen KB, Schieman S, Milkie MA. The life-course origins of mastery among older people. J Health Soc Behav 2007;48:164-179.

31. Skaff MM, Pearlin LI, Mullan JT. Transitions in the caregiving career: effects on sense of mastery. Psychol Aging 1996;11:247-257.

32. Bandura A. Self-efficacy: toward a unifying theory of behavioral change. Psychol Rev 1977;84:191-215. 
33. Shaul MP. From early twinges to mastery: the process of adjustment in living with rheumatoid arthritis. Arthritis Care Res 1995;8:290-297.

34. Stamm T, Lovelock L, Stew G, Nell V, Smolen J, Jonsson H, et al. I have mastered the challenge of living with a chronic disease: life stories of people with rheumatoid arthritis. Qual Health Res 2008;18:658-669.

35. Cott CA, Gignac MA, Badley EM. Determinants of self rated health for Canadians with chronic disease and disability. J Epidemiol Community Health 1999;53:731-736.

36. Surtees PG, Wainwright NW, Luben R, Khaw KT, Day NE. Mastery, sense of coherence, and mortality: evidence of independent associations from the EPIC-Norfolk Prospective Cohort Study. Health Psychol 2006;25:102-110.

37. Bosma H, Schrijvers $\mathrm{C}$, Mackenbach JP. Socioeconomic inequalities in mortality and importance of perceived control: cohort study. BMJ 1999;319:1469-1470.

38. Penninx BW, van Tilburg T, Kriegsman DM, Deeg DJ, Boeke AJ, van Eijk JT. Effects of social support and personal coping resources on mortality in older age: the Longitudinal Aging Study Amsterdam. Am J Epidemiol 1997;146:510-519.

39. Ward MM. Sense of control and sociodemographic differences in self-reported health in older adults. Qual Life Res 2012;21:1509-1518.

40. Bosma H, Van Jaarsveld CH, Tuinstra J, Sanderman R, Ranchor AV, Van Eijk JT, et al. Low control beliefs, classical coronary risk factors, and socio-economic differences in heart disease in older persons. Soc Sci Med 2005;60:737-745.

41. Pudrovska T, Schieman S, Pearlin LI, Nguyen K. The sense of mastery as a mediator and moderator in the association between economic hardship and health in late life. J Aging Health 2005; 17:634-660.

42. Morris A, Yelin EH, Wong B, Katz PP. Patterns of psychosocial risk and long-term outcomes in rheumatoid arthritis. Psychol Health Med 2008;13:529-544.

43. Mausbach BT, Patterson TL, Von Kanel R, Mills PJ, Dimsdale JE, Ancoli-Israel S, et al. The attenuating effect of personal mastery on the relations between stress and Alzheimer caregiver health: a five-year longitudinal analysis. Aging Ment Health 2007;11:637-644.

44. Mingo CA, Mcllvane JM, Baker TA. Explaining the relationship between pain and depressive symptoms in African-American and white women with arthritis. J Natl Med Assoc 2008;100:996-1003.

45. Gadalla TM. Determinants, correlates and mediators of psychological distress: a longitudinal study. Soc Sci Med 2009;68:2199-2205.

46. Infurna FJ, Okun MA. Antecedents and outcomes of level and rates of change in perceived control: The moderating role of age. Dev Psychol 2015;51:1420-1437.

47. Younger J, Finan P, Zautra A, Davis M, Reich J. Personal mastery predicts pain, stress, fatigue, and blood pressure in adults with rheumatoid arthritis. Psychol Health 2008;23:515-535.

48. Meesters JJ, Bremander A, Bergman S, Petersson IF, Turkiewicz A, Englund M. The risk for depression in patients with ankylosing spondylitis: a population-based cohort study. Arthritis Res Ther 2014;16:418. 
49. Mirowsky J, Ross Catherine E. Life Course Trajectories of Perceived Control and Their Relationship to Education. American Journal of Sociology 2007;112:1339-1382.

50. Cairney J, Krause N. Negative life events and age-related decline in mastery: are older adults more vulnerable to the control-eroding effect of stress? J Gerontol B Psychol Sci Soc Sci 2008;63:S162-170.

51. Penninx BW, Beekman AT, Ormel J, Kriegsman DM, Boeke AJ, van Eijk JT, et al. Psychological status among elderly people with chronic diseases: does type of disease play a part? J Psychosom Res 1996;40:521-534.

52. Gignac MA. An evaluation of a psychotherapeutic group intervention for persons having difficulty coping with musculoskeletal disorders. Soc Work Health Care 2000;32:57-75.

53. Eizenman DR, Nesselroade JR, Featherman DL, Rowe JW. Intraindividual variability in perceived control in an older sample: the MacArthur successful aging studies. Psychol Aging 1997;12:489-502.

54. Taylor SE. Adjustment to threatening events: A theory of cognitive adaptation. Am Psychol 1983;38:1161-1173.

55. Sturgeon JA, Finan PH, Zautra AJ. Affective disturbance in rheumatoid arthritis: psychological and disease-related pathways. Nat Rev Rheumatol 2016;12:532-542.

56. Prothero L, Barley E, Galloway J, Georgopoulou S, Sturt J. The evidence base for psychological interventions for rheumatoid arthritis: A systematic review of reviews. Int J Nurs Stud 2018;82:20-29.

57. Iversen MD, Hammond A, Betteridge N. Self-management of rheumatic diseases: state of the art and future perspectives. Ann Rheum Dis 2010;69:955-963.

58. Zangi HA, Ndosi M, Adams J, Andersen L, Bode C, Bostrom C, et al. EULAR recommendations for patient education for people with inflammatory arthritis. Ann Rheum Dis 2015;74:954-962.

59. van Genderen S, Plasqui G, Landewe R, Lacaille D, Arends S, van Gaalen F, et al. Social Role Participation in Patients With Ankylosing Spondylitis: A Cross-Sectional Comparison With Population Controls. Arthritis Care Res (Hoboken) 2016;68:1899-1905.

60. van der Heijde D, Ramiro S, Landewe R, Baraliakos X, Van den Bosch F, Sepriano A, et al. 2016 update of the ASAS-EULAR management recommendations for axial spondyloarthritis. Ann Rheum Dis 2017;76:978-991.

61. DiRenzo D, Crespo-Bosque M, Gould N, Finan P, Nanavati J, Bingham CO, 3rd. Systematic Review and Meta-analysis: Mindfulness-Based Interventions for Rheumatoid Arthritis. Curr Rheumatol Rep 2018;20:75.

62. Primdahl J, Wagner L, Horslev-Petersen K. Self-efficacy as an outcome measure and its association with physical disease-related variables in persons with rheumatoid arthritis: a literature review. Musculoskeletal Care 2011;9:125-140.

63. Kendler KS, Gardner CO, Prescott CA. Toward a comprehensive developmental model for major depression in men. Am J Psychiatry 2006;163:115-124.

64. Kendler KS, Gardner CO, Prescott CA. Toward a comprehensive developmental model for major depression in women. Am J Psychiatry 2002;159:1133-1145.

65. Raison CL, Lowry CA, Rook GA. Inflammation, sanitation, and consternation: loss of contact with coevolved, tolerogenic microorganisms and the pathophysiology and treatment of major depression. Arch Gen Psychiatry 2010;67:1211-1224. 
66. Stahl SM. Stahl's essential psychopharmacology: Neuroscientific basis and practical applications, 4th ed. New York, NY, US: Cambridge University Press; 2013.

67. Dowlati Y, Herrmann N, Swardfager W, Liu H, Sham L, Reim EK, et al. A meta-analysis of cytokines in major depression. Biol Psychiatry 2010;67:446-457.

68. Howren MB, Lamkin DM, Suls J. Associations of depression with C-reactive protein, IL-1, and IL-6: a meta-analysis. Psychosom Med 2009;71:171-186.

69. Gimeno D, Kivimaki M, Brunner EJ, Elovainio M, De Vogli R, Steptoe A, et al. Associations of C-reactive protein and interleukin-6 with cognitive symptoms of depression: 12-year follow-up of the Whitehall II study. Psychol Med 2009;39:413-423.

70. Duivis HE, de Jonge P, Penninx BW, Na BY, Cohen BE, Whooley MA. Depressive symptoms, health behaviors, and subsequent inflammation in patients with coronary heart disease: prospective findings from the heart and soul study. Am J Psychiatry 2011;168:913-920.

71. Au B, Smith KJ, Gariepy G, Schmitz N. The longitudinal associations between C-reactive protein and depressive symptoms: evidence from the English Longitudinal Study of Ageing (ELSA). Int J Geriatr Psychiatry 2015;30:976-984.

72. Wium-Andersen MK, Orsted DD, Nielsen SF, Nordestgaard BG. Elevated C-reactive protein levels, psychological distress, and depression in 73, 131 individuals. JAMA Psychiatry 2013;70:176-184.

73. Uguz F, Kucuk A, Aydogan S, Arslan S, Kurt HG, Toker A, et al. Is major depression associated with serum levels of tumor necrosis factor-alpha in patients with rheumatoid arthritis? J Psychosom Res 2015;79:530-532.

74. Cheon YH, Lee SG, Kim M, Kim HO, Sun Suh Y, Park KS, et al. The association of disease activity, pro-inflammatory cytokines, and neurotrophic factors with depression in patients with rheumatoid arthritis. Brain Behav Immun 2018;73:274-281.

75. Choy EHS, Calabrese LH. Neuroendocrine and neurophysiological effects of interleukin 6 in rheumatoid arthritis. Rheumatology (Oxford) 2018;57:1885-1895.

76. Liu Y, Ho RC, Mak A. The role of interleukin (IL)-17 in anxiety and depression of patients with rheumatoid arthritis. Int J Rheum Dis 2012;15:183-187.

77. Li YC, Chou YC, Chen HC, Lu CC, Chang DM. Interleukin-6 and interleukin-17 are related to depression in patients with rheumatoid arthritis. Int J Rheum Dis 2019;22:980-985.

78. Cattaneo A, Gennarelli M, Uher R, Breen G, Farmer A, Aitchison KJ, et al. Candidate genes expression profile associated with antidepressants response in the GENDEP study: differentiating between baseline 'predictors' and longitudinal 'targets'. Neuropsychopharmacology 2013;38:377-385.

79. Chamberlain SR, Cavanagh J, de Boer P, Mondelli V, Jones DNC, Drevets WC, et al. Treatmentresistant depression and peripheral C-reactive protein. Br J Psychiatry 2019;214:11-19.

80. Koh WH, Pande I, Samuels A, Jones SD, Calin A. Low dose amitriptyline in ankylosing spondylitis: a short term, double blind, placebo controlled study. J Rheumatol 1997;24:2158-2161.

81. Fiest KM, Hitchon CA, Bernstein CN, Peschken CA, Walker JR, Graff LA, et al. Systematic Review and Meta-analysis of Interventions for Depression and Anxiety in Persons With Rheumatoid Arthritis. J Clin Rheumatol 2017;23:425-434. 
82. Richards BL, Whittle SL, Buchbinder R. Antidepressants for pain management in rheumatoid arthritis. Cochrane Database Syst Rev 2011CD008920.

83. Rayner L, Price A, Evans A, Valsraj K, Higginson IJ, Hotopf M. Antidepressants for depression in physically ill people. Cochrane Database Syst Rev 2010CD007503.

84. Sparks JA, Malspeis S, Hahn J, Wang J, Roberts AL, Kubzansky LD, et al. Depression and subsequent risk for incident rheumatoid arthritis among women. Arthritis Care Res (Hoboken) 2020.

85. Vallerand IA, Lewinson RT, Frolkis AD, Lowerison MW, Kaplan GG, Swain MG, et al. Depression as a risk factor for the development of rheumatoid arthritis: a population-based cohort study. RMD Open 2018;4:e000670.

86. Rathbun AM, Harrold LR, Reed GW. Temporal effect of depressive symptoms on the longitudinal evolution of rheumatoid arthritis disease activity. Arthritis Care Res (Hoboken) 2015;67:765-775.

87. Matcham F, Norton S, Scott DL, Steer S, Hotopf M. Symptoms of depression and anxiety predict treatment response and long-term physical health outcomes in rheumatoid arthritis: secondary analysis of a randomized controlled trial. Rheumatology (Oxford) 2016;55:268-278.

88. Matcham F, Davies R, Hotopf M, Hyrich KL, Norton S, Steer S, et al. The relationship between depression and biologic treatment response in rheumatoid arthritis: An analysis of the British Society for Rheumatology Biologics Register. Rheumatology (Oxford) 2018;57:835-843.

89. Brenner P, Citarella A, Wingard L, Sundstrom A. Use of antidepressants and benzodiazepinerelated hypnotics before and after initiation of TNF-alpha inhibitors or non-biological systemic treatment in patients with rheumatoid arthritis, psoriatic arthritis or ankylosing spondylitis. BMC Rheumatol 2020;4:9.

90. Bournia VK, Tektonidou MG, Vassilopoulos D, Laskari K, Panopoulos S, Fragiadaki K, et al. Introduction and switching of biologic agents are associated with antidepressant and anxiolytic medication use: data on 42815 real-world patients with inflammatory rheumatic disease. RMD Open 2020;6.

91. Arisoy O, Bes C, Cifci C, Sercan M, Soy M. The effect of TNF-alpha blockers on psychometric measures in ankylosing spondylitis patients: a preliminary observation. Rheumatol Int 2013;33:1855-1864.

92. Ertenli I, Ozer S, Kiraz S, Apras SB, Akdogan A, Karadag O, et al. Infliximab, a TNF-alpha antagonist treatment in patients with ankylosing spondylitis: the impact on depression, anxiety and quality of life level. Rheumatol Int 2012;32:323-330.

93. Ersozlu-Bozkirli ED, Keskek SO, Bozkirli E, Yucel AE. The effect of infliximab on depressive symptoms in patients with ankylosing spondylitis. Acta Reumatol Port 2015;40:262-267.

94. Dougados M, Tsai WC, Saaibi DL, Bonin R, Bukowski J, Pedersen R, et al. Evaluation of Health Outcomes with Etanercept Treatment in Patients with Early Nonradiographic Axial Spondyloarthritis. J Rheumatol 2015;42:1835-1841.

95. van der Heijde D, Braun J, Dougados M, Sieper J, Pedersen R, Szumski A, et al. Sensitivity and discriminatory ability of the Ankylosing Spondylitis Disease Activity Score in patients treated with etanercept or sulphasalazine in the ASCEND trial. Rheumatology (Oxford) 2012;51:1894-1905. 
96. Felger JC, Haroon E, Patel TA, Goldsmith DR, Wommack EC, Woolwine BJ, et al. What does plasma CRP tell us about peripheral and central inflammation in depression? Mol Psychiatry 2020;25:1301-1311.

97. Leighton SP, Nerurkar L, Krishnadas R, Johnman C, Graham GJ, Cavanagh J. Chemokines in depression in health and in inflammatory illness: a systematic review and meta-analysis. $\mathrm{Mol}$ Psychiatry 2018;23:48-58.

98. Raison CL, Rutherford RE, Woolwine BJ, Shuo C, Schettler P, Drake DF, et al. A randomized controlled trial of the tumor necrosis factor antagonist infliximab for treatment-resistant depression: the role of baseline inflammatory biomarkers. JAMA Psychiatry 2013;70:31-41.

99. Haroon E, Fleischer CC, Felger JC, Chen X, Woolwine BJ, Patel T, et al. Conceptual convergence: increased inflammation is associated with increased basal ganglia glutamate in patients with major depression. Mol Psychiatry 2016;21:1351-1357.

100. Felger JC, Li Z, Haroon E, Woolwine BJ, Jung MY, Hu X, et al. Inflammation is associated with decreased functional connectivity within corticostriatal reward circuitry in depression. Mol Psychiatry 2016;21:1358-1365.

101. Marin I, Kipnis J. Learning and memory ... and the immune system. Learn Mem 2013;20:601-606.

102. Ostergaard SD, Jensen SO, Bech P. The heterogeneity of the depressive syndrome: when numbers get serious. Acta Psychiatr Scand 2011;124:495-496.

103. Kappelmann N, Lewis G, Dantzer R, Jones PB, Khandaker GM. Antidepressant activity of anti-cytokine treatment: a systematic review and meta-analysis of clinical trials of chronic inflammatory conditions. Mol Psychiatry 2018;23:335-343.

104. Matcham F, Galloway J, Hotopf M, Roberts E, Scott IC, Steer S, et al. The Impact of Targeted Rheumatoid Arthritis Pharmacologic Treatment on Mental Health: A Systematic Review and Network Meta-Analysis. Arthritis Rheumatol 2018;70:1377-1391.

105. Nicassio PM. The problem of detecting and managing depression in the rheumatology clinic. Arthritis Rheum 2008;59:155-158.

106. Baillet $A$, Gossec $L$, Carmona L, Wit M, van Eijk-Hustings $Y$, Bertheussen $H$, et al. Points to consider for reporting, screening for and preventing selected comorbidities in chronic inflammatory rheumatic diseases in daily practice: a EULAR initiative. Ann Rheum Dis 2016;75:965-973.

107. Rodrigues Manica S, Sepriano A, Ramiro S, Pimentel Santos F, Putrik P, Nikiphorou E, et al. Work participation in spondyloarthritis across countries: analysis from the ASAS-COMOSPA study. Ann Rheum Dis 2018;77:1303-1310.

108. Castillo-Ortiz JD, Ramiro S, Landewe R, van der Heijde D, Dougados M, van den Bosch F, et al. Work Outcome in Patients With Ankylosing Spondylitis: Results From a 12-Year Followup of an International Study. Arthritis Care Res (Hoboken) 2016;68:544-552.

109. van der Weijden MA, Boonen A, van der Horst-Bruinsma IE. Problems in work participation and resource use should not be underestimated in patients with early spondyloarthritis. J Rheumatol 2014;41:2413-2420. 
110. Huscher D, Thiele K, Rudwaleit M, Albrecht KC, Bischoff S, Krause A, et al. Trends in treatment and outcomes of ankylosing spondylitis in outpatient rheumatological care in Germany between 2000 and 2012. RMD Open 2015;1:e000033.

111. Boonen A, Chorus A, Miedema $H$, van der Heijde D, van der Tempel $H$, van der Linden S. Employment, work disability, and work days lost in patients with ankylosing spondylitis: a cross sectional study of Dutch patients. Ann Rheum Dis 2001;60:353-358.

112. van Lunteren M, Ez-Zaitouni Z, Fongen C, Landewe R, Ramonda R, van der Heijde D, et al. Disease activity decrease is associated with improvement in work productivity over 1 year in early axial spondyloarthritis (SPondyloArthritis Caught Early cohort). Rheumatology (Oxford) 2017; 56:2222-2228.

113. Strombeck B, Englund M, Bremander A, Jacobsson LT, Kedza L, Kobelt G, et al. Cost of illness from the public payers' perspective in patients with ankylosing spondylitis in rheumatological care. J Rheumatol 2010;37:2348-2355.

114. Franke LC, Ament AJ, van de Laar MA, Boonen A, Severens JL. Cost-of-illness of rheumatoid arthritis and ankylosing spondylitis. Clin Exp Rheumatol 2009;27:S118-123.

115. Huscher D, Merkesdal S, Thiele K, Zeidler H, Schneider M, Zink A, et al. Cost of illness in rheumatoid arthritis, ankylosing spondylitis, psoriatic arthritis and systemic lupus erythematosus in Germany. Ann Rheum Dis 2006;65:1175-1183.

116. Harvard S, Guh D, Bansback N, Richette P, Dougados M, Anis A, et al. Costs of early spondyloarthritis: estimates from the first 3 years of the DESIR cohort. RMD Open 2016;2:e000230.

117. Drummond M, Sculpher MJ, Claxton K, Stoddart GL, Torrance GW. Methods for the economic evaluation of health care programmes. Fourth edition. ed. Oxford: Oxford University Press; 2015.

118. Kigozi J, Jowett S, Lewis M, Barton P, Coast J. The Estimation and Inclusion of Presenteeism Costs in Applied Economic Evaluation: A Systematic Review. Value Health 2017;20:496-506.

119. Boonen A, Webers C. Chapter 17 - Economic Evaluations in Axial Spondyloarthritis. In: Mease P, Khan MA. Axial Spondyloarthritis. St. Louis: Elsevier 2019: 259-279.

120. OECD. Productivity Manual: A Guide to the Measurement of Industry-Level and Aggregate Productivity Growth. Paris: OECD, 2001.

121. Jones C, Payne K, Gannon B, Verstappen S. Economic Theory and Self-Reported Measures of Presenteeism in Musculoskeletal Disease. Curr Rheumatol Rep 2016;18:53.

122. Krol M, Brouwer W. How to estimate productivity costs in economic evaluations. Pharmacoeconomics 2014;32:335-344.

123. Zhang W, Bansback N, Anis AH. Measuring and valuing productivity loss due to poor health: A critical review. Soc Sci Med 2011;72:185-192.

124. Boonen A, Brinkhuizen T, Landewe R, van der Heijde D, Severens JL. Impact of ankylosing spondylitis on sick leave, presenteeism and unpaid productivity, and estimation of the societal cost. Ann Rheum Dis 2010;69:1123-1128. 
125. van Lier LI, Bosmans JE, van Hout HPJ, Mokkink LB, van den Hout WB, de Wit GA, et al. Consensus-based cross-European recommendations for the identification, measurement and valuation of costs in health economic evaluations: a European Delphi study. Eur $\mathrm{J}$ Health Econ 2018;19:993-1008.

126. Prasad M, Wahlqvist $P$, Shikiar R, Shih YC. A review of self-report instruments measuring healthrelated work productivity: a patient-reported outcomes perspective. Pharmacoeconomics 2004;22:225-244.

127. Reilly MC, Zbrozek AS, Dukes EM. The validity and reproducibility of a work productivity and activity impairment instrument. Pharmacoeconomics 1993;4:353-365.

128. Brouwer WB, Koopmanschap MA, Rutten FF. Productivity losses without absence: measurement validation and empirical evidence. Health Policy 1999;48:13-27.

129. Lerner D, Amick BC, 3rd, Rogers WH, Malspeis S, Bungay K, Cynn D. The Work Limitations Questionnaire. Med Care 2001;39:72-85.

130. van Roijen L, Essink-Bot ML, Koopmanschap MA, Bonsel G, Rutten FF. Labor and health status in economic evaluation of health care. The Health and Labor Questionnaire. Int J Technol Assess Health Care 1996;12:405-415.

131. Zhang W, Gignac MA, Beaton D, Tang K, Anis AH, Canadian Arthritis Network Work Productivity G. Productivity loss due to presenteeism among patients with arthritis: estimates from 4 instruments. J Rheumato/ 2010;37:1805-1814.

132. van der Burg L, Sepriano A, Landewe R, Geuskens G, Ottenheijm R, Dinant GJ, et al. Comparative construct validity of three presenteeism instruments in workers with musculoskeletal complaints: a prospective cohort study. RMD Open 2020;6.

133. Braakman-Jansen LM, Taal E, Kuper IH, van de Laar MA. Productivity loss due to absenteeism and presenteeism by different instruments in patients with RA and subjects without RA. Rheumatology (Oxford) 2012:51:354-361.

134. Lerner D, Amick BC, 3rd, Lee JC, Rooney T, Rogers WH, Chang H, et al. Relationship of employeereported work limitations to work productivity. Med Care 2003;41:649-659.

135. Severens JL, Mulder J, Laheij RJ, Verbeek AL. Precision and accuracy in measuring absence from work as a basis for calculating productivity costs in The Netherlands. Soc Sci Med 2000;51:243-249.

136. Evans C, Crawford B. Patient self-reports in pharmacoeconomic studies. Their use and impact on study validity. Pharmacoeconomics 1999;15:241-256.

137. Reilly MC, Bracco A, Ricci JF, Santoro J, Stevens T. The validity and accuracy of the Work Productivity and Activity Impairment questionnaire--irritable bowel syndrome version (WPAl:IBS). Aliment Pharmacol Ther 2004;20:459-467.

138. Noben CY, Evers SM, Nijhuis FJ, de Rijk AE. Quality appraisal of generic self-reported instruments measuring health-related productivity changes: a systematic review. BMC Public Health 2014;14:115.

139. Alheresh R, Vaughan M, LaValley MP, Coster W, Keysor JJ. Critical Appraisal of the Quality of Literature Evaluating Psychometric Properties of Arthritis Work Outcome Assessments: A Systematic Review. Arthritis Care Res (Hoboken) 2016;68:1354-1370. 
140. Beaton DE, Dyer S, Boonen A, Verstappen SM, Escorpizo R, Lacaille DV, et al. OMERACT Filter Evidence Supporting the Measurement of At-work Productivity Loss as an Outcome Measure in Rheumatology Research. J Rheumatol 2016;43:214-222.

141. Verstappen SMM, Lacaille D, Boonen A, Escorpizo R, Hofstetter C, Bosworth A, et al. Considerations for Evaluating and Recommending Worker Productivity Outcome Measures: An Update from the OMERACT Worker Productivity Group. J Rheumatol 2019;46:1401-1405.

142. Weisbrod BA. The Valuation of Human Capital. Journal of Political Economy 1961;69:425-436.

143. van den Hout WB. The value of productivity: human-capital versus friction-cost method. Ann Rheum Dis 2010;69 Suppl 1:i89-91.

144. Koopmanschap MA, Rutten FF, van Ineveld BM, van Roijen L. The friction cost method for measuring indirect costs of disease. J Health Econ 1995;14:171-189.

145. Krol M, Brouwer W, Rutten F. Productivity costs in economic evaluations: past, present, future. Pharmacoeconomics 2013;31:537-549.

146. Brouwer WB, Koopmanschap MA. The friction-cost method : replacement for nothing and leisure for free? Pharmacoeconomics 2005;23:105-111.

147. Richtlijn voor het uitvoeren van economische evaluaties in de gezondheidszorg [Guideline for economic evaluations in healthcare]. Diemen: Zorginstituut Nederland [National Health Care Institute of the Netherlands], 2015.

148. Pauly MV, Nicholson S, Polsky D, Berger ML, Sharda C. Valuing reductions in on-the-job illness: 'presenteeism' from managerial and economic perspectives. Health Econ 2008;17:469-485.

149. Zhang W, Bansback N, Boonen A, Severens JL, Anis AH. Development of a composite questionnaire, the valuation of lost productivity, to value productivity losses: application in rheumatoid arthritis. Value Health 2012;15:46-54.

150. Stromberg C, Aboagye E, Hagberg J, Bergstrom G, Lohela-Karlsson M. Estimating the Effect and Economic Impact of Absenteeism, Presenteeism, and Work Environment-Related Problems on Reductions in Productivity from a Managerial Perspective. Value Health 2017;20:1058-1064.

151. Krol M, Brouwer WB, Severens JL, Kaper J, Evers SM. Productivity cost calculations in health economic evaluations: correcting for compensation mechanisms and multiplier effects. Soc Sci Med 2012;75:1981-1988.

152. Jacob-Tacken KH, Koopmanschap MA, Meerding WJ, Severens JL. Correcting for compensating mechanisms related to productivity costs in economic evaluations of health care programmes. Health Econ 2005;14:435-443.

153. Noben C, Vilsteren MV, Boot C, Steenbeek R, Schaardenburg DV, Anema JR, et al. Economic evaluation of an intervention program with the aim to improve at-work productivity for workers with rheumatoid arthritis. J Occup Health 2017;59:267-279.

154. Knies S, Boonen A, Candel MJ, Evers SM, Severens JL. Compensation mechanisms for lost productivity: a comparison between four European countries. Value Health 2013;16:740-744.

155. Zhang W, Bansback N, Sun H, Pedersen R, Kotak S, Anis AH. Impact of etanercept tapering on work productivity in patients with early rheumatoid arthritis: results from the PRIZE study. RMD Open 2016;2:e000222. 
156. van den Berg R, de Hooge M, Rudwaleit M, Sieper J, van Gaalen F, Reijnierse M, et al. ASAS modification of the Berlin algorithm for diagnosing axial spondyloarthritis: results from the SPondyloArthritis Caught Early (SPACE)-cohort and from the Assessment of SpondyloArthritis international Society (ASAS)-cohort. Ann Rheum Dis 2013;72:1646-1653.

157. Boonen A, van den Heuvel R, van Tubergen A, Goossens M, Severens JL, van der Heijde D, et al. Large differences in cost of illness and wellbeing between patients with fibromyalgia, chronic low back pain, or ankylosing spondylitis. Ann Rheum Dis 2005;64:396-402.

158. Ramsey SD, Willke RJ, Glick H, Reed SD, Augustovski F, Jonsson B, et al. Cost-effectiveness analysis alongside clinical trials II-An ISPOR Good Research Practices Task Force report. Value Health 2015;18:161-172.

159. Ramonda R, Marchesoni A, Carletto A, Bianchi G, Cutolo M, Ferraccioli G, et al. Patient-reported impact of spondyloarthritis on work disability and working life: the ATLANTIS survey. Arthritis Res Ther 2016;18:78.

160. Gignac MA, Backman CL, Kaptein S, Lacaille D, Beaton DE, Hofstetter C, et al. Tension at the borders: perceptions of role overload, conflict, strain and facilitation in work, family and health roles among employed individuals with arthritis. Rheumatology (Oxford) 2012;51:324-332.

161. Beaton D, Bombardier C, Escorpizo R, Zhang W, Lacaille D, Boonen A, et al. Measuring worker productivity: frameworks and measures. J Rheumatol 2009;36:2100-2109.

162. O'Rourke B, Oortwijn W, Schuller T. Announcing the New Definition of Health Technology Assessment. Value Health 2020;23:824-825.

163. IJzerman MJ, Koffijberg H, Fenwick E, Krahn M. Emerging Use of Early Health Technology Assessment in Medical Product Development: A Scoping Review of the Literature. Pharmacoeconomics 2017;35:727-740.

164. Buisman LR, Rutten-van Molken MP, Postmus D, Luime JJ, Uyl-de Groot CA, Redekop WK. The Early Bird Catches the Worm: Early Cost-Effectiveness Analysis of New Medical Tests. Int J Technol Assess Health Care 2016;32:46-53.

165. IJzerman MJ, Steuten LM. Early assessment of medical technologies to inform product development and market access: a review of methods and applications. Appl Health Econ Health Policy 2011;9:331-347.

166. Grutters JPC, Govers T, Nijboer J, Tummers M, van der Wilt GJ, Rovers MM. Problems and Promises of Health Technologies: The Role of Early Health Economic Modeling. Int J Health Policy Manag 2019;8:575-582.

167. Bojke L, Claxton K, Bravo-Vergel Y, Sculpher M, Palmer S, Abrams K. Eliciting distributions to populate decision analytic models. Value Health 2010;13:557-564.

168. Retel VP, Grutters JP, van Harten WH, Joore MA. Value of research and value of development in early assessments of new medical technologies. Value Health 2013;16:720-728.

169. Grutters JPC, Govers TM, Nijboer J, Tummers M, van der Wilt GJ, Rovers MM. Exploratory, Participatory and Iterative Assessment of Value: A Response to Recent Commentaries. Int J Health Policy Manag 2020. 
170. Briggs AH, Weinstein MC, Fenwick EA, Karnon J, Sculpher MJ, Paltiel AD, et al. Model parameter estimation and uncertainty: a report of the ISPOR-SMDM Modeling Good Research Practices Task Force--6. Value Health 2012;15:835-842.

171. Vallejo-Torres L, Steuten LM, Buxton MJ, Girling AJ, Lilford RJ, Young T. Integrating health economics modeling in the product development cycle of medical devices: a Bayesian approach. Int J Technol Assess Health Care 2008;24:459-464.

172. Garrison LP, Jr. Rewarding value creation to promote innovation in oncology: The importance of considering the global product life cycle. Oncologist 2010;15 Suppl 1:49-57.

173. Drummond M, Griffin A, Tarricone R. Economic evaluation for devices and drugs--same or different? Value Health 2009;12:402-404.

174. Girling A, Young T, Brown C, Lilford R. Early-stage valuation of medical devices: the role of developmental uncertainty. Value Health 2010;13:585-591.

175. Smith AF, Sutton A, Shinkins B. Early Cost-Effectiveness Analysis of New Medical Tests: Response. Int J Technol Assess Health Care 2016;32:324-325.

176. Luime JJ, Buisman LR, Oppe M, Hazes JM, Rutten-van Molken MP. Cost-Effectiveness Model for Evaluating New Diagnostic Tests in the Evaluation of Patients With Inflammatory Arthritis at Risk of Having Rheumatoid Arthritis. Arthritis Care Res (Hoboken) 2016;68:927-935.

177. Aletaha D, Neogi T, Silman AJ, Funovits J, Felson DT, Bingham CO, 3rd, et al. 2010 Rheumatoid arthritis classification criteria: an American College of Rheumatology/European League Against Rheumatism collaborative initiative. Ann Rheum Dis 2010;69:1580-1588.

178. Buisman LR, Luime JJ, Oppe M, Hazes JM, Rutten-van Molken MP. A five-year model to assess the early cost-effectiveness of new diagnostic tests in the early diagnosis of rheumatoid arthritis. Arthritis Res Ther 2016;18:135.

179. Sykes MP, Doll H, Sengupta R, Gaffney K. Delay to diagnosis in axial spondyloarthritis: are we improving in the UK? Rheumatology (Oxford) 2015;54:2283-2284.

180. Braun A, Gnann H, Saracbasi E, Grifka J, Kiltz U, Letschert K, et al. Optimizing the identification of patients with axial spondyloarthritis in primary care--the case for a two-step strategy combining the most relevant clinical items with HLA B27. Rheumatology (Oxford) 2013;52:1418-1424.

181. Poddubnyy D, Vahldiek J, Spiller I, Buss B, Listing J, Rudwaleit M, et al. Evaluation of 2 screening strategies for early identification of patients with axial spondyloarthritis in primary care. $J$ Rheumatol 2011;38:2452-2460.

182. Poddubnyy D, van Tubergen A, Landewe R, Sieper J, van der Heijde D, Assessment of SpondyloArthritis international S. Development of an ASAS-endorsed recommendation for the early referral of patients with a suspicion of axial spondyloarthritis. Ann Rheum Dis 2015;74:1483-1487.

183. Sieper J, Srinivasan S, Zamani O, Mielants H, Choquette D, Pavelka K, et al. Comparison of two referral strategies for diagnosis of axial spondyloarthritis: the Recognising and Diagnosing Ankylosing Spondylitis Reliably (RADAR) study. Ann Rheum Dis 2013;72:1621-1627. 
184. van den Berg R, de Hooge M, van Gaalen F, Reijnierse M, Huizinga T, van der Heijde D. Percentage of patients with spondyloarthritis in patients referred because of chronic back pain and performance of classification criteria: experience from the Spondyloarthritis Caught Early (SPACE) cohort. Rheumatology (Oxford) 2013;52:1492-1499.

185. van Hoeven L, Luime J, Han H, Vergouwe Y, Weel A. Identifying axial spondyloarthritis in Dutch primary care patients, ages 20-45 years, with chronic low back pain. Arthritis Care Res (Hoboken) 2014;66:446-453.

186. Rudwaleit M, van der Heijde D, Khan MA, Braun J, Sieper J. How to diagnose axial spondyloarthritis early. Ann Rheum Dis 2004;63:535-543.

187. Jamal M, Korver AM, Kuijper M, Lopes Barreto D, Appels CWY, Spoorenberg APL, et al. The IMPACT study: A clustered randomized controlled trial to assess the effect of a referral algorithm for axial spondyloarthritis. PLoS One 2020;15:e0227025.

188. Maksymowych WP. Biomarkers in axial spondyloarthritis. Curr Opin Rheumatol 2015;27:343-348.

189. Brown MA, Li Z, Cao KL. Biomarker development for axial spondyloarthritis. Nat Rev Rheumatol 2020;16:448-463.

190. van Hoeven L, Vergouwe Y, de Buck PD, Luime JJ, Hazes JM, Weel AE. External Validation of a Referral Rule for Axial Spondyloarthritis in Primary Care Patients with Chronic Low Back Pain. PLoS One 2015;10:e0131963.

191. Underwood MR, Dawes P. Inflammatory back pain in primary care. Br J Rheumatol 1995;34:1074-1077.

192. Rudwaleit M, Listing J, Brandt J, Braun J, Sieper J. Prediction of a major clinical response (BASDAI 50) to tumour necrosis factor alpha blockers in ankylosing spondylitis. Ann Rheum Dis 2004;63:665-670.

193. Usher-Smith JA, Sharp SJ, Griffin SJ. The spectrum effect in tests for risk prediction, screening, and diagnosis. BMJ 2016;353:i3139.

194. Spondyloarthritis in over 16s: diagnosis and management. London: National Institute for Health and Care Excellence; 2017. 
Chapter 11

Impact paragraph 


\section{Summary of main findings}

The overarching objective of this thesis was to investigate health and economic outcomes of axial spondyloarthritis (axSpA) from a patient and societal perspective (Chapter 1). We conducted eight studies, resulting in a number of findings. Gender was shown to affect quality of life and spinal damage of patients with axSpA, with male patients having better quality of life, yet also more spinal damage (Chapter 2). Mastery, defined as the sense of control over life and disease, was revealed to be a key determinant of symptoms of depression in axSpA ('comorbid depression') (Chapter 3). In addition, infliximab, a biological disease-modifying antirheumatic drug (bDMARD) commonly used in the treatment of axSpA, also reduced comorbid depressive symptoms in these patients, mainly by improving symptoms of axSpA. Importantly, we observed no signs of a direct effect of inflammation on depressive symptoms (Chapter 4). Regarding work outcome in axSpA, patients with axSpA were still less often employed when compared to the general population (Chapter 5) and frequently reported sick leave. Importantly, sick leave itself predicted future sick leave, and thus was concluded to be a warning signal (Chapter 6). In the setting of a willingness-to-pay study, which is an alternative approach to value the benefit of treatments, the majority of patients would hypothetically be willing to pay for infliximab, especially if they responded well to this drug (Chapter $\mathbf{7}$ ). In a cost-effectiveness study of algorithms meant to guide diagnosis of axSpA, the currently recommended algorithm ('Modification 2 '), was confirmed to also be the most cost-effective option. However, this algorithm was not perfect, and it was revealed that a better algorithm could cost much more, yet still be worth its cost (Chapter 8). Finally, we successfully developed and implemented a new registry ('SpA-Net'), designed to monitor patients with SpA, in several hospitals in the Netherlands (Chapter 9).

\section{Implications for research}

Two studies in this thesis provided additional insights into the origin and treatment of the impact of axSpA on mental health, in particular depressive symptoms. 'Contextual factors', i.e. the personal and environmental factors that are not part of axSpA itself but influence how axSpA affects patients' functioning, likely play a larger role than axSpA-related factors themselves in comorbid depression. Future studies should therefore investigate whether prevention and management of comorbid depression could benefit more from a generic approach (incorporating context) instead of an axSpA-specific one. Also, the central role of mastery in comorbid depression suggests that mastery and related factors, such as self-efficacy, deserve attention in future research. It would be helpful to know if, and how, mastery could be improved in these patients, and whether this would also improve mental 
health. In addition, we observed no direct link between comorbid depressive symptoms and inflammation - hypothesized to be the main mechanism behind comorbid depression. In the future studies that are necessary to confirm this finding, inflammatory biomarkers other than C-reactive protein (which was used in this thesis) should be included. These studies could also explore whether certain subgroups with comorbid depression, for example those with higher levels of inflammation, are more likely to benefit from infliximab and similar drugs. Finally, many contradictory findings in this area of research remain, also between this thesis and other published studies, partly as a consequence of clinical and methodological heterogeneity across studies. Future studies need to be designed with clearly formulated study objectives and hypotheses on comorbid depression, provide a clear definition of what constitutes 'depression' and take relevant determinants of depression into account.

In another study in this thesis, we asked patients how much they would be hypothetically willing to pay for treatment with infliximab. This 'willingness-to-pay' (WTP) approach is used to express changes in health due to treatment in monetary terms. It is an alternative approach to the traditional methods for measuring treatment benefits, which are based on measuring symptoms of disease or overall health. WTP studies are at risk of bias, however, as patients might state they would not be willing to pay out of protest (against the idea of paying for drugs), even when it is stated explicitly that it concerns a purely hypothetical situation. In this thesis, this problem was overcome by specific statistical methods that allow for identification of those never willing to pay, i.e. the 'protesters'. We recommend that future WTP studies in axSpA and other diseases adopt similar methods.

Up till now, cost-effectiveness research in axSpA was focused on drug treatments. Our cost-effectiveness study was the first to investigate (mis)diagnosis of axSpA, and demonstrated that it is feasible to estimate the consequences of misdiagnosis, i.e. to what extent a wrong diagnosis can lead to more costs and loss of quality-adjusted lifeyears (QALYS). Also, we conducted an analysis to assess the expected value of a perfect diagnosis, revealing the hypothetical room for improvement in monetary terms. This type of modelling can support researchers to understand in which position (in the diagnostic process or treatment decision) innovative tools, often biomarkers, would be most beneficial for patients and society. This calls for a stronger integration of health technology assessment in basic/translational research.

\section{Implications for society}

The findings in this thesis on reduced employment and substantial sick leave among patients with axSpA indicate that valuable human capital is lost for society. This suggests that there is room for improvement, i.e. to increase employment rates and reduce sick leave in axSpA, thereby increasing patients' productivity and reducing costs for society. 
It requires careful thinking, however, how to support patients in healthy and sustainable workforce participation, to maximize societal health, wealth and welfare. Work-focused care and healthy workplaces could play an important role in this. Regarding sick leave, short-term sick leave often will actually promote recovery and thus protect patients from long-term sick leave or work disability. Society would not necessarily benefit most from averting all sick leave. We should also realise that gainful employment likely is not possible for all patients, or might not be possible in all phases of their life or disease-course.

Our cost-effectiveness study on diagnosis of axSpA investigated which diagnostic algorithm would be most cost-effective for society. This is important, as resources are scarce and healthcare budgets are limited. Decision-makers can spend money only once, meaning they should do so wisely and improve health in an efficient manner. This study revealed which algorithm would result in most value, in terms of both costs and quality of life, when implemented in current practice. In addition, the results also suggest that more accurate - but also more expensive - diagnosis of axSpA could still be 'worth it'. However, more accurate diagnosis likely requires new diagnostic tests, some of which are still in development. Both public funding bodies and private companies have to make investment choices: which technologies should we further invest in, and which should we abandon? Future studies could use the economic model that was developed for this thesis to answer such questions. If the expected benefits of a new technology are deemed to be too low, it could be considered to stop development and instead invest in other technologies that show more promise. This approach could help maximize the 'return on investment' for society.

In line with the above, society would benefit from transparency on health outcomes and costs of healthcare. Such transparency would help to identify areas for improvement in healthcare, but requires that relevant outcomes are measured in a regular and comprehensive manner. SpA-Net, a registry that is integrated in daily rheumatology practice as an electronic medical record, allows for monitoring of patients with SpA. The outcomes collected in SpA-Net can help inform the Dutch government, insurers and healthcare organisations on how to deliver efficient care and minimize any unwarranted variation in healthcare utilisation between practices.

\section{Implications for patients}

The findings on comorbid depression in this thesis are of value for patients. First, mental health problems, and specifically depressive symptoms, were quite common in patients with axSpA - and likely more common compared to the general population - which should make patients aware of this additional risk. It should also prompt them to discuss negative feelings with their healthcare provider. Second, patients should be aware of the factors associated with depression. In this thesis, axSpA-related disease activity contributed to depressive 
symptoms, indicating a need for treatment adherence in order to control disease activity. Also, mastery had a central role, indicating that interventions aimed at increasing mastery and related factors, such as self-efficacy, could be beneficial. It should be noted that, as stated above, it is unknown whether improving mastery and self-efficacy actually improves depressive symptoms. Third, treatment with infliximab improved depressive symptoms in the majority of patients with active axSpA. Other bDMARDs would be expected to give similar results. This provides a promising outlook for patients in practice with active axSpA and depressed feelings. However, these patients should be aware that there is a chance that they do not experience such benefit, and that other therapies are necessary.

Our findings that patients with axSpA were less often employed compared to the general population, and that sick leave was recurrent, indicate that patients fall behind when work is concerned. This is relevant for patients, as they themselves perceive 'work' as one of the most important roles they can fulfill in society. Patients should be aware that, once they experience sick leave due to axSpA, they are at increased risk for additional future sick leave. This suggests that sick leave is not only a warning signal, but also a potential starting point for interventions to prevent future sick leave. These findings should stimulate patients to discuss work-related matters with those who can support them in their work role, such as their healthcare provider, but also an occupational physician and their employer.

Patients will also benefit from the successful development and implementation of SpANet. Patients participating in SpA-Net can access their records, see the results of outcome measures and leave notes for care providers. They could benefit directly by gaining insight into their disease and its course, and by becoming empowered and more involved in the care they receive. This was supported by interviewed patients, who considered SpA-Net to be of additional value to current care. Future studies need to confirm these benefits for patients. Patients not involved in SpA-Net, for example because their centre is not participating, might benefit in the future when these centres adopt similar systems.

\section{Implications for healthcare professionals}

As a result of this thesis, healthcare professionals should become more aware that not only disease-related but also contextual factors affect the outcomes of their patients with axSpA. Patients are at risk of being not employed, especially when disease activity is high and mastery is low. They will incur sick leave, in particular when educational attainment is low and disease activity and functional impairment are high. Patients are also more likely to feel depressed, and low income, low satisfaction with role participation and high disease activity that mainly contribute to these feelings. Treatment with bDMARDs in those with active disease can alleviate these dismal feelings, yet a notable proportion of patients will maintain clinically relevant depressive symptoms despite bDMARD treatment. Female 
patients will likely experience lower health-related quality of life compared to male patients, independent of other factors. Some (perhaps most) of these relationships mentioned above are not easy to modify, or modifiable at all. However, appropriate awareness of outcomes outside disease activity - such as depression and work - and factors associated with these outcomes could help identify patients at risk for worse outcome and guide individualized disease management. Healthcare providers should discuss these outcomes with their patients. Systems such as SpA-Net help to monitor these patients in a comprehensive way, assessing such outcomes systematically, but also give patients a voice in care decisions, promoting shared-decision making. Finally, based on this thesis, healthcare providers should prefer Modification 2 over the alternative algorithms for diagnosis of axSpA, as this will provide the greatest benefits to patients and society. 
Addendum

Nederlandse samenvatting

Dankwoord

Curriculum vitae

List of publications 


\section{Nederlandse samenvatting}

Axiale spondyloartritis (axSpA) is een chronische ontstekingsziekte van het bewegingsapparaat die zich met name uit in de lage rug en het bekken, specifiek de sacro-iliacale (SI) gewrichten. ${ }^{1}$ De ziekte begint vaak tussen het $20^{\mathrm{e}}$ en $30^{\mathrm{e}}$ levensjaar, en wordt gekenmerkt door lage rugpijn. Bij axSpA kunnen ook andere manifestaties optreden, zoals ontsteking van de perifere gewrichten en entheses (bindweefsel tussen pezen of ligamenten en bot). Daarnaast komen psoriasis en ontstekingen van darmen en ogen regelmatig voor. ${ }^{2}$ AxSpA wordt tegenwoordig als een spectrum van ziekte beschouwd, waarbij er onderscheid wordt gemaakt tussen een vorm mét structurele schade aan de SI-gewrichten op röntgenbeelden (radiologische axSpA of r-axSpA, voorheen 'ankyloserende spondylitis' genoemd) en een vorm zónder dergelijke schade op röntgenbeelden (niet-radiologische axSpA, nr-axSpA). ${ }^{3}$ De diagnose axSpA wordt meestal gesteld door de reumatoloog, die daarbij gebruik maakt van een combinatie van klinische manifestaties en aanvullende onderzoeken, zoals bloedonderzoek en beeldvorming (röntgen- en MRI-onderzoek van de SI-gewrichten). Na diagnose zijn er verschillende behandelopties. ${ }^{4}$ Non-farmacologische behandeling omvat onder andere patiënteducatie en fysiotherapie of oefentherapie. Farmacologische behandeling begint vaak met pijnstillers met ontstekingsremmende werking ('non-steroidal anti-inflammatory drugs', NSAIDs). Indien NSAIDs onvoldoende effect hebben en de ziekte actief is, kan worden overgegaan op biologische geneesmiddelen ('biological disease-modifying antirheumatic drugs', bDMARDs). ${ }^{4,5}$ Aangezien axSpA een chronische aandoening is die wordt gekenmerkt door een relatief jonge aanvangsleeftijd, met het risico op het ontwikkelen van onherstelbare schade en potentiële betrokkenheid van meerdere orgaansystemen, heeft deze ziekte grote impact op de patiënt en de maatschappij.

\section{Perspectief van de patiënt}

AxSpA heeft een substantiële invloed op het dagelijks leven van patiënten. Door de ontstekingen van het bewegingsapparaat ervaren patiënten pijn, stijfheid en moeheid, en wordt het fysiek functioneren belemmerd. Als gevolg van deze symptomen worden patiënten in hun dagelijkse activiteiten beperkt. ${ }^{6}$ Dit heeft ook gevolgen voor hun participatie in de maatschappij. Hierbij kan worden gedacht aan bijvoorbeeld aan hun rol binnen de familie, sociale relaties, werk en opleiding. Patiënten hechten een grote waarde aan de verschillende rollen die ze in de maatschappij (kunnen) aannemen, maar blijken ook veel beperkingen te ervaren bij het uitvoeren ervan.7,8 Eerdere studies toonden dat patiënten met axSpA minder vaak werkzaam zijn, zich vaker ziek moeten melden, en vaker arbeidsongeschikt worden. ${ }^{9-12}$ Dit kan belangrijke consequenties hebben voor de patiënt, zoals psychologische stress en (op de lange termijn) beperkte carrièremogelijkheden. ${ }^{13}$ 
De relatie tussen een ziekte en het algehele functioneren (symptomen, activiteiten en participatie) is niet voor elke patiënt met de desbetreffende ziekte hetzelfde, maar wordt beïnvloed door de individuele context. Bij het schetsen van deze context wordt er een onderscheid wordt gemaakt tussen persoonlijke factoren, zoals geslacht of persoonlijkheid, en omgevingsfactoren, zoals het land waarin men woont en de daar geldende juridische en sociale regelingen of de financiële middelen die daar beschikbaar zijn voor zorg. ${ }^{14}$ Kennis over deze contextuele factoren, en de impact ervan op de verschillende aspecten van axSpA, is essentieel om de individuele patiënt de juiste behandeling en begeleiding te bieden. De laatste decennia is er dan ook in toenemende mate onderzoek gedaan naar contextuele factoren bij axSpA.

Ten slotte is het belangrijk om te realiseren dat axSpA is geassocieerd met verschillende andere aandoeningen (comorbiditeiten), en dat deze ook een belangrijke impact kunnen hebben op de patiënt. ${ }^{15-17}$ Bekende voorbeelden van comorbiditeiten van axSpA zijn cardiovasculaire aandoeningen en osteoporose. ${ }^{15}$ Recent is er ook aandacht voor depressie als mogelijke comorbiteit bij axSpA.16,18 Depressie en depressieve symptomen lijken vaker voor te komen bij patiënten met axSpA, en zijn geassocieerd met een verlaagd gevoel van psychologisch welbevinden en kwaliteit van leven in deze patiëntenpopulatie.19,20

\section{Perspectief van de maatschappij}

AxSpA heeft ook een substantiële impact op de maatschappij. Enerzijds is er een verlies van gezondheid, maar anderzijds zijn er ook belangrijke economische consequenties. Omdat axSpA een chronische aandoening is, zullen patiënten vaak levenslang behandeling ondergaan en regelmatig op controle komen bij zorgverleners, wat kan leiden tot hoge zorgkosten voor de maatschappij. ${ }^{21}$ De farmacologische behandeling met bDMARDs is effectief maar duur, met jaarlijkse kosten die variëren van $€ 10.000$ tot $€ 15.000$ per patiënt. ${ }^{22}$ Hierbij moet de kanttekening worden geplaatst dat er de laatste jaren een geleidelijke prijsdaling van deze geneesmiddelen te zien is, die zich mogelijk voort zal zetten. AxSpA gaat daarnaast ook gepaard met kosten buiten de gezondheidszorg. De impact van de ziekte op het werk van de patiënt, resulterend in verminderde productiviteit op het werk, een hoger ziekteverzuim en meer arbeidsongeschiktheid, leidt tot additionele kosten voor de maatschappij. Eerdere studies lieten zien dat een belangrijk deel van de totale kosten van axSpA konden worden toegeschreven aan werk-gerelateerde verliezen. ${ }^{23-25}$

Bij het ontwikkelen en implementeren van nieuwe medische technologieën, bijvoorbeeld een nieuwe behandeling of een nieuwe diagnostische test, moet er een afweging worden gemaakt door beleidsmakers en betalende partijen: niet elke technologie kan worden vergoed, het budget voor de gezondheidszorg is immers eindig. Economische evaluaties, waarvan kosteneffectiviteitsanalyses als meest bekende voorbeeld, zijn een manier om de mogelijke gezondheidswinst van een technologie af te wegen tegen de kosten voor de maatschappij. ${ }^{26}$ Binnen axSpA hebben deze evaluaties zich vrijwel uitsluitend gericht op 
medicatie, in het bijzonder de bDMARDs. ${ }^{27}$ Ondanks de toenemende interesse in vroege diagnose van axSpA, en de daarmee gepaard gaande risico's van onder- en overdiagnose (en onder- en overbehandeling), is er nog weinig inzicht in de mogelijk gevolgen hiervan wat betreft gezondheid en kosten op de lange termijn.

Het doel van dit proefschrift was om verschillende gezondheidsuitkomsten en economische uitkomsten van axSpA te onderzoeken, en om deze te beschouwen vanuit het perspectief van een patiënt en/of de maatschappij.

\section{Samenvatting van de studies in dit proefschrift}

In hoofdstuk 2 hebben wij ons gericht op genderverschillen in diverse gezondheidsuitkomsten in r-axSpA. Het was bij aanvang van ons onderzoek reeds bekend dat gender (een persoonlijke contextuele factor) invloed kan hebben op gezondheidsuitkomsten in r-axSpA. ${ }^{28-31}$ Met name de constatering dat de progressie van structurele schade in de wervelkolom in mannen substantieel hoger was dan in vrouwen, was breed geaccepteerd. ${ }^{32-34}$ Echter, van veel andere gezondheidsuitkomsten waren slechts cross-sectionele studies of studies met een korte follow-up periode beschikbaar. Kennis over de verschillen in uitkomsten tussen mannen en vrouwen met axSpA zou inzicht kunnen bieden in het verloop van de ziekte, en uiteindelijk helpen om deze uitkomsten te verbeteren bij zowel mannen als vrouwen. Ons doel was om genderverschillen bij r-axSpA over een langere periode te onderzoeken. Voor onze studie gebruikten we data van de 'Outcome in Ankylosing Spondylitis International Study' (OASIS), een prospectieve cohortstudie. In OASIS zijn patiënten in Nederland, België en Frankrijk met r-axSpA gedurende 12 jaar systematisch opgevolgd. We onderzochten de verschillen tussen mannen en vrouwen, op baseline en longitudinaal. Bij de baselinemeting hadden mannelijke patiënten een significant lagere zelf-gerapporteerde ziekteactiviteit (Bath Ankylosing Spondylitis Disease Activity Index [BASDAI]: 3.2 vs 3.9) maar een hogere C-reactive protein (CRP)-waarde in het serum (19.5 vs 14.2) en meer radiologische schade aan de wervelkolom (modified Stoke Ankylosing Spondylitis Spine Score [mSASSS]: 13.8 vs 6.5). Bij de longitudinale analyse van verscheidene uitkomsten (ziekteactiviteit, fysiek functioneren, kwaliteit van leven en radiologische schade) waren er alleen genderverschillen in kwaliteit van leven en radiologische schade. Mannelijke patiënten hadden een betere kwaliteit van leven (AS Quality of Life score: $B=-1.18,95 \%$ betrouwbaarheidsinterval [95\% BI] -2.17 tot -0.20 ), maar ook meer radiologische schade aan de wervelkolom (mSASSS: B = 8.24, 95\% BI 4.38 tot 12.09) over de tijd. Het genderverschil in kwaliteit van leven was onafhankelijk van andere factoren, zoals ziekteactiviteit, fysiek functioneren en radiologische schade. 
Dit leidde tot onze hypothese dat dit met name werd veroorzaakt door genderverschillen in psychologische factoren, niet door biologische factoren.

In hoofdstuk $\mathbf{3}$ en hoofdstuk $\mathbf{4}$ hebben we ons gericht op depressie bij r-axSpA ('comorbide depressie'). Voorafgaand aan ons onderzoek hadden verschillende studies reeds laten zien dat depressieve symptomen vaak voorkomen bij patiënten met axSpA, met een geschatte prevalentie van $11 \%$ tot $64 \%$ in verschillende studies. ${ }^{16}$ Het was echter onduidelijk welke factoren bijdragen aan deze depressieve symptomen, omdat eerdere studies zich met name hadden gericht op ziekte-gerelateerde factoren van r-axSpA, zoals pijn en fysiek functioneren. ${ }^{35-38}$ De rol van contextuele factoren, en zeker de onderlinge relatie tussen verschillende factoren, met betrekking tot comorbide depressie bij r-axSpA was grotendeels onduidelijk. ${ }^{39,40}$ In andere chronische aandoeningen was reeds gebleken dat de rol van contextuele factoren duidelijk groter was dan die van ziekte-gerelateerde factoren, en dit zou ook het geval kunnen zijn bij r-axspA. ${ }^{41,42}$ In hoofdstuk 3 was ons doel daarom om te exploreren welke factoren direct en indirect bijdragen aan depressie in r-axSpA, en om de onderlinge relaties tussen deze determinanten in kaart te brengen. We maakten hiervoor gebruik van 'structural equation modelling' (SEM), een methode om directe en indirecte relaties tussen variabelen te modelleren in één model. We hadden data tot onze beschikking van de 'Social Participation in Ankylosing Spondylitis Study' (SPASS), een crosssectioneel cohort van Nederlandse patiënten met r-axSpA. Eén op de vijf patiënten in deze patiëntenpopulatie bleek depressieve symptomen van dusdanige ernst te hebben dat er mogelijk sprake was van klinische depressie (score op depressie-subschaal van de Hospital Anxiety and Depression Scale $[$ HADS-D] $\geq 8$ ). Bij analyse van de mogelijke determinanten van depressie bleken meerdere contextuele factoren bij te dragen aan depressie: geslacht, werk, inkomen, participatie in sociale rollen en 'mastery' (de mate waarin de patiënt zich in controle voelt over zijn of haar leven en ziekte). Daar stond tegenover dat er slechts één ziekte-gerelateerde factor (zelf-gerapporteerde r-axSpA ziekteactiviteit) geassocieerd was met depressie, dat dit effect bovendien indirect verliep, en het ook nog om een relatief klein effect ging. Interessant was de observatie dat de persoonlijke contextuele factor 'mastery' een centrale rol innam in het model, als mediator van verschillende andere determinanten met elk een substantieel indirect effect op depressie. Deze observatie ondersteunt de focus in de huidige praktijk op het verbeteren van de zelfmanagementvaardigheden van patiënten met r-axSpA.

Het verhoogde risico op comorbide depressie zoals bij axSpA is ook geobserveerd in andere ontstekingsziekten. Bovendien worden er in sommige depressieve patiënten zonder r-axSpA of een andere aandoening ook verhoogde ontstekingswaarden in het bloed gezien. ${ }^{43-46}$ In laatstgenoemde groep, vaak met een depressie resistent voor conventionele antidepressieve therapie, blijkt in studieverband het gebruik van bDMARDs de depressieve symptomen te verbeteren. ${ }^{47}$ Dit heeft geleid tot de 'inflammatory 
hypothesis of depression', waarbij men vermoedt dat ontsteking een causale rol kan spelen bij depressie ('inflammatoire depressie'). ${ }^{48}$ Ten tijde van ons onderzoek was het onduidelijk of deze bevindingen geëxtrapoleerd kunnen worden naar axSpA. Vanuit klinisch oogpunt zou het relevant zijn om te weten of het gebruik van een bDMARD bij axSpA met comorbide depressie niet alleen de symptomen van axSpA zou verbeteren, maar óók de depressieve symptomen. Indien dit het geval is, zou het vanuit pathofysiologisch oogpunt interessant zijn om te weten welk mechanisme hieraan ten grondslag ligt. Komt een dergelijke verbetering van depressieve symptomen bij gebruik van bDMARDs alleen door een verbetering in axSpA symptomen, of speelt de afname van ontsteking ook een rol (onafhankelijk van een verbetering in axSpA symptomen)? Het laatste zou suggereren dat comorbide depressie bij axSpA niet louter secundair is, maar dat beide eenzelfde pathofysiologie delen. In hoofdstuk $\mathbf{4}$ hebben we onderzocht of het gebruik van de bDMARD infliximab, in vergelijking met placebo, is geassocieerd met een afname van depressieve symptomen, en welke factoren een dergelijke afname verklaren. Voor deze studie gebruikten we data van een subgroep van patiënten die deelnamen aan een groter gerandomiseerd en placebo-gecontroleerd onderzoek naar het effect van infliximab op r-axSpA ('Ankylosing Spondylitis Study for the Evaluation of Recombinant Infliximab Therapy', ASSERT). Patiënten met actieve r-axSpA ontvingen gedurende 24 weken infliximab of placebo, gevolgd door infliximab in alle patiënten gedurende 30 weken. Bij aanvang van de studie had 52\% van de patiënten depressieve symptomen van dusdanige ernst dat er mogelijk sprake was van klinische depressie. Na 24 weken was de ernst van depressieve symptomen in de infliximab-groep significant sterker afgenomen dan in de placebogroep (Center for Epidemiological Studies Depression [CES-D] schaal: $\mathrm{B}=-6.63,95 \% \mathrm{BI}-13.35$ tot 0.09$)$. Uit de analyses bleek dat dit effect grotendeels te verklaren was door de verbetering in de symptomen van r-axSpA, en waren er geen aanwijzingen voor een directe bijdrage van ontsteking aan de verbetering van depressieve symptomen. Na 54 weken, toen alle patiënten minstens 30 weken infliximab hadden ontvangen, had 20-25\% patiënten nog steeds depressieve symptomen passend bij een mogelijke depressie. Alhoewel infliximab (en mogelijk andere bDMARDs) depressieve symptomen dus lijken te verbeteren bij patiënten met actieve r-axSpA, ervaren waarschijnlijk niet alle patiënten dit effect.

In hoofdstuk $\mathbf{5}$ en hoofdstuk $\mathbf{6}$ onderzochten we de impact van r-axSpA op uitkomsten gerelateerd aan werk. Eerdere studies hadden laten zien dat ziekteverzuim in patiënten met r-axSpA hoger was dan in de algemene bevolking. ${ }^{9.49}$ Echter, er was een gebrek aan studies die ziekteverzuim over de tijd hadden bestudeerd. Ook was de rol van contextuele factoren bij ziekteverzuim van patiënten met r-axSpA grotendeels onbekend. In hoofdstuk 5 hebben we ons daarom gericht op het optreden van ziekteverzuim door r-axSpA over een langere periode van 6 tot 12 jaar, en op de mogelijke factoren die een eerste of terugkerend 
ziekteverzuim voorspellen. Voor onze analyse maakten we gebruik van een longitudinaal cohort van patiënten met r-axSpA (OASIS). Gedurende een periode van maximaal 12 jaar bleek $63 \%$ van de patiënten ten minste één keer te verzuimen vanwege r-axSpA, en 45\% van de patiënten rapporteerde terugkerend ziekteverzuim. Ziektegerelateerde factoren, namelijk ziekteactiviteit en fysiek functioneren, en comorbiditeiten bleken voorspellers van ziekteverzuim, maar alléén in patiënten met een laag opleidingsniveau: er was sprake van effectmodificatie door opleidingsniveau. Daarnaast bleek ziekteverzuim gedurende het eerste jaar een belangrijke en onafhankelijke voorspeller voor toekomstig ziekteverzuim in alle patiënten (odds ratio [OR] varieerde van 2.62 tot 8.37 in verschillende modellen, alle $p<$ 0.05). Opvallend genoeg was het type werk, dat we hadden gecategoriseerd als werk van 'witte boorden' of 'blauwe boorden' op basis van de fysieke werkbelasting, niet geassocieerd met ziekteverzuim. Opleidingsniveau speelde dus wel een rol bij ziekteverzuim, maar het type werk niet. Onze hypothese was dat opleidingsniveau niet alleen een surrogaat is voor de werkomgeving, maar ook een weerspiegeling is van de efficiëntie van het omgaan met stressfactoren gerelateerd aan ziekte en werk (coping). Dergelijke coping is mogelijk belangrijker dan de werkomgeving in het kader van ziekteverzuim. We concludeerden dat ziekteverzuim zelf een signaal is voor de noodzaak voor ondersteuning van de patiënt met r-axSpA om toekomstig ziekteverzuim te voorkomen.

Eerder Nederlands onderzoek had ook laten zien dat patiënten met r-axSpA minder vaak betaald werk hadden dan de algemene bevolking. ${ }^{49}$ Deze studie was echter uitgevoerd voordat bDMARDs beschikbaar kwamen, waarvan is gebleken dat ze tot een substantiële verbetering van de symptomen van r-axSpA kunnen leiden. In hoofdstuk $\mathbf{6}$ hadden we dan ook als doel om te onderzoeken of patiënten met r-axspA in een periode ná de introductie van de bDMARDs nog steeds minder vaak werk hadden dan de algemene bevolking. Daarnaast waren we geïnteresseerd of 'mastery', een persoonlijke factor die hierboven reeds werd beschreven (zie samenvatting van hoofdstuk 3), geassocieerd was met werk in patiënten met r-axSpA en in een controlegroep zonder r-axSpA. We maakten gebruik van een Nederlands cross-sectioneel cohort (SPASS), gevormd door patiënten met r-axSpA en een controlegroep zonder r-axspA. Patiënten bleek minder vaak betaald werk te hebben dan de controles. De verhouding tussen het percentage werkenden in de patiëntengroep en de controlegroep, gecorrigeerd voor leeftijd, geslacht en opleidingsniveau, was lager dan 1 (standardized employment ratio $[S E R]=0.83,95 \% \mathrm{BI} 0.69$ tot 0.98). Dit was met name het geval in patiënten met een langere symptoomduur en hogere zelfgerapporteerde ziekteactiviteit. Analyse van de rol van 'mastery' toonde dat deze factor geassocieerd was met het hebben van werk in patiënten met een laag opleidingsniveau (incidence rate ratio $[\mathrm{IRR}]=1.04,95 \% \mathrm{BI} 1.01$ tot 1.08), maar niet in controles. Onze verklaring hiervoor was dat patiënten met een chronische ziekte mogelijk kwetsbaarder zijn voor het effect van een lagere 'mastery'. Opvallend was dat het verschil in de percentages werkzame patiënten en werkzame controles - dit was $14 \%$ lager in de patiënten - van vergelijkbare grootte was als 
in de vroegere studie (toen er geen bDMARDs beschikbaar waren). Verdere vergelijking met deze eerdere studie, die zo'n 15 jaar eerder had plaatsgevonden, liet zien dat het absolute percentage werkenden was toegenomen in zowel patiënten als de algemene bevolking. Deze trend, in combinatie met de toenemende druk op het arbeidsproces in tijden van soberheid, verklaart mogelijk waarom patiënten nog steeds minder vaak werkzaam waren in onze studie.

In onderzoek naar medische behandelingen is het meten van het construct 'gezondheid' vaak essentieel, maar ook heel moeilijk. Traditionele methoden om de effectiviteit van behandeling te meten zijn vaak gebaseerd op het meten van (veranderingen in) symptomen of algehele 'gezondheid', waarbij het effect wordt uitgedrukt in een non-monetaire waarde. Een alternatieve benadering is de contingente-waarderingsmethode, waarbij een dergelijk effect in een monetaire waarde wordt uitgedrukt. ${ }^{50}$ Een veelgebruikte vorm van deze methode is 'willingness-to-pay' (WTP): door patiënten te vragen hoeveel ze hypothetisch bereid zijn om te betalen voor een bepaalde behandeling, wordt het effect van deze behandeling gewaardeerd in monetaire eenheden. ${ }^{50-52}$ De resultaten van WTP-studies kunnen worden vergeleken tussen verschillende ziekten, en gebruikt worden als input voor economische evaluaties. In axSpA was een dergelijke methode weinig toegepast, en nog helemaal niet bij moderne behandelingen. In hoofdstuk 7 hebben wij een WTPstudie uitgevoerd bij patiënten met $r$-axSpA, die reeds enige tijd de bDMARD infliximab hadden gebruikt. Deze patiënten werd gevraagd of, en zo ja, hoeveel zij hypothetisch bereid waren zelf te betalen voor het voortzetten van deze behandeling. Daarnaast wilden we ook kijken welke factoren geassocieerd waren met de bereidheid om te betalen, en de hoogte van het bedrag. We gebruikten data van een Europese open-label voortzetting ('European Ankylosing Spondylitis Infliximab Cohort', EASIC) van de hierboven reeds beschreven studie van infliximab in r-axSpA (ASSERT). In deze studiepopulatie bleek $74 \%$ van de patiënten bereid om te betalen voor het voortzetten van de behandeling met infliximab. Het gemiddelde bedrag dat men hypothetisch bereid was om te betalen was $€ 275$ per gift (dit was 11\% van de marktprijs van infliximab op dat moment). Als patiënten niet bereid waren om te betalen, was dit meestal om persoonlijke financiële redenen, en niet omdat zij het medicijn geen persoonlijke bijdrage waard vonden. Het optreden van een behandeleffect verlaagde de kans dat men geheel niet wilde betalen $(\mathrm{OR}=0.14,95 \% \mathrm{BI}$ 0.03 tot 0.71$)$ en verhoogde het bedrag dat men bereid was om te betalen $(\exp (\beta)=3.32$, $95 \%$ BI 1.44 tot 7.69). Het woonland bleek bovendien geassocieerd met de bereidheid om te betalen, maar niet de hoogte van het bedrag. Met betrekking tot laatstgenoemde was onze hypothese dat dit verklaard kon worden door verschillen tussen landen qua beleid omtrent de financiering van de gezondheidszorg. Deze hypothese werd gesteund door onze observatie dat patiënten woonachtig in landen waarin een eigen bijdrage voor zorg niet gebruikelijk was, ook vaker niet bereid waren om te betalen. De WTP-methode bevestigde 
de waarde van de voordelen van infliximab voor patiënten, maar leek ook te suggereren dat de prijs van deze middelen op dat moment te hoog was.

In hoofdstuk 8 richtten we ons op de kosteneffectiviteit van verschillende diagnostische algoritmes voor axSpA. Het tijdig herkennen en diagnosticeren van axSpA door verwijzers en reumatologen is een uitdaging. AxSpA kent dan ook een zogeheten 'delay in diagnosis': vaak verstrijken er meerdere jaren tussen de aanvang van de eerste symptomen, en het vaststellen van de diagnose. ${ }^{53}$ Tijdig behandelen van axSpA gaat gepaard met meerdere voordelen voor zowel de patiënt als de maatschappij, en de laatste decennia is er dan ook veel onderzoek verricht naar het verminderen van dit 'delay'. Hier staat tegenover dat er bij vroegdiagnose ook een risico is op overdiagnose. Met name sinds de recente introductie van het concept 'axSpA', met erkenning van het niet-radiologische fenotype (nr-axSpA), is een voortdurende discussie gaande over de risico's van overdiagnose en overbehandeling. Voorafgaand aan ons onderzoek waren er drie diagnostische algoritmes ontwikkeld om de reumatoloog te ondersteunen bij het stellen van de diagnose: het Berlijn algoritme (BER) en Modificaties 1 (M1) en 2 (M2). ${ }^{54,55}$ Deze algoritmes bevatten een combinatie van klinische symptomen en aanvullende onderzoeken. De diagnostische parameters van deze algoritmes, zoals de sensitiviteit en specificiteit, waren reeds bekend en het meest sensitieve algoritme (M2) werd aanbevolen door de experts. ${ }^{55}$ Echter, de gezondheidseconomische consequenties voor de lange termijn van het implementeren van deze algoritmes waren nog niet onderzocht. Geen van deze algoritmes bleek perfect, en het gebruik ervan zou kunnen resulteren in onder- en overdiagnose van axSpA, gepaard gaand met over- en onderbehandeling. Onderbehandeling van axSpA leidt tot gemiste kansen op tijdige behandeling en het verminderen van de ziektelast. Overbehandeling van axSpA leidt tot onnodige inzet van dure geneesmiddelen en tot vermijdbare bijwerkingen. Het was dan ook de vraag of het M2 algoritme nog steeds de voorkeur zou verdienen als deze consequenties op lange termijn werden meegenomen. Ons primaire doel was daarom om de kosteneffectiviteit van deze drie diagnostische algoritmes voor axSpA te onderzoeken in de Nederlandse setting, over een tijdshorizon van 60 jaar. Daarnaast wilden we weten wat de waarde was van een perfecte diagnose, om te tonen wat de winst in kwaliteit van leven en kosten zouden zijn indien er geen onder- of overdiagnose op zou treden. Ten slotte onderzochten we de waarde van het erkennen van de nr-axSpA (vergeleken met het niet erkennen of behandelen van nr-axSpA), om de additionele waarde van dit concept - de niet-radiologische vorm van axSpA - aan te tonen. We ontwikkelden een gezondheidseconomisch model dat de kosten en effecten (uitgedrukt in 'quality-adjusted life-years' of QALYS) van incorrecte diagnose en behandeling op lange termijn begroot, in een hypothetische patiëntenpopulatie verwezen naar de reumatoloog vanwege een verdenking van axSpA. Deze populatie bestond uit een mix van patiënten met axSpA en patiënten met chronische lage rugpijn zonder axSpA. Op basis van ons model was het 
meest sensitieve algoritme (M2) kosteneffectief in vergelijking met het meest specifieke algoritme (BER) en M1, ongeacht het gekozen perspectief: het maatschappelijke 'net monetary benefit' (NMB) van zowel BER als M1 was lager dan dat van M2 (incrementeel NMB: - €7412 voor BER vs M2, -€2569 voor M1 vs M2). Bovendien bleek het erkennen van nr-axSpA ook kosteneffectief, aangezien het tot meer QALYs en minder kosten leidde dan het niet erkennen of behandelen van nr-axSpA. Ten slotte bleek dat, in vergelijking met het optimale beschikbare algoritme (M2), een perfecte diagnose bijna €7500 per patiënt meer mocht kosten om nog steeds kosteneffectief te zijn. Deze studie toonde dat inzicht in de impact van diagnose op gezondheid en kosten belangrijk is. Onze belangrijkste conclusie was dat er financiële ruimte lijkt te zijn om de diagnose van axSpA verder te verbeteren.

Er zijn verschillende partijen betrokken bij de zorg voor axSpA, elk met hun eigen perspectief en hun eigen behoeften. Het is wenselijk dat patiënten met axSpA, en SpA in het algemeen, betrokken worden bij de medische besluitvorming en inzicht hebben in hun gezondheid. ${ }^{56}$ Dit vereist dat ze, op een voor hen begrijpelijke wijze, geïnformeerd zijn over het verloop van hun ziekte. Er wordt verwacht dat zorgverleners geïndividualiseerde zorg verlenen, daarbij rekening houdend met de context van de patiënt, en deze zorg richten op uitkomsten die belangrijk zijn voor patiënten. ${ }^{4,56}$ Dit vereist het regelmatig en gepersonaliseerd monitoren van relevant uitkomsten met behulp van gevalideerde instrumenten. ${ }^{57}$ De maatschappij en betalende partijen hebben vooral behoefte aan transparantie over uitkomsten, veiligheid en efficiëntie, en minimalisatie van onnodige praktijkvariatie. Dit vereist mogelijkheden om dergelijke gegevens te kunnen verzamelen in de dagelijkse praktijk en deze te kunnen vergelijken tussen centra (benchmarking). Met deze verschillende perspectieven in het achterhoofd, hebben we ons in hoofdstuk $\mathbf{9}$ gericht op de ontwikkeling en implementatie van een ziekte-specifiek register voor SpA ('SpA-Net'). Over een periode van enkele jaren werd SpA-Net geconceptualiseerd, ontwikkeld, getest en in de praktijk geïmplementeerd in 5 centra in Nederland. Het systeem is opgezet als een gezondheids- en kwaliteitsregister, en geïntegreerd in de dagelijkse reumatologiepraktijk als elektronisch patiëntendossier. Patiënten hebben op afstand ook toegang tot het systeem, en kunnen het gebruiken om inzicht te krijgen in hun ziekte en om vragenlijsten in te vullen. Hierbij is aandacht besteed aan het grafisch weergeven van gegevens op een begrijpelijke wijze. Ook zijn er mogelijkheden ingebouwd om een select aantal uitkomsten tussen deelnemende centra te vergelijken. In februari 2019, 3 jaar na de lancering, waren inmiddels meer dan 1.000 patiënten geïncludeerd. De bruikbaarheid en aanvaardbaarheid van SpA-Net, inclusief de gebruikstevredenheid, werd onderzocht met semi-gestructureerde interviews in focusgroepen van patiënten, en in groepsinterviews met zorgverleners. Verschillende potentiële barrières tegen het succesvol gebruik van SpA-Net werden geïdentificeerd. Zowel de patiënten als zorgverleners beschouwden SpA-Net als geschikt voor gebruik en een waardevolle aanvulling in de dagelijkse praktijk. 


\section{Samenvatting van de algemene discussie}

In hoofdstuk 10 zijn de resultaten van dit proefschrift uitgebreid besproken in de context van de huidige literatuur en kennis over de verschillende onderwerpen, vanuit het perspectief van de patiënt en de maatschappij. Hieronder volgt een samenvatting van deze discussie.

\section{Perspectief van de patiënt}

Vanuit het perspectief van de patiënt was deze discussie met name gericht op het thema van mentale gezondheid en psychiatrische comorbiditeit bij axSpA, in het bijzonder depressie en depressieve symptomen. Hierbij kwamen de volgende aspecten aan bod: de uitdaging van het meten van depressieve symptomen bij axSpA, de rol van contextuele factoren bij comorbide depressie (met name 'mastery'), en ontsteking als mogelijk causale factor van comorbide depressie.

Een belangrijke vraag bij onderzoek naar comorbide depressie is wellicht in hoeverre we meten wat we denken te meten. Onderzoek naar comorbide depressie gebeurt meestal met screeningsinstrumenten in de vorm van vragenlijsten. Los van het feit dat screeningsinstrumenten in algemene zin niet als diagnostisch middel bedoeld zijn, zijn er ook specifieke problemen van het gebruik van dergelijke instrumenten bij axSpA. Zo is er overlap tussen de symptomen van axSpA en die van depressie (zoals moeheid, slaapproblemen), wat bijdraagt op het risico op misclassificatie van depressie bij het gebruik van dergelijke screeningsinstrumenten. Verschillende screeningsinstrumenten voor depressie hebben subschalen, die mogelijk inzicht bieden in bovengenoemde overlap, maar de validiteit en betrouwbaarheid van deze subschalen zijn niet altijd goed onderzocht. ${ }^{58,59} \mathrm{Om}$ misclassificatie te beperken hebben we ons in onze studies (hoofdstuk

3 en hoofdstuk 4) vooral gericht op de mate van depressieve symptomen, en niet op mogelijke aan- of afwezigheid van depressie. Ook vanuit klinisch oogpunt vonden wij dit een betere keuze (voor een patiënt kan er sprake zijn van relevante depressieve symptomen zonder klinische depressie). Bovendien hebben we in onze SEM-analyse (hoofdstuk 3) niet de directe HADS-D score gebruikt als maat voor depressieve symptomen, maar een latente factor 'depressie' gegenereerd op basis van de individuele vragen van de HADS-D, die het depressie-construct beter reflecteert. Het alternatief voor een screeningsinstrument, namelijk een klinische diagnose van depressie door een specialist, gaat ook gepaard met mogelijke nadelen. Onderzoek naar depressie bij axSpA wordt ook bemoeilijkt door de waarschijnlijk bidirectionele relatie tussen beide, waardoor de daadwerkelijke aard van een geobserveerde associatie tussen beide onzeker is. Dit probleem wordt ingewikkelder als we ons realiseren dat de affectieve staat van een patiënt (bijvoorbeeld de aanwezigheid van sombere gevoelens) waarschijnlijk ook invloed heeft op hoe hij of zij de ziekte axSpA ervaart. ${ }^{60-63}$ Veel relevante uitkomsten van axSpA meten we met patiënt-gerapporteerde 
uitkomstmaten, die dus minder bruikbaar zullen zijn bij onderzoek naar depressie als blijkt dat ze worden verstoord door depressieve symptomen.

Als we kijken naar mogelijke determinanten van depressie bij axSpA, blijken contextuele factoren een belangrijke rollen te vervullen. Met name 'mastery' lijkt hierin centraal te staan (hoofdstuk 3). Het gevoel van mastery (een term die zich in deze context lastig lijkt te vertalen naar het Nederlands) wordt gedefinieerd als de mate waarin men zich in controle voelt over het leven. Mastery staat sinds de jaren 70 van de vorige eeuw bekend als een belangrijke persoonlijke bron voor effectieve coping (omgaan met problemen en stress).64,65 Naar aanleiding van onze bevindingen zou een vervolgvraag kunnen zijn of het verbeteren van het gevoel van mastery een manier zou kunnen zijn om depressieve symptomen bij axSpA te bestrijden. Indien dit het geval is, zou aan drie voorwaarden moeten worden voldaan. Ten eerste zou mastery niet een stabiele persoonlijkheidstrek moeten zijn, maar een factor die kan veranderen over de tijd. Op basis van literatuuronderzoek bleek dit het geval te zijn: mastery kent een globaal verloop gedurende het leven met een piek rond de middelbare leeftijd, en lijkt daarnaast ook op kortere termijn te kunnen veranderen bij bepaalde gebeurtenissen. ${ }^{66-68}$ Ten tweede zou mastery niet alleen veranderlijk, maar ook op een bewuste manier te veranderen moeten zijn, door een interventie. Hiervoor bleek weinig bewijs te bestaan, en al helemaal niet binnen axSpA. Veel studies binnen dit onderzoeksveld hebben zich gericht op zelfeffectiviteit, een construct dat gerelateerd is aan mastery. Er zijn aanwijzingen dat zelfmanagementprogramma's en cognitieve gedragstherapie kunnen leiden tot verbetering van zelfeffectiviteit bij reumatische aandoeningen ${ }^{69-71}$ Echter, het is onzeker of mastery op eenzelfde wijze zou verbeteren. Ten derde zou een bewuste verbetering van mastery ook moeten leiden tot een verbetering van depressieve symptomen. De studies die naar mastery of zelfeffectiviteit kijken bij reumatische aandoeningen, hebben vaak ook naar depressie gekeken. ${ }^{70,72,73}$ Echter, de relatie tussen beide werd nog niet onderzocht in dergelijke studies. Verder onderzoek hiernaar is dus aangewezen. Daar komt nog bij dat het grootste deel van het onderzoek naar comorbide depressie is uitgevoerd bij andere reumatische aandoeningen dan axSpA. Waarschijnlijk zijn de bevindingen van deze studies ook van toepassing op axSpA, maar dat zou nog bevestigd moeten worden.

Ten slotte is er steeds meer onderzoek naar de rol van ontsteking bij comorbide depressie. In hoeverre is er bewijs voor 'inflammatoire depressie' bij reumatologische aandoeningen? Basaal en translationeel onderzoek in populaties zonder reumatologische aandoeningen heeft laten zien via welke mechanismen perifere inflammatie zou kunnen leiden tot centrale inflammatie, gevolgd door veranderingen in neurotransmitters en neuronale circuits met uiteindelijk symptomen passend bij een depressieve stoornis. ${ }^{48}$ Biomarkeronderzoek in populaties zonder reumatologische aandoeningen en in populaties met reumatologische aandoeningen heeft associaties tussen perifere inflammatoire biomarkers en depressieve symptomen getoond. ${ }^{16,74,75}$ Ook zijn er klinische observaties 
die een link tussen inflammatie en depressie ondersteunen. De manifestaties van centrale inflammatie op neurotransmitters en neuronale circuits ondermijnen de werking van conventionele antidepressiva. Deze medicijnen werken dan ook minder goed bij personen met depressie en verhoogde inflammatieparameters (zonder reumatologische aandoening). ${ }^{76,77}$ Bij patiënten met reumatologische aandoeningen is dit helaas onvoldoende onderzocht. Bovendien zijn er ook observaties die het idee van de 'inflammatoire depressie' bij reumatologische aandoeningen lijken te ontkrachten. Zo blijken patiënten met een reumatologische aandoening en comorbide depressieve symptomen minder effect te ervaren van bDMARDs wat betreft symptomen van de reumatologische aandoening (zoals pijn en fysiek functioneren), ondanks een duidelijke afname van inflammatieparameters. ${ }^{62,63,78-80}$ Ook onze studie (hoofdstuk 4) toonde geen aanwijzingen voor een link tussen inflammatie en depressieve symptomen bij axSpA. Dit betekent niet dat een dergelijke link niet bestaat. Allereerst is depressie een heterogene aandoening, waar mogelijk verschillende mechanismen aan ten grondslag liggen. ${ }^{81}$ Onze studiepopulatie was te klein om naar verschillende subgroepen - met verschillende pathofysiologische mechanismen van depressieve symptomen - te kijken. Bovendien lijkt het waarschijnlijk dat er sprake is van een combinatie van factoren, dus niet of-of, maar zowel de impact van axSpA-symptomen op psychologisch welbevinden als een direct effect van inflammatie. Daarnaast gebruikten we alleen CRP als marker voor inflammatie. Wellicht zijn andere inflammatieparameters meer geschikt voor onderzoek naar comorbide depressie bij reumatologische aandoeningen.

\section{Perspectief van de maatschappij}

Vanuit het maatschappelijk perspectief richtte de discussie zich op twee thema's: (1) het meten en waarderen van productiviteit (werk) en (2) economische evaluaties en diagnose van axSpA.

Het meten en waarderen van productiviteit

De bespreking van productiviteit in deze thesis richtte zich specifiek op betaald werk. Bij ziekte kan de productiviteit afnemen als gevolg van absenteïsme (afwezigheid van het werk, dus ziekmelding of arbeidsongeschiktheid) en presenteïsme (verminderde productiviteit terwijl men werkt). Er zijn verschillende uitdagingen rondom het meten van veranderingen in productiviteit. Vrijwel altijd wordt voor dergelijke metingen gebruik gemaakt van vragenlijsten, waarmee men probeert in te schatten hoeveel werkuren er verloren zijn gegaan door absenteïsme en presenteïsme. Deze instrumenten verschillen echter in de benadering en het soort vragen dat ze gebruiken, en daarmee ook in de resultaten. ${ }^{82,83}$ In onze studie naar ziekteverzuim bij r-axSpA (hoofdstuk 5) werd patiënten gevraagd om aan te geven of en zo ja, hoe lang (open vraag), ze afwezig waren geweest van hun werk als gevolg van hun ziekte. Een dergelijke vraagstelling gaat gepaard met meerdere 
kanttekeningen. Allereerst is het de vraag in hoeverre patiënten kunnen inschatten of afwezigheid van werk ziektegerelateerd is of niet. Daarnaast bleek de open vraag betreffende de lengte van het ziekteverzuim te leiden tot wijd uiteenlopende antwoorden, die soms ook niet duidelijk te interpreteren waren, of zelfs implausibel. Naast dit soort uitdagingen omtrent de inhoud en formulering van werkgerelateerde vragenlijsten, is er een risico van herinneringsbias ('recall bias'). Patiënten kunnen zich gebeurtenissen van weken of maanden geleden niet altijd meer herinneren, of hechten (onbewust) meer waarde aan bepaalde herinneringen en zijn geneigd deze beter te rapporteren. ${ }^{84-86}$

De volgende stap is het waarderen van de gemeten veranderingen in productiviteit. Er zijn twee gebruikelijke methoden hiervoor, namelijk de 'frictiekostenmethode' en de 'human capital methode'. Waar de eerstgenoemde methode bij de waardering van productiviteitsverliezen ervan uitgaat dat een afwezige werknemer na een bepaalde periode wordt vervangen (en dat de productiviteitskosten dan eindigen), is dit bij laatstgenoemde niet het geval. Ondanks veel discussie is er nog geen internationale consensus over de beste methode..$^{87,88}$ De Nederlandse richtlijn voor economische evaluaties adviseert de frictiekostenmethode. ${ }^{89}$ Daarnaast spelen er andere uitdagingen bij de waardering van veranderingen in productiviteit. Zo is het onzeker in hoeverre verloren werkuren van een individuele werknemer één-op-één te vertalen zijn naar een productiviteitsverlies voor de maatschappij. Factoren zoals het werken in teamverband, de beschikbaarheid van geschikte vervanging en de tijdsgevoeligheid van het werk (urgentie/deadlines) bepalen ook in hoeverre er uiteindelijk productiviteitsverlies optreedt. ${ }^{90}$ Enerzijds kan de afwezigheid van een werknemer ook de productiviteit van andere werknemers verminderen ('multiplier' effect). Anderzijds kunnen collega's juist vaak taken overnemen van afwezige of minder productieve werknemers (compensatiemechanismen). Tijdsverlies leidt dus niet per se tot productiviteitsverlies.

Bovenstaande uitdagingen rondom het meten en waarderen van veranderingen in productiviteit hebben ook een rol gespeeld bij onze kosteneffectiviteitsanalyse van de diagnose van axSpA (hoofdstuk 8). In de hoofdanalyse van deze studie werden alleen verliezen door absenteïsme meegenomen, en in een sensitiviteitsanalyse ook verliezen als gevolg van presenteïsme. In het SPondyloArthritis Caught Early (SPACE) cohort, de belangrijkste databron voor werk in onze studie, heeft men de Work Productivity and Activity Impairment Questionnaire (WPAI) gebruikt voor het meten van productiviteit. De WPAI vraagt patiënten naar de impact van ziekte op werk in de afgelopen 7 dagen. Omdat we alleen de baseline data tot onze beschikking hadden, moesten we aannemen dat deze periode van 7 dagen representatief was voor een langere periode. Bovendien gingen we er bij het bepalen van de mate van presenteïsme van uit dat de ziekte normaliter geen impact had tijdens het werken. Dit kan hebben geleid tot een overschatting van presenteïsme, en de sensitiviteitsanalyse mét presenteïsme kan daarom worden beschouwd als een 'worst case scenario'. Overigens waren de resultaten in dit scenario vergelijkbaar met die 
van de hoofdanalyse. Ook wat betreft het percentage patiënten met axSpA of chronische lage rugpijn dat betaald werk had, moesten we aannames doen. Zo deden we, bij gebrek aan data of ondersteunende literatuur, de aanname dat de kans op het hebben van betaald werk vergelijkbaar was in alle patiënten, onafhankelijk of ze correct of incorrect gediagnosticeerd waren. Ook bij het waarderen van de productiviteitsverliezen in monetaire waarde waren er uitdagingen voor onze studie. Om praktische redenen presenteerden we de resultaten van zowel de frictiekostenmethode als de human capital methode. Voor de frictiekostenmethode moesten we bovendien extra aannames doen omtrent het optreden van langdurig absenteïsme, omdat dit (deels) niet mee zou tellen indien een werknemer na enige tijd vervangen zou zijn. Ook zijn we ervan uitgegaan dat een verloren werkuur qua maatschappelijke kosten gelijk staat aan een gemiddeld uurloon, en hebben we mogelijke 'multipliers' en compensatiemechanismen dus niet meegenomen.

\section{Economische evaluaties en diagnose van axSpA}

De bespreking van economische evaluaties en diagnose van axSpA in deze thesis richtte zich eerst op het concept van de vroege economische evaluatie. Vervolgens werd besproken hoe de diagnose van axSpA kan worden verbeterd, en welke rol (vroege) economische evaluaties hierbij kunnen spelen.

Economische evaluaties, zoals hierboven geïntroduceerd, zijn bedoeld om nieuwe medische technologieën te beoordelen door de voordelen voor gezondheid af te wegen tegen de (mogelijk hogere) kosten, en worden vaak uitgevoerd voor technologieën die zo goed als klaar zijn voor het gebruik in de dagelijkse praktijk. ${ }^{91}$ De vroege economische evaluatie daarentegen richt zich op technologieën die nog in ontwikkeling zijn. Door in een vroeger stadium de mogelijke voor- en nadelen (in termen van kosten en gezondheidseffecten) van een nieuwe technologie in te schatten, kan de potentiële waarde - of het gebrek daaraan - worden bepaald. Zo kan tijdig worden besloten in welke technologieën te investeren en, wellicht nog belangrijker, of het ontwikkelingsproces moet worden aangepast. ${ }^{92,93}$ Bovendien kan vroege economische evaluatie beschouwd worden als een iteratief proces, omdat de evaluatie herhaald kan worden als er meer informatie beschikbaar wordt. ${ }^{92,94-96}$

Een veelgebruikte methode voor vroege economische evaluatie is de 'headroom' methode. ${ }^{97}$ Hiermee wordt bepaald hoeveel een technologie mag kosten om nog kosteneffectief te zijn (of, indien de prijs van de technologie al vaststaat, welk effect deze moet hebben om kosteneffectief te zijn). De headroom methode kan bij elke technologie worden toegepast, of deze nu in vroege ontwikkeling, volledig uitontwikkeld, of geheel hypothetisch is. Bij axSpA is deze methode, voor zover bekend, nog niet toegepast. Een headroom-analyse van diagnose van axSpA zou zeker relevant zijn, ook gezien de discussie omtrent het risico op overdiagnose van axSpA door inclusie van de niet-radiologische vorm (nr-axSpA). Onze kosteneffectiviteitsanalyse van diagnose van axSpA (hoofdstuk 8) 
was een eerste stap. We analyseerden hoeveel een hypothetische perfect diagnostische test zou mogen kosten, om kosteneffectief te zijn: zo'n €7500 per verwezen patiënt (dit bedrag is de headroom voor een perfecte test). Dat er een dergelijke ruimte is om diagnose van axSpA te verbeteren met nieuwe technologie, is relevant. Zelfs met het beste momenteel beschikbare diagnostische algoritme voor axSpA (het M2 algoritme), zal 1 op de 6 verwezen patiënten een incorrecte diagnose krijgen. Er is dus zeker behoefte aan verbetering, en de vraag is hoe we dit kunnen bereiken op een acceptabele wijze. Vroege economische evaluatie kan ons helpen om te beslissen welke diagnostische technologieën voor axSpA die nu nog in ontwikkeling zijn, investering verdienen. Hierbij is de eerste stap om te kijken wáár in het $\mathrm{M} 2$ algoritme - in welke subgroepen/locaties in het algoritme - er de meeste incorrecte diagnoses plaatsvinden: verbeterde diagnose in deze subgroepen zal waarschijnlijk het meeste opleveren. Ook is het de vraag welke technologieën hiervoor in aanmerking komen. Enerzijds kunnen technologieën die reeds gebruikt worden in de diagnostische algoritmes voor axSpA, zoals het MRI-onderzoek van de SI-gewrichten, aan additionele locaties in het algoritme worden toegevoegd. De kosteneffectiviteit van een dergelijke wijziging in het algoritme is relatief eenvoudig om te onderzoeken, omdat er voldoende data beschikbaar zijn. De opbrengst van deze analyses is echter beperkt, omdat de technologie al is uitontwikkeld. Anderzijds kunnen technologieën die nog in ontwikkeling zijn aan het algoritme worden toegevoegd. Dit is moeilijker om te onderzoeken: deze nieuwe technologieën zijn immers niet in de populatie van het algoritme onderzocht, en er zijn minder data beschikbaar. Echter, de mogelijke opbrengst van een dergelijke analyse is hoog, omdat we daarmee kunnen bepalen welke technologie verdere ontwikkeling en investering waard kan zijn. Er is dus een 'trade-off' tussen de mate van zekerheid en de potentiële opbrengst van dergelijke analyses.

Ten slotte is het goed om te vermelden dat de rol van de reumatoloog niet alomvattend is in het diagnostisch proces van axSpA: de reumatoloog is afhankelijk van verwijzingen door andere zorgverleners, met name vanuit de eerste lijn (huisartsen). In plaats van het verbeteren van diagnose door reumatologen middels nieuwe technologieën, kan ook het beter herkennen van patiënten met axSpA door huisartsen het gewenste effect hebben. Alhoewel er verschillende verwijsstrategieën voor niet-reumatologen zijn onderzocht, is het in deze studies vaak niet bekend hoe groot (en hoe ziek) de groep van 'vals-negatieven' is: de patiënten die wél axSpA hebben, maar niet door de verwijsstrategie als zodanig worden herkend. ${ }^{98-101}$ Hierdoor is het moeilijk om de kosteneffectiviteit van deze verwijsstrategieën te onderzoeken. Daarnaast is het belangrijk om te beseffen dat verwijzing (door nietreumatologen) en diagnose (door reumatologen) onderdeel zijn van hetzelfde proces, en dat er een wisselwerking tussen beide plaatsvindt. Een verandering in de verwijzing door niet-reumatologen zal leiden tot een verandering in het soort patiëntenpopulatie (de casemix) die bij de reumatoloog verschijnt. Alhoewel complex, worden deze beide onderdelen van het diagnostische proces idealiter op een geïntegreerde wijze onderzocht. 


\section{Aanbevelingen voor toekomstig onderzoek}

Op basis van de studies in dit proefschrift werden in hoofdstuk 10 enkele aanbevelingen gedaan voor toekomstig onderzoek. Vanuit het perspectief van de patiënt is er behoefte aan inzicht in hoe de verschillende screeningsinstrumenten voor depressie en depressieve symptomen presteren in patiënten met axSpA. Om de pathofysiologie van comorbide depressie bij axSpA duidelijk te krijgen, is aanvullend onderzoek nodig naar zowel contextuele factoren als biomarkers voor inflammatie. Dergelijk onderzoek zou zowel patiënten met als zonder depressieve symptomen moeten includeren en een longitudinaal design hebben. Ten slotte is het voor de patiënten in de huidige praktijk belangrijk dat behandeling van comorbide depressieve symptomen wordt onderzocht. Hierbij moet er aandacht zijn voor zowel conventionele antidepressiva als non-farmacologische behandeling (gericht op mastery of zelf-management). Ten slotte geldt een overkoepelende aanbeveling, namelijk om studies specifiek te ontwerpen om comorbide depressie of depressieve symptomen te onderzoeken, in plaats van het beschouwen van deze symptomen als secundaire uitkomst.

Vanuit het perspectief van de maatschappij is aanvullend onderzoek nodig naar de verschillende meetinstrumenten voor presenteïsme. Ook is er behoefte aan validatie van de 'multipliers' en compensatiemechanismen, zodat deze correct kunnen worden toegepast bij het waarderen van veranderingen in productiviteit. Om het diagnostisch proces van axSpA te verbeteren, zijn er studies nodig in populaties met chronische lage rugpijn in de eerste lijn, om verwijzing door niet-reumatologen, diagnose door reumatologen, en de wisselwerking tussen de twee in kaart te brengen. Hierbij dient er specifiek aandacht te zijn voor de patiënten met axSpA die gemist worden bij verwijzing (de vals-negatieven), omdat we minder weten over deze groep. De resultaten kunnen gebruikt worden als input voor economische evaluaties van de verschillende verwijsstrategieën voor axSpA. Ten slotte zijn er verschillende diagnostische biomarkers voor axSpA in ontwikkeling. De potentiële waarde van deze technologieën moet worden onderzocht in vroege economische evaluaties, zodat men op geïnformeerde en gerichte wijze kan investeren in betere diagnose van axSpA.

\section{Impact}

In hoofdstuk 11 werd de wetenschappelijke en maatschappelijke impact van dit proefschrift besproken. Hieronder volgt een selectie van de implicaties van onze bevindingen voor de verschillende belanghebbenden. Voor onderzoek(ers) hebben we aangetoond dat een gezondheidseconomische evaluatie van de consequenties van (in) correcte diagnose haalbaar is, en hoe dergelijk onderzoek kan helpen bij het waarderen van nieuwe technologieën. Dit vraagt om een sterkere integratie van 'health technology 
assessment' in basaal en translationeel onderzoek. Voor de maatschappij wijzen onze bevindingen erop dat de werkstatus van patiënten met axSpA minder goed is dan die van de algehele populatie, en dat patiënten met axSpA herhaaldelijk verzuimen door hun ziekte. Alhoewel hier dus zeker ruimte voor verbetering lijkt te zijn, is het nog onduidelijk hoe patiënten op een duurzame en gezonde wijze ondersteund kunnen worden in hun arbeidsrol. Ook relevant voor de maatschappij is dat we toonden dat er (financieel) ruimte is om de diagnose van axSpA te verbeteren, en dat investeringen in onderzoek hiernaar waarschijnlijk de moeite waard zullen zijn. Voor patiënten heeft ons onderzoek duidelijk gemaakt dat depressieve symptomen regelmatig voorkomen bij axSpA, wat deze gevoelens hopelijk bespreekbaar maakt voor patiënten. Daarnaast hebben we met ons onderzoek aangetoond dat depressieve symptomen bij actieve axSpA in de meeste - maar niet alle - patiënten afnemen door behandeling met een bDMARD. Onze bevindingen wat betreft werk en ziekteverzuim zouden patiënten moeten stimuleren om werkgerelateerde zaken te bespreken met diegenen die hen in deze rol kunnen ondersteunen, zoals zorgverleners, de bedrijfsarts en hun werkgever. Het elektronische monitoringssysteem voor patiënten met SpA dat we ontwikkelden (SpA-Net) en waar patiënten actief in kunnen participeren, zal bijdragen aan gedeelde besluitvorming en 'empowerment' van patiënten. Voor zorgverleners, ten slotte, hebben we aangetoond dat zij zich bewust moeten zijn van de substantiële invloed van contextuele factoren (geslacht, opleiding, mastery) op relevante uitkomsten bij axSpA. Veel van de relaties tussen contextuele factoren en uitkomsten zijn waarschijnlijk niet eenvoudig om aan te passen, maar simpelweg het (h)erkennen ervan kan helpen om 'risicopatiënten' te identificeren in de dagelijkse praktijk en waar nodig extra ondersteuning te bieden. 


\section{Referenties}

1. Sieper J, Poddubnyy D. Axial spondyloarthritis. Lancet 2017;390:73-84.

2. Stolwijk C, Essers I, van Tubergen A, Boonen A, Bazelier MT, De Bruin ML, et al. The epidemiology of extra-articular manifestations in ankylosing spondylitis: a population-based matched cohort study. Ann Rheum Dis 2015;74:1373-1378.

3. Rudwaleit M, van der Heijde D, Landewe R, Listing J, Akkoc N, Brandt J, et al. The development of Assessment of SpondyloArthritis international Society classification criteria for axial spondyloarthritis (part II): validation and final selection. Ann Rheum Dis 2009;68:777-783.

4. van der Heijde D, Ramiro S, Landewe R, Baraliakos X, Van den Bosch F, Sepriano A, et al. 2016 update of the ASAS-EULAR management recommendations for axial spondyloarthritis. Ann Rheum Dis 2017;76:978-991.

5. van der Horst-Bruinsma IE, Oostveen JCM, van Denderen JC, de Sonnaville PB, Nurmohamed MT, van Tubergen A, et al. Guideline for the diagnosis and treatment of axial spondyloarthritis [Richtlijn voor de diagnostiek en behandeling van axiale spondyloartritis]. Nederlandse Vereniging voor Reumatologie 2014.

6. Kiltz U, Essers I, Hiligsmann M, Braun J, Maksymowych WP, Taylor WJ, et al. Which aspects of health are most important for patients with spondyloarthritis? A Best Worst Scaling based on the ASAS Health Index. Rheumatology (Oxford) 2016;55:1771-1776.

7. Gignac MA, Backman CL, Davis AM, Lacaille D, Mattison CA, Montie P, et al. Understanding social role participation: what matters to people with arthritis? J Rheumatol 2008;35:1655-1663.

8. van Genderen S, Plasqui G, Landewe R, Lacaille D, Arends S, van Gaalen F, et al. Social Role Participation in Patients With Ankylosing Spondylitis: A Cross-Sectional Comparison With Population Controls. Arthritis Care Res (Hoboken) 2016;68:1899-1905.

9. van der Weijden MA, Boonen A, van der Horst-Bruinsma IE. Problems in work participation and resource use should not be underestimated in patients with early spondyloarthritis. J Rheumatol 2014;41:2413-2420.

10. Castillo-Ortiz JD, Ramiro S, Landewe R, van der Heijde D, Dougados M, van den Bosch F, et al. Work Outcome in Patients With Ankylosing Spondylitis: Results From a 12-Year Followup of an International Study. Arthritis Care Res (Hoboken) 2016;68:544-552.

11. Gordeev VS, Maksymowych WP, Schachna L, Boonen A. Understanding presenteeism in patients with ankylosing spondylitis: contributing factors and association with sick leave. Arthritis Care Res (Hoboken) 2014;66:916-924.

12. Boonen A, Brinkhuizen T, Landewe R, van der Heijde D, Severens JL. Impact of ankylosing spondylitis on sick leave, presenteeism and unpaid productivity, and estimation of the societal cost. Ann Rheum Dis 2010;69:1123-1128.

13. Floderus B, Goransson S, Alexanderson K, Aronsson G. Self-estimated life situation in patients on long-term sick leave. J Rehabil Med 2005;37:291-299. 
14. World Health Organization. International classification of functioning, disability and health: ICF. Geneva: World Health Organization; 2001.

15. Molto A, Etcheto A, van der Heijde D, Landewe R, van den Bosch F, Bautista Molano W, et al. Prevalence of comorbidities and evaluation of their screening in spondyloarthritis: results of the international cross-sectional ASAS-COMOSPA study. Ann Rheum Dis 2016;75:1016-1023.

16. Zhao S, Thong D, Miller N, Duffield SJ, Hughes DM, Chadwick L, et al. The prevalence of depression in axial spondyloarthritis and its association with disease activity: a systematic review and meta-analysis. Arthritis Res Ther 2018;20:140.

17. Lowe B, Willand L, Eich W, Zipfel S, Ho AD, Herzog W, et al. Psychiatric comorbidity and work disability in patients with inflammatory rheumatic diseases. Psychosom Med 2004;66:395-402.

18. Baillet A, Gossec L, Carmona L, Wit M, van Eijk-Hustings Y, Bertheussen H, et al. Points to consider for reporting, screening for and preventing selected comorbidities in chronic inflammatory rheumatic diseases in daily practice: a EULAR initiative. Ann Rheum Dis 2016;75:965-973.

19. Meesters JJ, Bremander A, Bergman S, Petersson IF, Turkiewicz A, Englund M. The risk for depression in patients with ankylosing spondylitis: a population-based cohort study. Arthritis Res Ther 2014;16:418.

20. Shen CC, Hu LY, Yang AC, Kuo BI, Chiang YY, Tsai SJ. Risk of Psychiatric Disorders following Ankylosing Spondylitis: A Nationwide Population-based Retrospective Cohort Study. J Rheumatol 2016;43:625-631.

21. Huscher D, Merkesdal S, Thiele K, Zeidler H, Schneider M, Zink A, et al. Cost of illness in rheumatoid arthritis, ankylosing spondylitis, psoriatic arthritis and systemic lupus erythematosus in Germany. Ann Rheum Dis 2006;65:1175-1183.

22. Zorginstituut Nederland / www.medicijnkosten.nl; 2019 [cited 2019 December 1]. Available from: http://www.medicijnkosten.nl/.

23. Ward MM. Functional disability predicts total costs in patients with ankylosing spondylitis. Arthritis Rheum 2002;46:223-231.

24. Franke LC, Ament AJ, van de Laar MA, Boonen A, Severens JL. Cost-of-illness of rheumatoid arthritis and ankylosing spondylitis. Clin Exp Rheumatol 2009;27:S118-123.

25. Harvard S, Guh D, Bansback N, Richette P, Dougados M, Anis A, et al. Costs of early spondyloarthritis: estimates from the first 3 years of the DESIR cohort. RMD Open 2016;2:e000230.

26. Drummond MF, Sculpher MJ, Claxton K, Stoddart GL, Torrance GW. Methods for the Economic Evaluation of Health Care Programmes. 4th ed. Oxford: Oxford University Press; 2015.

27. Boonen A, Webers C. Chapter 17 - Economic Evaluations in Axial Spondyloarthritis. In: Mease P, Khan MA. Axial Spondyloarthritis. St. Louis: Elsevier 2019: 259-279.

28. Ibn Yacoub Y, Amine B, Laatiris A, Hajjaj-Hassouni N. Gender and disease features in Moroccan patients with ankylosing spondylitis. Clin Rheumatol 2012;31:293-297.

29. Roussou E, Sultana S. Spondyloarthritis in women: differences in disease onset, clinical presentation, and Bath Ankylosing Spondylitis Disease Activity and Functional indices (BASDAI and BASFI) between men and women with spondyloarthritides. Clin Rheumatol 2011;30:121-127. 
30. Lee W, Reveille JD, Davis JC, Jr., Learch TJ, Ward MM, Weisman MH. Are there gender differences in severity of ankylosing spondylitis? Results from the PSOAS cohort. Ann Rheum Dis 2007; 66:633-638.

31. Slobodin G, Reyhan I, Avshovich N, Balbir-Gurman A, Boulman N, Elias M, et al. Recently diagnosed axial spondyloarthritis: gender differences and factors related to delay in diagnosis. Clin Rheumatol 2011;30:1075-1080.

32. Rudwaleit M, Haibel H, Baraliakos X, Listing J, Marker-Hermann E, Zeidler H, et al. The early disease stage in axial spondylarthritis: results from the German Spondyloarthritis Inception Cohort. Arthritis Rheum 2009;60:717-727.

33. Tournadre A, Pereira B, Lhoste A, Dubost JJ, Ristori JM, Claudepierre P, et al. Differences between women and men with recent-onset axial spondyloarthritis: results from a prospective multicenter French cohort. Arthritis Care Res (Hoboken) 2013;65:1482-1489.

34. Feldtkeller E, Bruckel J, Khan MA. Scientific contributions of ankylosing spondylitis patient advocacy groups. Curr Opin Rheumatol 2000;12:239-247.

35. Brionez TF, Assassi S, Reveille JD, Learch TJ, Diekman L, Ward MM, et al. Psychological correlates of self-reported functional limitation in patients with ankylosing spondylitis. Arthritis Res Ther 2009;11:R182

36. Brionez TF, Assassi S, Reveille JD, Green C, Learch T, Diekman L, et al. Psychological correlates of self-reported disease activity in ankylosing spondylitis. J Rheumatol 2010;37:829-834.

37. Martindale J, Smith J, Sutton CJ, Grennan D, Goodacre L, Goodacre JA. Disease and psychological status in ankylosing spondylitis. Rheumatology (Oxford) 2006;45:1288-1293.

38. Hakkou J, Rostom S, Aissaoui N, Berrada KR, Abouqal R, Bahiri R, et al. Psychological status in Moroccan patients with ankylosing spondylitis and its relationships with disease parameters and quality of life. J Clin Rheumatol 2011;17:424-428.

39. Redeker I, Hoffmann F, Callhoff J, Haibel H, Sieper J, Zink A, et al. Determinants of psychological well-being in axial spondyloarthritis: an analysis based on linked claims and patient-reported survey data. Ann Rheum Dis 2018;77:1017-1024.

40. Barlow JH, Macey SJ, Struthers GR. Gender, depression, and ankylosing spondylitis. Arthritis Care Res 1993;6:45-51.

41. Leentjens AF, Aben I, Lodder J, Verhey FR. General and disease-specific risk factors for depression after ischemic stroke: a two-step Cox regression analysis. Int Psychogeriatr 2006;18:739-748.

42. Leentjens AF, Moonen AJ, Dujardin K, Marsh L, Martinez-Martin P, Richard IH, et al. Modeling depression in Parkinson disease: disease-specific and nonspecific risk factors. Neurology 2013;81:1036-1043.

43. Gimeno D, Kivimaki M, Brunner EJ, Elovainio M, De Vogli R, Steptoe A, et al. Associations of C-reactive protein and interleukin-6 with cognitive symptoms of depression: 12-year follow-up of the Whitehall II study. Psychol Med 2009;39:413-423.

44. Duivis HE, de Jonge P, Penninx BW, Na BY, Cohen BE, Whooley MA. Depressive symptoms, health behaviors, and subsequent inflammation in patients with coronary heart disease: prospective findings from the heart and soul study. Am J Psychiatry 2011;168:913-920. 
45. Au B, Smith KJ, Gariepy G, Schmitz N. The longitudinal associations between C-reactive protein and depressive symptoms: evidence from the English Longitudinal Study of Ageing (ELSA). Int J Geriatr Psychiatry 2015;30:976-984.

46. Wium-Andersen MK, Orsted DD, Nielsen SF, Nordestgaard BG. Elevated C-reactive protein levels, psychological distress, and depression in 73, 131 individuals. JAMA Psychiatry 2013;70:176-184.

47. Raison CL, Rutherford RE, Woolwine BJ, Shuo C, Schettler P, Drake DF, et al. A randomized controlled trial of the tumor necrosis factor antagonist infliximab for treatment-resistant depression: the role of baseline inflammatory biomarkers. JAMA Psychiatry 2013;70:31-41.

48. Miller $\mathrm{AH}$, Raison $\mathrm{CL}$. The role of inflammation in depression: from evolutionary imperative to modern treatment target. Nat Rev Immunol 2016;16:22-34.

49. Boonen A, Chorus A, Miedema H, van der Heijde D, van der Tempel H, van der Linden S. Employment, work disability, and work days lost in patients with ankylosing spondylitis: a cross sectional study of Dutch patients. Ann Rheum Dis 2001;60:353-358.

50. Klose T. The contingent valuation method in health care. Health Policy 1999;47:97-123.

51. O'Brien B, Gafni A. When do the "dollars" make sense? Toward a conceptual framework for contingent valuation studies in health care. Med Decis Making 1996;16:288-299.

52. Diener A, O'Brien B, Gafni A. Health care contingent valuation studies: a review and classification of the literature. Health Econ 1998;7:313-326.

53. Sykes MP, Doll H, Sengupta R, Gaffney K. Delay to diagnosis in axial spondyloarthritis: are we improving in the UK? Rheumatology (Oxford) 2015;54:2283-2284.

54. Rudwaleit M, van der Heijde D, Khan MA, Braun J, Sieper J. How to diagnose axial spondyloarthritis early. Ann Rheum Dis 2004;63:535-543.

55. van den Berg R, de Hooge M, Rudwaleit M, Sieper J, van Gaalen F, Reijnierse M, et al. ASAS modification of the Berlin algorithm for diagnosing axial spondyloarthritis: results from the SPondyloArthritis Caught Early (SPACE)-cohort and from the Assessment of SpondyloArthritis international Society (ASAS)-cohort. Ann Rheum Dis 2013;72:1646-1653.

56. Smolen JS, Schols M, Braun J, Dougados M, FitzGerald O, Gladman DD, et al. Treating axial spondyloarthritis and peripheral spondyloarthritis, especially psoriatic arthritis, to target: 2017 update of recommendations by an international task force. Ann Rheum Dis 2018;77:3-17.

57. Porter ME, Larsson S, Lee TH. Standardizing Patient Outcomes Measurement. N Engl J Med 2016;374:504-506.

58. Ensel WM. 4 - Measuring Depression: The CES-D Scale. In: Lin N, Dean A, Ensel WM. Social Support, Life Events, and Depression. Orlando: Academic Press 1986: 51-70.

59. Carleton RN, Thibodeau MA, Teale MJ, Welch PG, Abrams MP, Robinson T, et al. The center for epidemiologic studies depression scale: a review with a theoretical and empirical examination of item content and factor structure. PLoS One 2013;8:e58067.

60. Disner SG, Beevers CG, Haigh EA, Beck AT. Neural mechanisms of the cognitive model of depression. Nat Rev Neurosci 2011;12:467-477.

61. Gotlib IH, Joormann J. Cognition and depression: current status and future directions. Annu Rev Clin Psychol 2010;6:285-312. 
62. Michelsen B, Kristianslund EK, Sexton J, Hammer HB, Fagerli KM, Lie E, et al. Do depression and anxiety reduce the likelihood of remission in rheumatoid arthritis and psoriatic arthritis? Data from the prospective multicentre NOR-DMARD study. Ann Rheum Dis 2017;76:1906-1910.

63. Kekow J, Moots R, Khandker R, Melin J, Freundlich B, Singh A. Improvements in patient-reported outcomes, symptoms of depression and anxiety, and their association with clinical remission among patients with moderate-to-severe active early rheumatoid arthritis. Rheumatology (Oxford) 2011;50:401-409.

64. Pearlin LI, Lieberman MA, Menaghan EG, Mullan JT. The stress process. J Health Soc Behav 1981;22:337-356

65. Taylor SE, Stanton AL. Coping resources, coping processes, and mental health. Annu Rev Clin Psychol 2007;3:377-401.

66. Mirowsky J, Ross Catherine E. Life Course Trajectories of Perceived Control and Their Relationship to Education. American Journal of Sociology 2007;112:1339-1382.

67. Cairney J, Krause N. Negative life events and age-related decline in mastery: are older adults more vulnerable to the control-eroding effect of stress? J Gerontol B Psychol Sci Soc Sci 2008;63:S162-170.

68. Eizenman DR, Nesselroade JR, Featherman DL, Rowe JW. Intraindividual variability in perceived control in an older sample: the MacArthur successful aging studies. Psychol Aging 1997;12:489-502.

69. Sturgeon JA, Finan PH, Zautra AJ. Affective disturbance in rheumatoid arthritis: psychological and disease-related pathways. Nat Rev Rheumatol 2016;12:532-542.

70. Prothero L, Barley E, Galloway J, Georgopoulou S, Sturt J. The evidence base for psychological interventions for rheumatoid arthritis: A systematic review of reviews. Int J Nurs Stud 2018;82:20-29.

71. Iversen MD, Hammond A, Betteridge N. Self-management of rheumatic diseases: state of the art and future perspectives. Ann Rheum Dis 2010;69:955-963.

72. DiRenzo D, Crespo-Bosque M, Gould N, Finan P, Nanavati J, Bingham CO, 3rd. Systematic Review and Meta-analysis: Mindfulness-Based Interventions for Rheumatoid Arthritis. Curr Rheumatol Rep 2018;20:75.

73. Primdahl J, Wagner L, Horslev-Petersen K. Self-efficacy as an outcome measure and its association with physical disease-related variables in persons with rheumatoid arthritis: a literature review. Musculoskeletal Care 2011;9:125-140.

74. Dowlati Y, Herrmann N, Swardfager W, Liu H, Sham L, Reim EK, et al. A meta-analysis of cytokines in major depression. Biol Psychiatry 2010;67:446-457.

75. Howren MB, Lamkin DM, Suls J. Associations of depression with C-reactive protein, IL-1, and IL-6: a meta-analysis. Psychosom Med 2009;71:171-186.

76. Cattaneo A, Gennarelli M, Uher R, Breen G, Farmer A, Aitchison KJ, et al. Candidate genes expression profile associated with antidepressants response in the GENDEP study: differentiating between baseline 'predictors' and longitudinal 'targets'. Neuropsychopharmacology 2013;38:377-385.

77. Chamberlain SR, Cavanagh J, de Boer P, Mondelli V, Jones DNC, Drevets WC, et al. Treatmentresistant depression and peripheral C-reactive protein. Br J Psychiatry 2019;214:11-19. 
78. Rathbun AM, Harrold LR, Reed GW. Temporal effect of depressive symptoms on the longitudinal evolution of rheumatoid arthritis disease activity. Arthritis Care Res (Hoboken) 2015;67:765-775.

79. Matcham F, Norton S, Scott DL, Steer S, Hotopf M. Symptoms of depression and anxiety predict treatment response and long-term physical health outcomes in rheumatoid arthritis: secondary analysis of a randomized controlled trial. Rheumatology (Oxford) 2016;55:268-278.

80. Matcham F, Davies R, Hotopf M, Hyrich KL, Norton S, Steer S, et al. The relationship between depression and biologic treatment response in rheumatoid arthritis: An analysis of the British Society for Rheumatology Biologics Register. Rheumatology (Oxford) 2018;57:835-843.

81. Ostergaard SD, Jensen SO, Bech P. The heterogeneity of the depressive syndrome: when numbers get serious. Acta Psychiatr Scand 2011;124:495-496.

82. Zhang W, Gignac MA, Beaton D, Tang K, Anis AH, Canadian Arthritis Network Work Productivity G. Productivity loss due to presenteeism among patients with arthritis: estimates from 4 instruments. J Rheumatol 2010;37:1805-1814.

83. Braakman-Jansen LM, Taal E, Kuper IH, van de Laar MA. Productivity loss due to absenteeism and presenteeism by different instruments in patients with RA and subjects without RA. Rheumatology (Oxford) 2012;51:354-361.

84. Severens JL, Mulder J, Laheij RJ, Verbeek AL. Precision and accuracy in measuring absence from work as a basis for calculating productivity costs in The Netherlands. Soc Sci Med 2000;51:243-249.

85. Evans C, Crawford B. Patient self-reports in pharmacoeconomic studies. Their use and impact on study validity. Pharmacoeconomics 1999;15:241-256.

86. Reilly MC, Bracco A, Ricci JF, Santoro J, Stevens T. The validity and accuracy of the Work Productivity and Activity Impairment questionnaire--irritable bowel syndrome version (WPAI:IBS). Aliment Pharmacol Ther 2004;20:459-467.

87. Krol M, Brouwer W, Rutten F. Productivity costs in economic evaluations: past, present, future. Pharmacoeconomics 2013;31:537-549.

88. Brouwer WB, Koopmanschap MA. The friction-cost method : replacement for nothing and leisure for free? Pharmacoeconomics 2005;23:105-111.

89. Richtlijn voor het uitvoeren van economische evaluaties in de gezondheidszorg [Guideline for economic evaluations in healthcare]. Diemen: Zorginstituut Nederland [National Health Care Institute of the Netherlands], 2015.

90. Pauly MV, Nicholson S, Polsky D, Berger ML, Sharda C. Valuing reductions in on-the-job illness: 'presenteeism' from managerial and economic perspectives. Health Econ 2008;17:469-485.

91. IJzerman MJ, Koffijberg H, Fenwick E, Krahn M. Emerging Use of Early Health Technology Assessment in Medical Product Development: A Scoping Review of the Literature. Pharmacoeconomics 2017;35:727-740.

92. Buisman LR, Rutten-van Molken MP, Postmus D, Luime JJ, Uyl-de Groot CA, Redekop WK. The Early Bird Catches the Worm: Early Cost-Effectiveness Analysis of New Medical Tests. Int J Technol Assess Health Care 2016;32:46-53. 
93. IJzerman MJ, Steuten LM. Early assessment of medical technologies to inform product development and market access: a review of methods and applications. Appl Health Econ Health Policy 2011;9:331-347.

94. Vallejo-Torres L, Steuten LM, Buxton MJ, Girling AJ, Lilford RJ, Young T. Integrating health economics modeling in the product development cycle of medical devices: a Bayesian approach. Int J Technol Assess Health Care 2008;24:459-464.

95. Grutters JPC, Govers TM, Nijboer J, Tummers M, van der Wilt GJ, Rovers MM. Exploratory, Participatory and Iterative Assessment of Value: A Response to Recent Commentaries. Int J Health Policy Manag 2020.

96. Drummond M, Griffin A, Tarricone R. Economic evaluation for devices and drugs--same or different? Value Health 2009;12:402-404.

97. Girling A, Young T, Brown C, Lilford R. Early-stage valuation of medical devices: the role of developmental uncertainty. Value Health 2010;13:585-591.

98. Poddubnyy D, Vahldiek J, Spiller I, Buss B, Listing J, Rudwaleit M, et al. Evaluation of 2 screening strategies for early identification of patients with axial spondyloarthritis in primary care. $J$ Rheumatol 2011;38:2452-2460.

99. Sieper J, Srinivasan S, Zamani O, Mielants H, Choquette D, Pavelka K, et al. Comparison of two referral strategies for diagnosis of axial spondyloarthritis: the Recognising and Diagnosing Ankylosing Spondylitis Reliably (RADAR) study. Ann Rheum Dis 2013;72:1621-1627.

100. van den Berg R, de Hooge $M$, van Gaalen F, Reijnierse $M$, Huizinga T, van der Heijde D. Percentage of patients with spondyloarthritis in patients referred because of chronic back pain and performance of classification criteria: experience from the Spondyloarthritis Caught Early (SPACE) cohort. Rheumatology (Oxford) 2013;52:1492-1499.

101. Jamal M, Korver AM, Kuijper M, Lopes Barreto D, Appels CWY, Spoorenberg APL, et al. The IMPACT study: A clustered randomized controlled trial to assess the effect of a referral algorithm for axial spondyloarthritis. PLoS One 2020;15:e0227025. 


\section{Dankwoord}

Allereerst wil ik graag mijn promotieteam bedanken. De samenwerking tussen jullie als promotoren is een mooi voorbeeld van hoe het geheel groter kan zijn dan de som der delen.

Prof. Boonen, Annelies, ik wil je ontzettend bedanken voor de begeleiding van mijn promotieonderzoek. Al vanaf onze eerste kennismaking heb ik niets anders dan bewondering voor jouw toewijding aan de wetenschap, en jouw kennis en kunde. Telkens als we resultaten van ons onderzoek interpreteerden, kwam je met nieuwe inzichten. Meestal vergde dat wat extra uitleg van jouw kant. Waar ik van a naar b ging, was jij inmiddels al bij z. Tegenwoordig heb ik wel eens de illusie dat ik zelf ook de weg naar $z$ kan vinden, maar vaak is het niet meer dan dat, een illusie. Vooral de integere wijze waarop je de wetenschap bedrijft, heeft indruk gemaakt op me. Altijd blijven nadenken over de validiteit van ons onderzoek, nooit de resultaten overdrijven, duidelijk benoemen waar de beperkingen liggen... Helaas zijn er genoeg voorbeelden in de wetenschap van 'bad research practice', en ik ben blij dat ik onder jouw begeleiding heb kunnen zien en leren hoe het wél moet. Ik ben dan ook tevreden, en vooral heel trots, dat ik mijn wetenschappelijke carrière bij jou mag voortzetten.

Prof. Van Tubergen, Astrid, ook voor jou niets dan dank. Mijn onderzoeksstage bij jou was mijn eerste echte kennismaking met klinisch onderzoek. Zonder jouw enthousiaste begeleiding tijdens deze stage was ik wellicht nooit aan een promotieonderzoek begonnen (en had ik dit alles moeten missen). Wat ik vooral van je heb geleerd in de afgelopen jaren, is hoe belangrijk het is om onderzoek op een gestructureerde en systematische wijze te verrichten. Het einddoel voor ogen houden, het overzicht bewaren, je taken plannen, prioriteiten stellen... Ik hoop in de komende jaren te bewijzen dit zelf inmiddels ook te kunnen. Ook heb ik bewondering voor je oog voor details, zowel wat betreft het uitvoeren van onderzoek alsook de wijze waarop we ons onderzoek op papier zetten. Inmiddels zijn mijn door jou gecorrigeerde teksten toch duidelijk minder rood, wat ik maar interpreteer als verbetering van mijn kant (en niet als opgave van jouw kant). Ik kijk er ontzettend naar uit om in de nabije toekomst opnieuw samen te werken. Inmiddels hebben we ook al wat nieuwe ideeën, dus dat komt helemaal goed.

Prof. Joore, Manuela, bedankt voor de inspirerende discussies over economische evaluaties en in het bijzonder ons kosteneffectiviteitsmodel. Naast je enorme kennis en zeer enthousiaste benadering waardeer ik de wijze waarop je telkens onze klinische invalshoek wist te 'vertalen' naar een gezondheidseconomische vraag, en hoe je altijd wel een pragmatische oplossing had voor de problemen waar we tegenaan liepen. Ik ben blij dat we onze samenwerking voortzetten, want ik leer elke keer weer bij. 
Prof. Van der Heijde, Désirée, ik ben dankbaar dat je met jouw uitgebreide ervaring mijn onderzoek telkens naar een hoger niveau wist te tillen. Vooral de wijze waarop je snel tot de essentie van complexe materie kon komen, heb ik zowel bewonderd als gewaardeerd.

Prof. Landewé, Robert, jouw inzicht in de methodologie van onderzoek is enorm, misschien wel ongeëvenaard. Hier heb ik dankbaar gebruik van gemaakt bij meerdere studies in dit proefschrift.

Prof. Van den Bosch, Filip, ik wil je bedanken voor je bijdrage aan dit proefschrift. Ik ben erg blij dat ik nu een rol mag vervullen in jullie nieuwe project.

Sabine, thank you so much for helping me with the development of our health economic model. You deserve a lot of credit, for the technical aspects and for your role in the conceptualization of the project as a whole. I am delighted that we will be working together soon!

Floris, ik wil je bedanken voor de samenwerking voor ons gezondheidseconomisch model. Dit is mede dankzij jouw inzichten, en jullie data uit Leiden, tot stand gekomen.

Sofia, bedankt dat ik met mijn vragen over statistische analyses bij jou terecht kon. Je duidelijke adviezen hebben mijn werk heel wat makkelijker gemaakt.

Seb en Carsten, jullie wil ik bedanken voor de prettige wijze waarop we hebben samengewerkt voor ons depressie-project. Bij het begin van mijn promotietraject had ik het niet verwacht, maar comorbide depressie is uiteindelijk een belangrijk onderdeel van dit proefschrift geworden. Seb, dankzij jouw kennis over 'structural equation modelling' hebben we een mooi model over depressie bij axiale spondyloartritis ontwikkeld. Een dergelijke statistische benadering was een eye-opener voor me. Carsten, je inzichten vanuit een psychologisch perspectief waren zeer welkom, en hebben me geleerd om anders te denken over psychiatrische aandoeningen.

Harald, Mart, Peter, Laura en Carly, jullie wil ik bedanken voor de samenwerking in SpA-Net. Vooral in de voorbereidende fase hebben we intensief contact gehad om alle kinderziektes uit het systeem te halen, waarvoor dank.

I want to thank all the other co-authors of the manuscripts that were part of this thesis: Xenofon Baraliakos, Jürgen Braun, Maxime Dougados, Yvonne van Eijk-Hustings, Frank Heldmann, Liesbeth Heuft, Jolanda Luime, Olga Schiepers, Anneke Spoorenberg and Thea Schoonbrood. You all contributed to this work, in one way or another, for which I am grateful. 
De leden van de beoordelingscommissie (prof. Dirksen, prof. Fautrel, prof. Kooman, dr. Pierik en prof. Weel-Koenders) wil ik bedanken voor het lezen en beoordelen van mijn proefschrift.

De stafleden, AIOS en verpleegkundigen van de afdeling Reumatologie van het MUMC+ (Annelies, Astrid, Bert, Caroline, Claudia, Christel, Debby, Elise, Inge, Ivette, Janine, Laura, Lara, Marloes, Mehmet, Sandrine, Simone, Summer, Thea en Yvonne) wil ik bedanken voor hun enthousiasme en de gezelligheid. Debby, jou wil ik in het bijzonder bedanken, voor je steun, je luisterend oor, je advies bij moeilijke beslissingen, en vooral je eerlijkheid. Inmiddels loop ik alweer ruim 7 jaar bij jullie rond, en heb ik me geen seconde verveeld. Ik ben blij dat ik bij/met jullie blijf werken!

Daarnaast wil ik ook mijn dank uitspreken voor de secretariële ondersteuning bij de Reumatologie (Peggy, Yvonne, Marian en Sandra). Naast de goede sfeer hebben jullie me talloze keren geholpen om mijn weg te vinden in de talloze administratieve en bureaucratische procedures die blijkbaar nodig zijn in een academisch ziekenhuis.

Ook wil ik alle stafleden en AIOS van de afdeling Interne Geneeskunde van het MUMC+ bedanken, voor de begeleiding en samenwerking in de afgelopen periode. In het bijzonder wil ik prof. Stehouwer en prof. Koopmans bedanken voor het in mij gestelde vertrouwen. Alhoewel ik heb besloten om verder te gaan in het onderzoek en niet in de patiëntenzorg, hebben jullie me de kans geboden om dit zelf te ontdekken. Hiervoor ben ik jullie zeer dankbaar.

Veel dank gaat uit naar mijn collega-onderzoekers bij de Reumatologie: Andrea, Antje, Bart, Carmen, Cindy, Dennis, Ellis, Esther, Fiona, Frans, Ivette, Joost, Kasper, Lennart, Lieke, Maarten, Mark, Mayke, Michiel, Polina, Ritch, Simon en Yannick. Jullie zijn geweldig! Mijn onderzoekstijd is omgevlogen, mede dankzij jullie. Ik wil jullie bedanken voor de barbecues, de terrasjes en stapavonden (hopelijk kan het snel weer), de uitjes, de spelletjes-avonden, de congressen (onder andere in Rome, Madrid, Washington, Amsterdam en Chicago), de lachbuien (Ellis), de lunches (Dönderdag), de discussies (die rondom het Oekraïne-referendum en de verkiezingen van 2017 staan me nog goed bij), de dilemma's (op dinsdag), de koffiepauzes en de ijsjes (met name de Cornetto's), maar vooral waar dit alles voor staat: een fantastische sfeer, zowel op het werk als daarbuiten. Ivette, jou wil ik in het bijzonder bedanken voor de introductie in het onderzoek, eerst als student en later als beginnend promovendus.

My fellow EMEUNET Working Group members, I want to thank you for the wonderful time. For me, it was a great learning experience and a welcome opportunity to make new friends. Special thanks go out to the members of the Newsletter subgroup (Antonis, Achilleas, 
Daniele, George, James, Mikhail, Gonçalo, Sarah, Tadeja and Yuz), and to the Steering Committee (Alessia, Alexandre and Felice) and Leadership Team (Diederik, Francesca, Julia, Kim, Manouk, Simone and Tue) during my year as Subgroup Leader.

Dan 'de mannen': Erik, Rob, Roel en Xavier. Inmiddels kennen we elkaar ruim 20 jaar, en beschouw ik jullie nog steeds als mijn beste vrienden. We zien elkaar niet zo vaak meer als vroeger, maar als we elkaar zien voelt het als vanouds. Ik wil jullie bedanken voor de goede gesprekken, de mooie discussies over belangrijke - en minder belangrijke - zaken, gezellige stapavonden, de weekendjes weg, de vakanties, carnaval (inclusief het klussen), de Vierdaagsefeesten, en vooral jullie onvoorwaardelijke vriendschap. We zijn allemaal nogal burgerlijk geworden (huisje/boompje/beestje), maar ik begrijp nu dat dat nou eenmaal bij het volwassen worden hoort. Eigenlijk moet ik ook jullie vrouwen/verloofden (Lorain, Marjolein, Dianne en Fabienne) bedanken. Zij maken jullie gelukkig, en dat maakt mij gelukkig.

Joost en Michiel, mijn paranimfen. Het heeft even geduurd, maar het lijkt erop dat ik nu dan echt ga promoveren. Wat begon als collegialiteit is inmiddels vriendschap geworden, en daar ben ik erg blij mee. Vanwege het coronavirus hebben we helaas al enige tijd niet meer op het terras gezeten of in de kroeg gestaan, maar hopelijk kunnen we dat straks nog eens inhalen. De spelletjes-avonden zijn voorlopig een prima vervanger, ondanks mijn significant hoge loss rate (het zou waarschijnlijk helpen als ik minder zou praten, maar dat gaat vast niet lukken). Naast de vriendschap wil ik jullie ook bedanken als paranimfen: voor jullie steun tijdens deze laatste loodjes, en voor jullie waardevolle adviezen omtrent promoveren en alles wat erbij komt kijken. Het is nog onduidelijk of we het straks écht kunnen vieren, maar ook dat halen we vast wel in.

Max en Marijke, mijn 'schoonouders', ik vind het fijn dat we altijd welkom zijn bij jullie in Leiderdorp, en dan ook mogen logeren in het 'M\&M hotel' (inclusief ontbijt!). Stefan en Elphire, jullie natuurlijk ook bedankt voor alle gezellige momenten. Wat mij betreft gaan we snel weer eens minigolfen!

Valentijn en Tiara, ik wil jullie bedanken voor alle steun en liefde. Ik ben erg trots op alles wat jullie hebben bereikt. En om dan ook maar meteen jullie mooiste prestatie te benoemen: met de komst van Emilia mag ik mezelf inmiddels oom noemen. Het is soms nog even wennen, maar ik zal proberen me verantwoordelijk te gedragen. Ik ben heel blij dat we elkaar, ondanks de afstand tussen ons, regelmatig zien. Frédérique, jou wil ik bedanken voor alle liefde, en ook voor de inspiratie. Ik zeg het veel te weinig, maar ik ben heel trots op de manier waarop je je eigen pad trekt in het leven. Dat vraagt een kracht waar ik alleen maar bewondering voor kan hebben (inmiddels spreek ik ook een beetje 
uit ervaring, natuurlijk). Hopelijk kunnen alle grenzen snel weer open, want we hebben elkaar al veel te lang niet gezien.

Pap en mam, bedankt voor jullie liefde en voor alle goede adviezen, zowel op professioneel als persoonlijk vlak. Jullie zijn mijn grote voorbeeld, elk op jullie eigen manier. Ik heb het jullie niet altijd makkelijk gemaakt, maar toch waren jullie er voor mij. Ik ben dankbaar voor de manier waarop jullie me helpen om alles in perspectief te plaatsen: veel 'hoofdzaken' zijn meestal maar bijzaken. Zonder jullie was dit proefschrift niet tot stand gekomen.

Dr. Van den Bos, nu ik ook bijna ben gepromoveerd mag ik je volgens mij weer tutoyeren, dus bij deze. Lieve Jacqueline, Jacq, inmiddels zijn we bijna 8 jaar samen en hebben we (wellicht wat dramatisch) lief en leed gedeeld. Bedankt dat je er elke dag voor me bent, me steunt in de keuzes die ik maak, me accepteert zoals ik ben en, wellicht nog het meest belangrijk, me tot een beter mens maakt. Ik ben ongelofelijk trots op je, en prijs mezelf gelukkig dat ik deel mag uitmaken van je leven. Ondanks meerdere uitdagingen en tegenslagen is het ons gelukt om onze weg te vinden, en zijn we alleen maar dichter tot elkaar gekomen. Voor mijn gevoel zijn we pas net begonnen aan onze reis, en ik kan dan ook niet wachten om te zien wat de toekomst ons brengt. 


\section{Curriculum vitae}

Casper Johannes Petrus Webers was born on October 20th 1987 in Nijmegen, the Netherlands. After completing secondary school at the Stella Maris College in Meerssen in 2005, he studied Medicine at Maastricht University. During his master he conducted his research graduation project on gender-attributable differences in radiographic axial spondyloarthritis, under the supervision of prof. Astrid van Tubergen at the Department of Rheumatology (Maastricht University Medical Centre, MUMC+). After graduating in 2015, he got the opportunity to continue his research at the MUMC+ and Care and Public Health Research Institute (CAPHRI) of Maastricht University, under supervision of prof. Annelies Boonen and prof. Van Tubergen. During his time as a PhD student, he presented his work at national and international meetings, published in peer-reviewed journals, tutored students of Medicine and completed a 3-year rotation as member and Subgroup leader of the EMerging EULAR NETwork (EMEUNET) Working Group. After a brief period of working as a resident in internal medicine, he decided to pursue a scientific career. Currently, Casper is working as a postdoctoral researcher for prof. Boonen at CAPHRI and the Department of Rheumatology (MUMC+). 


\section{List of publications}

\section{Journal articles}

Webers C, Essers I, Ramiro S, Stolwijk C, Landewe R, van der Heijde D, et al. Genderattributable differences in outcome of ankylosing spondylitis: long-term results from the Outcome in Ankylosing Spondylitis International Study. Rheumatology (Oxford) 2016;55:419-428.

Spaetgens B, van Durme C, Webers C, Tran-Duy A, Schoonbrood T, Boonen A. Construct validity of radiographs of the feet to assess joint damage in patients with gout. J Rheumatol 2017;44:91-94.

Webers C, Van Tubergen A. 'SpA-Net': een initiatief tot zorgverbetering van spondyloartritis in de dagelijkse praktijk ['SpA-Net': an initiative to improve care for sponyloarthritis in daily practice]. Nederlands Tijdschrift voor Reumatologie 2017;20:22-25.

Webers C, Essers I, van Tubergen A, Braun J, Heldmann F, Baraliakos X, et al. Valuing treatment with infliximab for ankylosing spondylitis using a willingness-to-pay approach. Arthritis Care Res (Hoboken) 2018;70:608-616.

Webers C, Ramiro S, Landewe R, van der Heijde D, van den Bosch F, Dougados M, et al. Sick leave and its predictors in ankylosing spondylitis: long-term results from the Outcome in Ankylosing Spondylitis International Study. RMD Open 2018;4:e000766.

Webers C, Vanhoof L, van Genderen S, Heuft L, van de Laar M, Luime J, et al. Employment and the role of personal factors among patients with ankylosing spondylitis: a Dutch crosssectional case-control study. RMD Open 2018;4:e000680.

Webers C, Beckers E, Boonen A, van Eijk-Hustings Y, Vonkeman H, van de Laar M, et al. Development, usability and acceptability of an integrated eHealth system for spondyloarthritis in the Netherlands (SpA-Net). RMD Open 2019;5:e000860.

Webers C, Vanhoof L, Leue C, Boonen A, Kohler S. Depression in ankylosing spondylitis and the role of disease-related and contextual factors: a cross-sectional study. Arthritis Res Ther 2019;21:215. 
Beckers E, Webers C, Boonen A, Ten Klooster PM, Vonkeman HE, van Tubergen A. Validation and implementation of a patient-reported experience measure for patients with rheumatoid arthritis and spondyloarthritis in the Netherlands. Clin Rheumatol 2020;39:2889-2897.

Webers C, Stolwijk C, Schiepers O, Schoonbrood T, van Tubergen A, Landewe R, et al. Infliximab treatment reduces depressive symptoms in patients with ankylosing spondylitis: an ancillary study to a randomized controlled trial (ASSERT). Arthritis Res Ther 2020;22:225.

Webers C, Grimm S, Van Tubergen A, Van Gaalen F, Van der Heijde D, Joore M, et al. Costeffectiveness of diagnostic algorithms for axial spondyloarthritis in the Netherlands: a model-based economic evaluation. Submitted for publication.

Beckers E, Been M, Webers C, Boonen A, Ten Klooster PM, Vonkeman H, et al. Performance of the DAPSA and ASDAS in peripheral spondyloarthritis. Submitted for publication.

Molto A, Lopez-Medina C, Van den Bosch F, Boonen A, Webers C, Dernis E, et al. Efficacy of a tight-control and treat-to-target strategy in axial spondyloarthritis: results of the openlabel, pragmatic, cluster-randomised TICOSPA trial. Submitted for publication.

Beckers E, Boonen A, Webers C, Ten Klooster PM, Vonkeman H, Efde M, et al. Is treat-totarget applied in axial spondyloarthritis in daily practice? An observational study in three rheumatology centers with an electronic monitoring tool available. Manuscript in preparation.

\section{Editorials}

Webers C, Boonen A, Spaetgens B. Costs of disease: the perspective matters. Int J Rheum Dis 2021.

\section{Book chapters}

Boonen A, Webers C. Chapter 17 - Economic evaluations in axial spondyloarthritis. In: Mease P, Khan MA. Axial Spondyloarthritis. St. Louis: Elsevier 2019: 259-279. 